PNL-MA-572

UC-66d

Materials Department

\title{
SAMPLING AND ANALYSIS \\ METHODS FOR GEOTHERMAL \\ FLUIDS AND GASES
}

J.C. Watson

Prepared for the U.S. Department of Energy under Contract EY-76-C-06-1830

Pacific Northwest Laboratory Richland, Washington 99352

This report was preticE- NOT sponsored by the Unied Sals an account of whe United States unithe

Energy nor any of their employes, Doparment of

contractors, suby or their employees, nor any of their

any warranty, expess or, or their employees, makes

libity oxpress or ingled, or assumes any legal

or usefulness of any infor the accuracy, completeness

process disclos any infomman, apparatus, product or

infringe privately owned rights.

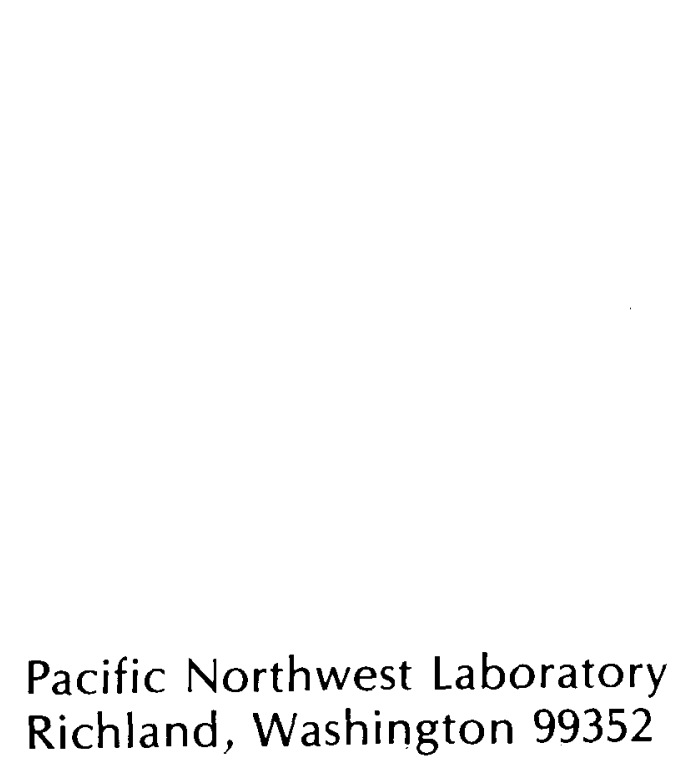


DISCLAIMER

This report was prepared as an account of work sponsored by an agency of the United States Government. Neither the United States Government nor any agency Thereof, nor any of their employees, makes any warranty, express or implied, or assumes any legal liability or responsibility for the accuracy, completeness, or usefulness of any information, apparatus, product, or process disclosed, or represents that its use would not infringe privately owned rights. Reference herein to any specific commercial product, process, or service by trade name, trademark, manufacturer, or otherwise does not necessarily constitute or imply its endorsement, recommendation, or favoring by the United States Government or any agency thereof. The views and opinions of authors expressed herein do not necessarily state or reflect those of the United States Government or any agency thereof. 


\section{DISCLAIMER}

Portions of this document may be illegible in electronic image products. Images are produced from the best available original document. 
The material contained in this manual is the result of the combined efforts of the following individuals and organizations. Their contributions are gratefully acknowledged.
D. W. Shannon,
Project Manager
E. M. Woodruff
J. G. Doublas
S. J. Thompson
R. J. Serne

\author{
Allied Chemical Corporation \\ Idaho Falls, ID 83401 \\ Ames Laboratory \\ Ames, IA 50011 \\ Physical Dynamics, Inc. \\ Atomics International \\ Canoga Park, CA 91304 \\ Bellevue, WA 98005 \\ Radian Corporation \\ Austin, TX 78766 \\ TRW Sys tems \& Energy \\ Redondo Beach, CA 90278 \\ Cherron 0il Field Research Co. \\ La Habra, CA 90631 \\ Union 0 il Company \\ Research Center \\ Brea, CA 92621 \\ U.S. Environmental Protection Agency \\ EMSL-LV \\ Las Vegas, NV 89114 \\ U.S. Bureau of Mines \\ GHT Laboratories \\ Brawley, CA 92227 \\ College Park, MD 20740 \\ Gulf South Research Institute \\ New Orleans, LA 70186 \\ U.S. Geological Survey \\ Geologic Division \\ Men1o Park, CA 94025 \\ University of Southern California \\ Lawrence Berkeley Lab \\ Holtville, CA 92250 \\ Los Angeles, CA 90007 \\ Vetter Associates \\ Costa Mesa, CA 92626 \\ LFE Environmental Analysis labs \\ Richmond, CA 94804 \\ Westec Services, Inc. \\ Oak Ridge National Laboratory \\ Calipatria, CA 92233 \\ Analytical Chemistry Division \\ Oak Ridge, TN 37830
}




\section{\% Bantelle \\ Pacific Northwest Laboratories \\ P. O. Box 999 \\ Richland, Washington 99352 \\ Telephone (509) 942-5941 \\ Telex 32-6345}

July 26,1978

To: Recipients of manual "Sampling and Analysis Methods for Geothermal Fluids and Gases, July 1978"

This document is the culmination of efforts to assemble a manual of sampling and analysis methods for geothermal fluids and gases. Although an effort has been made to eliminate grammatical errors in the content, some will undoubtedly appear in this edition.

The sampling and analysis methods contained have been evaluated under field situations. The appendices contain the data generated during field evaluations. Appendix 1 dealing with the field evaluation of sampling methods at the Republic Geotherma 1, Inc., East Mesa, CA, site is currently being written and will be mailed separately.

Comments on the content of this manual are welcome and should be submitted to:

J. C. Watson

Battelle Pacific Northwest Laboratories

314 Building/300 area

RichTand, WA 99352

Phone: (509) 942-5941

FTS 444-5941 
Table of Contents

\begin{tabular}{|c|c|c|}
\hline & & Page \\
\hline Introduction & & $A 7-A 3$ \\
\hline Matrix & of Geothermal Tasks and Related & A4-A8 \\
\hline Chemica & 1 Analyses & \\
\hline Sampling Pro & cedures for Geothermal Fluids and Gases & B1 -B39 \\
\hline Recommended & Analytical Methods for Geothermal Liquids & $C 7-C 227$ \\
\hline $\begin{array}{r}\text { Correction o } \\
\text { Steam LosS }\end{array}$ & $\begin{array}{l}\text { f Brine Component Concentrations for } \\
\text { During Flashing }\end{array}$ & D) -D9 \\
\hline Appendices & & \\
\hline $\begin{array}{l}\text { 1. Fie } \\
\text { Eas }\end{array}$ & $\begin{array}{l}\text { 1d Test-1978 (Republic Geothermal, Inc., } \\
\text { t Mesa Site, CA) }\end{array}$ & El \\
\hline 2. GRR & -1 and GRR-2 Analytical Round Robin Data & $F]-F-211$ \\
\hline 3. Com & ments from Round Robin Participants & G] $-G 27$ \\
\hline a) & Notes from Geothermal Sampling and & \\
\hline & Analysis Workshop BRSC, May 24 and & \\
\hline & 25,1977 & \\
\hline b) & Geothermal Round Robin Discussion & \\
\hline & Session I, August 2-3, 1977, San & \\
\hline & Francisco & \\
\hline c) & Meeting Notes from the Third Geothermal & \\
\hline & Round Robin Workshop Session: San & \\
\hline & Francisco, September 13 and 14, 1977 & \\
\hline
\end{tabular}




\section{INTRODUCTION}

This manual is the third document issued in the process of formulating a manual of sampling and analysis methods for geothermal fluids and gases. This document is the result of efforts begun in 1975 to assemble a manual of recommended methods of sampling and analysis.

The first manual issued in August 1976 as a "Comment Issue," ${ }^{(a)}$ included tables of analytic options for liquids and gases and summaries of standard methods of analysis. They were selected from standard references for constituents of interest to geothermal investigators, however, no attempt was made to recommend or rank their suitability. It was a place to start and in this role served its purpose in stimulating interest and comment. Also included was a graphic presentation of the concentration ranges of constituents found in a variety of brines and a matrix devised to relate constituents or properties of interest to specific tasks and objectives in the development and utilization of geothermal systems. The purpose of the matrix is to help those using the manual to determine the scope of analytic programs that meet specific needs without including unnecessary analyses. Reviewers of the "Comment Issue" suggested new references, corrected errors and inconsistencies, and proposed alternate ways to arrange or emphasize the material presented. Responding to specific requests for suggestions on sampling and on the conduct of round robin comparison of analytic methods, the reviewers were in general

(a) J. G. Douglas et a1., Geothermal Water and Gas -- Collected Methods for Sampling and Analysis - Comment Issue, BNWL-2094, Battelle-Northwest, Richland, WA, August 1976. 
agreement that it was perhaps too early to standardize sampling methods, particularly the hardware and methodology necessary to representatively sample wells producing two phase flow. They felt that premature attempts to standardize might slow rather than contribute to progress in this difficult area of methods development.

Favorable reactions to the proposed evaluation of analytic methods through a round robin program came from reviewers and others contacted during visits to several laboratories. To implement this program, a workshop was conducted at the Battelle Seattle Research Center in Seattle, WA on May 24-25, 1977. Fourteen Taboratories representing industry, commercial analytic services, and government agreed to an ambitious summer schedule for sampling and analyzing two brines. Two subsequent discussions were scheduled to review results and refine procedures and ground rules. Battelle coordinated the effort, preparing control samples to accompany the brines, collecting and shipping the brines and compiling results. The USGS monitored and assisted in obtaining samples from East Mesa 6-2 in July and the more complex brine from Woolsey \#1 near the Salton Sea in August. Additional laboratories became involved with nineteen participating in the first round robin and twenty-two in the second. Otto Vetter of Vetter Associates, Costa Mesa, CA, served as a consultant throughout the program and assisted in the arrangements and conduct of field work.

An "Interim Manual"(b) was issued in January 1978 as a result of the above program. In this manual we attempted to establish the format of the

(b) D. W. Shannon et al., Sampling and Analysis Methods for Geothermal Fluids and Gases, January 1978, Preliminary Edition, PNL-2750, BatteTTe Pacific Northwest Laboratories, Richland, WA. 
final manual. The content reflected input from over twenty-five sources, including a productive exchange of information and data generated by twenty laboratories participating in round robin analyses of two geothermal brines. The sampling section was written with the aid of otto Vetter and included sampling methods reported from literature sources. Copies of the interim manual were sent to participants of the round robin program and others for comment on content and modifications of format.

A field evaluation conducted by PNL personnel of some of the methods contained in the sampling section was conducted during March and April of 1978. Otto Vetter served as a consultant and assisted in arrangement of the field tests. These tests were performed at the Republic Geothermal, Inc., East Mesa, CA, site. Sampling methods were evaluated utilizing two producing geothermal wells, Republic wells 56-30 and 16-29. Comments from this field evaluation of the sampling methods have been included in a rewritten sampling section contained in this manual. The sampling field test report (Appendix 1) is currently being written and will be available shortly. The analysis section has also been corrected to incorporate the comments of reviewers of the interim manual. Additional features of this manual include a statistical evaluation of the round robin data generated during 1977 and the addition of some sampling methods which have recently been reported.

The input from the contributing organizations as well as the comments of reviewers will hopefully make this document beneficial to those involved in geothermal endeavors. 


\section{MATRIX OF GEOTHERMAL TASKS AND RELATED CHEMICAL ANALYSES}

The complexities of geothermal sources, the phases included in samples, and the varying applications for analytic results in exploration, development, and utilization all influence the scope of an analytic program. The interrelationships of these variables are presented here in matrix form as an aid to defining the scope and capabilities of an analytic program. References cited are the basis for the matrix in its present form and typically place greater emphasis on the evaluation and application of analytic results than on the methods used to obtain data.

Because the matrix emphasizes chemical aspects, it obviously cannot be regarded as a basis for complete sample characterization. Obvious omissions essential to full characterization include: temperature, pressure, flow rate at time of sample, flow history, documentation of sampling and storage methods. Categories related to the operational phase of energy recovery have been included though entries are few. The intent here is to provide users a format for making their own entries and establish a basis for later revision as the industry and its needs develop. 


\section{MATRIX OF GEOTHERMAL TASKS AND RELATED CHEMICAL ANALYSES}

EXPLORATION

LOCAII POIENTIAL RESERVIR

TRACE PAREN AQUIFFR

WALUAT GEORERMA FIELO POTENTIAL

ESTIMATE RESERVOIR RMPERAAURE

CHARACTRRIZZ ISS TWELL FLUI

DEFRMMING GAS CONIENT

DERTMNE POTNAR FOR MINERAL RECOVERY

DETRRMINE TOTENTIAL ENVIRONMENTAL IMPACTS

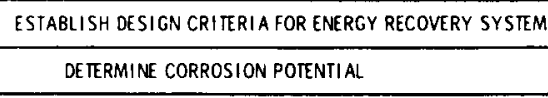

DE IRPMINE SCALING POIENTIAL

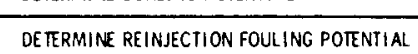

SUPPORT OPRRATING ENRECY RECOVERY SYSTEM

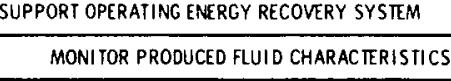

MONITOR PROOUCED GAS CONIENT

MONITOR CONEENSAI

MONI TOR GAS RELEASED TO ATMOSPHER

MONI TOR LIOUIO WASTE - SURFACE RUN-OFF

GROUND WAIR

MONITR OEEP RE-INECTION FUII

MONITR DESALINATION PROOUCCT - LIOU1D

MINERAL


REFERENCES FOR MATRIX OF GEOTHERMAL TASKS AND RELATED CHEMICAL ANALYSES

1. J. Combs and L. P. J. Muffler, "Exploration for Geothermal Resources," Geothermal Energy, P. Kruger and C. Otte, editors, Stanford University Press, pp. 95-128, 1973.

2. D. E. White, "Geochemistry Applied to the Discovery, Evaluation, and Exploitation of Geothermal Energy Resources," Geothermics Special Issue 2, Vol. 1, pp. 58-80, 1970

3. A. J. Ellis, "Magnesium Concentrations in the Presence of Magnesium Chlorite, Calcite, Carbon Dioxide, Quartz," Am. J. of Sci., Vol. 271 Pp. $481-489,1971$.

4. R. 0. Fournier and A. H. Truesde11, "Chemical Indicators of Subsurface Temperature Applied to Hot Spring Waters of Yellowstone National Park, Temperature Applied to Hot Spring Waters of Yellowstone National
Geothermics Special Issue 2, Vol. 2, pt. 1, pp. 529-535, 1970.

5. A. J. Ellis, "Quantitative Interpretation of Chemical Characteristics of Geothermal Systems," Geothermics Special Issue 2, Vol. 2, pp. 516-528, 1970.

6. G. W. Morey, "Field Measurements of Silica in Water from Hot Springs and Geysers in Yellowstone National Park," U.S.G.S. Prof. Paper 424-C, pp. C333-C336, 1961.

7. F. Tonani, "Geochemical Methods of Exploration for Geothermal Energy," Geothermics Special Issue 2, Vol. 2, pt. 1, pp. 492-515, 1970.

8. A. A. Roberts et al, "Helium Survey, A Possible Technique for Locating Geothermal Reservoirs," Geophysical Research Letters, Vol. 2, No. 6, pp. 209-210, June 1975 .

9. A. J. Ellis, "Chemical and Isotopic Techniques in Geothermal Investigations," Geothermics, Vol. 5, pp. 3-12, 1977.

10. J. S. Matlick, III, and P. R. Buseck, "Exploration for Geothermal Areas Using Mercury: A New Geochemical Technique," Proceedings of the Second U.N. Symposium on the Development and Use of Geothermal Resources, Vo1. 1, pp. 785-792, 1975.

11. W. A. J. Mahon, "Chemistry in the Exploration and Exploitation of Hydrothermal Systems," Geothermics Special Issue 2, Vol. 2, pt. 2, pp. 1310-1322, 1970.

12. E. Mazor, "Geothermal Tracing with Atmospheric and Radiogenic Noble Gases," Geothermics, Vo1. 5, pp. 21-36, 1977.

13. W. A. J. Mahon, "Silica in Hot Water Discharged from Drillholes in Wairakei, New Zealand," New Zealand J. of Sci., Vol. 9, No. 1, pp. 135-144, March 1966 
14. R. O. Fournier and J. J. Rowe, "Estimation of Underground Temperatures from the Silica Content of Water from Hot Springs and Wet Steam Wells," Am. J. of Sci., 264, p. 685, 1966.

15. S. Arnorsson, "Underground Temperatures in Hydroghermal Areas in Iceland as Deduced from the Silica Content of the Thermal Water," Geothermics Special Issue 2, Vol. 2, pt. 1, pp. 536-541, 1970.

16. S. Arnorsson, "Application of the Silica Geothermometer in Low Temperature Hydrothermal Areas in Iceland," Am. J. of Sci., Vol. 265, pp. 763-784, 1975.

17. D. E. White, "Saline Waters of Sedimentary Rocks," Symposium on Fluids in Subsurface Environments, Am. Assoc. Petrol. Geol. Mem. 4, pp. 342-366, 1965.

18. R. 0. Fournier and A. H. Truesdell, "An Empirical Na-K-Ca Geothermometer for Natural Waters," Geochimica et Cosmochimica Acta, Vol. 37, pp. 1255-1275, 1973.

19. J. R. Hulston, "Isotope Geology in the Hydrothermal Areas of New Zealand," U. N. Conf. New Sources of Energy, paper 35/G/31, Rome, 1961.

20. T. S. Presser and I. Barnes, "Special Techniques for Determining Chemical Properties of Geothermal Waters," U.S. Geol. Survey Water Resources Investigation 22-74, 1974.

21. R. 0. Fournier and A. H. Truesdell, "A Device for Measuring Down-Hole Pressures and for Sampling Fluids in Geothermal Wells," U. S. Geol. Survey Prof. Paper 750-C, pp. C146-C150, 1971.

22. D. E. Donaldson, "Fluorometric Analysis of the Aluminum Ion in Natural Waters," U. S. Geol. Survey Prof. Paper 550-D, pp. D258-261, 1966.

23. A. J. Ellis et al, "Methods of Collection and Analysis of Geothermal Fluids," Report No. C.D. 2103 New Zealand Dept. of Sci. and Ind. Res., New Zealand, July 1968.

24. A. H. Truesdell and K. L. Pering, "Geothermal Gas Sampling Methods," U.S.G.S. open file Report 74-361, Menlo Park, CA, 1974.

25. W. F. Giggenbach, "A Simple Method for Collection and Analysis of Volcanic Gas Samples," in press Bul. Volc.

26. R. O. Fournier and J. C. Morganstern, "A Device for Collecting Down-Hole Water and Gas Samples in Geothermal Wells," U.S.G.S. Prof. Paper 750-C, pp. C151-155, 1971.

27. J. H. Hill and C. J. Morris, "Sampling a Two-Phase Geothermal Brine Flow for Chemical Analysis," Lawrence Livermore Laboratory Report UCRL-77544, Dec., 1975. 
28. J. B. Finlayson, "The Collection and Analys is of Volcanic and Hydrotherm Gases," Geothermics Special Issue 2, Vol. 2, pp. 1344-1354, 1970.

29. B. G. Weissberg, "Gold-Silver Ore-grade Precipitates from New Zealand Thermal Waters," Economic Geology, Vol. 64, pp. 95-108, 1969.

30. B. Lindal, "The Production of Chemicals from Brine and Seawater Using Geothermal Energy," Geothermics Special Issue 2, Vol. 2, pt. 1, pp. 910-917, 1970 .

31. A. V. Shcherbakov and V. I. Dvorov, "Thermal Waters as a Source for Extraction of Chemicals," Geothermics Special Issue 2, Vol. 2, pt. 2, pp. 1636-1639, 1970.

32. H. H. Werner, "Contribution to the Mineral Extraction from Supersaturated Geothermal Brines, Salton Sea Area, California," Geothermics Special Issue 2, Vol. 2, pt. 2, pp. 1651-1655, 1970.

33. D. E. Robertson, J. S. Fruchter, J. D. Ludwick, C. L. Wilkerson, E. A. Crecelius, and J. C. Evans, A Chemical Characterization of Pollutants Released During Geothermal Energy Development, Battelle, Pacific Northwest Laboratories, to be presented at the AAAS Annual Meeting, Washington D.C., February 12-17, 1978.

34. R. C. Axtmann, "An Environmental Study of the Wairakei Power Plant," PEL Report No. 445, Physics and Engineering Laboratory, DSIR, New Zealand, 1974.

35. R. G. Bowen, "Environmental Impact of Geothermal Development," Geothermal Energy, P. Kruger and C. Otte, editors, Stanford University Press, Stanford, CA, 1973.

36. D. W. Shannon, Economic Impact of Corrosion and Scaling Problems in Geothermal Energy Systems, BNWL-1866, Battelle-Northwest, Richland, WA, January 1975.

37. G. H. Nancollas and M. M. Reddy, "Kinetics of Crystallization of Scale Forming Minerals," Oilfield Chemistry Symposium, 1973, Society of Petroleum Engineers, paper SPE 4360.

38. S. H. Wilson, "Statistical Interpretation of Chemical Results from Drillholes as an Aid to Geothermal Prospecting and Exploration," Geothermics Special Issue 2, Vol. 2, pt. 2, pp. 1232-1329, 1970.

39. R. B. Glover, "Interpretation of Gas Compositions from the Wairakei Field Over 10 Years," Geothermics Special Issue 2, Vol. 2, pt 2, pp. 1355-1366, 1970.

40. A. L. Austin et al, The LLL Geothermal Energy Development Program Status Report, January 1975 through August 1975, UCID 16954, Lawrence Livermore Laboratory, September 1975. 


\section{Sampling Procedures \\ for Geotherma] Fluids and Gases}

I. The sampling methods contained in this section are taken from literature sources and also communicated by those people currently involved in geothermal sampling.

II. Some of the sampling methods were evaluated during a field test at the Republic Geothermal Inc. Facility, East Mesa Site, CA during February - April 1978. Comments relevant to this field test are contained on the pages describing the appropriate method.

III. A format of the presentation for each method is given on the following page.

IV. The sequence of methods in this section is:
a) Sampling hot springs, fumaroles, etc.
b) Sampling condensed brine and entrained gases.
c) Sampling steam-1ines.
d) Low pressure separator systems.
e) High pressure separator systems.
f) Two phase sampling.
g) Downhole samplers.
h) Miscellaneous methods.

v. Illustrations and descriptions of some of the sample methods contained in this section are under copyright 1977, by Academic Press, Inc. These sections were reproduced with the permission of Academic Press, Inc., 111 Fifth Ave., New York, NY 10003. 
METHOD TITLE:

Descriptive statement of method

APPLICATION:

Sampling operation to be performed.
Sampling Reference Number

SAMPLE TYPE: SAMPLE POINT:

Pipeline, wellbore,

fumarole, etc.

\section{REFERENCES:}

Literature source of sampling method.

\section{DESCRIPTION}

Summary of sampling procedure and special equipment required.

COMMENTS:

Limitations of method including field experience with method.

EDITION:

Month and

year of

current page
PAGE:

B-2 


\section{METHOD TITLE:}

Immersible bottle method for collecting air-free water.

\section{APPLICATION:}

Sampling hot springs or weir boxes (from silencers).

\begin{tabular}{l|l} 
NO. & $1-S$ \\
\hline SAMPLE TYPE:
\end{tabular}

Liquid

\section{REFERENCES:}

Ellis, A.J. and W.A.J. Mahon, "Chemistry and Geothermal Systems," Academic Press, New York, 1977. (See note $V$ on page B-T)

Ellis, A.J. et al., "Methods of Collection and Analysis of Geothermal Fluids," Report No. C.D. 2103, New Zealand Dept. of Sci. and Ind. Res., New Zealand, July 1968.

\section{DESCRIPTION}

Two glass, or polyethylene, sample bottles with 15-cm lengths of wide-bore butyl rubber tubing over their necks and with a screw clip placed halfway up the tube are used. Rubber stoppers fitted with stainless steel tubing are placed in the ends of the wide-bore tubing. The assembly is submerged so that the shorter tube is under the surface and the long tube is exposed. Both bottles fill, with one bottle being purged with an extra $500 \mathrm{~m} 1$ of water. The screw clamp on the tube is closed, allowing the water in the purged bottle to cool in the absence of air.

\section{COMMENTS:}

Sample bottle contains water that has not been exposed to the atmosphere (as would happen if a bottle were placed directly within the hot spring). 


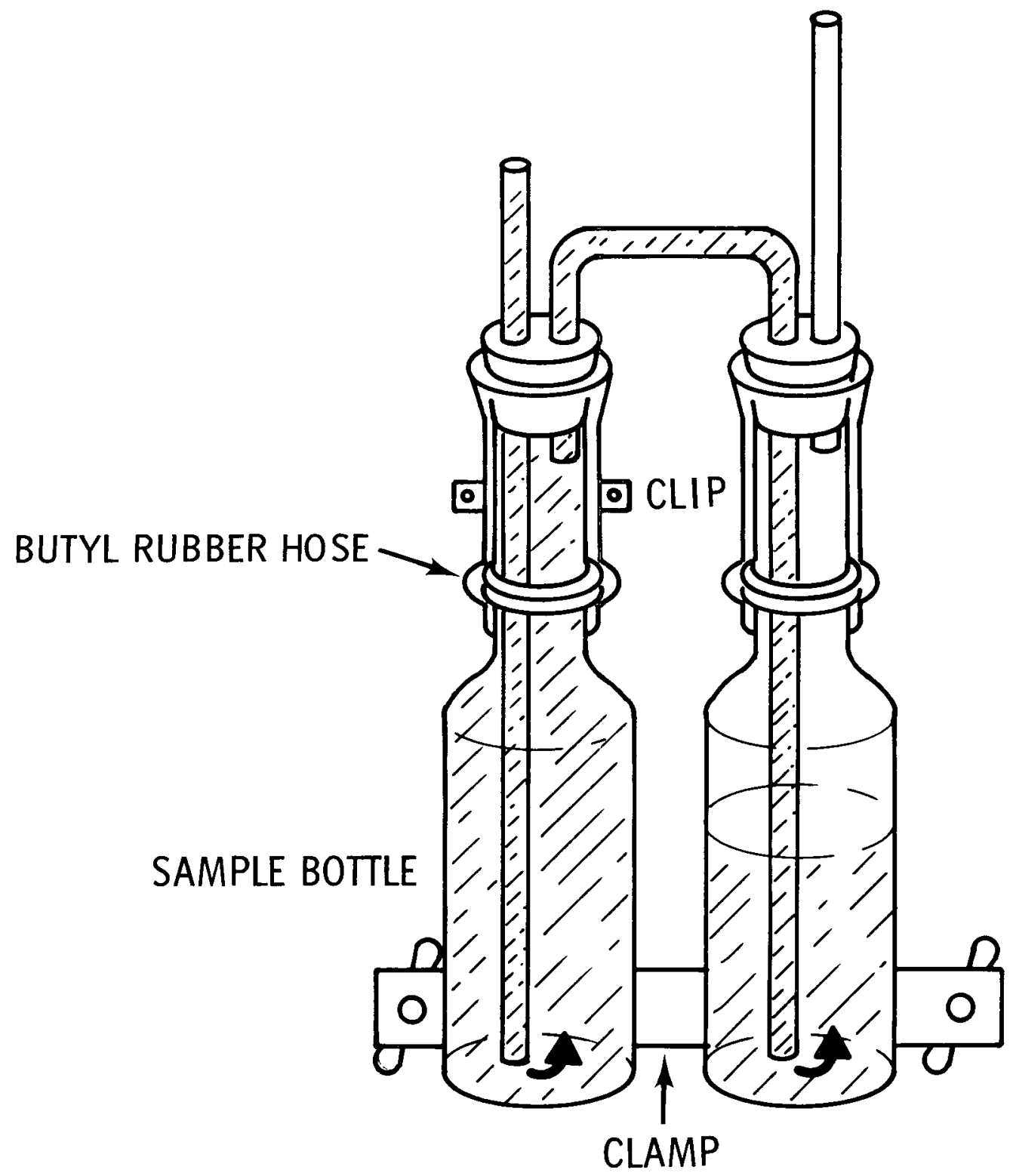

APPARATUS FOR COLLECTING AIR-FREE WATER SAMPLES FROM A WEIR BOX OR HOT SPRINGS 
METHOD TITLE:

Water displacement method for collecting gases from hot springs.

APPLICATION:

Sampling gases from hot springs.
NO.| $2-5$

SAMPLE TYPE: SAMPLE POINT:

Gas

Hot springs

REFERENCES:

Finlayson, J.B. "The Collection and Analys is of Volcanic and Hydrothermal Gases," Geothermics Special Issue 2, Vol. 2, p. $\overline{1344}-$ $1354,1970$.

Ellis, A.J. and W.A.J. Mahon, "Chemistry and Geothermal Systems," Academic Press, New York, 1977. (See note $V$ on page B-7)

\section{DESCRIPTION}

1. Glass or polyethylene funnel is attached to the top of a glass bottle with rubber tubing (Figure 1). The bottle and funnel, attached to a pole if necessary, are immersed in the hot spring and filled with water. The assembly is then positioned

with the funnel over the most active bubbling area of the spring. The lip of the funnel must be kept beneath the water surface at all times to prevent air contamination; a lead ring around the funnel lip will help keep it submerged. A clamp on the rubber tubing joining the funnel with the bottle seals the bottle when it has filled with gas.

2. A polyethylene funnel fitted into a butyl rubber hose attached to the flask is placed below water level above a stream of gas bubbles (Figure 2). Carbon dioxide and hydrogen sulfide are the predominant gases in hot springs and may be absorbed into solution by the addition of a caustic soda solution to the flask. This allows the collection of larger volumes of nonacidic gases. 


\section{ILLUSTRATION:}

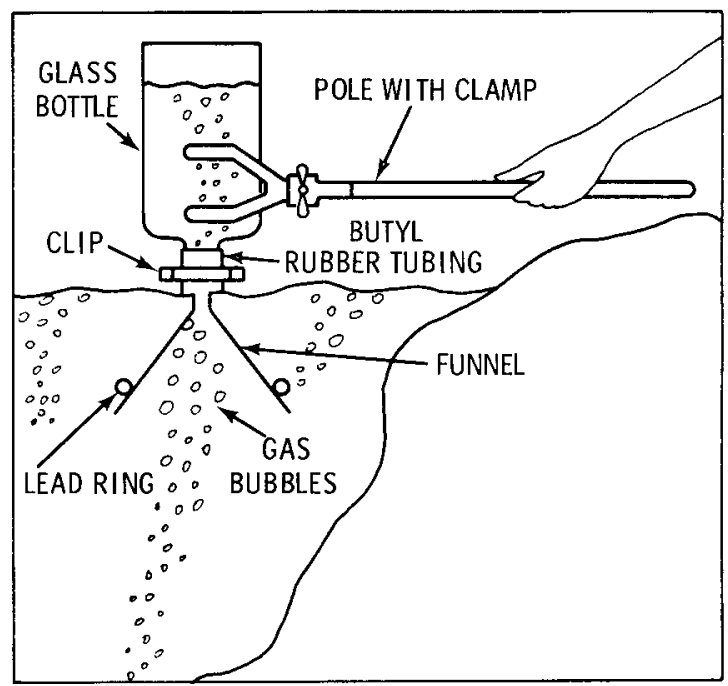

FIG 1. GAS COLLECTION FROM A BUBBLING SPRING BY WATER DISPLACEMENT

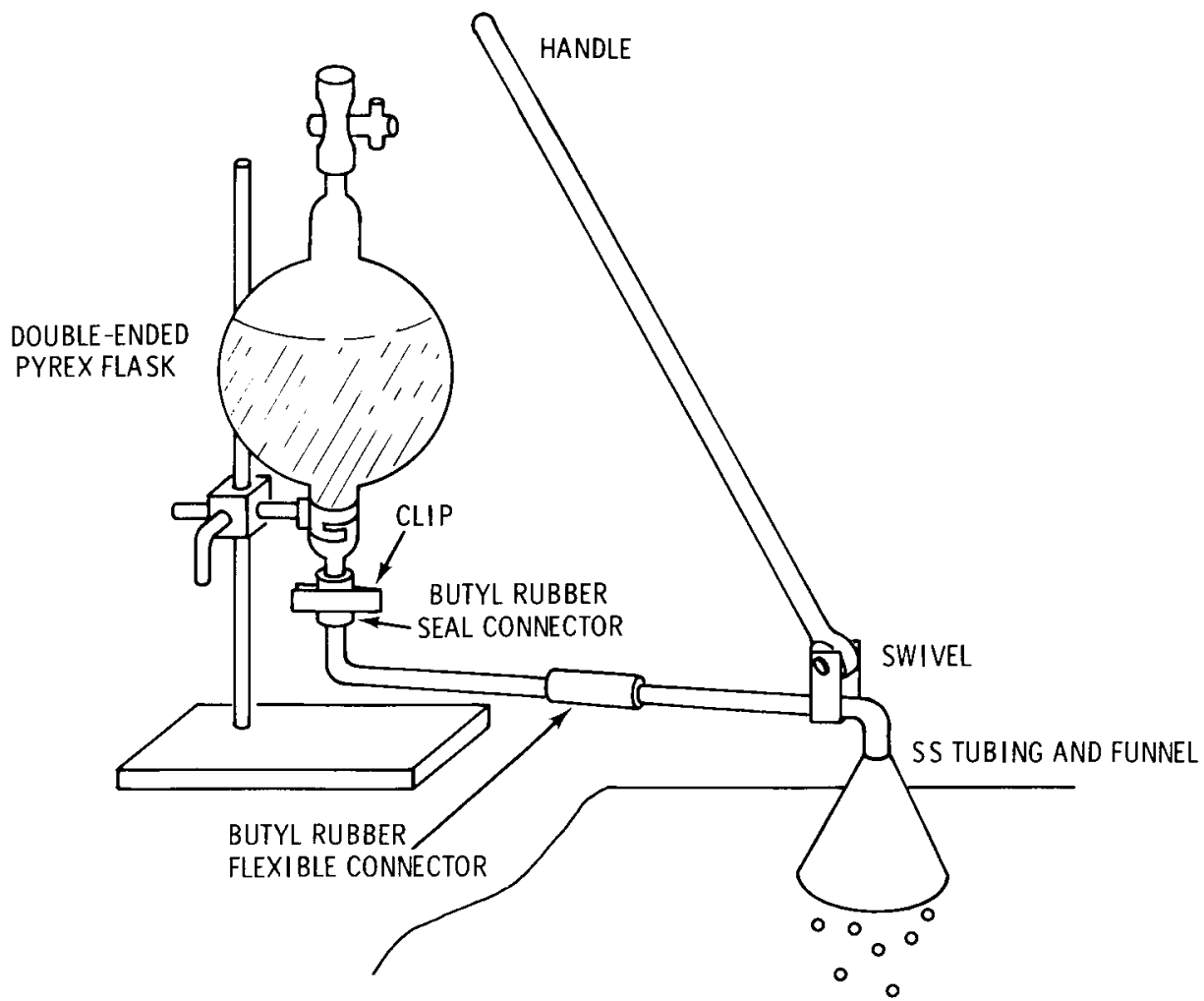

FIG 2. APPARATUS FOR COLLECTING GAS SAMPLES FROM SPRINGS 
METHOD TITLE:

NO. $3-S$

Seep (from hot springs) sampling method.

SAMPLE TYPE: SAMPLE POINT:

Liquid Hot springs seep

APPLICATION:

Sampling of seeps from hot springs where limited amount of liquid is available.

\section{REFERENCES:}

Wollenberg, H.A. "Sampling Hot Springs for Radioactive and Trace Elements," Lawrence Berkeley Laboratory Report LBL-4422, October 1975.

\section{DESCRIPTION}

1. For sampling seeps from hot springs where only a limited amount of fluid is available, a $1 / 4$ " diameter tygon tube is inserted directly into the flow, and water is drawn with a hand-operated vacuum pump. Instead of passing directly into the collection bottle, the water can also be drawn directly through a $0.45 \mu$ cellulose acetate filter.

2. $500 \mathrm{ml}$ Nalgene bottles were used for collecting bottles. Nalge also manufactures the hand operated vacuum pump.

COMMENTS: 


\section{ILLUSTRATION:}

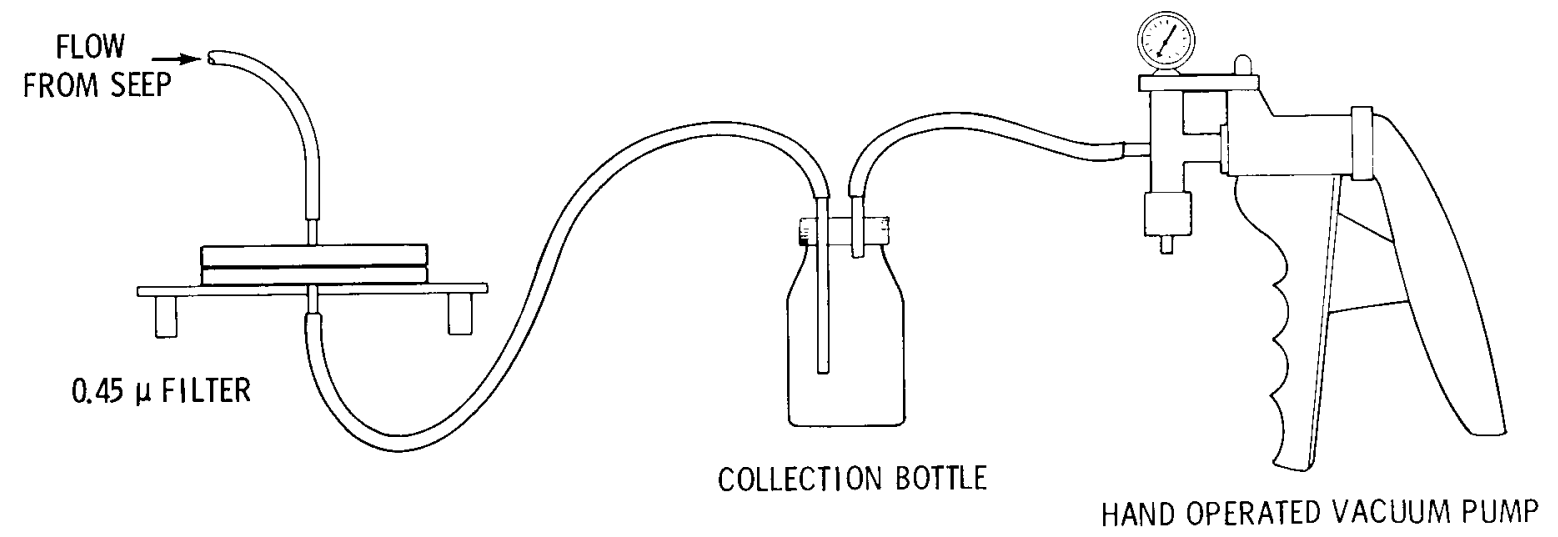

Portable filtering apparatus with hand-operated vacuum pump. 
Round bottom flask method for collecting volcanic gases.

\section{APPLICATION:}

Sampling volcanic gases.
NO. $\quad 4-S$

SAMPLE TYPE: $\quad$ SAMPLE POINT:

Gas

Fumarole

\section{REFERENCES:}

Giggenbach, W. F., "A Simple Method for Collection and Analys is of Volcanic Gas Samples," in press Bul. Volc.

\section{DESCRIPTION}

1. The apparatus in Figure 1 of the illustration has been used to sample volcanic gases. The use of a right angle bend in the intake tube ca. $10 \mathrm{~cm}$ from the end allows for convenient connection of the sample bottles for any fumarolic outlet configuration encountered. The sample bottles are $300 \mathrm{ml}$ cylindrical round-bottomed flasks, equipped with a Rotaflo teflon stopcock and containing $50 \mathrm{ml} 4 \mathrm{~N} \mathrm{NaOH}$.

2. A variation (Figure 2) consists of 2 flasks joined on the bottom by a two-way teflon stopcock. One flask contains $25 \mathrm{ml} 0.1 \mathrm{~N} \mathrm{As}_{2} \mathrm{O}_{3}$ solution in $1 \mathrm{~N} \mathrm{HClO}_{4}$, the other contains $50 \mathrm{ml} 4 \mathrm{~N} \mathrm{NaOH}$. Both bottles are evacuated and weighed. In the field, the collection tubes are connected to the arsenic-containing bottle, the flask is tilted to allow passage of the gas through the absorbent. After pressure equalization due to accumulation of unabsorbed $\mathrm{CO}_{2}$, the connecting stopcock is opened carefully and the acid gases are rapidly absorbed by the alkaline solution. The first bottle is used primarily for trapping sulfur containing gases while the second is primarily for trapping $\mathrm{CO}_{2}$.

\section{COMMENTS:}

In Figure 1, the use of titanium intake tubes prevents reaction of the tubes with volcanic gases. 


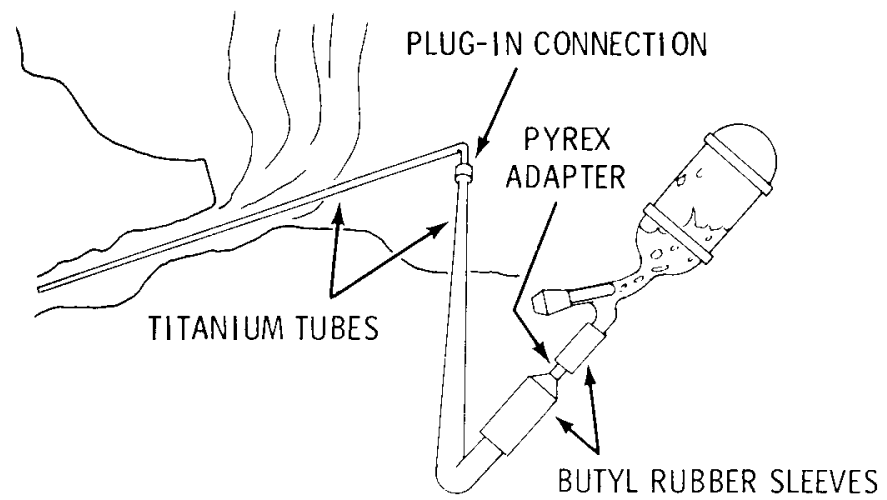

Figure 1. Apparatus for collection of volcanic gas samples.

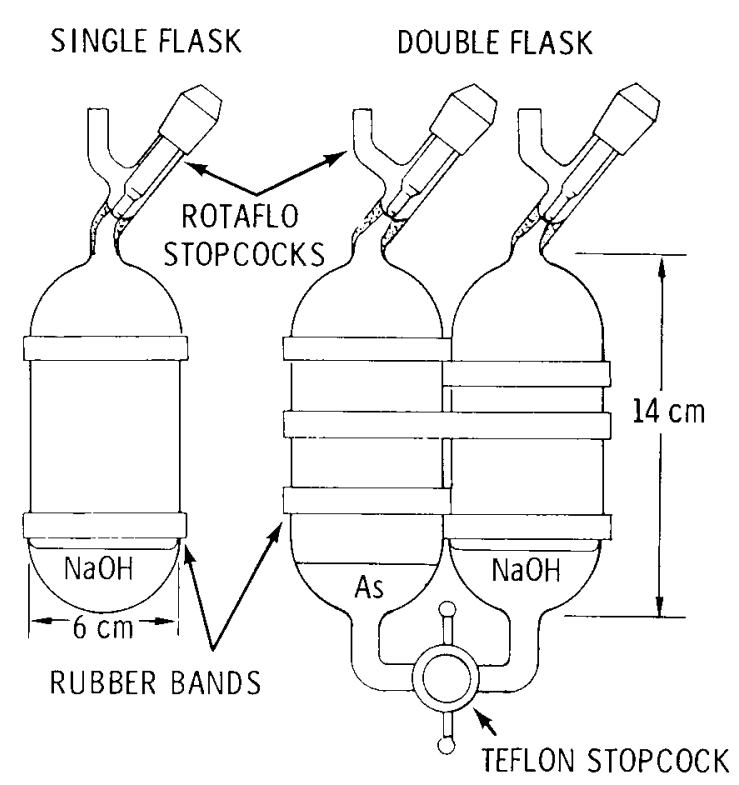

Figure 2. Collection bottles for volcanic gas samples. 
METHOD TITLE:

Evacuated flask method for fumarole sampling.

NO. $5-S$

SAMPLE TYPE: SAMPLE POINT:

Gas

Fumarole

APPLICATION:

Sampling steam and gas from volcanic

fumaroles.

\section{REFERENCES:}

Ellis, A.J. et al., "Methods of Collection and Analysis of Geothermal Fluids," Report No. C.D. 2103 New Zealand Dept. of Sci. and Ind. Res., New Zealand, July 1968.

Finlayson, J.B. "The Collection and Analysis of Volcanic and Hydrothermal Gases," Geothermics Specia1 Issue 2, Vo1. 2, p. 1344-1354, 1970. Ellis, A.J. and W.A.J. Mahon, "Chemistry and Geothermal Systems," Academic Press, New York, 1977. (See note $V$ on page B-1)

\section{DESCRIPTION}

7) The gas and steam emanating from a fumarole is collected in an evacuated collecting flask containing 100-200 ml 50-70 Vol. \% NaOH or $\mathrm{KOH}$ solution. The flask capacity is $0.5-10$ liters. A stainless steel dome is placed over the vent of the steam fumarole. The base of the dome is covered for insulation and to prevent air infiltration through cracks between the lip of the dome and the edge of the vent. A vertical pipe, lagged to reduce condensation, leaks excess discharge to the atmosphere and sample discharge through a tee-joint near its base to an air condenser. When the dome and condenser have been purged of air by the fumarole discharge, the flask is attached to the condenser and opened, gradually, to avoid drawing in air through the pipe in the dome.

2) The alkaline condensates are analyzed as soon as possible after collection, if necessary in the field. Alkaline sodium sulfide oxidizes rapidly in the presence of small amounts of air. Aliquots of the sample are withdrawn from the flask by means of a probe similar to that shown in Figure 3. The probe is evacuated by a hand vacuum pump or filled with distilled water before use. Sodium carbonate solutions are stable, and may be retained for long periods before analysis.

The partial pressure of residual gases can be measured in a simple field laboratory and the gases transferred to small glass ampoules for storage, using the apparatus shown in Figure 3. All connections are made of thick-walled (OD $22 \mathrm{~mm}$; ID $7 \mathrm{~mm}$ ) butyl rubber, which is impervious to gases. The pressure of residual gas in the storage ampoule is kept as near atmospheric pressure as possible. The residual gases are analyzed in the laboratory using standard PVT techniques or gas chromatography. The composition of the steam discharged from a fumarole is assessed from the analyses of carbon dioxide and hydrogen sulfide, the partial pressure and analysis of the residual gases, the temperature of the flask during residual gas pressure measurement, and the known volumes of the flask, condensate, and sodiuni hydroxide.

COMMENTS:

1. The flow of vapor through the sampling outlet can be controlled with a gravity flap valve on top of the stainless steel tube in the fumarole (Figure 4). The flap valve can be weight adjusted according to the velocity of the discharge.

2. Flask is cooled by water or by air when water is not available.

3. Collection in $\mathrm{KOH}$ or $\mathrm{NaOH}$ traps $\mathrm{CO}_{2}$ and $\mathrm{H}_{2} \mathrm{~S}$. Separate collections for $\mathrm{NH}_{3}, \mathrm{~F}, \mathrm{~B}$, and $\mathrm{SiO}_{2}$ are made in evacuated flasks containing no alkali.

4. The residual gases $\mathrm{N}_{2}, \mathrm{CH}_{4}, \mathrm{H}_{2}$, etc. remain undissolved in caustic. The pressure of the residual gases is initially low and a pressure gradient is maintained between the steam EDITION: inlet and the flask. Collection ceases when the residual gas pressure equals the steam inlet pressure. Additional collecPAGE: tion for $\mathrm{H}_{2} \mathrm{~S}$ and $\mathrm{CO}_{2}$ can be achieved by attaching a vacuum pump to the flask outlet and removing the residual gases. 


\section{ILLUSTRATION:}

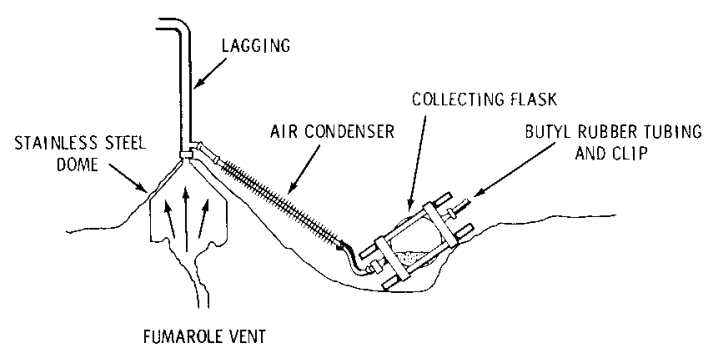

FIG 1. METHOD OF SAMPLING FUMAROLIC GAS \& STEAM BY CONDENSATION IN EVACUATED FLASKS

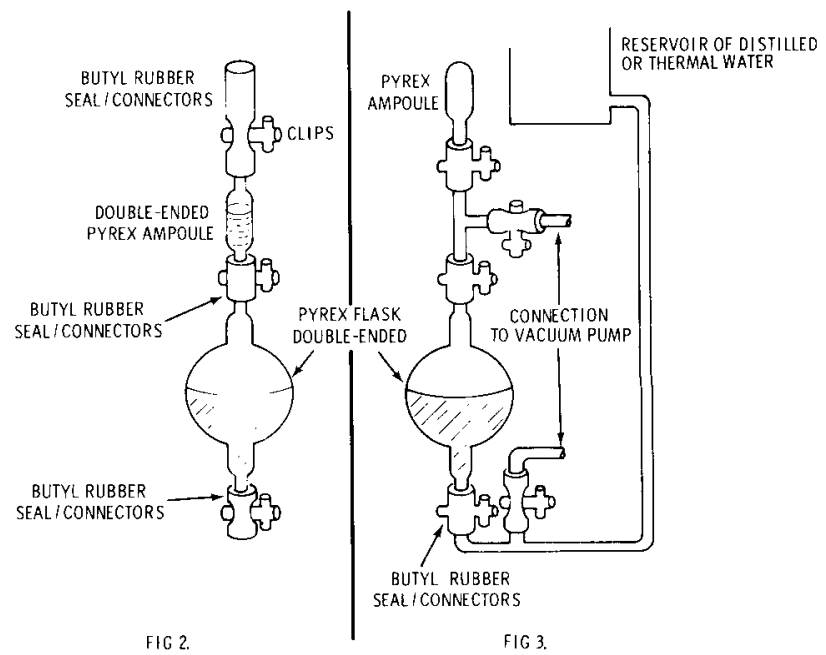

FIGS 28 3. APPARATUS FOR TRANSFERRING STEAM CONDENSATE AND GAS SAMPLES IN THE FIELD

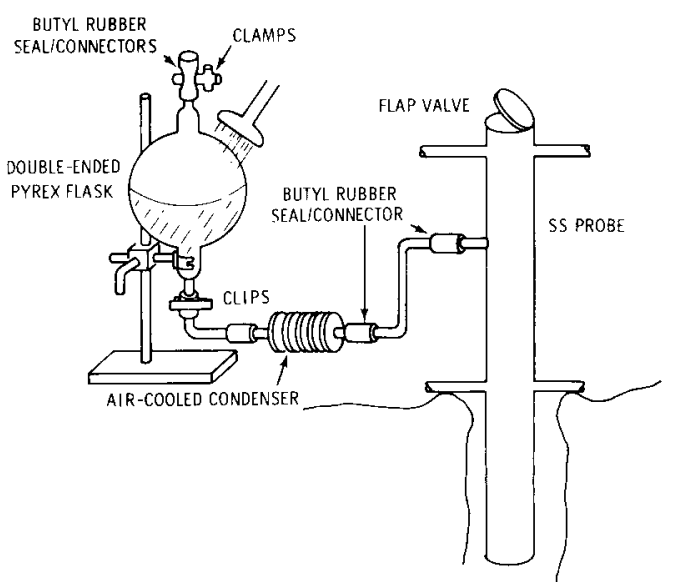

FIG 4 APPARATUS FOR SAMPLING LARGE FUMAROLES 


\section{METHOD TITLE:}

Naughton tube method for sampling volcanic fumaroles.
APPLICATION:

Sampling of gases from fumaroles.
NO. $\quad 6-5$

SAMPLE TYPE: $\quad$ SAMPLE POINT:

Gas

Fumarole

\section{REFERENCES:}

Finlayson, J.B. "The Collection and Analysis of Volcanic and Hydrothermal Gases," Geothermics Special Issue 2, Vol. 2, p. $\overline{1344}-1354$, 1970 .

\section{DESCRIPTION}

1. The Naughton tube shown in the illustration consists of a one meter length of Pyrex glass tube (10 mm OD) with an enlarged section near one end and break-seals at each end (one for sampling and one for analysis).

2. Silica gel, for adsorption of the acid gases and water vapor, fills the narrow section and is activated by heating to $350^{\circ} \mathrm{C}$ during evaucation of the tube.

3. The break-seal at the sampling end is hook-shaped to facilitate opening of the tube with a wire pul1-off.

A constriction between the silica gel section and the sampling tip allows the tube to be sealed with a portable gas-oxy torch while the tip remains in the vent.

5. For analysis, the gases are released through the enclosed break-seal to a pressure measuring and gas transfer system. The gases adsorbed on the silica gel are desorbed by gradually bringing the temperature of the adsorbent up to $300^{\circ} \mathrm{C}$.

\section{COMMENTS:}

Reactions between collected gases (especially $\mathrm{H}_{2} \mathrm{~S}$ and $\mathrm{SO}_{2}$ ) are prevented in the Naughton tubes by adsorption and separation of the acid gases on activated silica gel, which acts in the same manner as a chromatographic column. 


\section{ILLUSTRATION:}

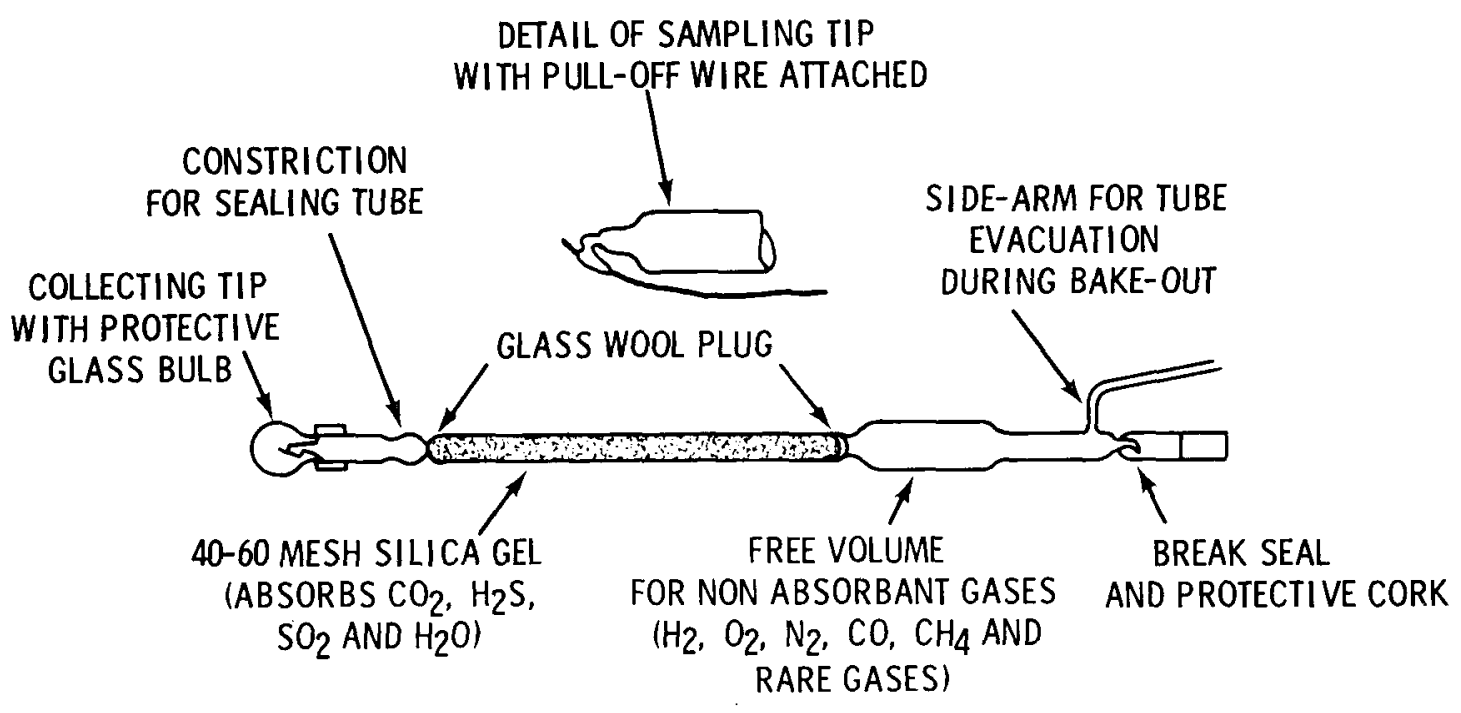

Silica gel gas sampling tube.

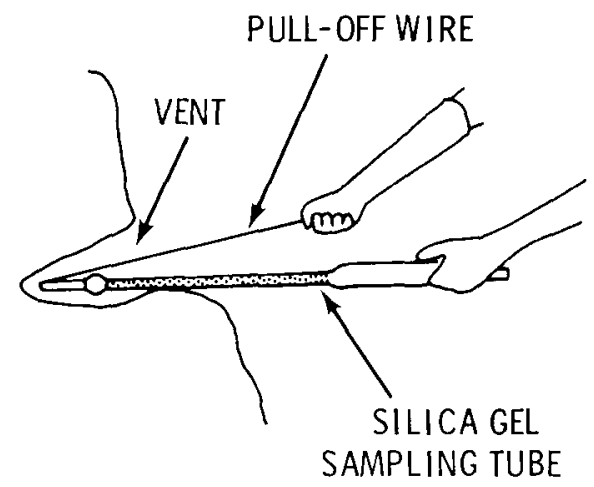

Method of sampling volcanic gases from a fumarole with the silica gel sampling tube. 
IVIE I HUU IIILE:

Air displacement method for sampling fumaroles,

APPLICATION:

Sample fumarole gases
NO. $\quad 7-5$

SAMPLE TYPE: SAMPLE POINT:

Gas

Fumarole

\section{REFERENCES:}

Finlayson, J.B. "The Collection and Analysis of Volcanic and Hydrothermal Gases," Geothermics Special Issue 2, Vol. 2, p. 1344-1354, 1970.

\section{DESCRIPTION}

Apparatus consists of an intake tube attached to one end of a sample flask. A sample is collected by inserting the intake tube into the gas vent. When the sampling train is judged to be swept free of air, the sample flask is sealed.

A condenser, usual1y a glass bottle or tube cooled by ice water or air circulation is often placed between the intake tube and the sample flask to separate and collect the steam fraction of the discharge.

A water aspirator or pump is often used to pull the sample through the collecting Grain if insufficient pressure is present.

\section{COMMENTS:}

Copper, iron, and stainless steel intake tubes tend to react with volcanic gases and may contaminate the sample. Pyrex glass or, for high temperature vents, silica tubing, are preferable, although strength is sacrificed. This might be overcome by placing the intake tube inside a stainless steel tube. 


\section{ILLUSTRATION:}

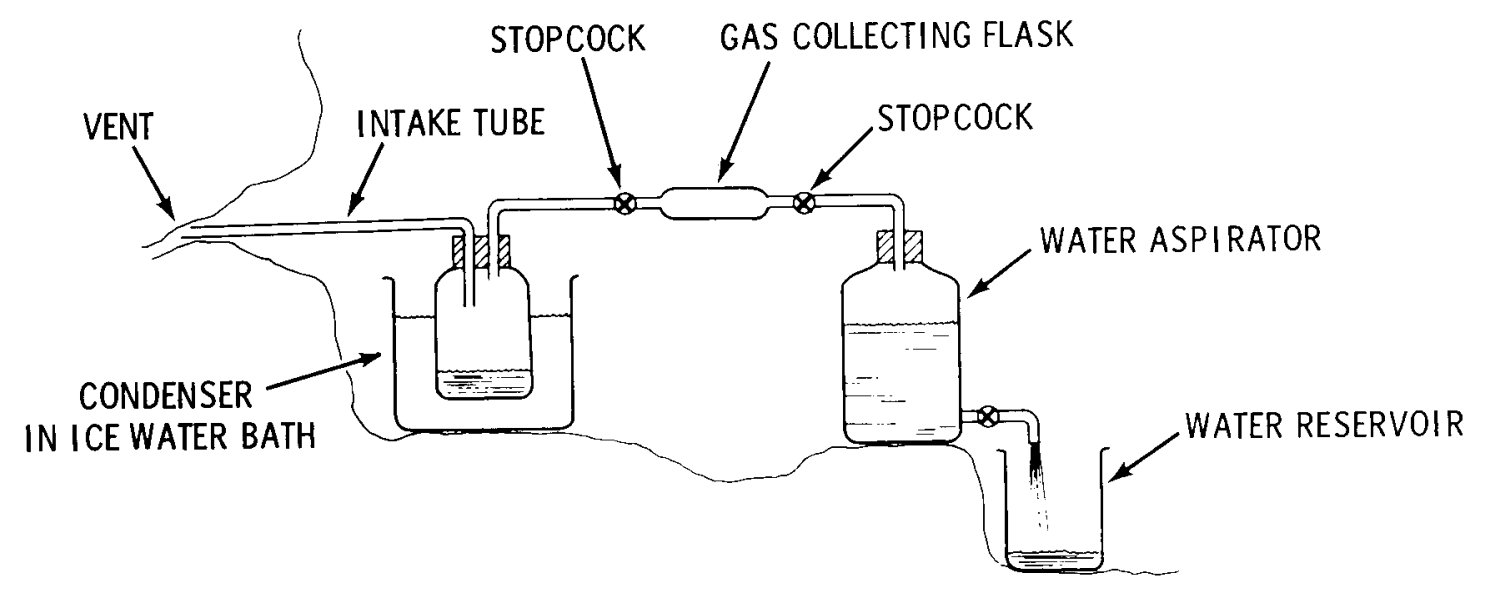

Gas collection from a fumarole by air displacement. 
METHOD TITLE:

Syringe method for sampling entrained gases

NO. $8-5$

SAMPLE TYPE: SAMPLE POINT:

Gas

steam weil.

APPLICATION:

Sampling dissolved and entrained gases in fumaroles, hot springs, or steam wells.
REFERENCES:

Truesdel1, A. H. and K. L. Pering, "Geothermal Gas Sampling Methods," U.S.G.S. Openfile Report 74-361, Menlo Park, CA, 1974.

DESCRIPTION

Two $60 \mathrm{ml}$ polypropylene syringes (Monoject) and an evacuated $50 \mathrm{ml}$ pyrex gas sample bottle with an o-ring seal (constructed using Ace glass adapter 5027 modified by the addition of a second o-ring so that the exit tube can be evacuated) are connected by 1/8" ID Tygon tubing and four 3-way polypropylene stopcocks (Pharmaseal) with short pieces of tubing used to seal the joints.

At the start of each collection, 10 or $20 \mathrm{ml}$ of $3 \mathrm{~m} \mathrm{NaOH}$ (prepared from low carbonate reagent) is drawn into syringe B through stopcock 4. Dissolved air in the solution is reduced by closing the stopcock to the syringe (the stopcock handle indicates the closed direction: see detail in illustration), pulling the plunger to produce a partial vacuum over the solution, shaking to join the air bubbles and releasing the accumulated air through the stopcock. An inverted funnel connected to the apparatus with 1/8" Tygon tubing is dipped in the hot spring and filled with water. With stopcock 1 closed to the side tube, syringe $A$ and cock 2 are used to pump water through the tubing and out of the sidearm of stopcock 4 ch is closed toward the gas bottle. When this part of the tubing is water filled, the inverted funnel is moved over the gas vent and gas is allowed to accumulate. Further pumping with syringe $A$ displaces the water in the tube with gas from the vent. When the tubing is flushed with gas, stopcock 4 is closed by moving it $45^{\circ}$ to an intermediate position. Syringe $A$ is then filled with $50 \mathrm{ml}$ of gas which is allowed to cool to near air temperature. The cooled gas, its volume noted, is then transferred into syringe $B$ through stopcocks 2 and 3 . With stopcock 2 closed to the sidearm the apparatus is shaken and the $\mathrm{CO}_{2}$ and $\mathrm{H}_{2} \mathrm{~S}$ are rapidly absorbed into the $\mathrm{NaOH}$ solution. The volume of the non-absorbable or residual gas may be measured from the change in the position of the plunger of syringe $B$. This procedure is repeated until approximately $25 \mathrm{ml}$ of residual gas has accumulated in syringe $B$. The tubing from stopcock 2 to the glass sample bottle is then partially evacuated by closing stopcock 4 to the vent, stopcock 3 to the $\mathrm{NaOH}$ solution, and stopcock 2 to the funnel and pulling the plunger of syringe $A$ out as far as possible without breaking the seal while the plunger is out. Stopcock 2 is then closed toward the gas bottle and the evacuated air and gas is released through stopcock 1. This procedure is repeated twice more. The evacuated glass sample bottle is then opened by unscrewing its threaded bushing slightly

COMMENTS:

(over)

1. In collecting from high temperature springs, some condensate will accumulate in the syringe and this may be either discarded or collected through stopcock 1.

2. For volume measurements in the syringe, it is not accurate to note the position of the meniscus because the ends of the syringe and plunger are conical: The plunger is usually slightly sticky and an accurate volume measurement requires manipulation and bracketing by feel.

EDITION:

PAGE:

$7 / 78$ 


\section{ILLUSTRATION:}
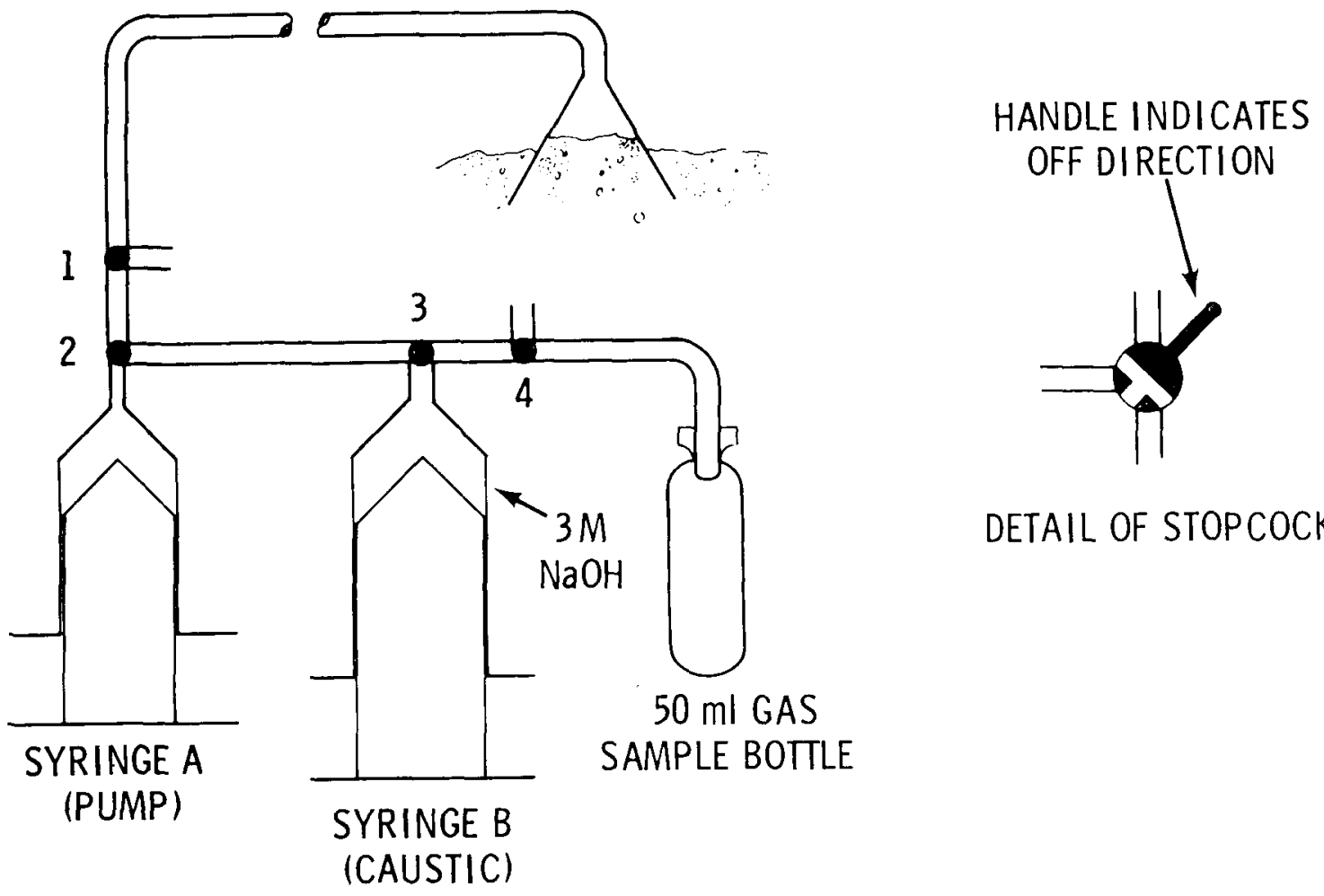

DETAIL OF STOPCOCK

Apparatus for gas sampling of fumaroles, hot springs or steam wells.

and pushing the closure tube into the bottle until the small hole in the tube is within the bottle. Now, with syringe B held upright, gentle opening of stopcock 3 to connect the glass bottle to syringe $B$ allows the residual gas to flow into the bottle. When $4 \mathrm{ml}$ residual gas remains in syringe $B$, stopcock 3 is closed, the gas bottle is closed by gently pulling its closure tube out of the bottle until its side hole is no longer connected to the bottle interior, and the bushing is tightened. The $4 \mathrm{ml}$ of remaining gas is then pushed into the tuting to reduce the possibility of air contamination. 


\section{METHOD TITLE:}

Sealable bottle method for sampling weir boxes.
NO. $9-5$

SAMPLE TYPE: SAMPLE POINT:

Liquid
Weir box
APPLICATION:

Sampling silencer weir boxes for liquid.

\section{REFERENCES:}

Ellis, A.J. and W.A.J. Mahon, "Chemistry and Geothermal Systems," Academic Press, New York, 1977.

\section{DESCRIPTION}

The apparatus consists of a bottle holder, into which a different bottle is fitted for each sampling, attached to a long handle. Connected to the handle is a spring-operated rubber block which covers the top of the bottle during its immersion and withdrawal from the weir box. This prevents evaporation of the sample. 


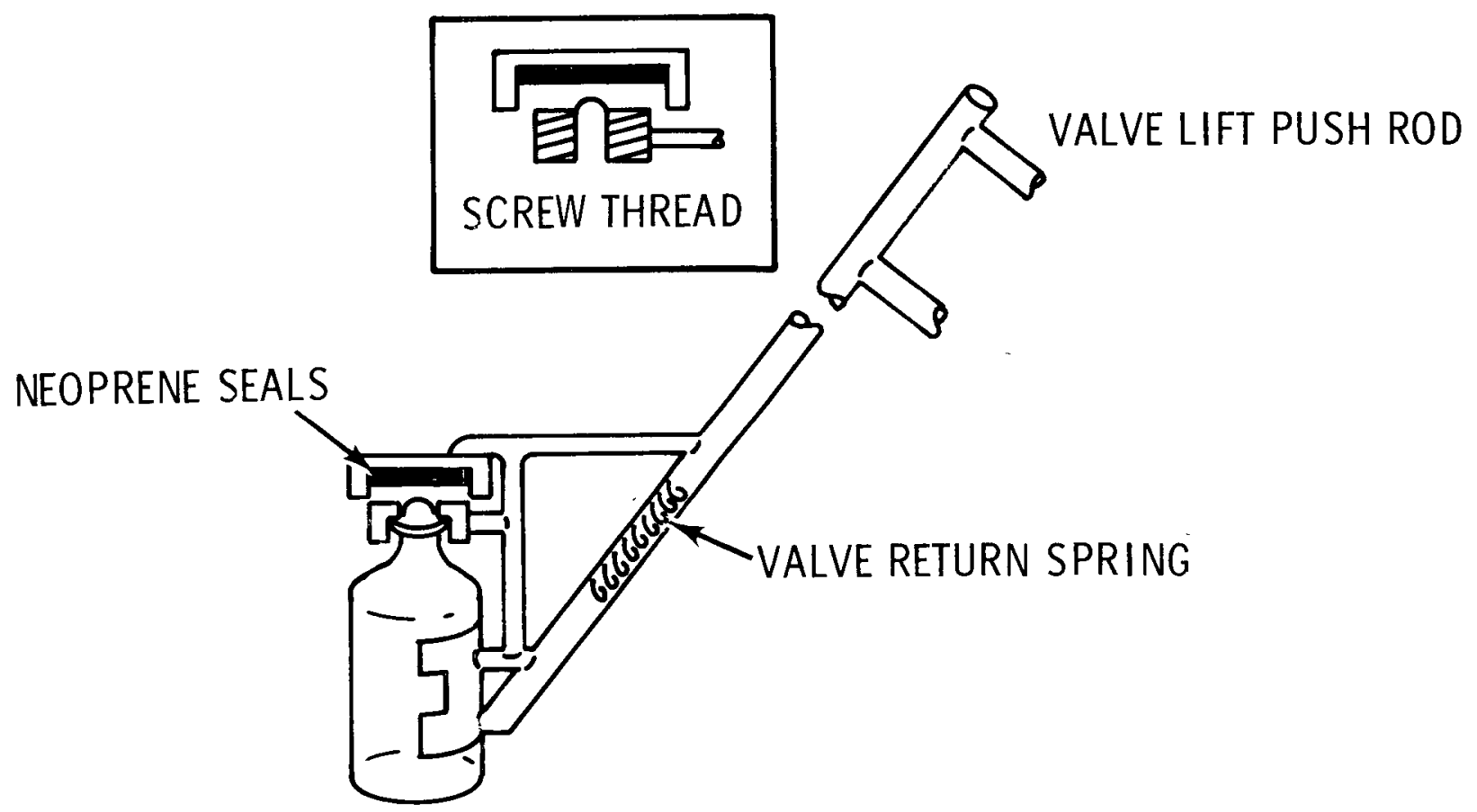

SAMPLER FOR COLLECTING WATER SAMPLES FROM THE WEIR BOX OF A GEOTHERMAL WELL 


\section{METHOD TITLE:}

Naughton tube method for sampling volcanic gases.
NO. $10-\mathrm{S}$

SAMPLE TYPE: SAMPLE POINT:

Gas

Dritl hole
APPLICATION:

Sampling volcanic gases.

\section{REFERENCES:}

Finlayson, J. B. "The Collection and Analyses of Volcanic and Hydrothermal Gases," Geothermics Special Issue 2, Vol. 2, p. $\overline{1344}-$ 1354,1970 .

\section{DESCRIPTION}

1. Naughton tubes containing a silica gel absorbent are thermally insulated by placing them in a silica jacket with the annular space filled with crushed fire brick.

2. Stainless steel wire cable is used to lower the tubes into the drill holes and a wire pull-off is used to open the tip at the desired depth.

3. Thermal inertia of the insulation is such that heat is supplied to the inner sampling tube for a short time after withdrawal. The collected gas expands and will be "blowing out" as the tube is sealed. The tube is closed with a portable gas-oxy torch.

\section{COMMENTS:}

1. Insulated tubes can be exposed to $1000^{\circ} \mathrm{C}$ for periods up to one minute without the temperature of the silica gel exceeding $100^{\circ} \mathrm{C}$.

2. Collections were reported to be made within one minute time limit (at maximum depth of 15 meters) with the tubes being sealed immediately on withdrawal from the drill hole. During closing the flow of gas through the tube opening does not prevent the flow of air in the opposite direction. The flow rate of each gas through the opening depends primarily on the difference in the partial pressure of the gas on each side of the opening and on the size of the opening.

\section{EDITION:}

PAGE: 
ILLUSTRATION:

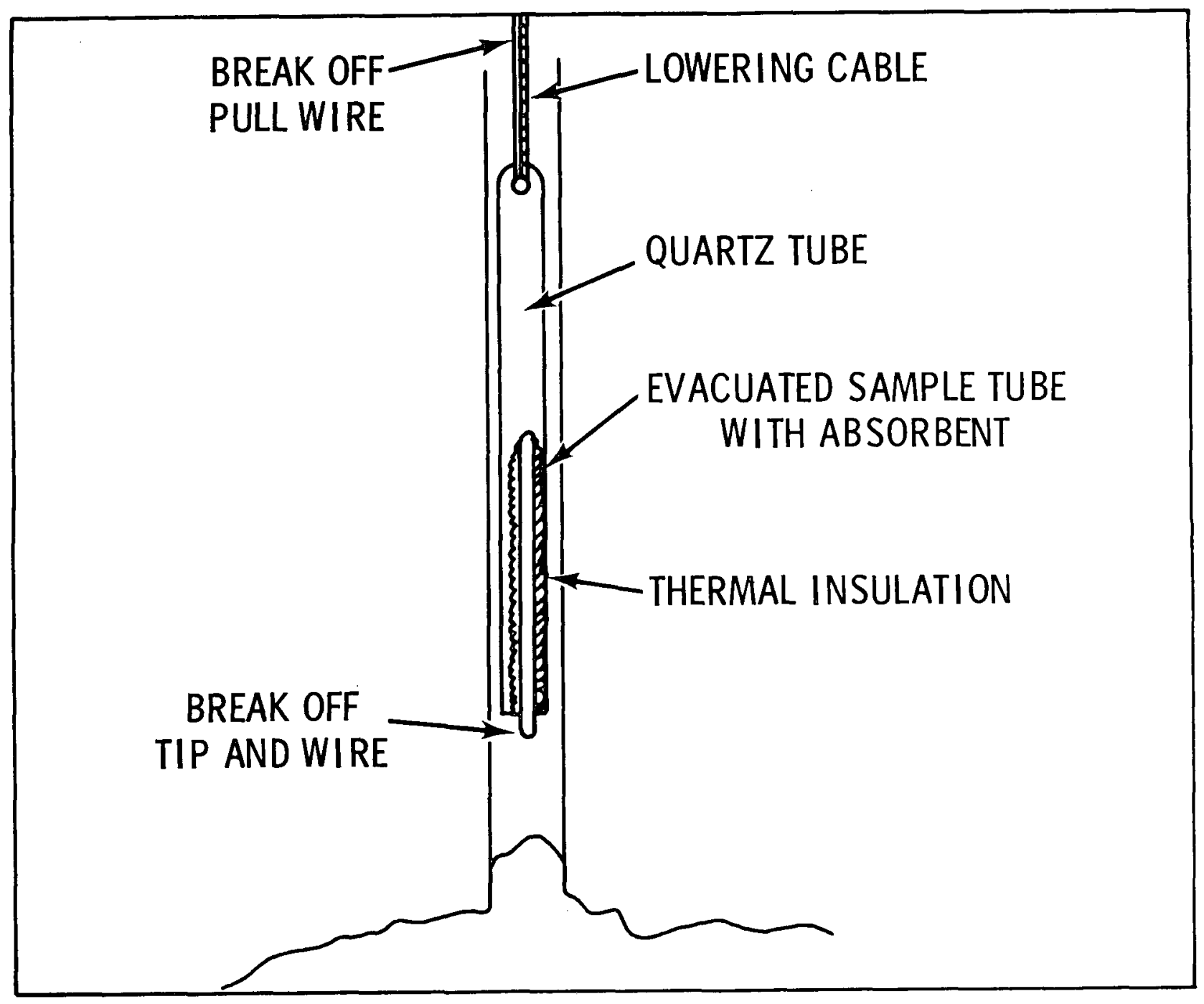

Method of sampling gases in holes drilled through the crust of a lava lake. 
METHOD TITLE:

Cooling coils
NO. $11-S$

SAMPLE TYPE:

Liquid
SAMPLE POINT:

Pipeline, separator or other
APPLICATION:

Sampling condensed brine
REFERENCES:

Appendix 1: Field Test 1978.

\section{DESCRIPTION}

1. Cooling coils are made of stainless steel with total length 20 - $24 \mathrm{ft}$., ID 0.25 $0.50 \mathrm{in}$. and $000.25-0.50 \mathrm{in.}$. Wall thickness not less than 0.02 in. fulfills most requirements for sample cooling.

2. Varying diameters of tubing are used because of variability in sampling requirements.

3. Coil diameter is normally 8 - $10 \mathrm{in}$. to fit into container that acts as cooling bath. Five gallon buckets are most frequently used for this purpose.

4. Two coils commonly used; first is immersed in a water bath to cool sample to boiling point of water, second coil is immersed in an ice bath. This saves usage of large amounts of ice.

5. Flow of brine through coils must be carefully watched to avoid flashing of the sample in the coils.

6. Alternatively, a water cooled condenser can be used if a sufficient supply of cooling water is available.

\section{COMMENTS:}

1. During field test Whitey or equivalent shutoff or requlating needle valves were used for maintaining proper flow rates through the coils. Gate or ball valves are not suitable for regulating flow,

2. Flexible armored lines equipped with quick disconnect fittings were used upstream of coils to connect to $1^{1 "}$ ball valves on pipelines, etc. This allowed for portability of cooling coils for various sample locations.

3. Coils of $1 / 4^{\prime \prime}$ ID or larger normally used for condensing brine. Smaller (1/8" ID) lines may be used to sample steam lines.

EDITION: 4. During field test, brine surging in pipelines resulted in pulsating effects while collecting through coils. It is not advisable to attempt to correct this effect with the 
SAMPLING CONDENSED BRINE USING COOLING COILS

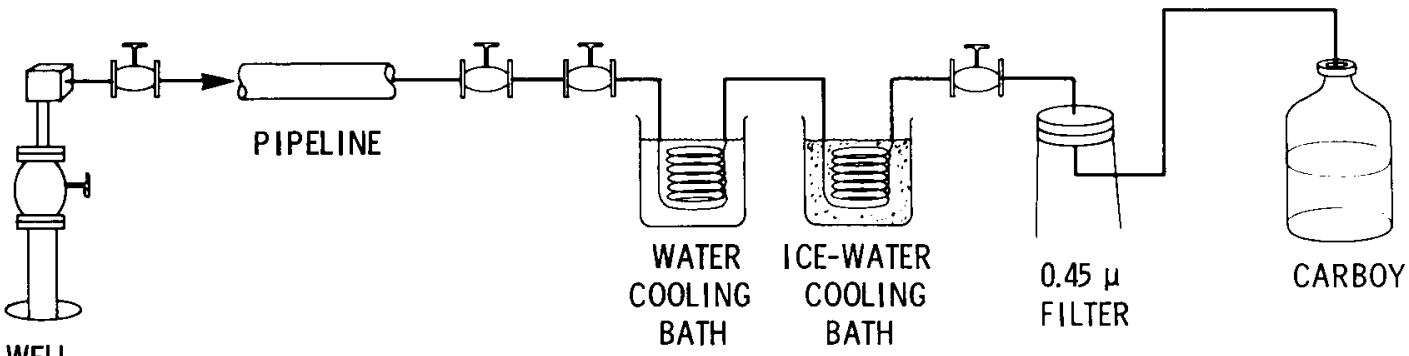

WELL

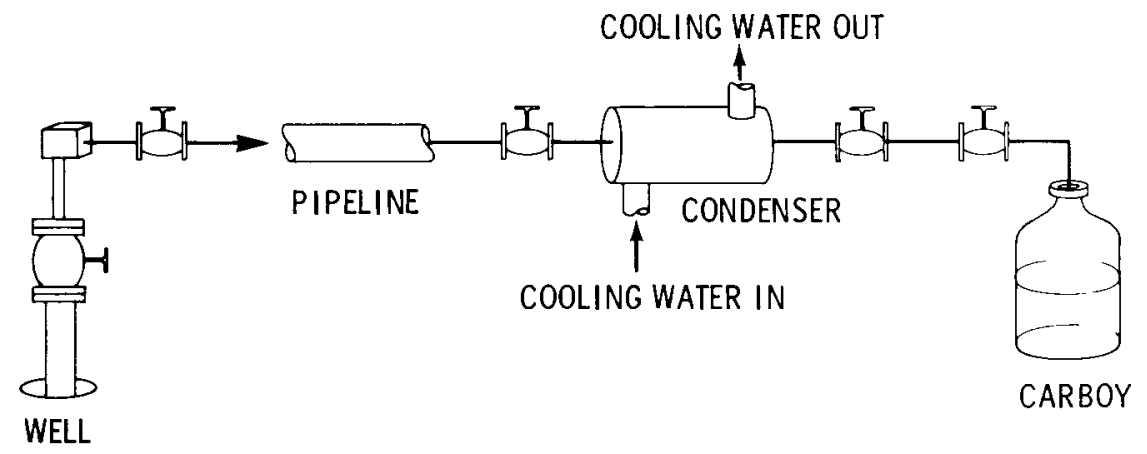

SAMPLING CONDENSED BRINE USING JACKETED CONDENSER

high velocity through the coils resulting in a potentially dangerous burn situation for the operator. 


\section{METHOD TITLE:}

Sparging method for trapping gases.
NO. $12-5$

SAMPLE TYPE: $\quad$ SAMPLE POINT:

Gas

Pipeline
APPLICATION:

Sampling of dissolved and entrained gases in brine.
REFERENCES:

Appendix 1: Field Test 1978.

DESCRIPTION

1. Condensed brine is allowed to flow into a series of tubes or carboys containing absorbing solutions. The entrained gas is dispersed through fritted glass to allow for more complete absorption. (Figure 1)

2. Examples of absorbing solutions include sodium hydroxide solution for trapping $\mathrm{H}_{2} \mathrm{~S}$ and $\mathrm{CO}_{2}$, ammonium hydroxide solution saturated with $\mathrm{SrCl}_{2}$ for trapping $\mathrm{CO}_{2}$, zinc acetate or cadmium chloride solution for trapping $\mathrm{H}_{2} \mathrm{~S}$, etc.

3. Efficiency of absorption can be improved by the addition of more absorbing tubes in series (Figure 2) to allow the head space gas to be dispersed through additional absorbing solutions. During a field test of this arrangement the first sample tube on the left was filled with 750-1000 $\mathrm{ml} 2 \mathrm{~N} \mathrm{NaOH}$ sol'n for collecting $\mathrm{CO}_{2}$. The second tube was filled with $100 \mathrm{ml} 2 \mathrm{~N} \mathrm{NaOH}$. Brine + gas entered the first tube through the sparger and mixed with the $2 \mathrm{~N} \mathrm{NaOH}$ until the final volume (in first tube) was 1000-1500 ml. Blanks were also taken by filling the 1st tube (on left) with $2 \mathrm{~N} \mathrm{NaOH}$ and pouring this into linear polyethylene sample bottles.

4. Fisher-Milligan bottles were also used in series during the field test to collect entrained gas (Figure 3). The long path length due to the spiral inner coil allows for long contact with the trapping solution.

\section{COMMENTS:}

1. During field test the apparatus in Figure 2 proved to be cumbersome to employ after sampling due to its large size. Some redesign is contemplated.

2. It was also found during the field test that it was unnecessary to fill the second (smaller) tube with trapping solution (2N NaOH) and that the larger tube was sufficient for trapping. This was based on the concentration levels of $\mathrm{CO}_{2}$ encountered.

3. Fisher-Milligan bottles were found to be easy to operate and minimize contact of the operator with the $\mathrm{NaOH}$ sol' $n$. A contemplated modification to the bottles is an addition of a sparger stone to the bottom brine inlet tube. 


\section{ILLUSTRATION:}

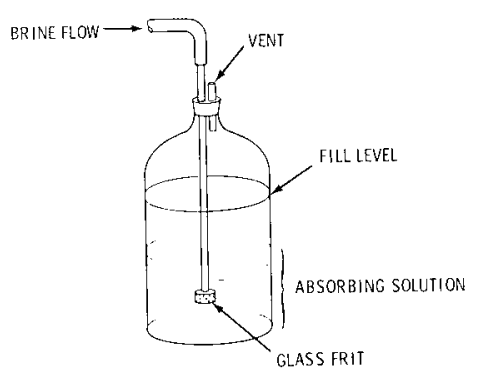

FIG 1. CARBOY CONTAINING ABSORBING SOLUTION TO TRAP ENTRAINED GAS

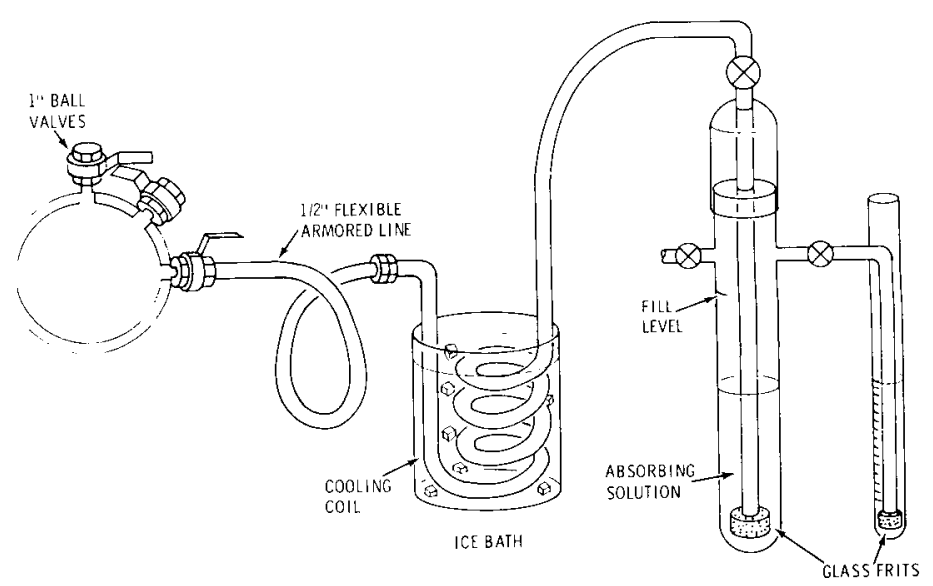

FIG 2. SPARGER ARRANGEMENT USED IN FIELO TEST FOR TRAPPING ENTRAINED GASES

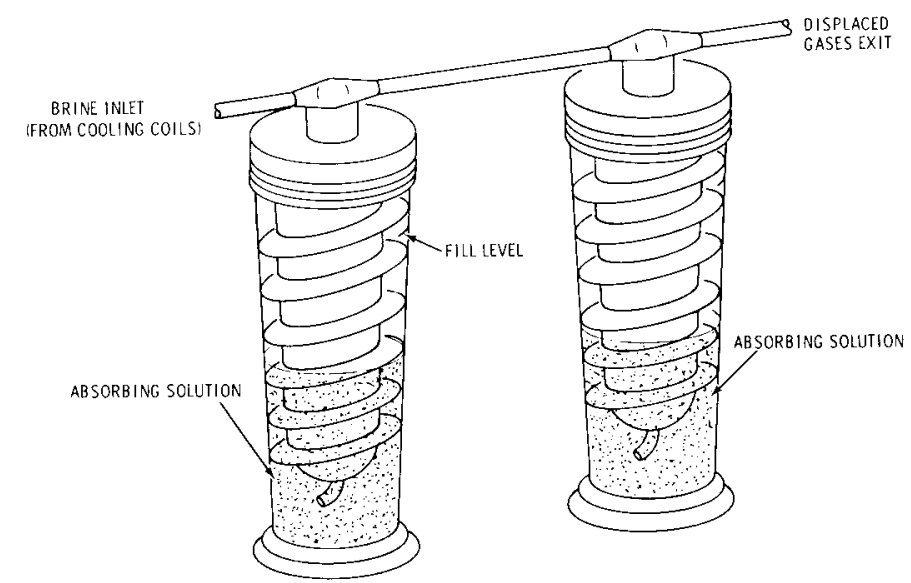

FIG 3. FISHER-MILLIGAN BOTLE SYSTEM USED IN FIEL.D TEST FOR TRAPPING NONCONDENSABLE GASES 
Cerro Prieto method for sampling noncondensables and $\mathrm{CO}_{2}$.

APPLICATION:

Sampling noncondensable gases and $\mathrm{CO}_{2}$. \begin{tabular}{l|l|l|l|l} 
NO. & $13-S$
\end{tabular}

SAMPLE TYPE: SAMPLE POINT:

Gas and Liquid

Pipeline from separator
REFERENCES:1. Mercado, Sergio, "Prelimnary Geothermochemical Exploration of $\mathrm{La}$ Primavera, Jalisco," Fifth Mexican Chemistry Congress, Merida, Yucatan, Apri1 1970.

2. Mercado, Sergio, "Hydrothermal Fluid Sampling for Isotopic C-13 and C-14: Geothermic Zone of La Primavera, Jalisco and Surroundine reas," Federal Electricity Commission, Electr city Industry Research Institute, Apri1 1971. 3. Appendix 1: Field Test 1978.

\section{DESCRIPTION}

1. The steam and noncondensable gases pass from the separator through a cooling coil immersed in an ice-water bath (Figure 1). The condensed steam and noncondensables pass into a 5-liter preweighed evacuated sampling vessel. While the vessel is still partially evacuated a predetermined amount of $10 \% \mathrm{NaOH}$ solution is allowed to enter. This reacts with the $\mathrm{CO}_{2}$ allowing more sample to be withdrawn from the separator. Following collection for a specified period of time, the 5-1iter vessel is removed and reweighed to determine the amount of condensed steam phase. The liquid phase is analyzed for $\mathrm{CO}_{2}$ while the gas phase is analyzed for residual gases $\left(\mathrm{CH}_{4}, \mathrm{~N}_{2}, \mathrm{H}_{2}\right.$, etc. $)$

2. During a field test of this method (Figure 2) the 5-1iter flask was initially fillec with $500 \mathrm{ml} 2 \mathrm{~N} \mathrm{NaOH}$ and weighed. The flask was attached to a vacuum pump and evacuated for $1 / 2 \mathrm{hr}$. Steam and noncondensables were removed from the steam line through a 1/2" ID insertable sample probe. The flow then proceeded through a water cooling bath followed by an ice water cooling bath. The flask was connected to the outlet side of the second condensing coil. Steam condensate and gas were allowed tc fill the flask until the flask pressure had equilibrated with the steam line pressur The flask was then removed and reweighed.

\section{COMMENTS:}

1. The liquid phase is removed from the flask in the lab by using a suction flask and using care so that gas is not removed. The liquid is subsequently analyzed for $\mathrm{CO}_{2}$.

2. The gas phase is removed in the lab by attaching an evacuated gas sampling bulb to the flask and drawing off a sample or alternatively by allowing a synthetic brine solution to enter through the bottom of the flask and displace the gas through the top stopcock. This has the disadvantage of allowing the gas to dissolve in the synthetic brine thus leadina to some error. (See Figures 2 and 3 under evacuated flask method for fumarole sampling.)

EDITION: 3. The fragile nature of the collecting flasks does not allow for easy transport of the sample without the risk of breakage. 


\section{ILLUSTRATION:}

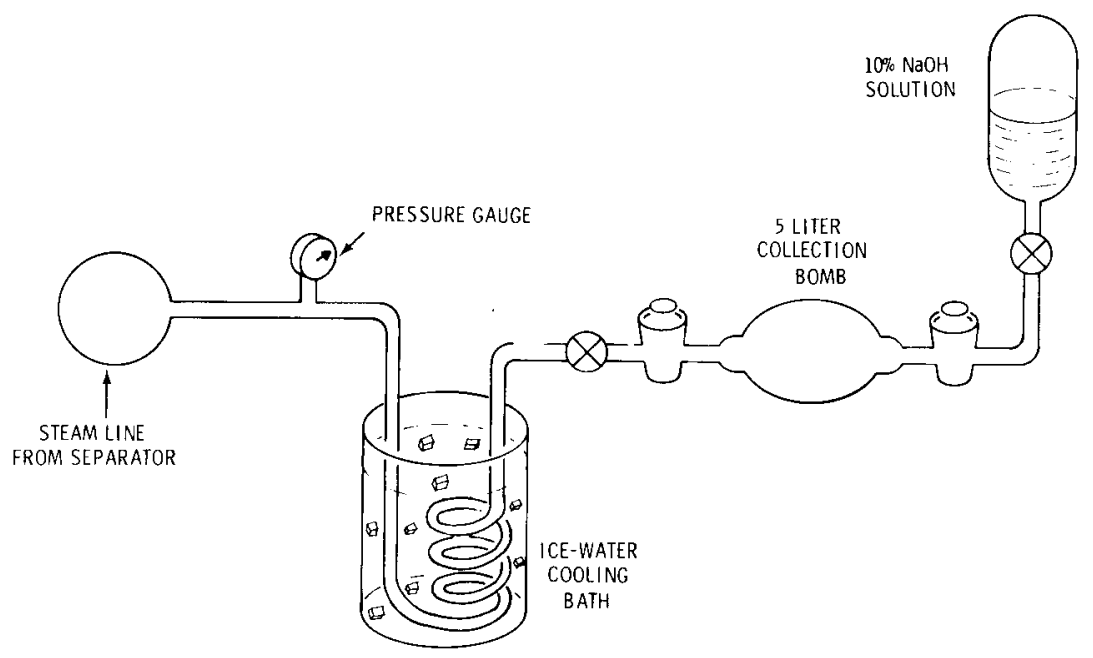

FIG 1. CERRO PRIEIO METHOD FOR COLLECTING NON-CONOENSABLES \& $\mathrm{CO}_{2}$

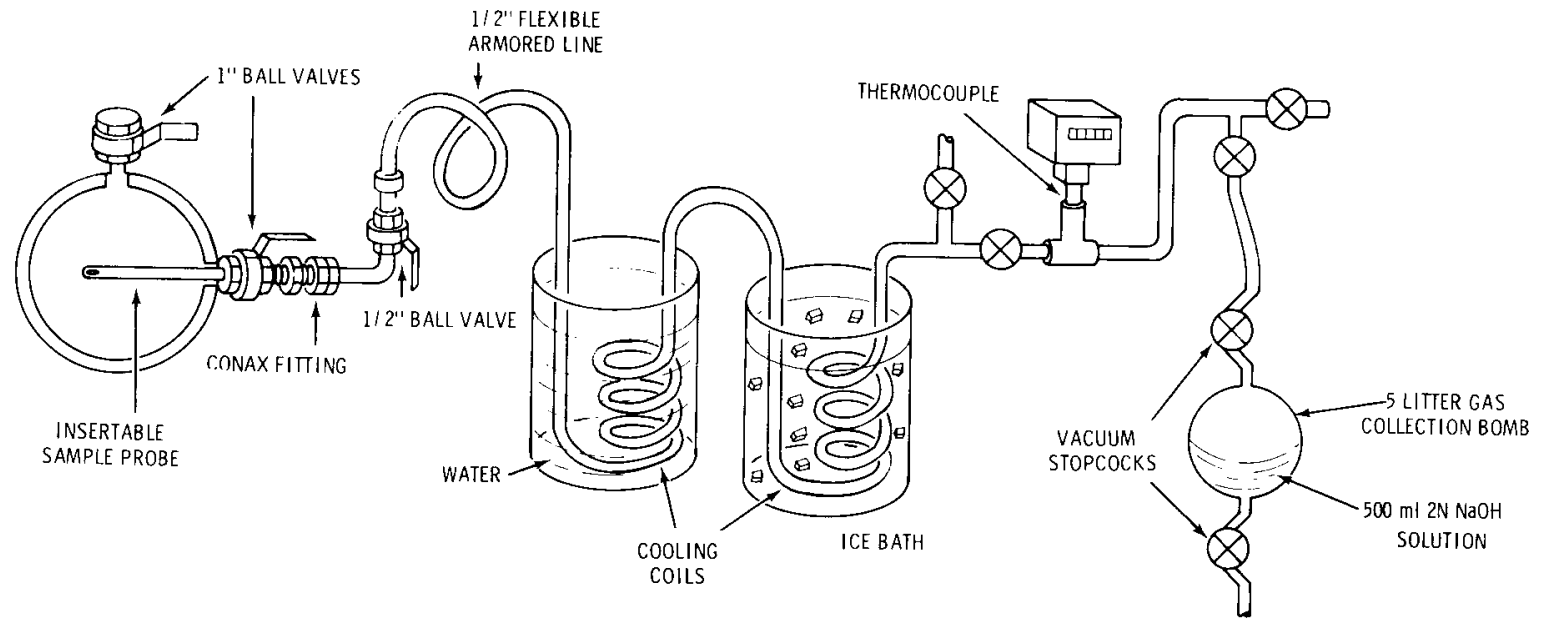

FIG 2. CERRO PRIETO METHOD USED IN FIELD TEST 
METHOD TITLE:

Hypodermic syringe method for sampling noncondensables.

\begin{tabular}{l|l} 
NO. & $14-5$ \\
SAMPLE TYPE:
\end{tabular}

SAMPLE POINT:

Steam Tine from

separator

APPLICATION:

Sampling noncondensable gases in steam line.

\section{REFERENCES:}

MicheTs, D.E. "CO 2 in Geothermal Steam. A

Rapid, Precise, and Accurate Field Assav

Technique," presented at Geothermal Resources

Council Meeting, Hilo, Hawaii, July 1978.

\section{DESCRIPTION}

1. Steam and noncondensables flow from the steam line through an insertable sample probe into cooling coils in an ice bath. A line from a tee after the insertable probe goes to a manometer which is used to measure the inlet pressure. The flow from the cooling coils goes into the calibrated hypodermic syringe after passing through a short section of Tygon tubing. The steam 1 ine pressure is used to fill the syringe. A predetermined volume is collected in the syringe. Equilibration is achieved when bubble movement is no longer observed in the Tygon tube. The equation below is used to calculate $\% \mathrm{CO}_{2}$ :

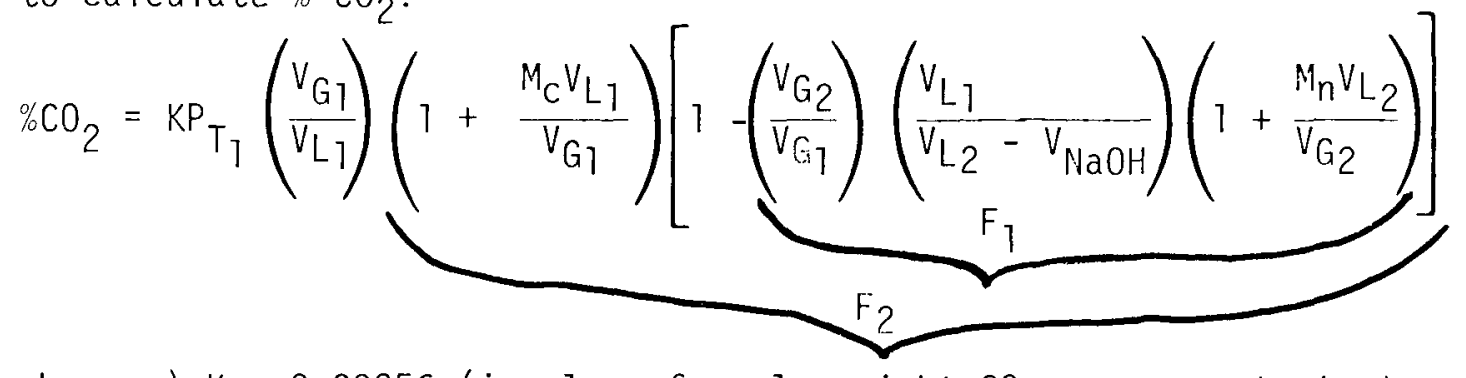

where a) $\mathrm{K}=0.00256$ (involves formula weight $\mathrm{CO}_{2}$, gas constant, temperature. and fluid density appropriate for press. measured in $\mathrm{cm} \mathrm{Hg}$, vol. in $\mathrm{ml}$ and density in grams per $\mathrm{ml}$ ).

b) $V$ and $P$ refer to $v 01$. and press., $L$ and $G$ refer to 1 iq. and gas phase and 1 and 2 refer to the collections, specifically 2 refers to that involving $\mathrm{NaOH}$.

c) Subscript $T$ on pressure refers to total pressure inside syringe (barometric + manometer pressure).

d) $\mathrm{F}_{1}$ represents fraction of $\mathrm{P}_{\mathrm{T}_{1}}$, due to non- $\mathrm{CO}_{2}$ gases.

e) Factor $M_{n}$ represents mol.wt. nitrogen in equation above assuming nitrogen (ovel

\section{COMMENTS:}

1. This method should be used for low pressure lines only:

2. Six to eight field determinators per hour can be made using this method.

3. Absolute pressure (barometric) must be known to make accurate calculations. 


\section{ILLUSTRATION:}

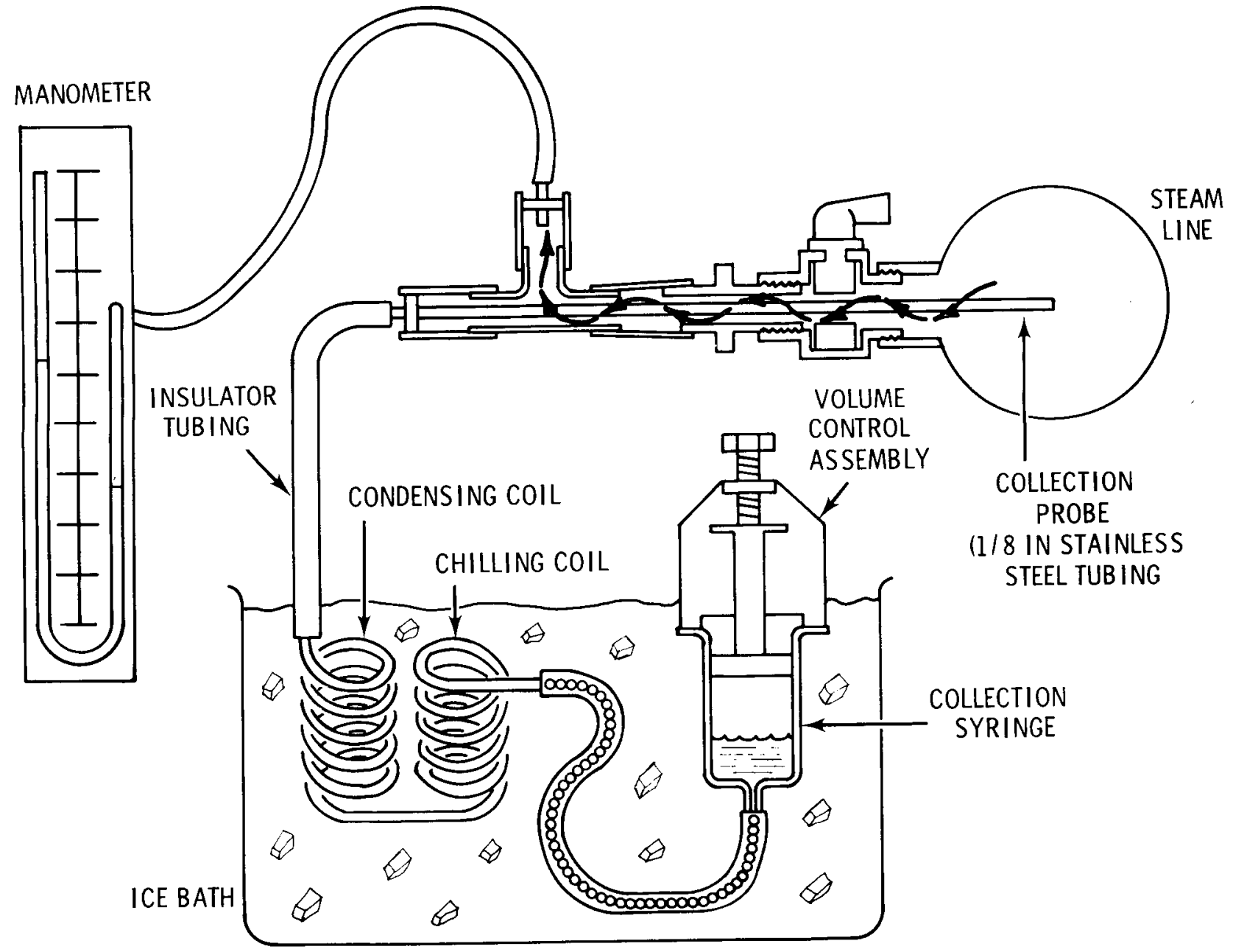

SYSTEM FOR SAMPLING \& MEASURING NON-CONDENSABLE GAS IN STEAM

dominates the non- $\mathrm{CO}_{2}$ fraction.

f) $\mathrm{F}_{2}$ represents virtual pressure fraction for $\mathrm{CO}_{2}$.

The non- $\mathrm{CO}_{2}$ fraction is given by: non- $\mathrm{CO}_{2}$ fraction $=\frac{\mathrm{F}_{1}}{\mathrm{~F}_{1}+\mathrm{F}_{2}}$

2. Two syringe collections are necessary for samples containing $\mathrm{CO}_{2}$ mixed with other gases. One syringe contains $\mathrm{NaOH}$ solution to trap the $\mathrm{CO}_{2}$. 
METHOD TITLE:

Tedlar bag method for sampling steam condensate and noncondensable gases
APPLICATION:

Sampling of steam condensate and noncondensable gases.
NO.

$15-5$

SAMPLE TYPE:

Gas and condensate

SAMPLE POINT:

Particle separators, condensate traps, cooling towers, off gás ejectors.

REFERENCES:Soinski, A.J., D.E. Claridge, and Rodney Melgard, "Field Sampling of Radioactive Geothermal Effluents, "Proceedings of the 1st Workshop on Sampling Geothermal Effluents, Las Vegas, NV, Oct, 1975, p. 126-142. Soinski, A.J., "The Use of Gas Sampling Bags for the Collection and Storage of Hydrothermal Gases," Proceedings, 2nd Workshop on Sampling and Analys is of Geothermal Effluents, Las Vegas, NV, February 7977.

Personal Communication, Letter of March 30 , 1978.

\section{DESCRIPTION}

The arrangement of the sampling apparatus is shown in the illustration. The total volume of the tubing is approximately 1 liter. The stainless steel probe is inserted into the flow stream in such a way that only steam passes through the collection train; the high steam flow rates make this simple to achieve. Two condensers are used; the first being water cooled, and the second ice-water cooled. The system is purged and equilibrated without a collection bag attached for approximately $10 \mathrm{~min}$. or until 10 to $20 \mathrm{~cm}^{3}$ of condensate has passed through the system. Collection is then initiated and continued until 1 to 2 liter of non-condensable gas has been collected in a Tedlar bag. The gas contents are analyzed later in the laboratory. The condensate is collected in a trapping bottle upstream of the tedlar bag.

\section{COMMENTS:}

1. Sulfur-containing species are unstable in plastic bags and should be analyzed on site.

2. Diffusional losses of hydrogen are appreciable.

3. Use of plastic bags should be limited to collection of chemically stable and higher molecular weight gases. 


\section{ILLUSTRATION:}

\section{TEDLAR GAS COLLECTION BAG}

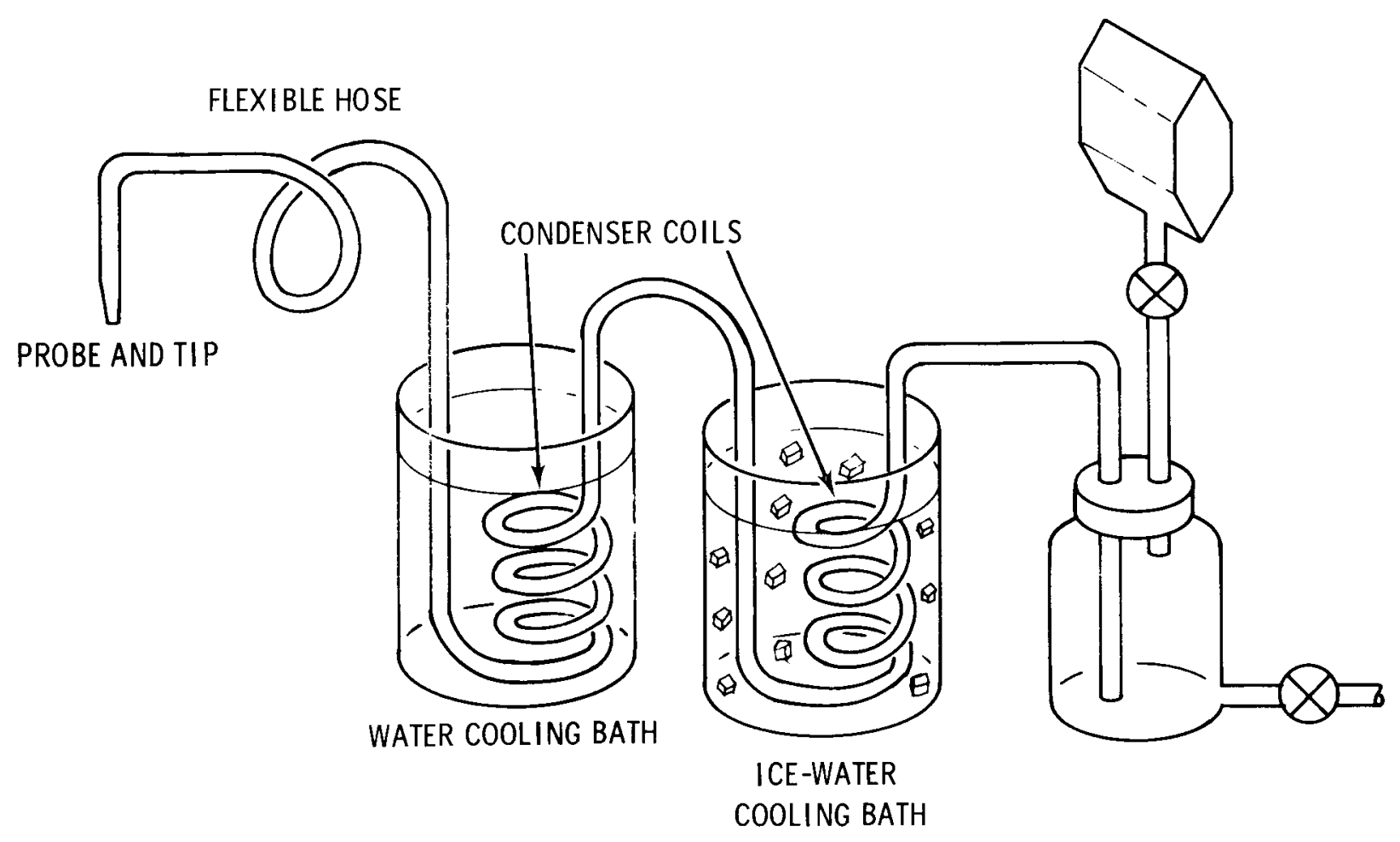

STEAM SAMPLING SYSTEM USING TEDLAR BAG 
Wet test meter method.
SAMPLE TYPE:

Gas
SAMPLE POINT:

Steam 1 ine from separator.
APPLICATION:

Sampling steam for noncondensable gases.
REFERENCES:

1. Christofferson, D.J., R.N. Wheatley, and J.A. Baur, "Union 0il Co. of California's Geothermal Sampling Techniques," Proceedings of the 1st Workshop on Sampling Geothermal Ef -

fluents, Las Vegas, NV, Oct. 1975, pp. 165-173

2. Appendix 1: Field Test 1978.

\section{DESCRIPTION}

1. The condenser coil in an ice water bath is connected to the steam line via a by-pass valve by means of a 25-foot flexible, stainless steel tubing using appropriate fittings at both ends (Figure 1). The by-pass valve is positioned to vent with no flow to the condenser and the sample port valve on the steam line is fully opened. After flowing steam through the connecting tubing for sufficient time (usually 10 to 15 minutes) for the tubing to come to temperature, steam is valved to the disconnected condenser until a condensate flow rate of about $50 \mathrm{ml} / \mathrm{min}$ is obtained. Approximately one 1 iter of condensate is purged through the condenser. This allows the condenser system to come to an equilibrated condition and also cleans the tubing of any possible residue or contamination from prior samplings.

The wet test meter is equilibrated by attaching the equilibrated condenser to the sample train and passing the noncondensible gases through the wet test meter for 10 to 15 minutes. The condenser is disconnected from the sample train. The collection bottle is replaced by a tared one-quart bottle and the wet test meter reading is noted. The condenser is quickly attached to the sample train by means of rubber tubing and actual sampling begins. Sampling continues until the collection bottle is filled or 3 to 4 liters of noncondensible gas volume is reached. The condenser is then disconnected from the train and the noncondensible gas content of the steam determined from the weight of water collected and the volume of gas measured after appropriate corrections for temperature and barometric pressure.

2. The system shown in Figure 2 was used to evaluate the method under field conditions. The steam and noncondensable flow passed from the steam 1 ine through an insertable sample probe (inserted to the center of the steam line) into a flexible armored line. Flow then continued to a cooling bath filled with water followed by a second cooling bath filled with ice water. The flow then passed into the glass separator with the condensed steam being removed from the bottom for analysis or alternatively the rate could be measured with a graduated cylinder. Noncondensables from the top of the glass separator passed through the wet test meter or alternatively were (cont.)

COMMENTS:

1. Wet test meters must be properly equilibrated to prevent absorption of gases such as carbon dioxide for accurate volume measurements.

2. Glass separator should only be used under low pressure conditions (for field test the steam 1 ine inlet pressure was 7-9 psig).

3. Field test showed improved collection results are obtained and more controllable flow regulation using $1 / 2^{\prime \prime}$ ID insertable probes instead of smaller ID probes (1/4" ID) due to better collection rates from the steam line.

4. Filling the gas collection bulb initially with water (in

EDITION: field test) and allowing the gas to displace the water proved to be a useful way to determine if air was excluded. Collection is continued for 3-4 volume displacements.

PAGE:

B- 13 


\section{ILLUSTRATION:}

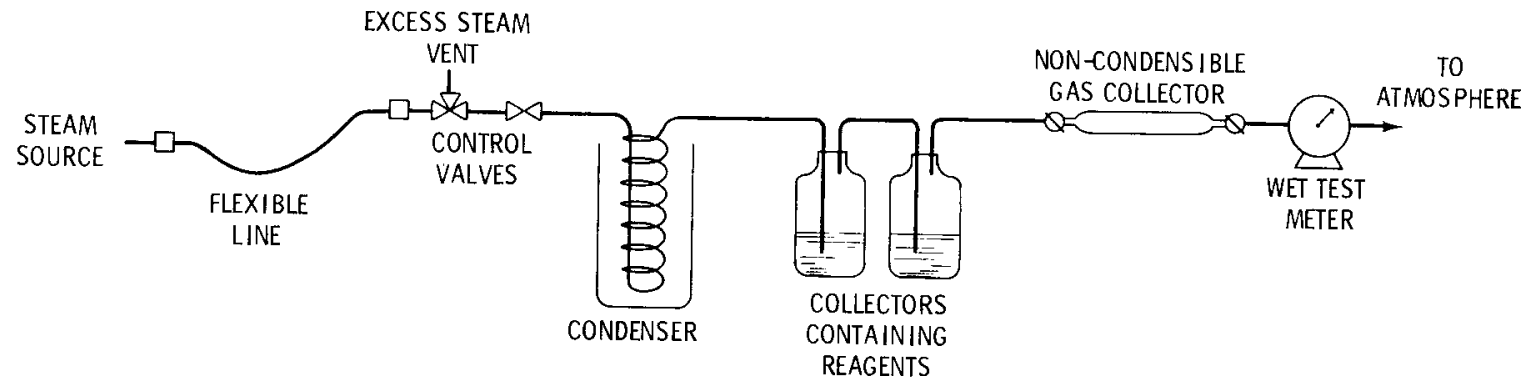

FIG 1. STEAM SAMPLING APPARATUS

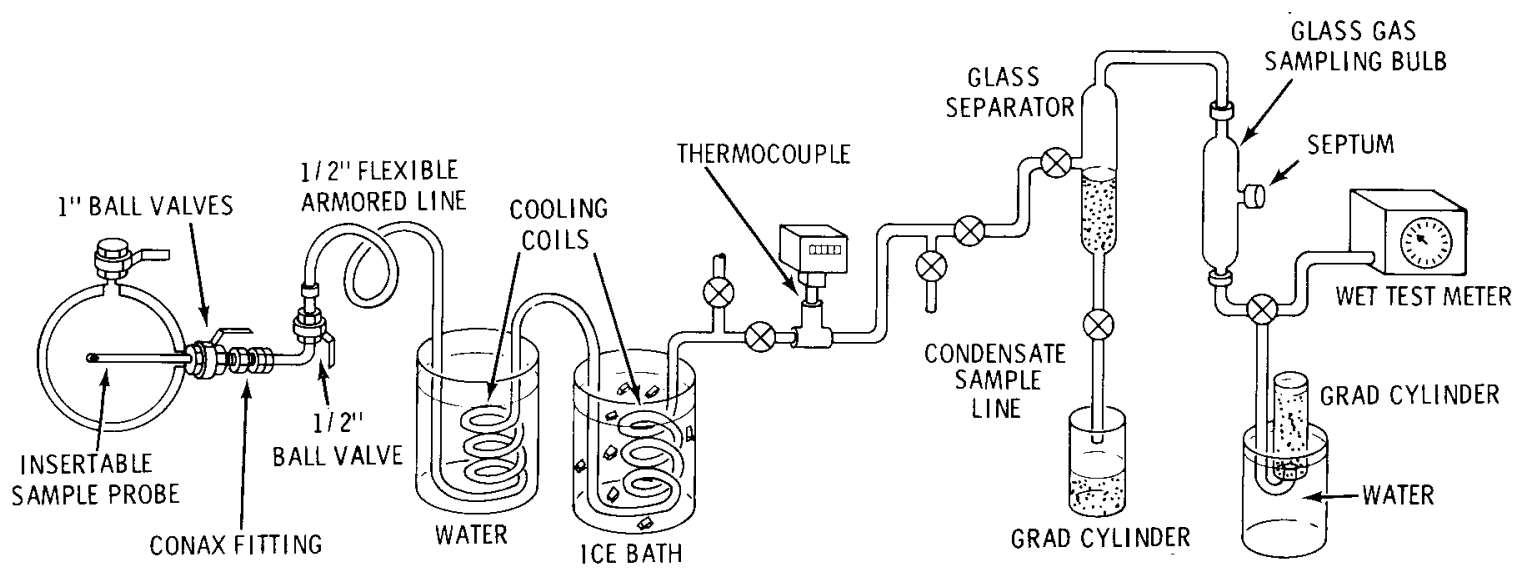

FIG 2. WET TEST METER METHOD USED IN FIELD TEST TO SAMPLE NONCONDENSABLES IN STEAM LINE

collected in gas sampling bulbs. The noncondensable gas flow rate can be checked using the graduated cylinder water displacement method. 


\section{METHOD TITLE:}

Radon Gas Collection and Measurement

APPLICATION:

Measurement of radon gas concentrations in geothermal gases.
NO. $17-S$

SAMPLE TYPE: SAMPLE POINT:

Noncondensable gas
Noncondensable gas line

\section{REFERENCES:}

J. D. Ludwick, Battelle, Pacific Northwest Laboratories, Richland, WA 99352.

H. F. Lucas, Rev. Sci. Inst., 28, 680 (1957).

\section{DESCRIPTION}

Radon concentrations in most geothermal gases are sufficiently high to measure directly in filled Lucas tubes. A Lucas tube is a glass sphere with a flat quartz window on one end and a stopcock on the other. The inside surfaces of the Lucas tube, except for the quartz window, are coated with activated zinc sulfide/silver scintillator. Prior to sampling the tubes are evacuated with a vacuum pump. The gas sample is then taken by connecting the Lucas tube to the noncondensable gas line, opening the stopcock and allowing the Lucas tube to pressurize slightly. Before entering the Lucas tube the gas is filtered through a $2 \mu$ membrane filter to remove any radon daughters. The tube is then disconnected, the stopcock opened briefly to allow the tube to equilibrate to atmospheric pressure and the stopcock is then closed. After a period of about 4 hours to allow buildup of the radon daughter products the Lucas tube is optically coupled to a multiplier phototube. The alpha decay of the radon and its daughters produces scintillation of the zinc sulfide layer and the light pulses are amplified and counted. Each Lucas tube is of known volume and individually calibrated.

COMMENTS: 
ILLUSTRATION:

\section{LUCAS TUBE RADON COUNTER}

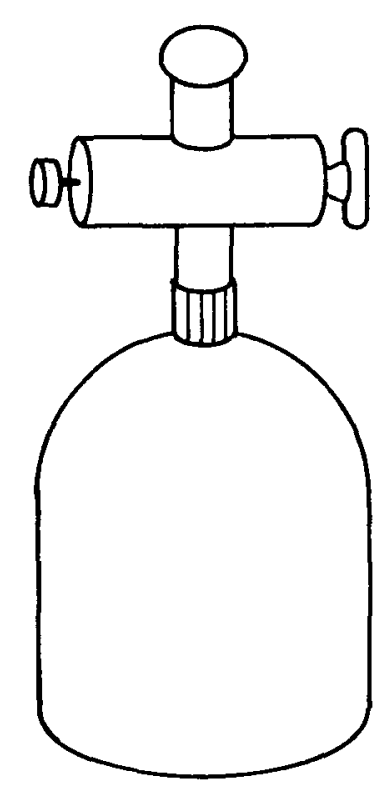

GROWTH AND DECAY OF RADON DAUGHTERS

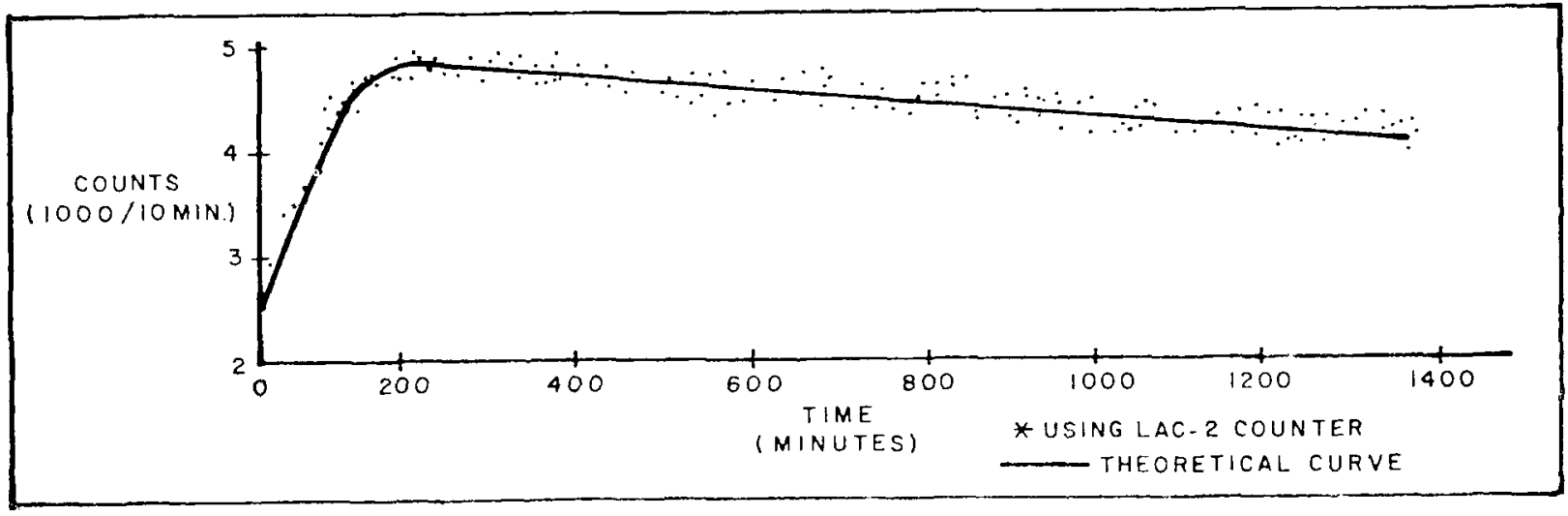




\section{METHOD TITLE:}

Determination of the Chemical Forms of Gaseous Mercury.

APPLICATION:

NO. $18-5$

SAMPLE TYPE: SAMPLE POINT:

Gaseous Mercury

Noncondensable gas line

Determining the concentrations and chemical forms of mercury in geothermal noncondensable gases and in ambient air.

REFERENCES:

D. E. Robertson, E. A. Crecelius, J.S. Fruchter and J. D. Ludwick. "Mercury Emissions from Geotherma 1 Power Plants," Science 196, 1094-1097 (1977).

R. W. Braman and D. L. Johnson, "Selective Adsorption Tubes \& Emissions Techniques for Determination of Ambient Forms of Mercury in Air." Env. Sci. Tech. 12, 996-1003 (1974).

\section{DESCRIPTION}

Geothermal noncondensable gases contain highly elevated levels of mercury compared to ambient air, and a sampling technique has been developed which simultaneously quantifies and determines the chemical species of mercury in the gas or air phase. The sampling technique is based on the selective adsorption of various mercury forms on adsorption tubes connected in series. The gas or air is first flowed through a fiberglass filter to remove any microparticulate mercury and then through a quartz tube containing chromasorb-W which has been pretreated with 3\% SE-30 silicone and HCl gas. This tube selectively removes $\mathrm{Hg}^{++}$compounds and passes all other forms. The gas or air then flows through a tube containing chromasorb-W which has been pretreated with $\mathrm{NaOH}$. This adsorbent selectively removes methyl mercury and passes all other forms. The gas or air then flows through a tube containing silver coated glass beads to selectively remove elemental $\mathrm{Hg}^{\circ}$ vapor. The final tube is filled with gold coated glass beads and removes dimethyl mercury or any other form which passes through the first three tubes. The tubes are then disconnected and heated in resistance coils to drive the mercury off in a stream of nitrogen into a mercury analyzer for quantification.

COMMENTS: 


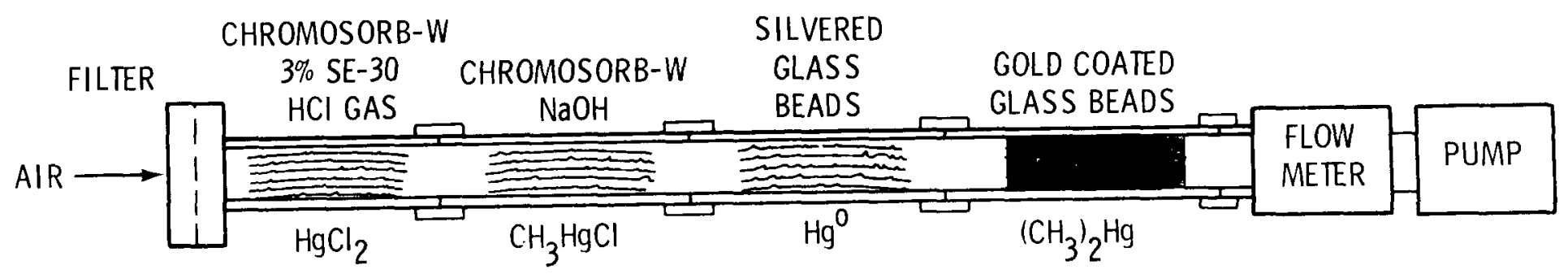

PARTICULATE

$\mathrm{Hg}$ 


\section{METHOD TITLE:}

Evacuated bottle method for collecting residual, dissolved and entrained gases.

\section{APPLICATION:}

Sampling dissolved gases in equilibrium with water.

NO. ${ }^{19-S}$
SAMPLE TYPE:
GaS

SAMPLE POINT:

Steam and gas from steam condensate, condensed

\section{REFERENCES:}

Nehring, Nancy, and Alfred H. Truesde11, "Collection of Chemical, Isotope and Gas Samples from Geothermal Wells," Proceedings, 2nd Workshop on Sampling and Analys is of Geothermal Effluents, Las Vegas, February, 1977.

\section{DESCRIPTION}

1. Brine is collected in an evacuated pre-weighed $300-500 \mathrm{ml}$ bottle by attaching vinyl tubing from the condenser to the bottle.

2. Gases in equilibrium with the water (in head space) are analyzed by gas chromatography or other means.

3. Dissolved gases such as $\mathrm{CO}_{2}$ are determined in the liquid phase. For steam condensate and gas samples, the bottle is filled with 50 - $100 \mathrm{ml} 4 \mathrm{~N} \mathrm{NaOH}$ (as carbonate free as possible). This traps both $\mathrm{CO}_{2}$ and $\mathrm{H}_{2} \mathrm{~S}$. Flow from the condenser should be reduced by regulating the valve on the separator or steam bypass. Pressure relief valve may be used to prevent overpressuring the gas bottle.

\section{COMMENTS:}

These bottles may also be used to sample the top of the gas water separator (gas only sample without condensate). A larger quantity of caustic is needed $(100-150 \mathrm{ml})$. Since flow into the bottle may exceed flow into the gas water separator, the bottle flow should be restricted by pinching the vinyl tubing until a balance is achieved. 


\section{ILLUSTRATION:}

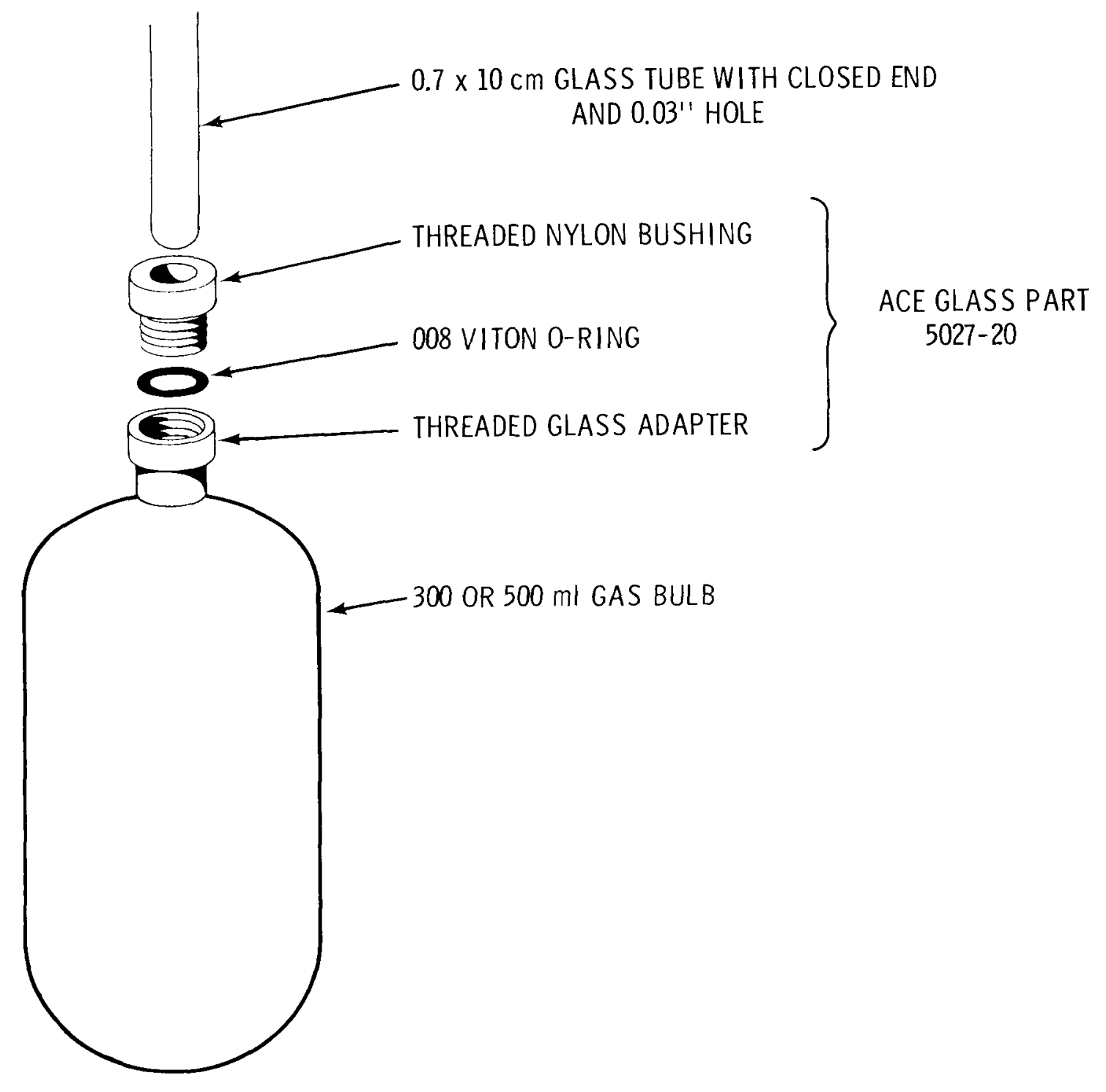

Exploded view of gas sample bottle. The bottle is opened by sliding the hole inside the o-ring. The tube may be evacuated with the bottle closed by clamping a second o-ring and washer to the top of the adapier. Gas bottles with $\mathrm{NaOH}$ solution are evacuated by a water aspirator with gentle boiling of the solution. 
METHOD TITLE:

Glass separator method for determining liquid and gas.

NO. $20-S$

SAMPLE TYPE: $\quad$ SAMPLE POINT:

Liquid and gas

Pipeline

REFERENCES:

APPLICATION:

Separating two phase flow from low pressure

Appendix 1: Field Test 1978. source.

\section{DESCRIPTION}

1. Two phase flow enters tangentially into the glass separator through a flexible armored line (Figure 1). This armored line is connected to the pipeline through a 7 " Whitey (or equivalent) ball valve equipped with a quick disconnect attachment. The steamnoncondensable phase pressure is measured and the flow passes through a cooling coil immersed in an ice bath. The steam gas-flow then proceeds to a second glass separator. The flow rate of noncondensable gas can be measured using an inverted graduated cylinder and the water displacement technique. Alternatively, the gas can be collected in gas sampling bulbs for Tater analysis. Another modification shown in Figure 2 allows for the introduction of a carbon dioxide sparger trap to remove $\mathrm{CO}_{2}$ and $\mathrm{H}_{2} \mathrm{~S}$ prior to collecting the residual gases $\left(\mathrm{CH}_{4}, \mathrm{H}_{2}\right.$, $\mathrm{N}_{2}$, etc.) in the glass sampling bulbs $(500 \mathrm{cc})$. liquid from the first separator passes through a cooling coil immersed in an ice bath ind is collected for analysis. Flow rates of liquid from the first separator and steam condensate from the second separator are measured with graduated cylinders.

2. A second arrangement using a glass separator is shown in Figure 3 . This setup was used to sample the steam line coming from the large site separator. Steam and gas were removed from the pipeline through an insertable probe. The flow next went through an ice water cooling bath and then into the 1st glass separator. Condensate was removed from the bottom of the first glass separator or alternatively the rate of condensate production could be measured. The second glass separator was used as a liquid (steam condensate) level controller. Noncondensable gas was taken from the top of the first glass separator and collected in a glass sampling bulb. Alternatively, the gas flow rate can be measured by displacing the water in an inverted graduated cylinder.

\section{COMMENTS:}

1. During field evaluation of this method the steam noncondensable phase pressure (from the lst separator) was maintained at 5 psig.

2. Field test showed that difficulty was encountered regulating flow rates when $1500 \mathrm{cc}$ 2N $\mathrm{NaOH}$ was used in the sparger (back pressure was created). Reduction to $750 \mathrm{cC}$ $\mathrm{NaOH}$ sol' $\mathrm{n}$ in the sparger remedied this problem.

During field test gas collection in the gas sampling bulbs proceeded until the equivalent of 5 bulb volumes of gas had passed through (to remove air contamination).

EDITION:
4. This system should be used for low pressure sources only.

(cont. on back)
PAGE: 


\section{ILLUSTRATION:}
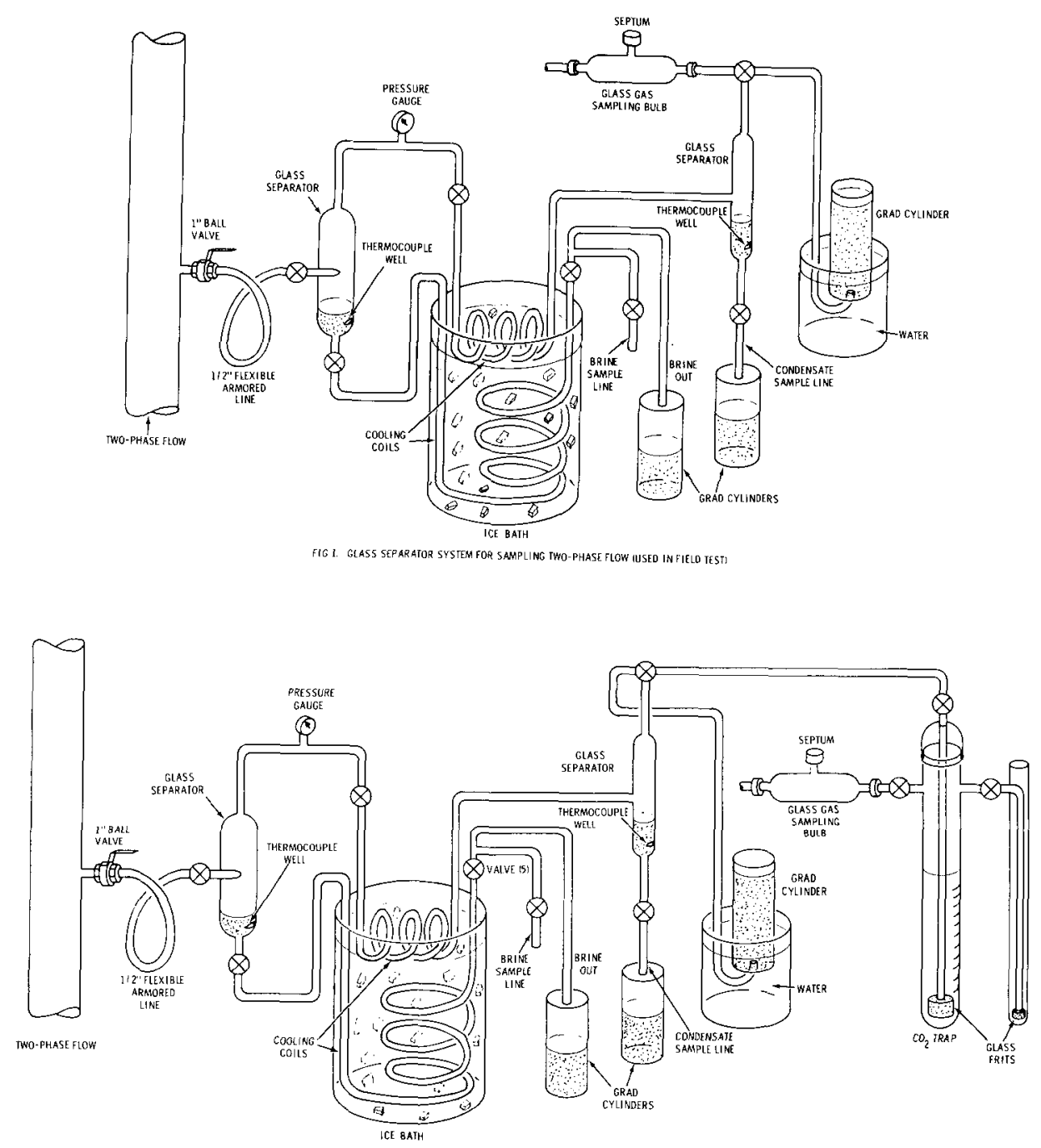

FIG 2 GLASS SEPARATOR SYSTEM USED IN FEED TEST FOR SAMPIING TWO-PHASE FIOW
IWITH CO, 2 RAP ATACHEDI

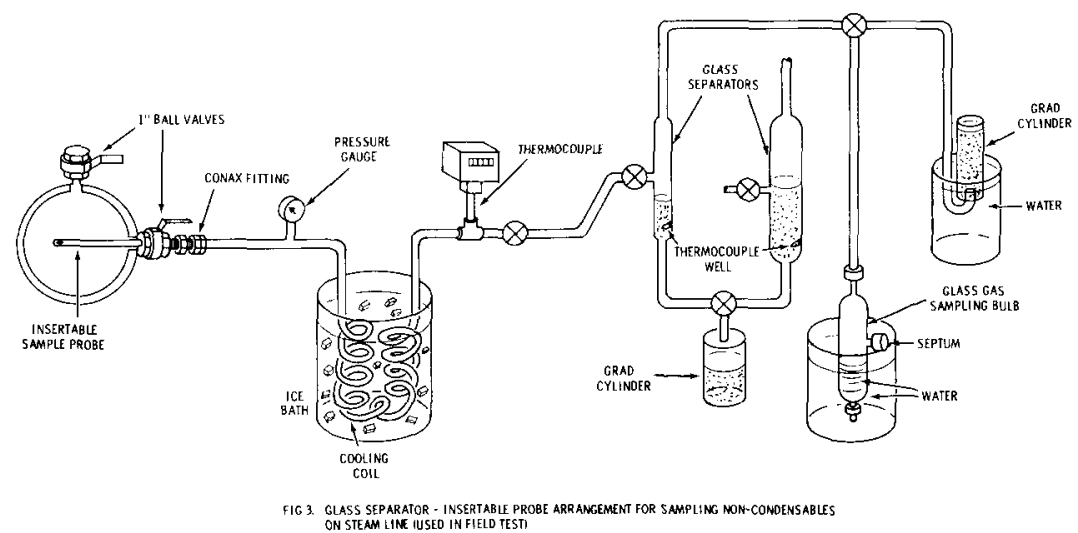

5. Vortex formation (in the glass separator) should be minimized by adjusting inlet and outlet pressure and liquid level in the glass separator.

6. Filling the gas collection bulb initially with water (in field test) and allowi..... the gas to displace the water proved to be a useful way to determine if air wa excluded, (Figure 3). Collection is continued for 3-4 volume displacements. 
APPLICATION:

Condensing steam for analyses of condensate and noncondensable gases, and for determining steam/gas ratios. Especially applicable for sampling for trace metal analyses.

\section{REFERENCES:}

D. E. Robertson and J. D. Ludwick, Battelle, Pacific Northwest Labs. Richland, WA 99352.

\section{DESCRIPTION}

Incoming steam from a steam-brine separator or from a dry steam well-head enters the 20-liter Pyrex glass sphere which is cooled by a spray of circulating cold water. The steam swirls around in the sphere and condenses on the walls. A final Pyrex glass condenser coil assures complete steam condensation, and only noncondensable gases exit via the sidearm tube of the final condenser. Fresh condensate can be withdrawn from a tap at the bottom of the sphere for analyses without disturbing the condensing process. The noncondensable gases are normally of a sufficient flow rate and pressure to monitor the flow with a rotameter during gas sampling. The temperature of the cooling water is recorded for correcting gas data to STP. This condenser is quite efficient and approximately $500 \mathrm{gm}$ of steam per minute can be condensed.

\section{COMMENTS:}

This condenser can be used for obtaining accurate steam/gas ratios by simultaneously measuring the volume of noncondensable gases and the weight of steam condensed. The gas volume is measured with a wet test meter and the condensate is measured volumetrically. 
ILLUSTRATION:

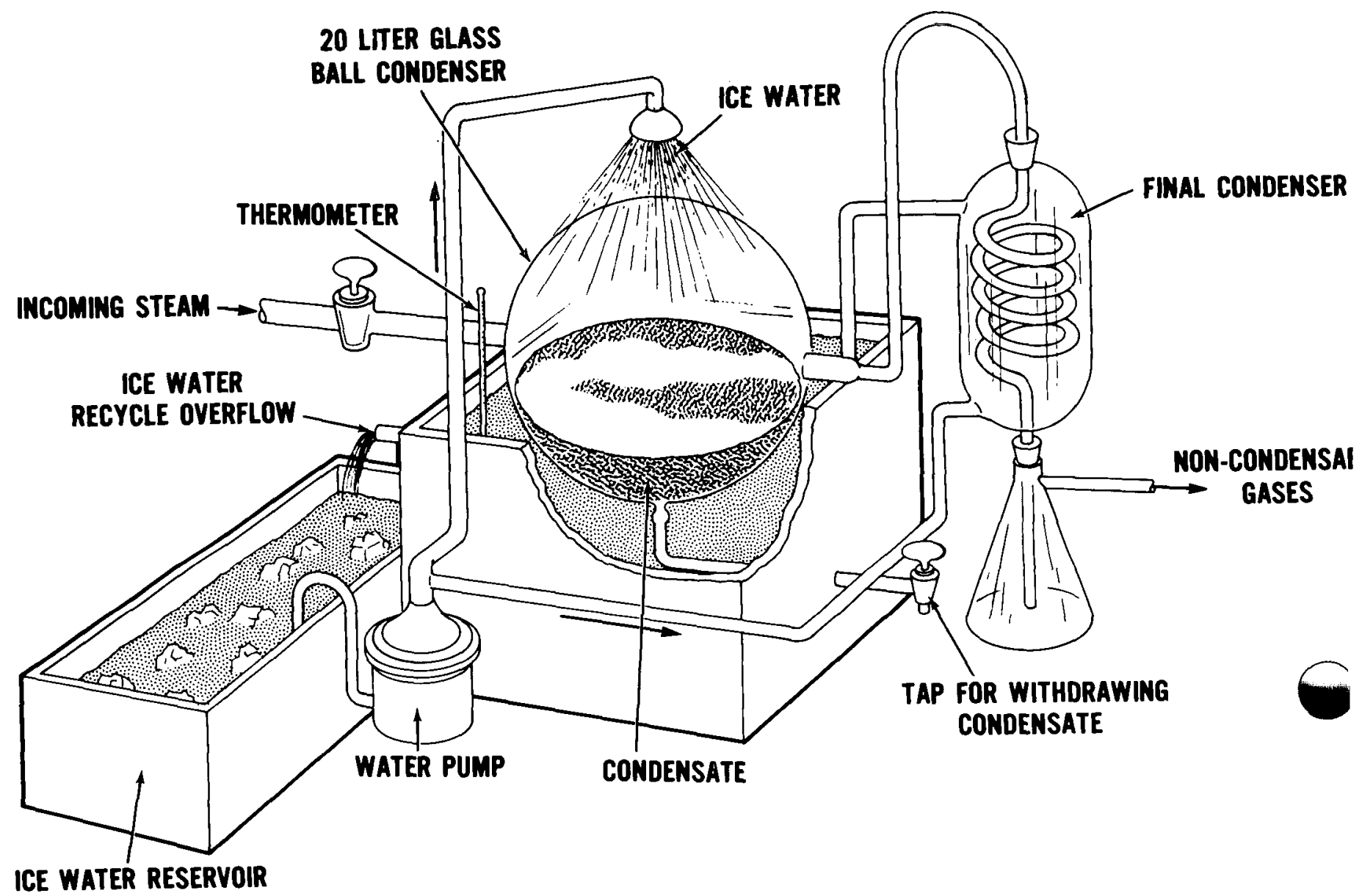


METHOD TITLE:

Low pressure separator method.
APPLICATION:

Separation of steam-gas phase from liquid phase for low pressure source:
NO. $22-5$

SAMPLE TYPE: $\quad$ SAMPLE POINT:

Two-phase flow source

\section{REFERENCES:}

Ellis, A.J. et al., "Methods of Collection and Analysis of Geothermal Fluids." Report No. C.D. 2103, New Zealand Dept. of Sci. and Ind. Res., New Zealand, JuTy 1968.

P.B. Needham, Jr., and W.D. Riley, "Chemical Analyses for the Brines of Four Imperial Valley Geothermal Wells," College Park Metallurgy Research Center, Bureau of Mines, U.S. Department of the Interior, College Park, MD 20740.

\section{DESCRIPTION}

1. In Figure 1, a simple separator operating at atmospheric pressure is used for sampling low pressure (30-40 psig) two phase flow. The source enters tangentially with the liquid phase being removed at the bottom and steam-gas phase removed from the top. Enthalpy of the discharge is measured by a calorimeter so separate results from steam and water analyses can be related to concentrations in the total flow.

2. The separator in Figure 2 is a modification of the above separator to allow for more efficient separation of $\mathrm{CO}_{2}$ from the 1 iquid phase. The baffles prevent liquid droplets from being carried over into the steam sample. Brine and steam enter near the middle of the miniflasher. Water droplets containing entrained carbon dioxide are condensed on the series of baffles and fall to the bottom. Liquid sample is removed from the bottom and the steam sample is taken from the top.

\section{COMMENTS:}

1. The separator, calorimeter, and piping must be heavily insulated to prevent heat losses, otherwise diluted water samples and concentrated steam samples will result. Before taking samples the separator is allowed to warm up for 15 minutes.

2. At sampling pressures of a few tens of pounds, the errors due to steam and water being sampled in incorrect proportions are often small, but the proportions of steam and water entering the separator should be checked by a simple water calorimeter and corrections to concentrations made (see section on steam loss corrections). A discharge of almost pure steam or water is sometimes obtained from low-pressure sample pqints, in which case extreme dilution of the small quantity of

EDITION: water by condensed steam will occur, or of the steam by 


\section{ILLUSTRATION:}

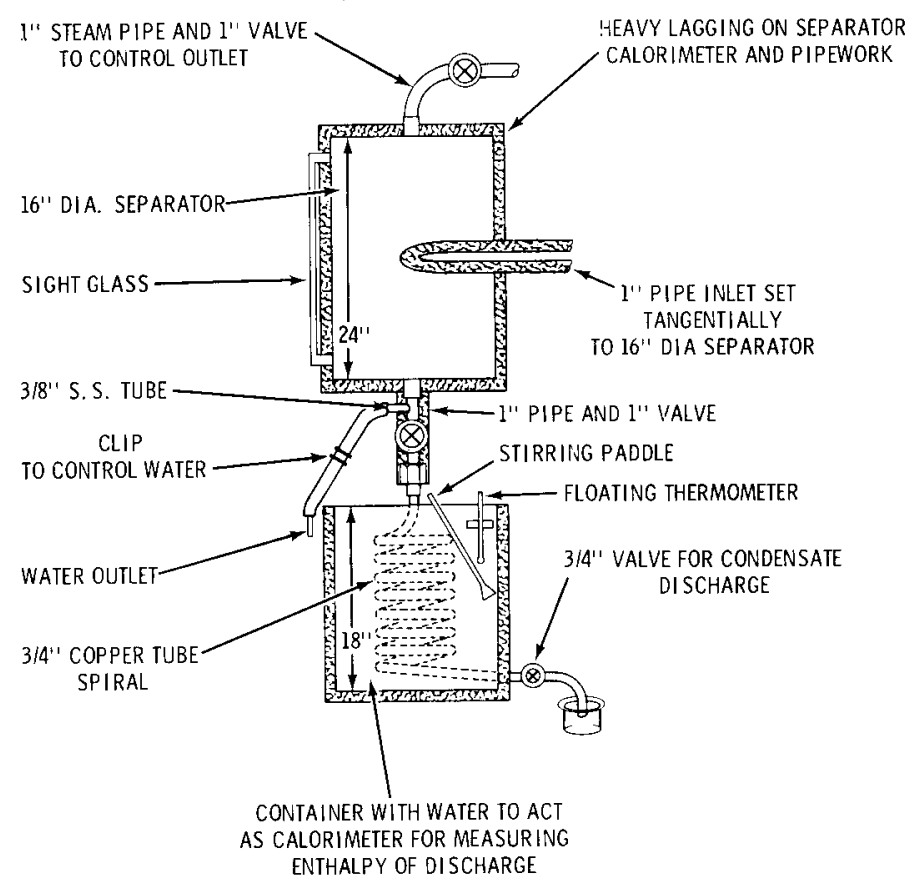

FIG 1. LOW PRESSURE SEPARATOR SAMPLING APPARATUS

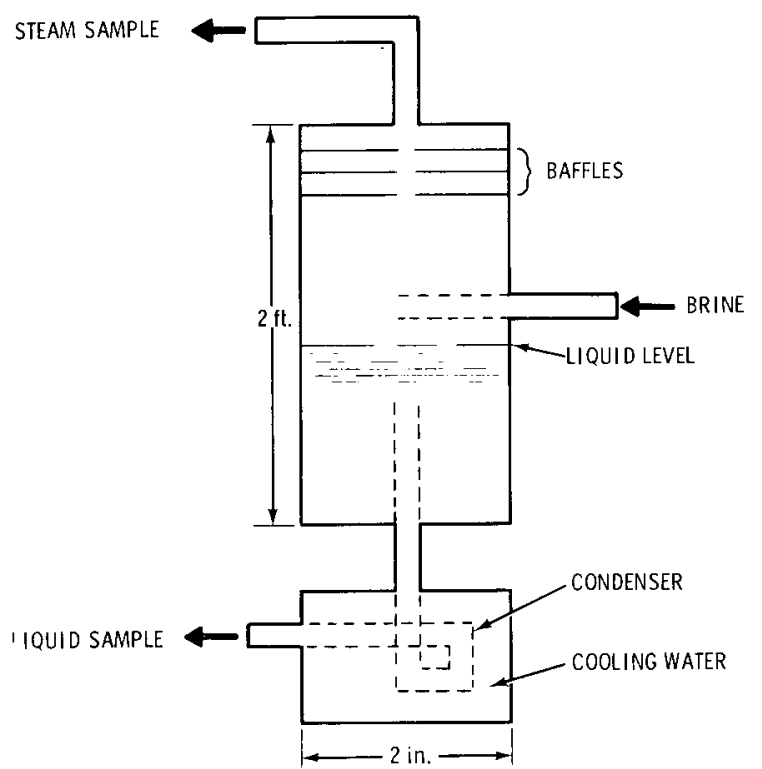

FIG 2. BRINE SAMPLING SYSTEM USED TO MINIMIZE READSORPTION OF NONCONDENSABLE GASES IN FLUID SAMPLES 
METHOD TITLE:

Steam-gas separator using modified graduated cylinder.

NO. $23-5$

SAMPLE TYPE: SAMPLE POINT:

Condensate and Gas

Condenser or separator

APPLICATION:

Separation of steam condensate from gas.

REFERENCES:

Nehring, Nancy and Alfred H. Truesdell, "Collection of Chemical, Isotope and Gas Samples from Geothermal Wells," Proceedings, 2nd Workshop on Sampling and Analyses of Geothermal Effluents, Las Vegas, February, 1977.

\section{DESCRIPTION}

This steam condensate-gas separator is constructed from a graduated cylinder by attaching two tubulations at the top and one at the bottom. Flow from the condenser enters at the top (vinyl tubing is used for all connections) and the flow of condensate from the bottom is restricted with a clamp so that gas alone issues from the remaining top tubulation. Tubing at bottom is inserted in a large bottle of steam condensate to prevent backflow of air into the separator.

COMMENTS:

1. This apparatus allows for checking incomplete steam separation in the separator.

2. Use of $1 / 4^{\prime \prime}$ vinyl tubing provides for smal1, relatively uniform slugs from the separator. The average composition of issuing fluid is uniform over the period of collection. 


\section{ILLUSTRATION:}

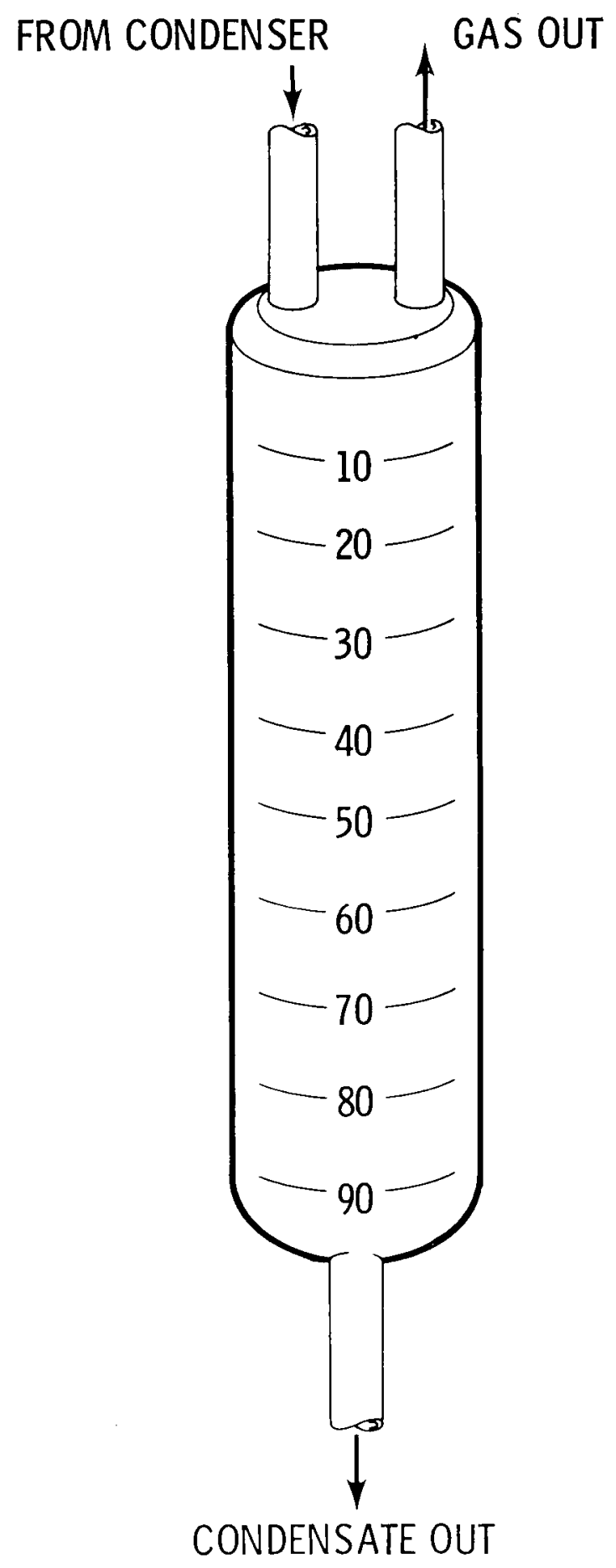

- Steam-gas separator modified from a $100 \mathrm{ml}$ graduated cylinder. 
METHOD TITLE:

NO. $24-5$

Portable gas-liquid separator.

SAMPLE TYPE: SAMPLE POINT:

Liquid and gas $\quad$ Pipeline

REFERENCES:

Separating two-phase flow into liquid and gas.

Christoffersen, D.J., R.N. Wheatley and J.A. Baur, "Union $0 i l$ Company of California's Geothermal Sampling Techniques," Proceedings, First Workshop on Sampling Geothermal Effluents," Las Vegas, NV, October 1975.

\section{DESCRIPTION}

A simple gas-liquid separator which can be used in situations where a larger separator is not available is shown in the illustration. The volume of noncondensable gases is measured by water displacement in a graduated cylinder. Noncondensable gases are trapped in gas collectors for later laboratory analysis.

COMMENTS: 


\section{ILLUSTRATION:}

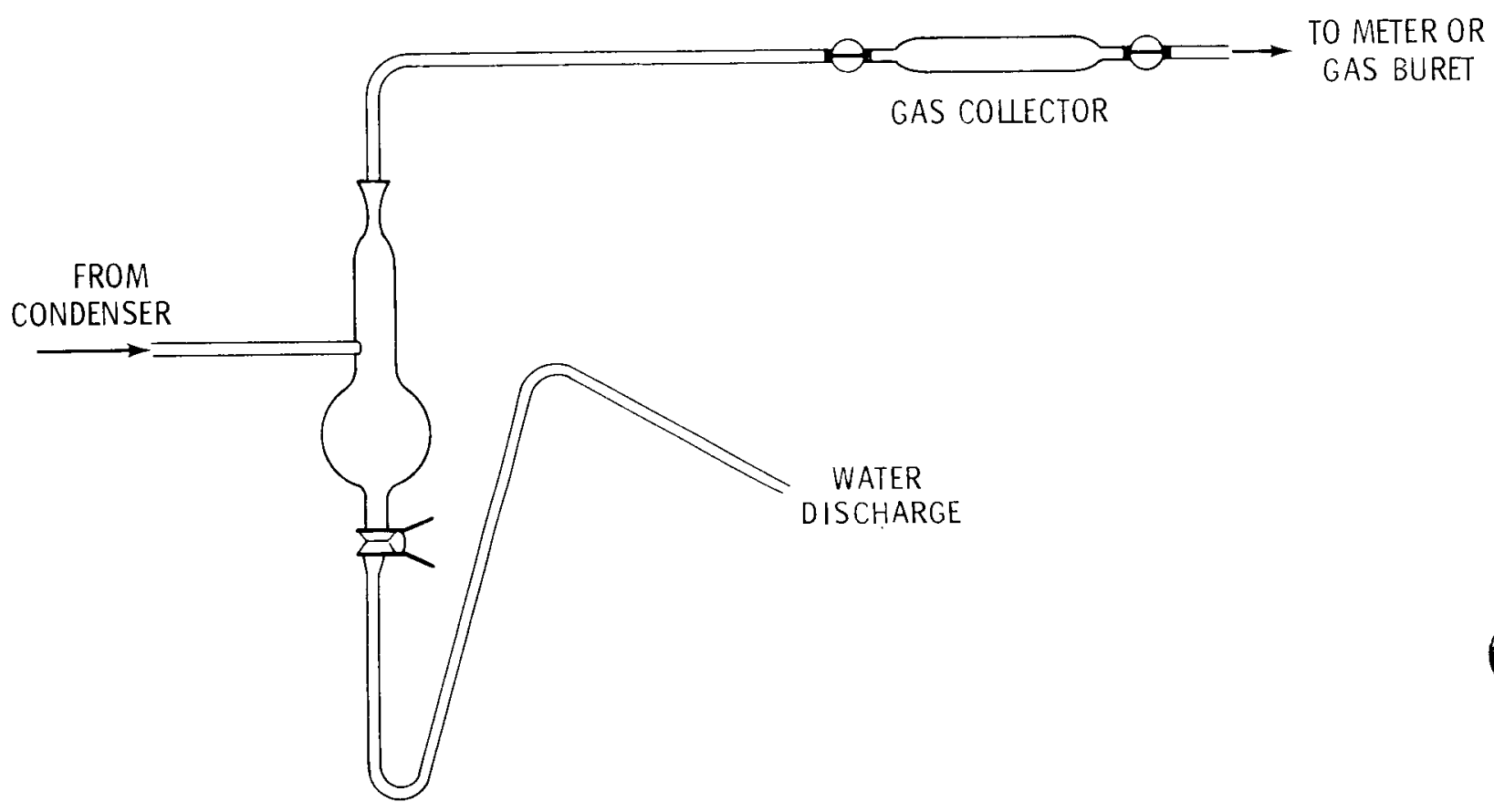

GAS SEPARATOR

Collection of air free gas sample. 
METHOD TITLE:

Webre separator method

NO. $25-\mathrm{S}$

SAMPLE TYPE: SAMPLE POINT:

Liquid and gas

Two phase source

APPLICATION:

Separation of steam noncondensable gas phase from liquid phase in high pressure two phase sources.
REFERENCES:1. Pollak, A., and L.E. Work Amer. Soc. Mech. Eng., 64 (1942), 31.

2. A.J. Ellis et al, "Methods of Collection an. Analysis of Geothermal Fluids" Report No. C.D. 2103, New Zealand Dept. of Sci. \& Rad. Re: New ZeaTand, 1968. 3. Nehring, Nancy L. and Alfred $H$. Truesdel1, "Collection of Chemical, Isotope and Gas Samples from Geothermal Wells, Proceedings, 2nd Workshop on Sampling and Analyses of Geothermal Efflunets, Las Vegas, February 1977

4. Appendix $\{$ : Field Test 1978.

\section{DESCRIPTION}

1. High pressure (>100 psig) samples are taken using small Webre separators which have very small pressure drops (Figure 1). The Webre separator consists of a vertical drum with a tangential inlet at the center, an outlet for water at the bottom, and a central outlet tube open at the top which collects the steam. The two-phase fluid enters tangentially at the center, spins rapidly around the outer wall of the drum with the water collecting on the outside and falling to the bottom and the steam moving to the inside and flowing down the central tube. Steam samples are condensed in evacuated glass flasks cooled by water. The flasks may be partly prefilled with alkaline solution to absorb $\mathrm{CO}_{2}$ and $\mathrm{H}_{2} \mathrm{~S}$ for laboratory analys is by titrations. water samples are collected after passing the hot pressurized water through a cold-water jacketed pipe.

2. A field arrangement using a Webre separator is shown in Figure 2. The separator is equipped with a sight glass for viewing the liquid level. Two phase flow tangentially enters the separator through a flexible armored line. The armored lino is connected to the pipeline through a 1 " White ball valve equipped with a quick disconnect fitting. Steam and gas exit the separator through the central standpipe. The steam-gas flow then goes through a series of condensing coils (first one water cooled and second one ice water cooled) then into a glass separator. Noncondensable gases are removed from the ton of the glass separator while condensate is removed from the bottom. Flow rates are measured with graduated cylinders (water displacement method for gas flow). The main liquid flow from the Webre separator is from an outlet on the side of the separator. The liquid sample line comes from the bottom of the separator below the main liquid line (to avoid steam contamination). The liquid sample line is cooled through the series of cooling baths. Flow rates are measured with graduated cylinders.

COMMENTS:

1. Water samples should be taken, if possible, from a separate tap below the water outlet of the separator where the water is less likely to be contaminated with steam.

2. See comments under dual Webre separator method.

3. During the field test, to operate the separator as a gas separator the separator pressure was maintained above the steam flash point but below the $\mathrm{CO}_{2}$ flash point. A gas bubble was allowed to build up in the top of the separator by adjusting the liquid outlet (from separator) line.

EDITION:

4. Under operating conditions it was found to be difficult to maintain Tiquid level and operating pressure in the Webre separator/PAGE: Careful constant adjustment of the brine inlet and liquid outlet lines is required. 


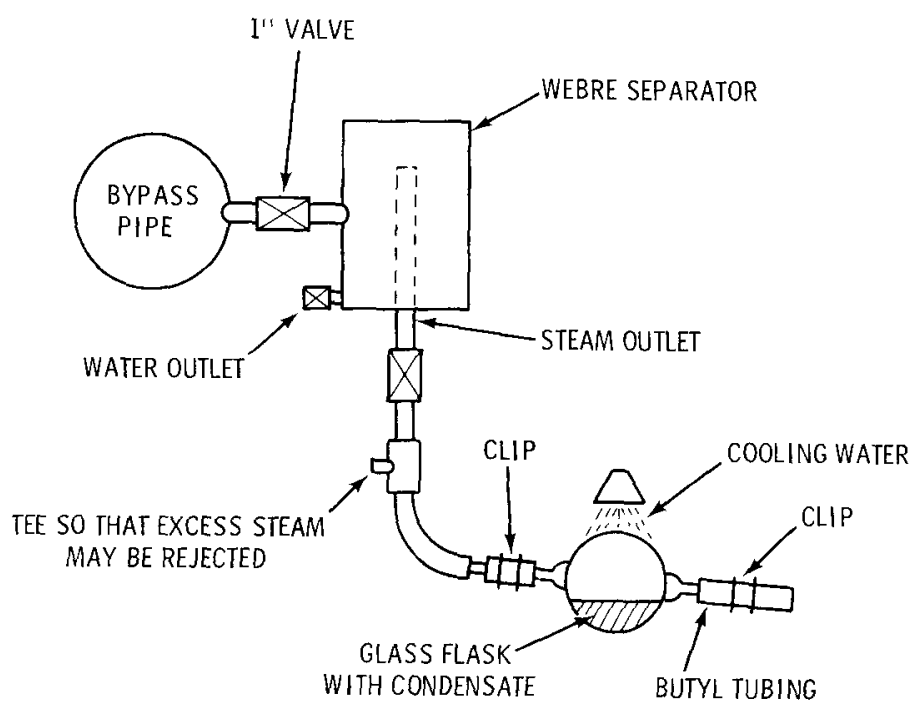

FIG 1. HIGH PRESSURE SEPARATOR SAMPLING APPARATUS

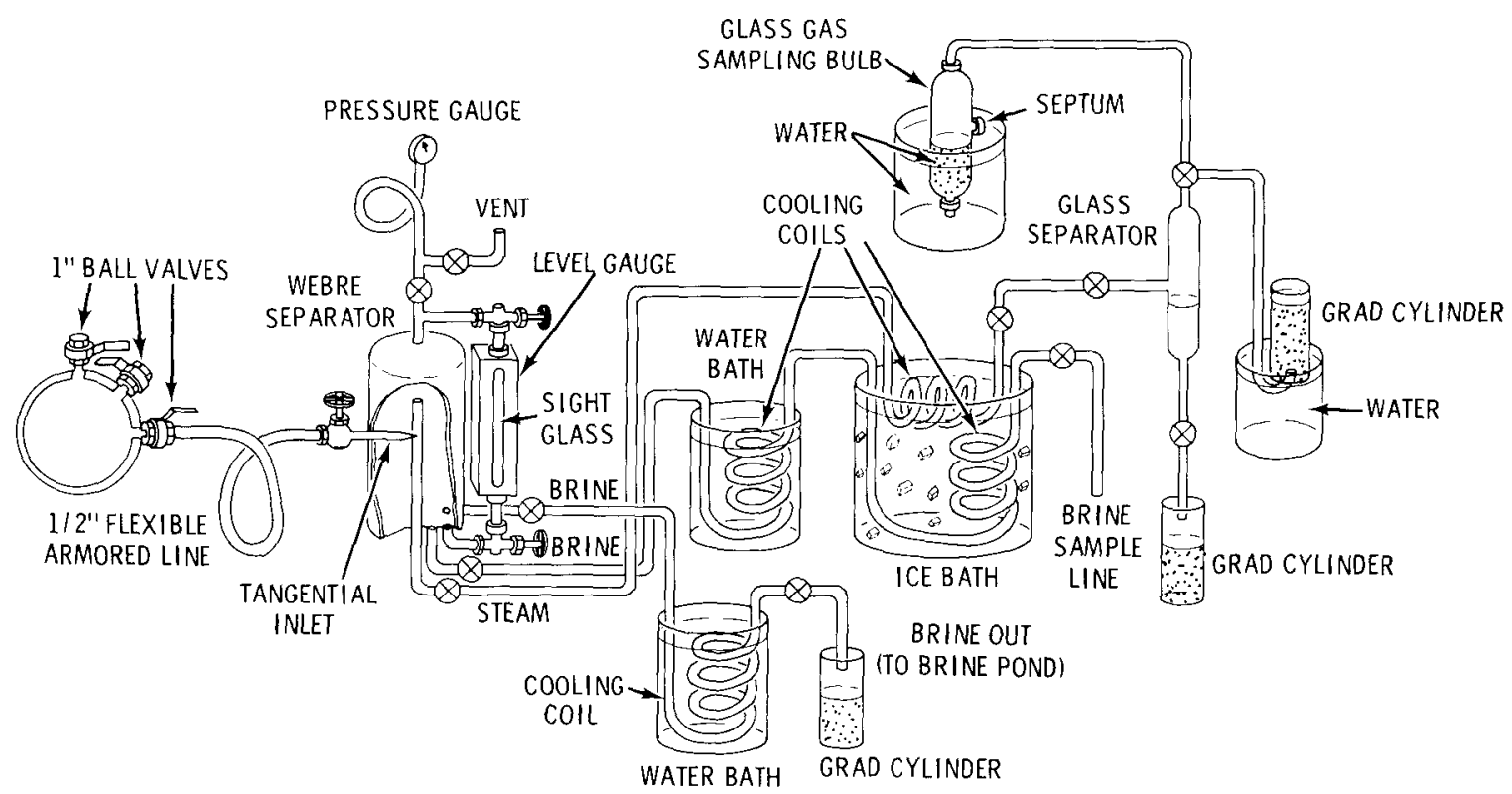

FIG 2. WEBRE SEPARATOR SAMPLING SYSTEM USED IN FIELD TEST

5. Vortex formation (which cannot be seen) inside the separator can lead to steam and gas emanating from the liquid outlet. Careful control of the separator pressure and liquid level is therefore necessary.

6. Filling the gas collection bulb initially with water (in field test) and allowing the gas to displace the water proved to be a useful way to determine if air was excluded, (Figure 2). Collection is continued for 3-4 volume displacements. 
METHOD TITLE:

Dual Webre separator method.

SAMPLE TYPE:

Gas and Liquid
SAMPLE POINT:

High pressure two-phase source
APPLICATION:

Separation of steam-gas phase from liquid phase while sampling a high pressure source.

\section{REFERENCES:}

1. Ellis, A. J. and W. A. J. Mahon, "Chemistr: and Geothermal Systems, "Academic Press, New York, 1977. (See note $V$ on page B-1) 2. Nehring, Nancy and Alfred H. Truesde11, "Collection of Chemical, Isotope and Gas Samples from Geothermal We11s," Proceedings, 2nd Workshop on Sampling and Analyses of Geothermal Effluents, Las Vegas, February, 1977.

\section{DESCRIPTION}

1. When the equipment in Figure 1 is used, the discharge from the sampling point enters the first unit at 1 and valves 2 and 3 are adjusted to obtain dry steam from outlet 4. The second separator is adjusted with the valves at 3 and 9 to operate slightly flooded, a condition which is recognized by the presence of water in the steam discharged from the steam outlet 5 . This ensures that water entering the cooling coils in cylinder 6 contains no condensed steam. The unit must be operated with a minimum pressure drop ( 0.2 bar) through the separators, the gauge at 7 ensuring that this condition can be controlled through the sampling period. The unit is heavily insulated to prevent heat losses and to reduce the possibility of water samples being diluted with condensed steam.

2. The apparatus in Figure 2 is a similar type of dual separator used by the U.S. Geological Survey.

3. Figure 3 shows a sampling arrangement on a pipeline using a dual Webre separator.

\section{COMMENTS:}

1. In Figure 1, the unit operates effectively over a sampling pressure range of 1.5-30 bars and a discharge enthalpy range of 190-475 cal/g. At lower or higher enthalpies, there is difficulty in obtaining both dry steam and undiluted water samples at the same valve settings. In these cases the valves are adjusted to collect either steam or water. The presence of condensed steam in a water sample is recognized from gas bubbles in the water emerging from the water cooler. The occurrence of boiling within the separators is more difficult to recognize. Some indication may be obtained if large fluctuations in pressure $( \pm 0.3$ bar) are recorded on the pressure gauge.

2. If minimum pressure drop through the separators is not maintained, the steam sample

EDITION:

$7 / 78$ is diluted by extraneous steam formed from water boiling as it enters lower-pressure zones in the separators.
PAGE:

$B-28$ 


\section{ILLUSTRATION:}

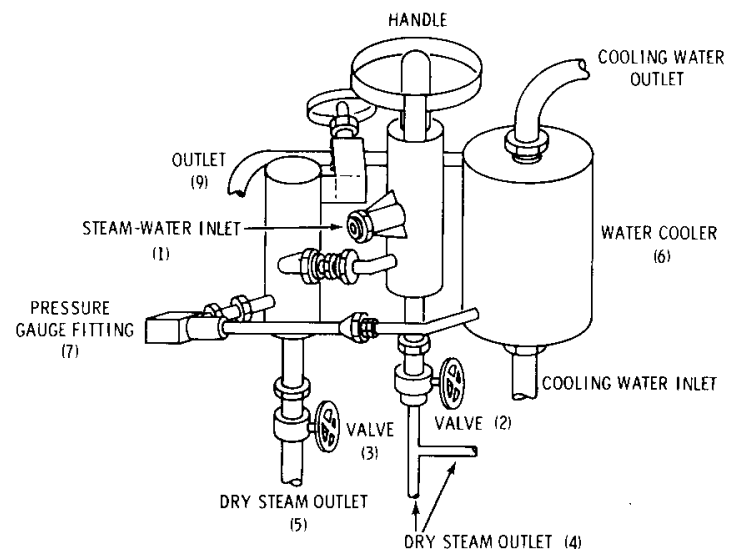

FIG 1. WEBRE CYCLONE SEPARATOR FOR COLLECTING STEAM \& WATER SAMPLES UNDER PRESSURE FROM A DISCHARG ING GEOTHERMAL WELL

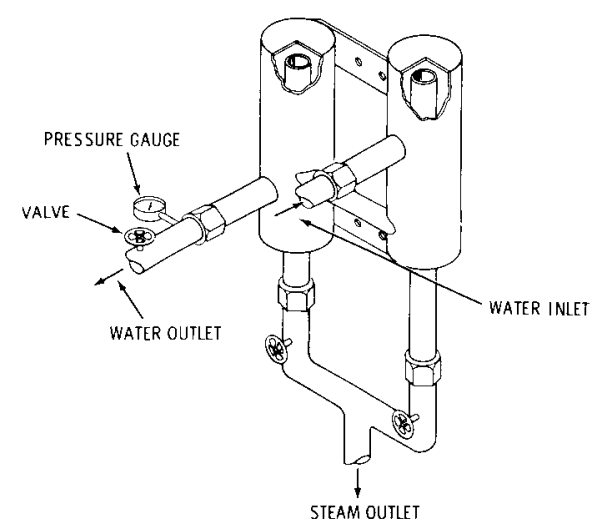

FIG 2. MINI CYCLONE SEPARATOR OF NEW ZEALAND DESIGN

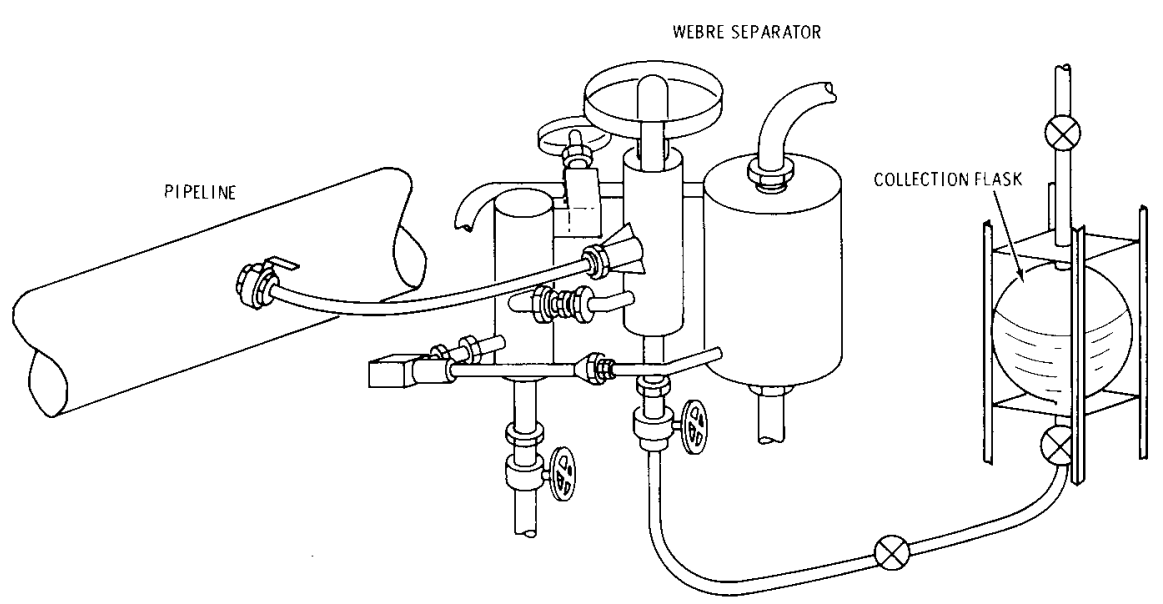

FIG 3. FIELD ARRANGEMENT FOR DUAL WEBRE SEPARATOR SYSTEM 
APPLICATION:

Separation of Flashed Steam from Hot Water, and for Determining Steam/Brine Ratios.

\section{REFERENCES:}

J. D. Ludwick and D. E. Robertson, Battelle, Pacific Northwest Labs., Richland, WA 99352.

\section{DESCRIPTION}

Incoming steam and hot water (or unflashed brine) enter through the top of a 4-1iter teflon-coated stainless steel cylinder from a pipe extending about one-third of the way into the cylinder. Flashed steam is removed from a sidearm at the top of the cylinder and the brine is withdrawn through a tap at the bottom. The water level in the cylinder is kept constant by equilibrating the rate of incoming fluid and outgoing brine. A sightglass is used to keep the cylinder about one-half full. Pressure gauges are installed at the point of incoming fluid and at the steam exit. If necessary, the separated brine can be passed through a cooling coil to collect the brine without a further loss of steam. The separated steam can then be passed into a condenser. This separator can be used for obtaining accurate steam/brine ratios by simultaneously measuring the weight of brine and condensed steam passing through the separator.

\section{COMMENTS:}

Great emphasis should be placed on obtaining representative fluids from the pipeline, and isoenthalphic sampling ports are desirable. Faulty steam/brine ratios can be obtained when unrepresentative samples of partially flashed fluids are withdrawn for phase separation and measurement. 
ILLUSTRATION:

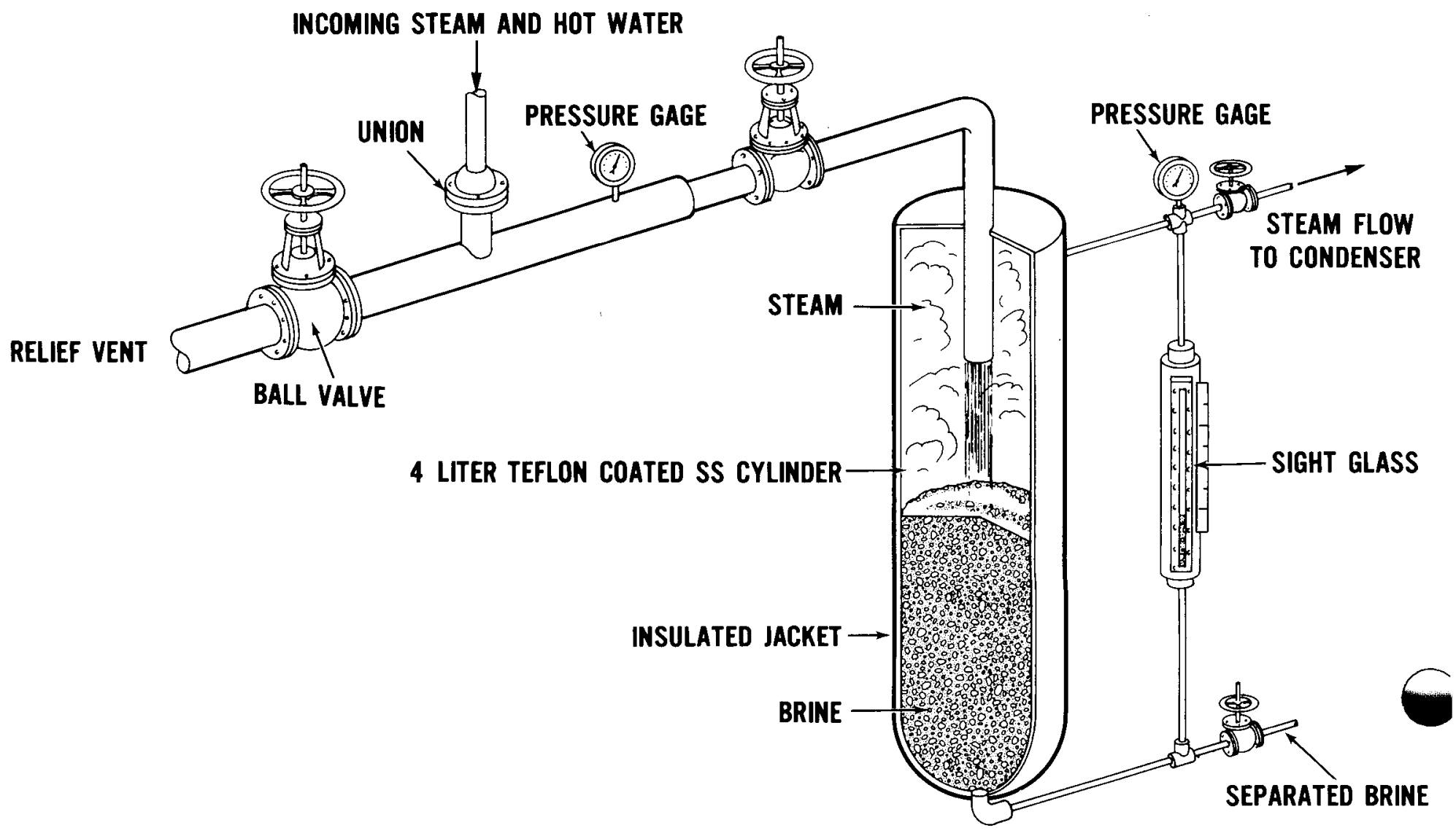


Insertable sample probe method.

\begin{tabular}{l|l} 
NO. & $28-5$ \\
\hline SAMPLE TYPE: & SAMPLE POINT: \\
Liquid and gas & Pipeline
\end{tabular}

APPLICATION:

Sampling two phase systems for liquid and gas.

\section{REFERENCES:}

1. Hill, J.H. and C.J. Morris, "Sampling a Two-Phase Geothermal Brine Flow for Chemical Analys is," Lawrence Livermore Laboratory Repor UCRL-77544, December 1975.

2. Appendix 1: Field Test 1978.

\section{DESCRIPTION}

1. The probe in Figure 1 can be inserted through a one-inch valve on the top of the pipeline. For the six inch line sampled, the probe was positioned 3/4" below the top of the pipe to obtain top ("vapor" phase) samples and 3/4" above the bottom of the pipe to obtain bottom ("1iquid" phase) samples. Samples were collected in stainless steel bottles with inner Teflon coating after passing through the probe. Bombs were flushed with nitrogen prior to collection.

2. The insertable probe shown in Figure 2 was fabricated for field test use. It consists of Inconel $6001 / 4^{\prime \prime}$ and 1/8" OD tubing with a $45^{\circ}$ bevel at one end. A $1^{\prime \prime}$ handle is welded $3^{\prime \prime}$ from the opposite end (on same side as bevel) to aid in determining the orientation of the bevel when the probe is inserted in the pipe. The probe is attached to 1" Whitey (or equivalent) ball valves on the pipeline by means of a conax fitting. This fitting allows the operator to move the probe and thereby traverse the pipe diameter by loosening the Conax fitting.

\section{COMMENTS:}

1. These probes as demonstrated by the field test allow the operator to traverse the pipe diameter. A horizontal and vertical traverse is useful in profiling the flow pattern in the pipe.

2. Larger diameter (1/2" ID) probes were found during field testing to be more useful for sampling separator steam lines due to the lower pressures involved in these lines.

3. Care must be exercised when inserting probes through the ball valves (on pipeline). The probe is inserted into the closed valve until resistance is felt, and the Conax fitting loosely tightened on the ball valve. The ball valve is then opened slowly

EDITION:

$7 / 78$ while pushing carefulty on the probe to push it through the valve. The Conax fitting is then fully secured and tightened. 4. See also "porcupine" arrangement method.
PAGE: 


\section{ILLUSTRATION:}

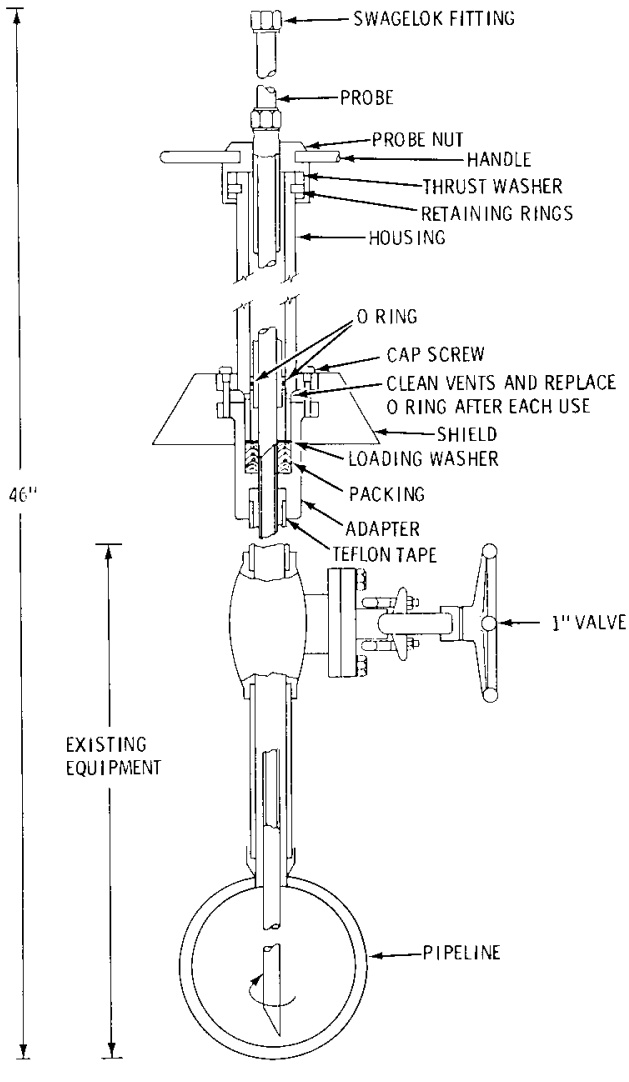

FIG 1. INSERTABLE SAMPLING PROBE (LLLL DESIGN)

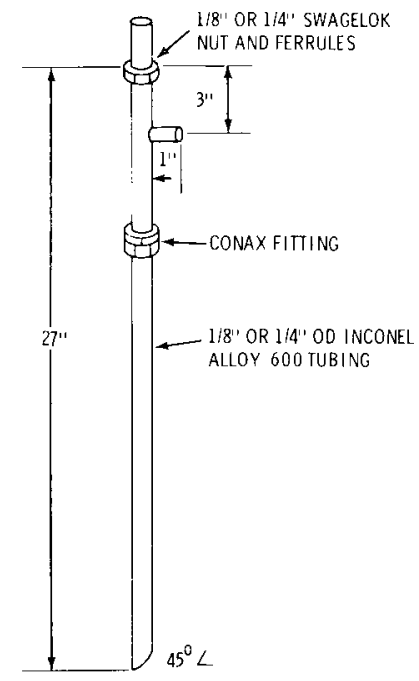

FIG 2. INSERTABLE SAMPLING PROBE USED IN FIELD TEST 
"Porcupine" arrangement.

APPLICATION:

REFERENCES:

Sampling multiphase systems.

Appendix 1: Field Test 1978.

DESCRIPTION

1. Sample points are arranged around the circumference of a pipe. The sample points may be fixed or of the insertable probe type. Fixed sample points have tubes inserted to various depths in the pipe to enable the operator to sample the various phases present in the pipe. Insertable probes accomplish the same purpose with the additional advantage that they can be moved to sample various pipe depths.

2. This configuration called a "porcupine" arrangement allows for sampling various flow regimes inside the pipe.

3. Samples coming from these sample points can be condensed with cooling coils, introduced directly into bombs or collected in other sampling arrangements.

4. The illustration shows an arrangement used in a field test. The valves on the pipeline are 1" Whitey ball valves mounted on welded sockets which are on the pipeline. In this illustration the two ball valves are mounted in the vertical and horizontal positions. An insertable sampling probe is shown in the horizontal position connected to the ball valve through a Conax fitting. This arrangement allows for traversing the pipe diameter (see insertable probes method). The brine-gas sample is cooled in an ice-water bath downstream of the probe.

\section{COMMENTS:}

1. Using this arrangement it is possible to study the flow profile of the pipe using insertable probes.

2. By using the "porcupine" arrangement and evacuated cylinders (see evacuated cylinder method) it was possible to show during a field test that primarily gas was removed from the vertical sample port and primarily liquid was removed from the horizontal sample part (inlet brine sample).

3. During actual field use it is a simple matter to mount another ball valve on top of a leaking valve if this situation develops. 


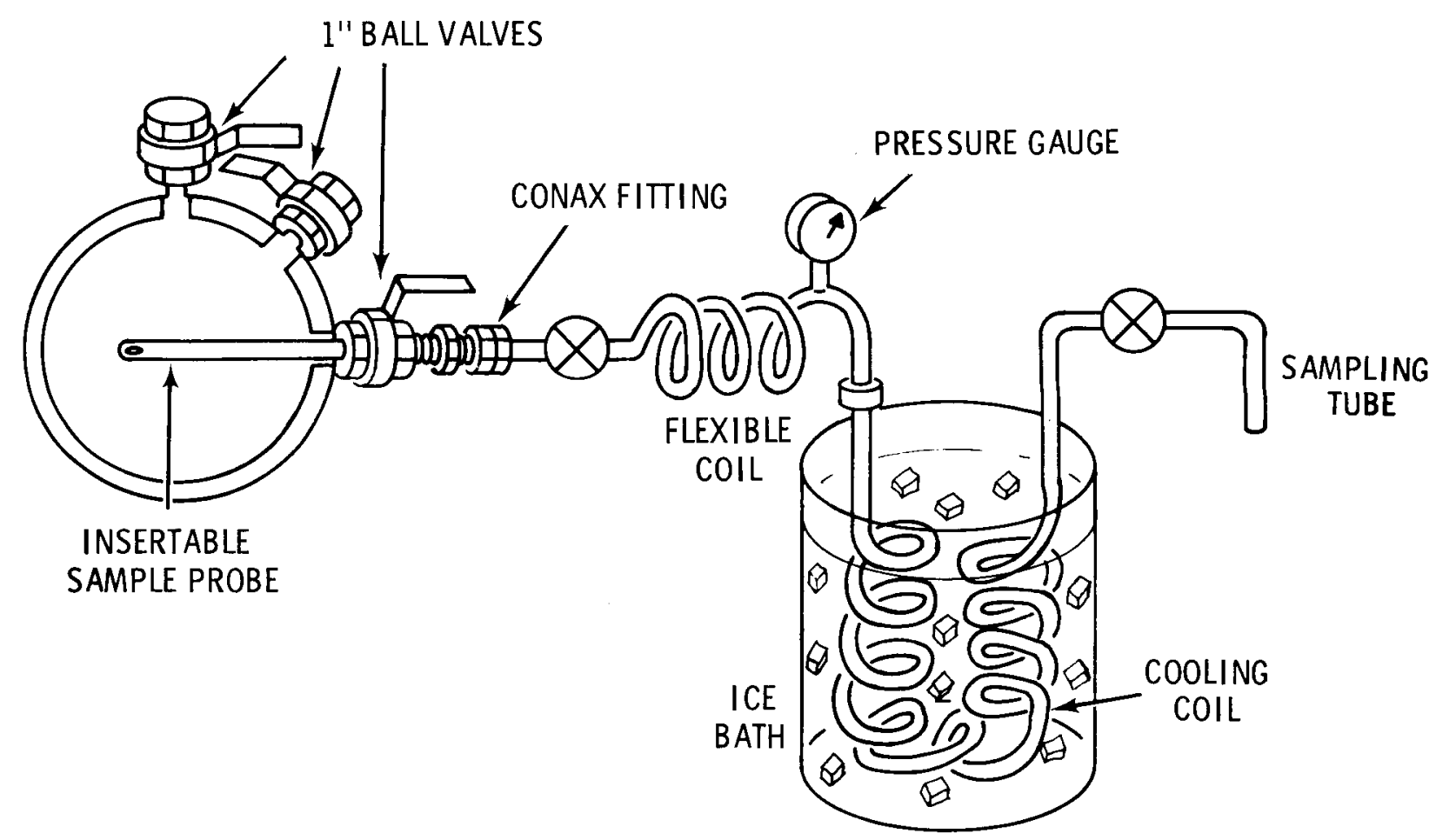

CROSS SECTION OF PIPE SHOWING "PORCUPINE" ARRANGEMENT OF BALL VALVES WITH INSERTABLE TRAVERSING PROBE PRESENT (USED IN FIELD TEST) 
METHOD TITLE:

Evacuated cylinders
APPLICATION:

Sampling of gas and liquid from wellheads, pipelines, etc.
NO. $30-S$

SAMPLE TYPE: SAMPLE POINT:

Gas and Liquid

Wellhead, pipeline, etc.

\section{REFERENCES:}

1) Stoker, A. K. and W. D. Purtyman, "Some Problems Involved With Sampling Geothermal Sources," Las Alamos Scientific Lab, Report LA-UR-75-2335, 1975.

2)Appendix 1: Field Test 1978.

\section{DESCRIPTION}

1. Evacuated cylinders can be used for sampling total discharge (Figure 1). An evacuated pressure cylinder can be connected directly to a tap on the wellhead or delivery line. A "T" fitting with a valve and bleed line permits purging of air from the connecting line and fittings.

2. Corrosive gases, e.g., $\mathrm{H}_{2} \mathrm{~S}$, react with the container walls and fittings. Measurement of concentrations of these types of components from the cylinder contents should be regarded with caution.

3. Alternatively, the evacuated cylinder can be used to sample downstream of a cooling coil, for sampling steam phase from a separator, etc.

4. The arrangement in Figure 2 was used to evaluate the method in a field test. Double valving (Whitey shutoff valves) of the S.S. bombs was necessary to prevent air contamination while shipping. Results show that for this test primarily gas was collected in the vertically mounted cylinder while primarily liquid was obtained from the horizontal collection port.

\section{COMMENTS:}

1. Field evaluation showed that gross metals contamination of the liquid phase occurs inside the cylinder after collection. In particular iron, nickel, and chromium concentrations showed dramatic increases. Results for these metals should be regarded with caution.

2. Evaluation of $\mathrm{CO}_{2}$ and $\mathrm{H}_{2} \mathrm{~S}$ should be regarded with caution due to the reactive metal environment of the cylinder. 


\section{ILLUSTRATION:}

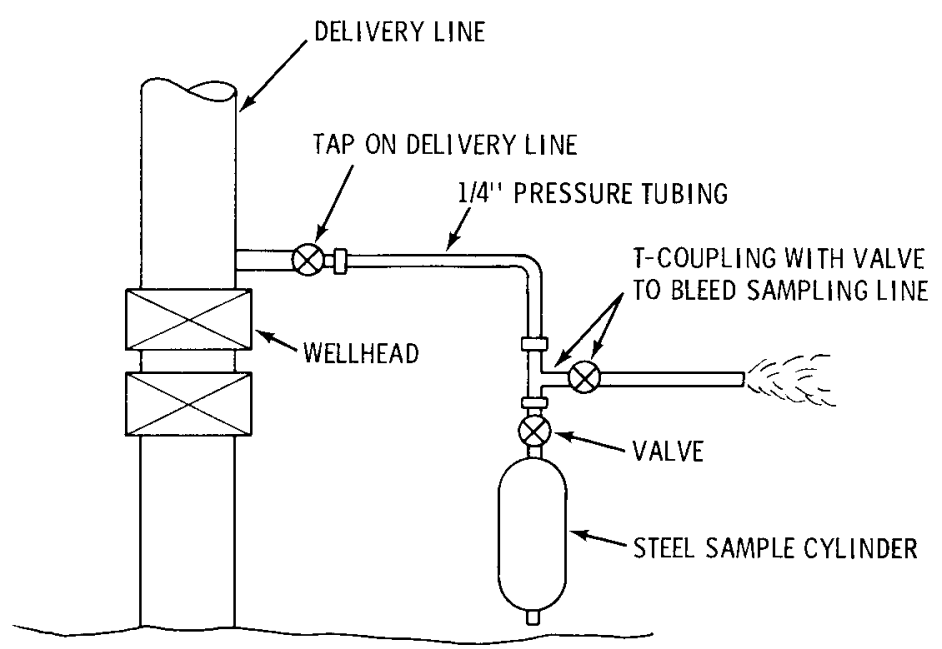

FIG 1. EVACUATED CYLINDER SAMPLING APPARATUS

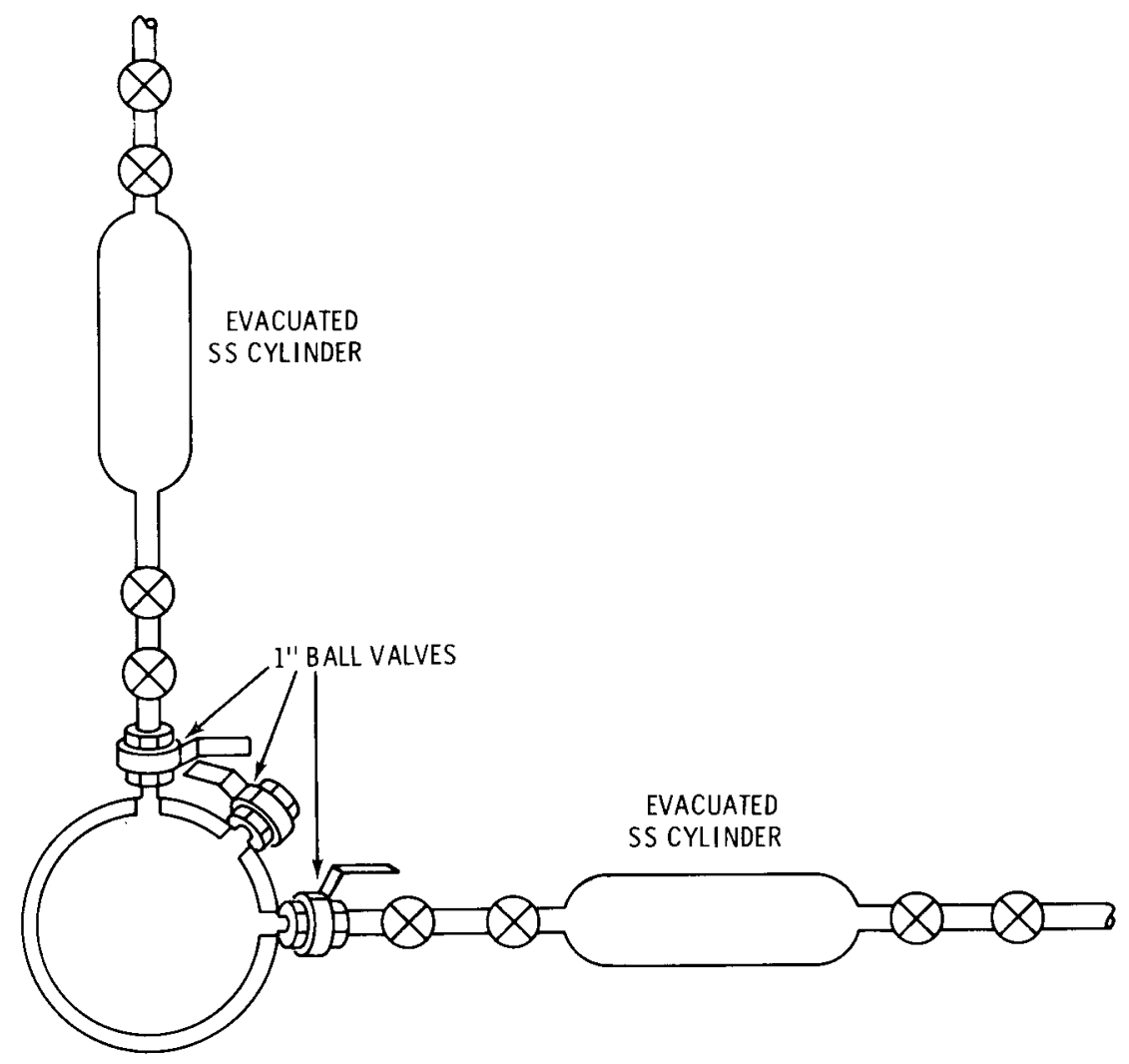

FIG 2. EVACUATED CYLINDER ARRANGEMENT USED IN FIELD TEST 
METHOD TITLE:

Evacuated cylinder-storage oven method.

APPLICATION:

Sampling hot pressurized fluid systems.
NO.

$37-5$

SAMPLE TYPE:

Liquid

\section{REFERENCES:}

Allen, C.A., J.M. Baldwin and R.E. McAtee, "Status Report. Raft River Project. Sampling Analysis, and Environmental Effects Studies, Allied Chemical Corp., Idaho National Engineering Laboratory, Idaho Fal1s, Idaho. Proceedings, 2nd Workshop on Sampling and Analyses of Geothermal Effluents, Las Vegas, February 1977.

\section{DESCRIPTION}

The sampling system consists of three parts; the sample vessels, the storage oven, and the desampler. The sampler is a 304 stainless steel sample cylinder equipped with stainless steel valves and purge line, as shown in Figure 1. Some samplers are equipped with a stainless steel in-line filter holder. This unit used a $25 \mathrm{~mm}$ diameter, 5-micron Teflon filter. Gas samples are collected in these samplers, but are not kept at we 11 temperature. The oven is constructed for rugged use, as shown in Figure 2. It is a stainless steel box with three inches of Marinite insulation, a stainless steel liner, and a 1100-watt heater. The desampler is used to cool and dilute hot pressurized geothermal fluid while keeping it at a pressure that will not allow phase separation. A nonreactive gas, such as helium or nitrogen, is used to pressurize the system. It can also be used to purge air or other reactive gases from the sample.

\section{COMMENTS:}

1. Storage oven used to maintain sampling conditions during transport of the sample to the laboratory.

2. See comments under evacuated cylinder method based on 1978 Field Test results. 


\section{ILLUSTRATION:}

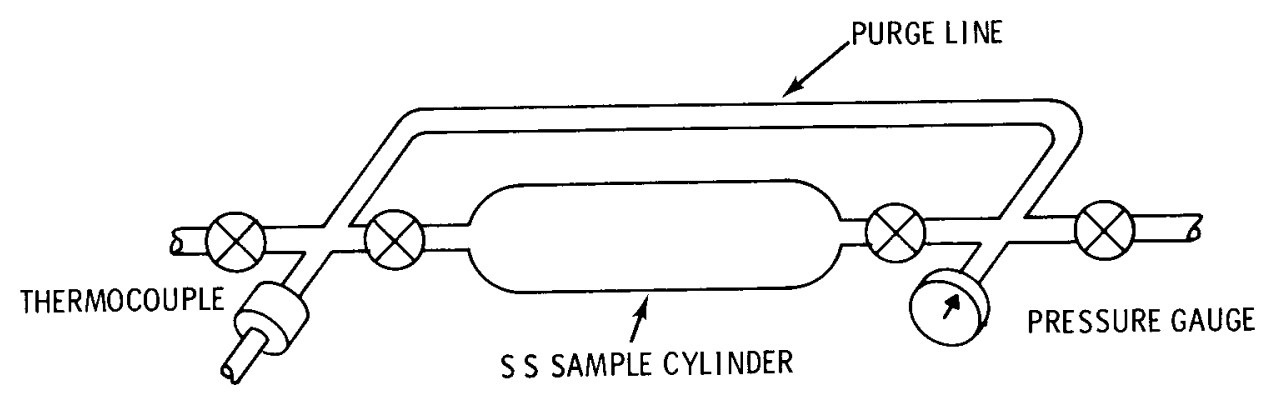

FIG 1. GEOTHERMAL HIGH PRESSURE SAMPLER

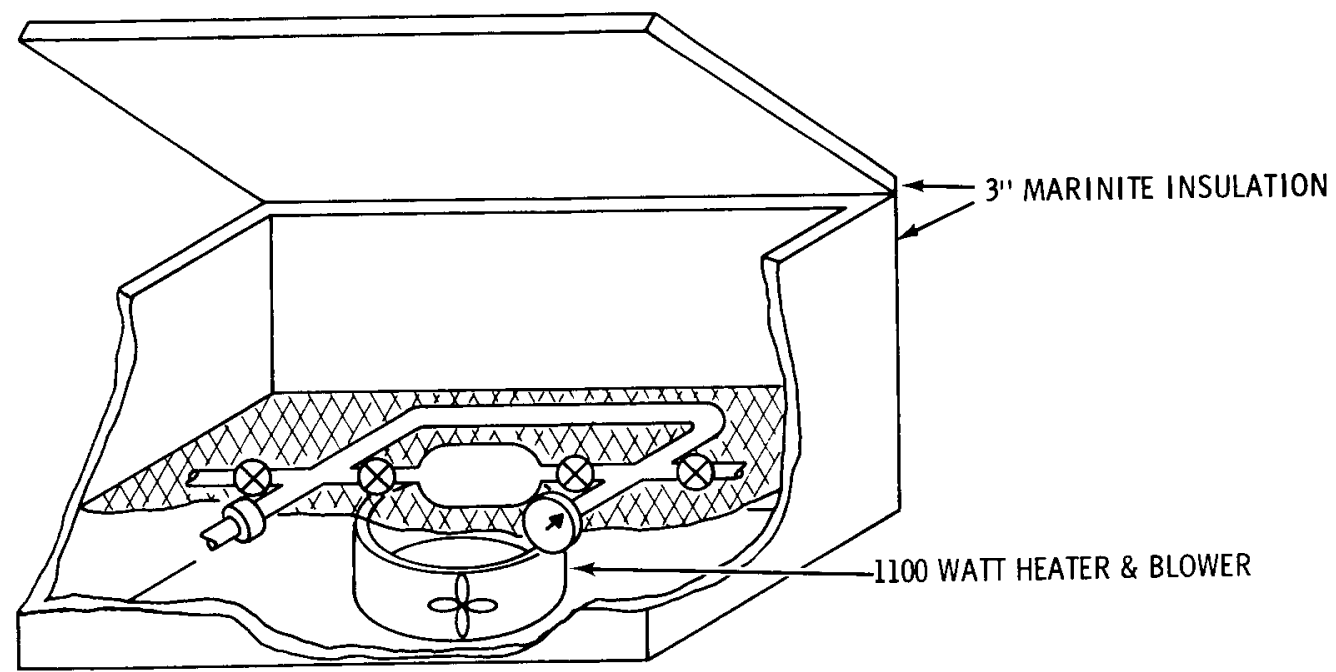

FIG 2. SAMPLE STORAGE OVEN 
METHOD TITLE:

Klyen downhole sampler
APPLICATION:

Downhole sampling of liquid and gas.
NO. $\quad 32-5$

SAMPLE TYPE: SAMPLE POINT:

Liquid and Gas

Wellbore

\section{REFERENCES:}

1. Klyen, L. E. "A Vessel for Collecting Subsurface Water Samples from Geothermal Drillholes," Geothermics, Vol. 2, p. 56-60. 1973.

2. Literature from Kuster Co., P.0. Box 7038 Long Beach, CA 90807.

\section{DESCRIPTION}

The loaded sampler is shackled to the suspension wire of a suitable winch which must be fitted with a depthometer. It is then lowered into a recovery tube on the top of the borehole, the suspension wire passing over a pulley wheel and through a threaded gland, which is screwed on to the top of the recovery tube to ensure effective sealing against borehole pressure.

At the sampling station, the suspension wire is jerked such that the activated inertia mechanism (A) breaks the tube $(C)$. The non-return valve (E) is opened by the external downhole fluid pressure allowing the fluids to flow into the sample chamber $(F)$. When the interior pressure together with the spring pressure equal the exterior pressure, the non-return valve closes. The vessel is then withdrawn from the borehole and if necessary cooled, to prevent the pressurized sample from boiling off when the sample release valve is opened.

\section{COMMENTS:}

An important additional feature is the vessel's capability to hold a vacuum in the loaded position, thereby enabling collection of air-free gas and water samples. 


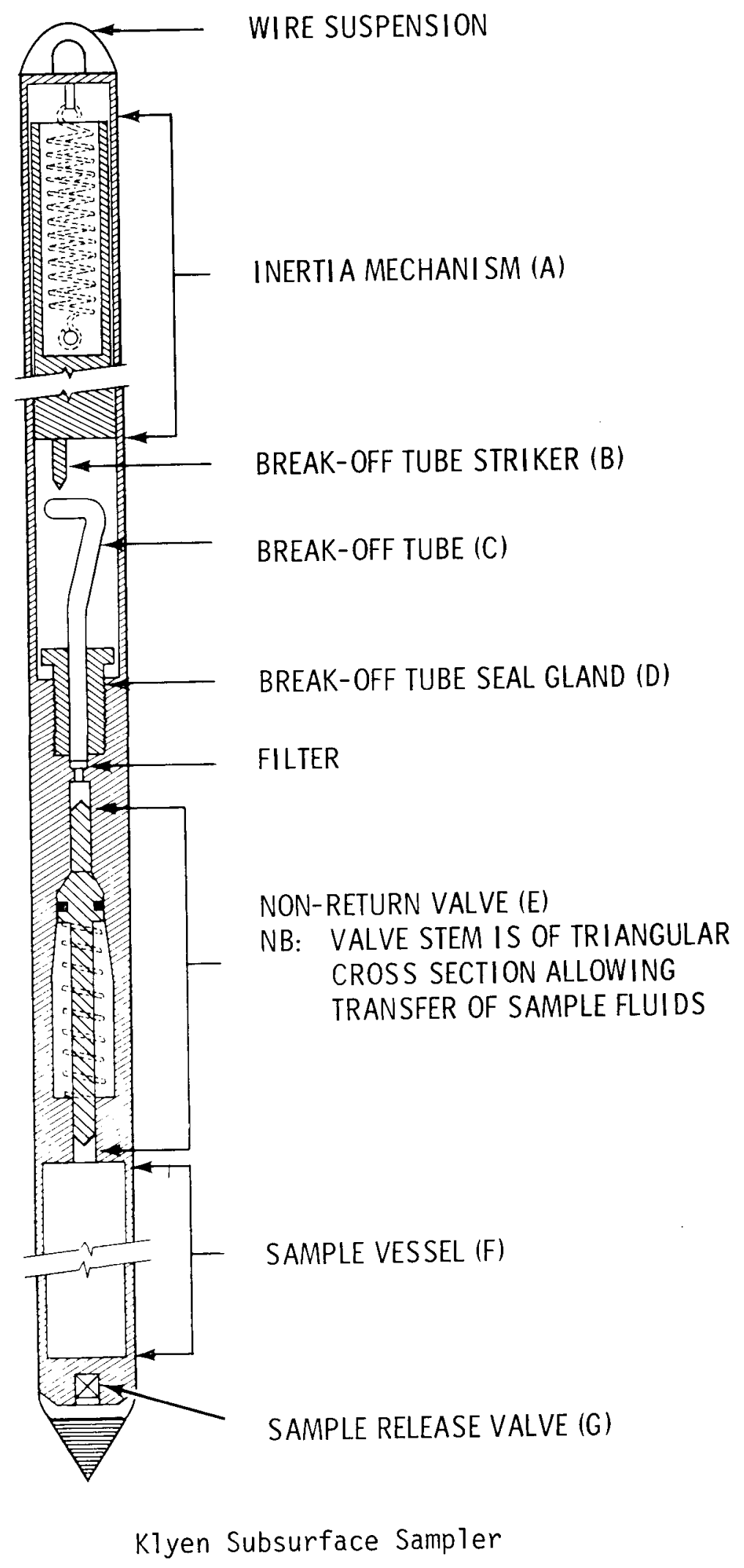




\section{METHOD TITLE:}

Down-hole water and gas sampling in geothermal vells using a down-hole sampler

APPLICATION:

Down-hole sampling

NO. $33-5$

SAMPLE TYPE:

Liquid and Gas
SAMPLE POINT:

Wellbore
REFERENCES:Fournier, R.0. and J.C. Morgenstern, "A Device for Collecting DownHole Water and Gas Samples in Geothermal Wells" U.S.G.S. Prof. Paper, 750-C, p. C151-155, 1971. Fournier, R.O. and A.H. Truesde 11, "A Device for Measuring Down-Hole Pressures and for Sampling Fluids in Geothermal Wells," U.S.G.S. Prof Paper 750-3, p. C146-C150, 1971.

Fournier, R.0. and J.M. Thompson, "Geothermal Down-Hole Sampling Instrumentation, "Proceedings, 2nd Workshop on Sampling and Analys is of Geotherma 1 Effluents, Las Vegas, NV, $2 / 77$.

\section{DESCRIPTION}

Sampler in open position is lowered using a long flexible stainless steel tube into the wellbore and fluid flows through it during descent. Closure is accomplished by nitrogen gas pressure applied from the surface through the flexible tube to a piston and plunger within the sample chamber. Continued application of nitrogen gas pressure during withdrawal of the device prevents leakage caused by changing conditions of temperature and pressure.

\section{COMMENTS:}

1. All materials are stainless steel except for one teflon o-ring, two viton o-rings, and several other tefion parts.

2. A modification of the lower end of the sampler using a special gas extraction fitting allows the sampler to be used for gas sampling.

3. Sample device can be used at temperatures up to $280^{\circ} \mathrm{C}$. 


\section{ILLUSTRATION:}

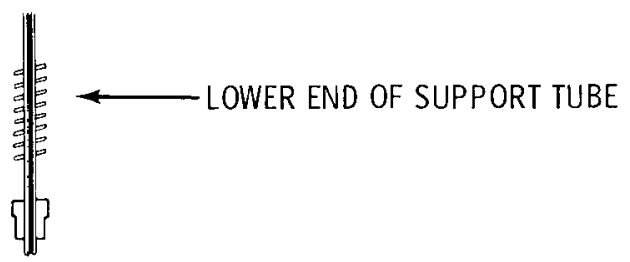

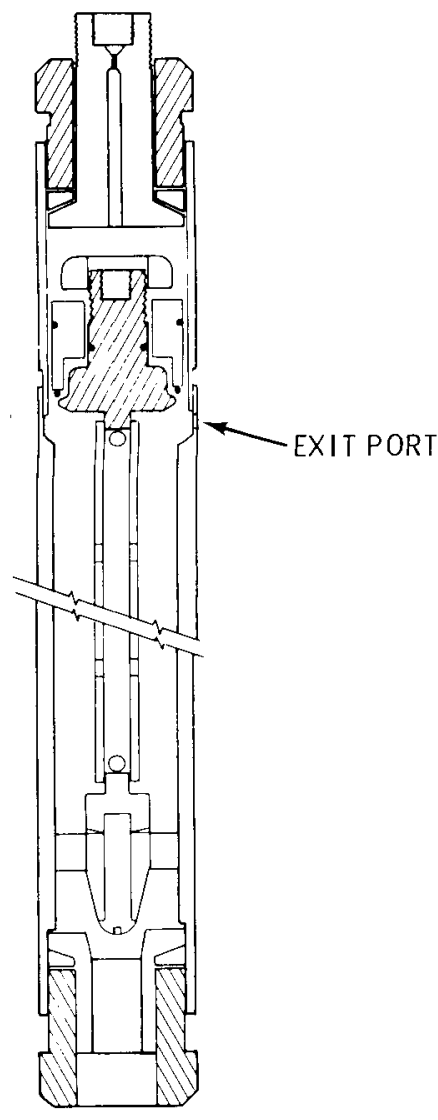

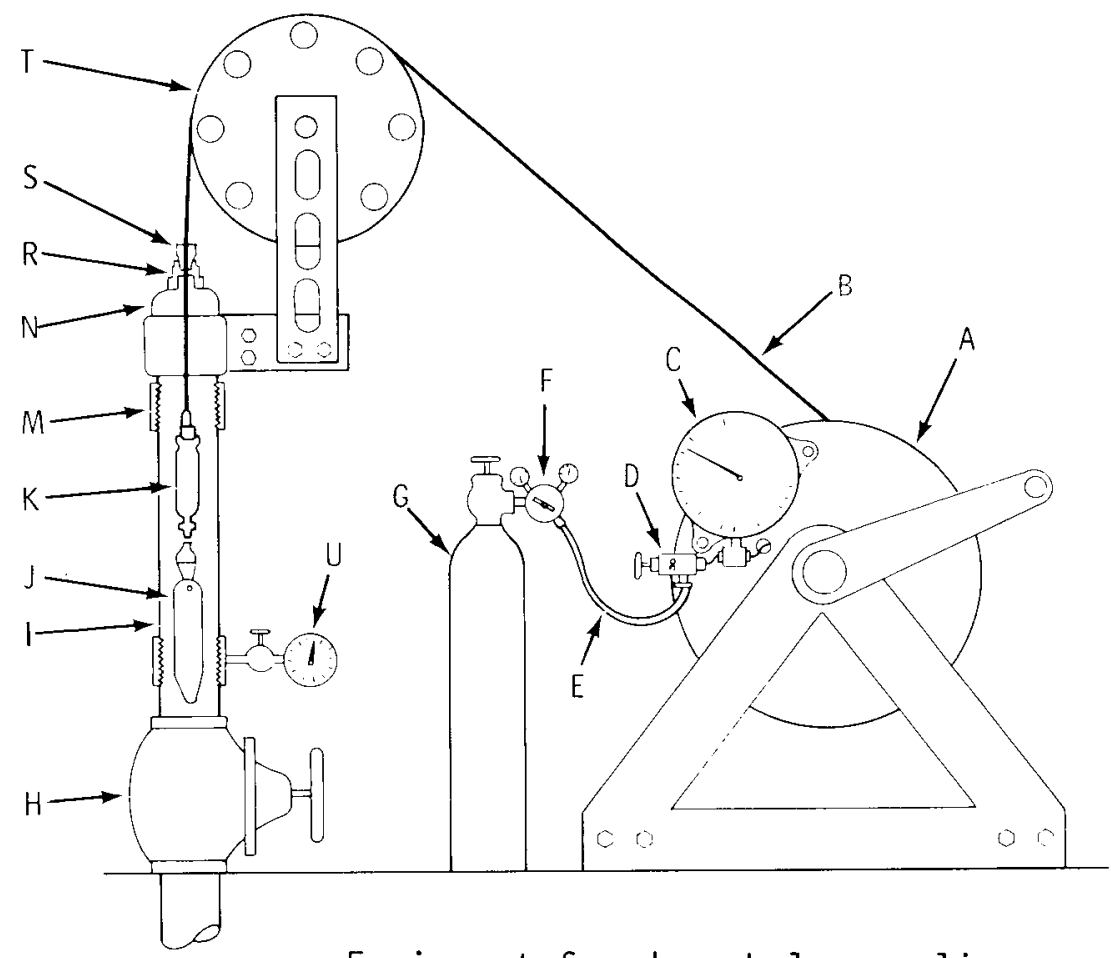

Equipment for down-hole sampling: a, reel with flexible stainless steel tube, $b$, wound upon it, $c$, precision pressure gage, d, high-pressure valve, $e$, flexible high-pressure connecting tubing, $f$, gas. regulating valve, $g$, cylinder of nitrogen gas, $h$, gate valve, $i$, short length of pipe, $j, 5$-pound lear weight, $k$, check valve, $m$, coupling that serves as support ring for sheave, $n$, reducer, $r$, plug, $s$, packing gland, $t$, sheave with automatic counter 1 tally the number of revolutions, $u$, pressure gage $f(c$ wellhead pressures.
Working drawing of device for collecting down-hole samples of water and gas in geothermal wells.

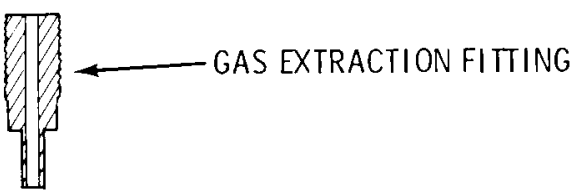$$
\text { wethead pressures. }
$$

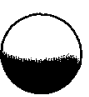


\begin{tabular}{|l|l|} 
NO. & $34-\mathrm{S}$ \\
\hline
\end{tabular}

SAMPLE TYPE: SAMPLE POINT:

Gas

Silencer
APPLICATION:

Sampling of reactive gases $\left(\mathrm{CO}_{2}\right.$ and $\left.\mathrm{H}_{2} \mathrm{~S}\right)$ from silencers.

\section{REFERENCES:}

Ellis, A.J. and W.A.J. Mahon, "Chemistry and Geothermal Systems," Academic Press, New York, 1977. (See note $V$ on paqe $B-1$ )

\section{DESCRIPTION}

A stainless steel or aluminum cone is suspended over the top of the silencer, or alternatively, a stainless steel probe is inserted through the silencer wall near the top of the structure. Steam and gas entering the cone (or probe) pass to a water condenser by stainless steel tube or butyl rubber hose. An evacuated double-ended thin-walled glass flask partially filled with a solution of sodium hydroxide is attached to the condenser.

Air entering the steam at the silencer inlet is collected in the flask with the geothermal gases. Air rapidly fills the flask, and must be removed to allow carbon dioxide and hydrogen sulfide to be collected in sufficient quantities for analysis. Removal is by a hand vacuum pump, or by a simple pump operated by steam or water discharged from a convenient tapping on the horizontal discharge pipe. A capsule filled with sand saturated with lead acetate is fitted between the flask and pump to detect hydrogen sulfide escaping through the alkaline solution.

\section{COMMENTS:}

The method is not applicable for collecting residual gas $\left(\mathrm{CH}_{4}, \mathrm{~N}_{2}, \mathrm{H}_{2}\right.$, etc.) samples. 


\section{ILLUSTRATION:}

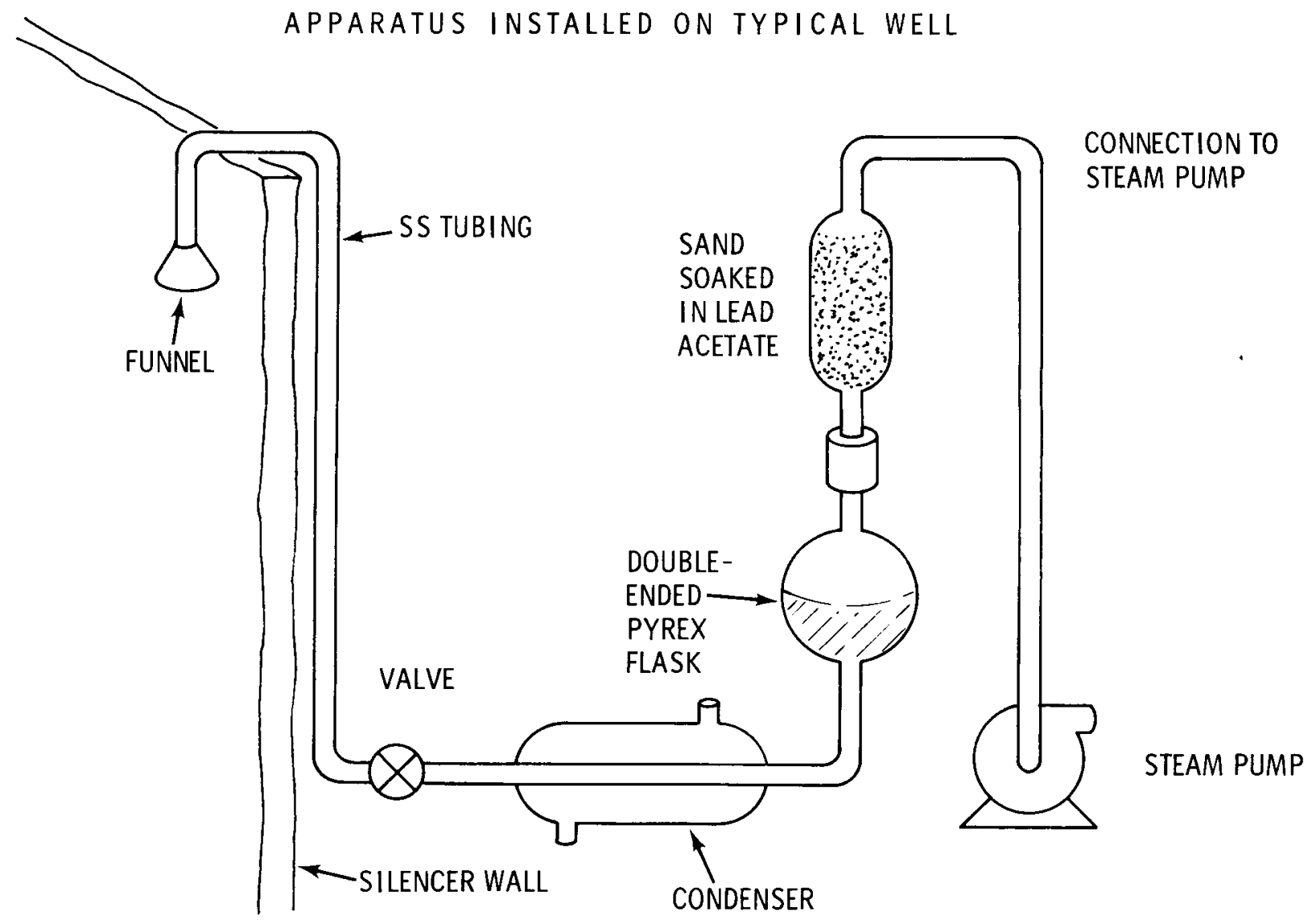

APPARATUS FOR COLLECTING STEAM AND GAS SAMPLES FROM THE SILENCER OF A GEOTHERMAL WELL 
METHOD TITLE:

Liquid sampling from unsilenced discharge pipes.
APPLICATION:

Sampling of liquid from discharge pipes.
NO. $35-\mathrm{S}$

SAMPLE TYPE: SAMPLE POINT:

Liquid

Discharge pipe

\section{REFERENCES:}

Ellis, A.J. and W.A.J. Mahon, "Chemistry and Geothermal Systems," Academic Press, New York, 1977. (See note $V$ on page B-1)

\section{DESCRIPTION}

The sampling apparatus is welded to the discharge pipe or held in the hand if the discharge is small. If held in the hand, the sampler should be inserted very slowly into the discharge, preferably toward the bottom of the pipe. Evaporative heat losses are generally small and samples at close to boiling temperature are obtained.

\section{COMMENTS:}

Extreme caution should be exercised sampling total discharge. If held by hand the apparatus can easily be pulled into the discharge and then violently out of the hand by the force of the flowing fluid. 


\section{ILLUSTRATION:}

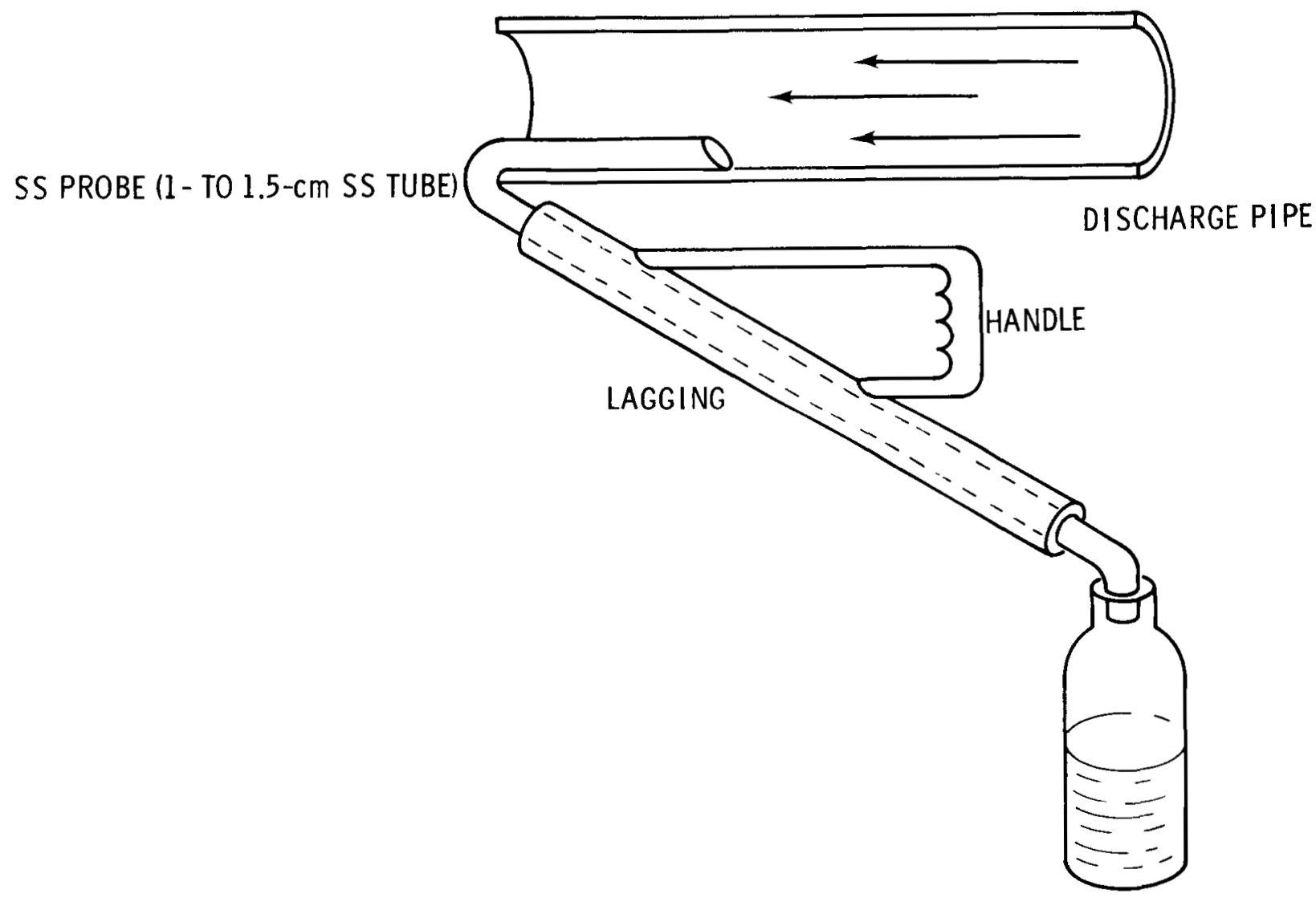

APPARATUS FOR COLLECTING WATER SAMPLES FROM THE END OF THE HORIZONTAL DISCHARGE PIPE OF A GEOTHERMAL WELL 
METHOD TITLE:

Gas concentration measurement method.

APPLICATION:

Measurement of the gas concentration in a steam or steam-water discharge.

\section{REFERENCES:}

1. McDowe11, G.D. Geothermics 3, 100 (1974)

2. Ellis, A.J. and W.A.J. Mahon," Chemistry and Geothermal Systems", Academic Press, New York, 1977. (See note $V$ on page B-1)

\section{DESCRIPTION}

The apparatus is shown in the illustration (Figures 1 and 2). A mixture of steam, water, and gas, discharged from a standard sampling point on the horizontal or vertical discharge pipe of a well, is passed into the heavily lagged, heat-insulated vessel B. A small stainless steel capsule $C$, which is partially filled with degassed distilled water during measurements, is sealed into the center of $B$. The interiors of $B$ and $C$ are connected to a standard mercury manometer or differential pressure gauge capable of accurately recording pressure differences down to 0.006 bar. The temperature of the water in $C$ rapidly attains the temperature of the discharge, and a pressure equivalent to the vapor pressure of water at the temperature is exerted on one leg of the manometer or gauge. The pressure in $B$, which is equal to the vapor pressure of water plus the sum of the partial pressures of the gases in the discharge, is exerted on the second leg of the gauge, and a reading of the total gas pressure is obtained.

The percentage by volume of gas in the discharge is readily obtained by assuming ideal gas behavior. To obtain the percentage by weight of gas in steam, the gas composition is required. For a large number of geothermal systems only a small error is introduced by assuming that $\mathrm{CO}_{2}$ is the only gas present.

Convenient formulas for converting the measured partial pressure of gas into pounds of gas per pound of steam or kilograms of gas per kilogram of steam are

$$
W(1 \mathrm{~b})=\frac{M 144 \mathrm{P}_{\mathrm{g}} V_{\mathrm{S}}}{1545 \mathrm{~T}} \text { and } W(\mathrm{~kg})=\frac{M P_{\mathrm{g}} V_{\mathrm{S}}}{83.13 \mathrm{~T}}
$$

where $W$ is pounds of gas per pound of steam or kilograms of gas per kilogram of steam; $P_{g}$ partial pressure of gas in pounds per square inch or bars; $v_{s}$ specific volume of steam at the vapor pressure of the water discharged in cubic feet per pound or cubic centimeters per gram (vapor pressure = total pressure - partial pressure of gas); $T$ absolute temperature in ${ }^{\circ} \mathrm{F}$ or degrees Kelvin and $M$ is the mol. wt. of the gas.

\section{COMMENTS:}




\section{ILLUSTRATION:}

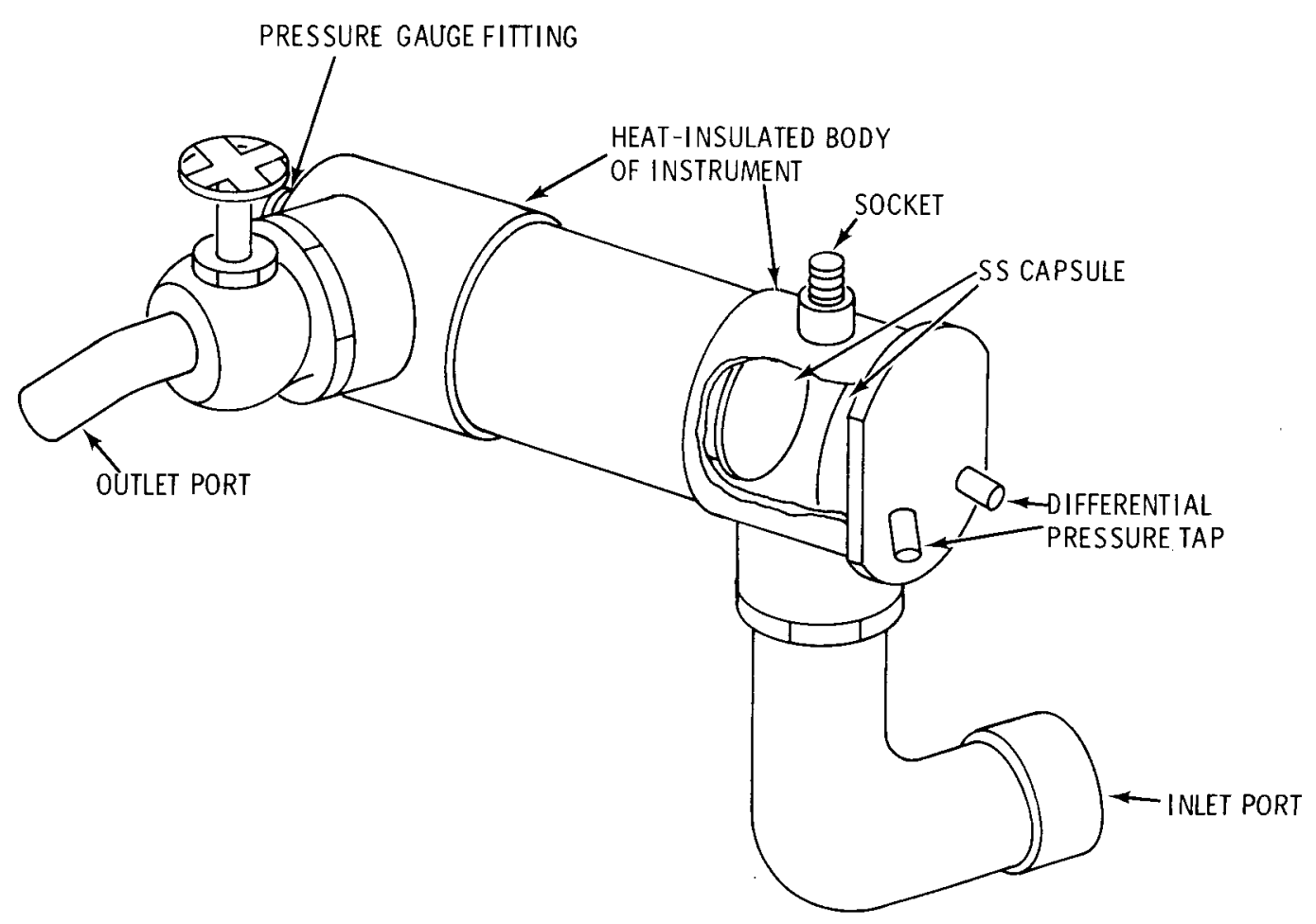

FIG 1. APPARATUS FOR MEASURING THE GAS CONTENT OF THE DISCHARGE FROM A GEOTHERMAL WELL

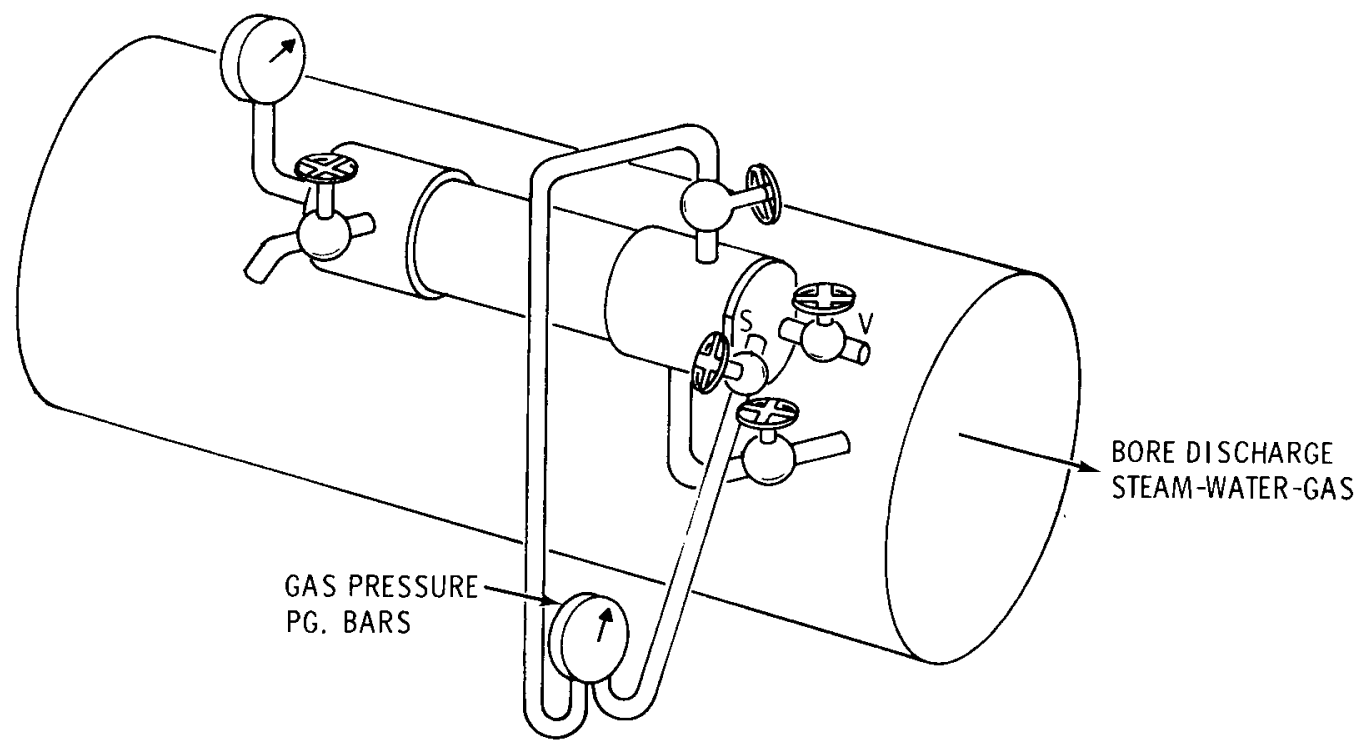

FIG 2. SCHEMATIC ARRANGEMENT OF GAS PROBE IN USE 


\section{METHOD TITLE:}

Gas sample inlet system for gas chromatograph.
SAMPLE TYPE: $\quad$ SAMPLE POINT:

Gas
APPLICATION:

Injecting gas samples into gas chromatograph system.

\section{REFERENCES:}

A. H. Truesde11, U.S. Geological Survey, Menlo Park, CA, Personal Communication.

\section{DESCRIPTION}

1. This system allows the operator to introduce a gas sample from a sample bomb into a gas chromatograph without air contamination. Figure 1 of the illustration shows the arrangement of the system. All tubing and valves are 1/16" stainless steel to minimize volume. The sample bomb is first connected at the sample inlet. With the valve to the bomb closed, valves 1-4 are opened with valves 5 and 6 closed and the system evacuated with a vacuum pump. After evacuation valves 2, 3, and 4 are closed, the sample valve on the bomb is opened and the pressure read. If the pressure is high enough, the sample may be directly introduced into the chromatograph sample 10op. If the pressure is not high enough, the pressure may be increased by using the mechanical syringe. The syringe will have to be withdrawn and evacuated prior to sample introduction. After the sample is introduced and the pressure read, valves 1 and 2 are closed and the gas compressed with the syringe. Valve 2 is then opened to allow the sample to be introduced into the sampling loop. A standard gas mixture may also be introduced by evacuating the system, introducing the standard mix through valve 5 and proceeding as before.

2. Details of the syringe are given in Figure 2. Additional detail of the piston inside the syringe is given in Figure 3.

\section{COMMENTS:}




\section{ILLUSTRATION:}

Figure 1

GC INLET SYSTEM

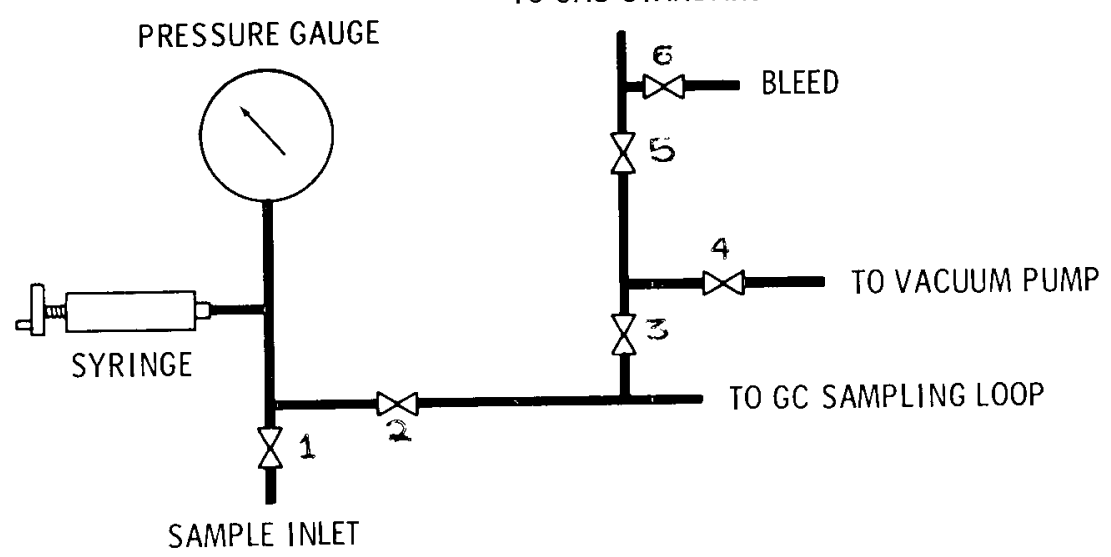

Figure 2

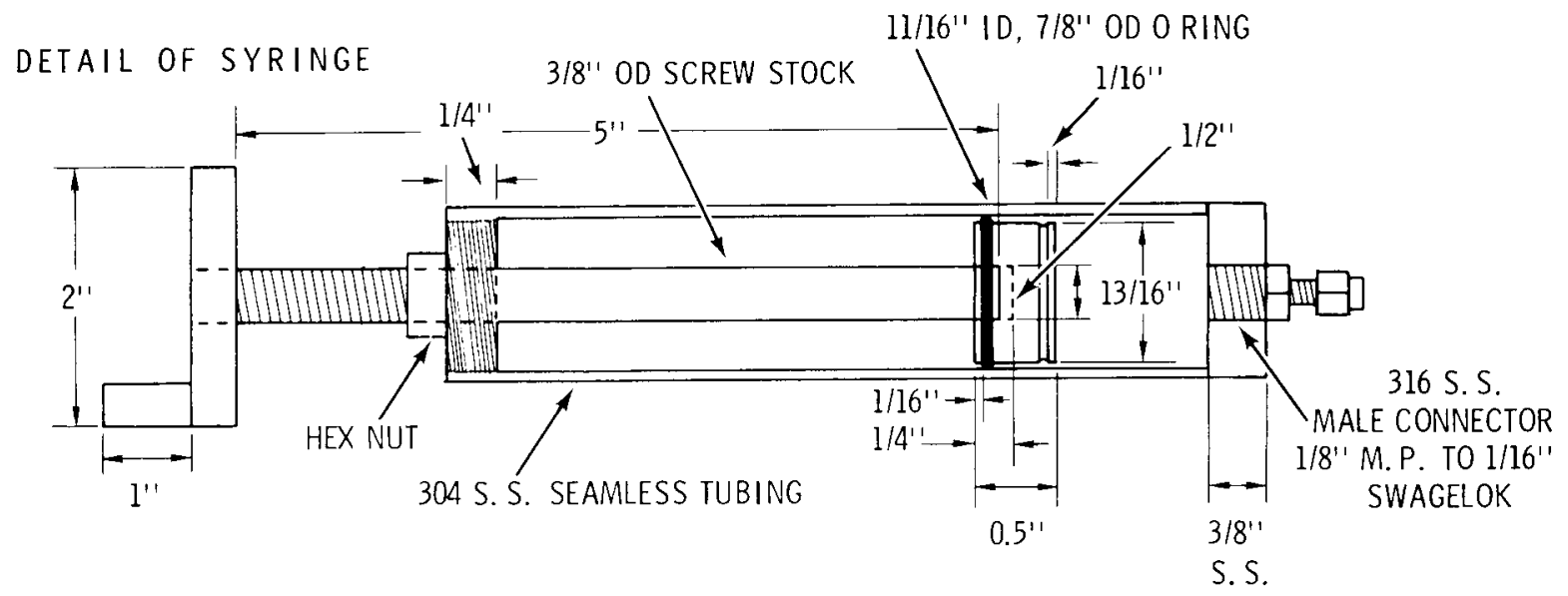

Figure 3

DETAIL OF PISTON

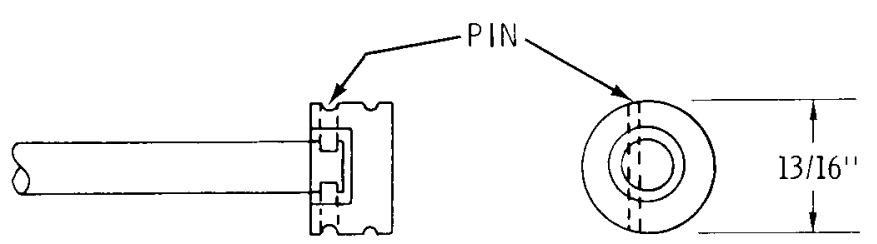




\section{Recommended Analytical Methods for Geothermal Liquids}

1. Purpose: The analytical methods compiled herein were included by virtue of being used to analyze two types of geothermal brines $(0.5 \%$ and $22 \%$ dissolved solids) in round robin testing. They are presented here to solicit further refinement of analytical methods for the geothermal industry.

II. Scope: The methods in this manual cover the following general properties of geothermal brines:

- Physical properties: pH, conductivity, alkalinity, etc.

- Dissolved solids: both metallic and non-metallic species.

- Dissolved and entrained gases: $\mathrm{H}_{2} \mathrm{~S}$ and $\mathrm{CO}_{2}$.

The methods do not cover analysis of gaseous or solid phase components associated with geothermal brines.

III. The sequence of methods listed for each parameter is:
a) Wet chemical.
b) Gravimetric.
c) Colorimetric.
d) Electrode.
e) Atomic absorption.
f) Flame emission.
g) X-ray fluorescence.
h) Inductively coupled plasma-atomic emission spectroscopy.
i) Ion exchange chromatography.
j) Spark source mass spectrometry.
k) Neutron activation analysis.
1) Emission spectrometry. 
Analysis: Method Name

No. Analys is Reference Nunber

Method: Brief description of fundamental theory of analysis and manipulations required.

Sample Handling: Type of sample used in this analysis and any extra necessary treatment of sample before analysis.

Useful range of method

Range: for geothermal brine. Precision:

Cross Reference:

References, appendices, other sampling numbers, and analyses numbers in this manual

Reagents:

Chemicals used in this method
Literature Reference:

References literature outside

this marual - see bibliography for details.

\section{Equipment:}

Required equipment, instrumentation and special apparatus for this method.

Remarks: Includes interferences, special observations about this method, and other miscellaneous information. 
Sampling and Sample Stabilization Procedures Used in Collecting Round Robin Samples:

A. Preparation of Sample Bottles and Containers Used to Collect Geotherma 7 Round Robin Samples:

1. Bottles and Containers:

Brine samples were collected in virgin linear polyethylene bottles and carboys with polypropylene caps. No glass containers were used for collection.

2. Preparation of Containers:

All bottles and carboys were washed prior to sample collection using the following sequence:

a) Distilled water rinse,

b) Nitric acid rinse (nitric acid suitable for $\mathrm{Hg}$ determination),

c) Two more distilled water rinses.

B. Methods Used to Collect Brine Samples for Analyses:

1. Raw Intreated (RU) brine was collected through two stainless steel cooling coils. The first coil was cooled by a water bath and the second was cooled in an ice bath; pH was determined on this sample in the field.

2. Filtered Untreated (FU) brine was collected through the two previously mentioned cooling coils followed by passing the brine through a $0.45 \mu$ membrane filter. Parameters determined using this FU sample included alkalinity, bicarbonatecarbonate, chloride, fluoride, bromide, iodide, phosphate, sulfate, and total dissolved solids.

3. Raw Acidified (RA) brine was collected through the cooling coils and acidified with $10 \mathrm{mls}$ of high purity concentrated $\mathrm{HCl}$ per liter of unfiltered brine. Parameters determined using the RA sample included hardness, aluminum, ammonia, antimony, arsenic, barium, boron, calcium, cesium, copper, iron, lead, lithium, magnesium, manganese, mercury, potassium, rubidium, silver, sodium, strontium, zinc, and silicon. 
4. Filtered Acidified (FA) brine was acidified with $10 \mathrm{mls}$ of high purity concentrated $\mathrm{HCl}$ per liter of brine. This brine was collected by passing the brine through the previously mentioned cooling coils and through a $0.45 \mu$ membrane filter. Parameters determined using the FA sample were the same as for the RA sample.

5. A 20:1 dilution for silica $\left(\mathrm{SiO}_{2}\right)$ using cooled filtered brine and distilled, deionized water for the dilution.

6. A sample was collected for entrained $\mathrm{H}_{2} \mathrm{~S}$ by passing cooled filtered brine through a sintered glass frit immersed in a solution of $0.5 \mathrm{~N}$ zinc acetate; the sample collected represents a $1: 1$ dilution of the brine.

7. A sample was collected for entrained $\mathrm{CO}_{2}$ by passing cooled filtered brine through a sintered glass frit immersed in a solution of $2 \mathrm{~N} \mathrm{NaOH}$; the sample collected represents a $1: 1$ dilution of the brine. 


\section{ALKALINITY}

Alkalinity

Analysis: Acid Titration

\begin{tabular}{|l|l|}
\hline No. & $1-A$ \\
\hline
\end{tabular}

Method: The sample is titrated with a strong acid $\left(\mathrm{H}_{2} \mathrm{SO}_{4}\right.$ or $\left.\mathrm{HCl}\right)$ to separate equivalence points for $\mathrm{OH}^{-}, \mathrm{CO}_{3}^{2-}$, and $\mathrm{HCO}_{3}^{-}$. Equivalence points are determined either potentiometrically or with visual indicators.

Sample Handling: Use RU brine, determine as quickly as possible after sampling to avoid $\mathrm{CO}_{2}$ losses.

Range: $>20 \mathrm{mg} / 1 \mathrm{CaCO}_{3} \quad$ Precision: $\pm 3 \% \quad$ Accuracy: $\pm 10 \%$

Cross Reference:

Appendix 2

Sampling Methods: 11-S, 29-S

Analysis Methods: $38-\mathrm{A}, 39-\mathrm{A}, 61-\mathrm{A}$, $62-A, 63-A, 64-A, 65-A, 141-A$

Reagents:

Standard $\mathrm{HCl}$ or $\mathrm{H}_{2} \mathrm{SO}_{4}$

Phenolphthalien indicator

Mixed methyl red-bromocresol green

indicator or methyl orange indicator

Standard $\mathrm{pH}$ buffers
Literature Reference: API 2.21-2.22 (68)

USGS Book 5 Chapter Al (1974) EPA 00710 (76)

APHA $403(75)$

ASTM 1067-70 (77)

\section{Equipment:}

Buret, $\mathrm{pH}$ meter and electrodes

Remarks: 1. Interferences: determinations of $\mathrm{OH}^{-}, \mathrm{CO}_{3}^{2-}$, and $\mathrm{HCO}_{3}^{-}$contributions to total alkalinity possible only with absence of other weak bases; residual $\mathrm{Cl}_{2}$, color, and turbidity affect visual indicator titrations; loss or gain of atm. $\mathrm{CO}_{2}$ affects results; erratic results obtained when oxidizing or reducing species are present; some constituents may cause buffering at endpoint.

2. Field determination recommended.

Edition: 
Analysis: Atomic Absorption (Direct)

$$
2-A
$$

Method: The sample containing aluminum is aspirated directly into a nitrous oxide-acetylene flame of an atomic absorption instrument, the absorbance is measured at $309.3 \mathrm{~nm}$ and compared with a standard curve.

Sample Handling: Use RA or FA brine.

Range: (1inear) $0.7-60 \mathrm{mg} / 1 \quad$ Precision: $\pm 5 \%$

Accuracy: $\pm 10 \%$

\section{Cross Reference:}

Appendix 2 Sampling Methods: 11-S, 29-S

Analys is Methods: $3-A, 4-A, 5-A$

Reagents:

A1 standard solutions

Nitrous oxide gas cylinder

Potassium chloride
Literature Reference:

APHA 301 IV (75)

EPA 01105 (76)

Instrument Manufacturer's Standard Methods Manua]

\section{Equipment:}

Atomic Absorption Spectrophotometer $\mathrm{N}_{2} \mathrm{O}$ burner head

\section{Remarks: 1. High Fe, $\mathrm{PO}_{4}$, and $\mathrm{Cl}$ may interfere.}

2. Careful matrix matching between sample and standards of the more predominant alkali and alkali earth metals and interferents required to ensure accurate measurement. Use of standard additions arid background correction recommended.

3. To minimize ionization interference; sample, standards and blanks should contain $2000 \mathrm{mg} / \mathrm{l} \mathrm{K}$. 


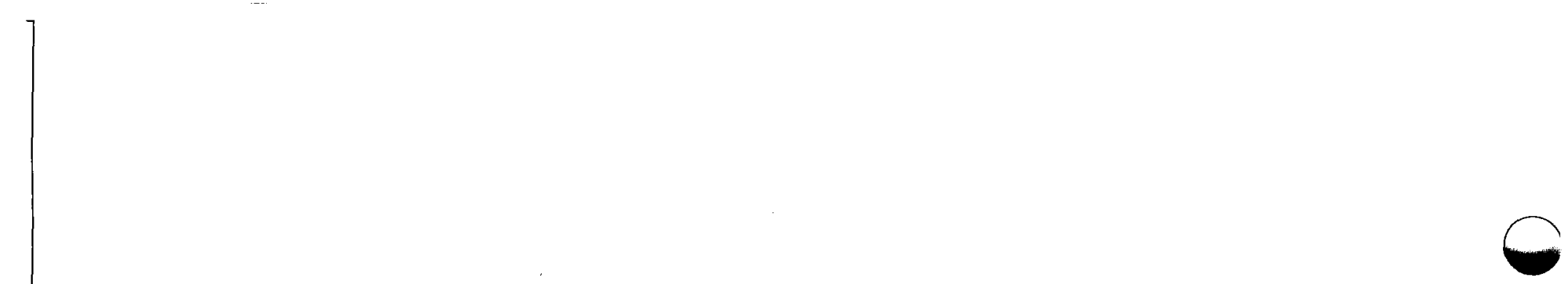


Analysis: Atomic Absorption (Graphite Furnace) \begin{tabular}{|l|l|}
\hline No. & $3-A$ \\
\hline
\end{tabular}

Method: Aluminum is determined using a graphite furnace and the following atomization conditions:

Dry: $20 \mathrm{sec}$ at $200^{\circ} \mathrm{C}$

Ash: $40 \mathrm{sec}$ at $1080^{\circ} \mathrm{C}$

Atomize: $10 \mathrm{sec}$ at $2500^{\circ} \mathrm{C}$

Wave length: $309.3 \mathrm{~nm}$

Sample Handling: Use RA or FA brine.

Range:

Accuracy:

\section{Cross Reference:}

Appendix 2

Sampling Methods: 11-S, 29-S

Analysis Methods: 2-A, 4-A, 5-A

Reagents:

Aluminum standards

Argon gas

\section{Literature Reference:}

Instrument Manufacturer's Methods Manual

\section{Equipment:}

Atomic absorption spectrophotometer

Graphite furnace

Plastic tip pipets

Remarks: Matrix matching between sample and standards, standard additions and background correction recommended.

Edition: 
Analysis: Atomic Absorption (Extraction) No. $4-A$

Method: $A 7$ is complexed in the aqueous sample with 8-quinolinol, then extracted from the aqueous phase with chloroform or methyl isobutyl ketone. The organic solution is then aspirated directly into an $\mathrm{N}_{2} \mathrm{O}$-acetylene burner and the absorption measured at $309.3 \mathrm{~nm}$.

Sample Handling: Use RA or FA brine; extraction in field may be aesirable.

Range:

Precision: $\pm 15 \%$

Accuracy: $\pm 6 \%$

\section{Cross Reference:}

Appendix 2

Sampling Methods: 11-S, 29-S

Analysis Methods: 2-A, 3-A, 5-A

\section{Reagents:}

Methy? isobutyl ketone or chloroform Ammonium acetate Ammonium hydroxide 8-Hydroxyquinol ine (8-Quinolinol) Aluminum standards Nitrous oxide gas cylinder

\section{Literature Reference:}

APHA 301 V (75)

Presser and Barnes, USGS WRI-22-74

Instrument Manufacturer's Standard Methods Manual

\section{Equipment:}

Atomic Absorption Spectrophotometer

$\mathrm{N}_{2} \mathrm{O}$ burner head

Separatory funnels

Remarks: 1. Interferences: Ionization of $A 1$ in flame reduces sensitivity.

2. Extraction technique measures only "extractable aluminum polymeric aluminum will not be extracted.

3. Extraction enhances detection limit of aluminum by flame AA.

4. Use of background correction recommended,

Edition:

5. High iron and salt concentrations may interfere. 


\section{Al}

Aluminum

Analysis: Flame Emission

$5-A$

Method: Aluminum is determined by aspirating the sample into a nitrous oxideacetylene flame and the emission intensity at $396.7 \mathrm{~nm}$ from aluminum is measured by a spectrophotometer.

Sample Handling: Use filtered acidified or raw acidified brine. Sample may be stabilized by adding $5 \mathrm{ml} \mathrm{HNO}_{3}$ per liter of sample.

\begin{tabular}{|c|c|}
\hline Range: $>0.05 \mathrm{mg} / 1$ & $\begin{array}{ll} & <0.5 \mathrm{mg} / 1 \pm 25 \% \\
\text { Accuracy: } & >0.5 \mathrm{mg} / 7 \pm 5 \%\end{array}$ \\
\hline $\begin{array}{l}\text { Cross Reference: } \\
\text { Appendix } 2 \\
\text { Sampling Methods: } 11-S, 29-S \\
\text { Analysis Methods: } 2-A, 3-A, 4-A\end{array}$ & $\begin{array}{l}\text { Literature Reference: } \\
\text { Dean and Rains, Flame Emission and Atomic Absorp- } \\
\text { tion Spectrometry, Vol. III, 1975, pp. 95-116. } \\
\text { W. Snelleman, Spectrochim. Acta, 23B, } 4.03 \text { (1968). }\end{array}$ \\
\hline $\begin{array}{l}\text { Reagents: } \\
\text { Aluminum a tomic absorption standard } \\
\text { solution or aluminum metal } \\
\text { Hydrochloric acid if zinc metal is used } \\
\text { Nitrous oxide gas cylinder } \\
\text { Potassium chloride }\end{array}$ & $\begin{array}{l}\text { Equipment: } \\
\text { Atomic absorption spectrophotometer with emission } \\
\text { mode or flame emission spectrophotometer. } \\
\text { Nitrous oxide burner head. }\end{array}$ \\
\hline
\end{tabular}

Remarks: 1. High iron, phosphate, and chloride may interfere.

2. Careful matrix matching between sample and standards must be made (i.e. using some amounts of $\mathrm{NaCl}$, other alkali metal and alkaline earth metal ions).

3. Use of standard additions and background correction recommended.

4. Severe spectral interference due to calcium must be corrected by pre-

Edition: paring blank, when measuring low concentrations of aluminum. 
5. In lab, dilute sample and add $2000 \mathrm{mg} / \ell$ potassium chloride as an ionization buffer. 
Aluminum

Analysis: X-Ray Fluorescence

\begin{tabular}{|l|l|}
\hline No. & 6-A \\
\hline
\end{tabular}

Method: The sample containing aluminum is caused to fluoresce by $X$-ray bombardment.

The fluorescent radiation is dispersed by a crystal and detected by a scintillation counter and/or a flow proportional counter.

Sample Handling: Use RA or FA brine; sample may be run as is or evaporated to dryness depending upon instrumentation.

Range: Precision: Accuracy:

\section{Cross Reference:}

Appendix 2

Sampling Methods: 11-S, 29-S

Reagents:

Aluminum standards
Literature Reference:

Cooper, J.A., Nuc. Inst. and Methods, Vol. 106, pp. 525-538, 1973 .

\section{Equipment:}

$X$-ray fluorescence spectrophotometer

Remarks: 1. Computer program usualiy required to interpret data.

2. Standardization of instrument required.

3. X-ray fluorescence provides simultaneous, multi-element determinations of selected metals and non-metals. 
\begin{tabular}{l|l|l} 
Analysis: $\begin{array}{l}\text { Inductively Coupled Plasma- } \\
\text { Atomic Emission Spectroscopy }\end{array}$ & No. & $7-A$ \\
\hline
\end{tabular}

Method: The brine sample is aspirated into a radiofrequency generated, inductively coupled argon plasma and the intensity of the emission spectrum of aluminum is measured by the instrument and compared with standards. Intensity is measured at $308.22 \mathrm{~nm}$ or alternate wavelength.

Sample Handling: Use RA or FA brine.

3-5 orders of magnitude from a

Range: single spectral 1ine Precision: $\pm 1-10 \% \quad$ Accuracy:

Cross Reference:

Appendix 2

Samnling Methods. 71-S. 29-5

Literature Reference:

"Evaluation of an Inductively Coupled Plasma, Multichanne] Spectrometric Analys is System!' EPA-600/4-77-032, June 1977.

\section{Reagents:}

Aluminum standards

\section{Equipment:}

Inductively coupled plasma-atomic emission spectrometer

Remarks: 1, NaCl matrix of samples and standards should be matched to minimize differences in solution properties which can affect vaporization characteristics. Background correction and standard additions recommended.

2. Inductively coupled plasma technique provides simultaneous, multielement determinations of metals.

Edition:

3. Additional reference: R. H. Scott and M. L. Kokot, "Application

$7 / 78$ of Inductively Coupled Plasmas to the Analys is of Geochemical Samples", Ana 1. Chim. Acta 75, 257-270 (1975).

$$
\text { (cont. on back) C-11 }
$$


4. Upper limit of concentration range may be extended by using alternate spectral lines. 


\section{Al}

A luminum

Analysis: Spark Source Mass Spectrometry 8-A

Method: A dehydrated sample containing aluminum is vaporized and ionized by an arc source and enters the analytical chamber. Aluminum is separated and detected by its mass/charge ratio, and the quantitative determination is made by comparison to standard curves.

Sample Handling: Use RA or FA brine. Evaporate samples to dryness before analysis.

Range: $0.7-1000 \mathrm{mg} / 7$ Cross Reference:

Appendix 2

Sampling Methods: 11-S, 29-S

\section{Precision: $\pm 25 \%$}

\section{Literature Reference:}

Trace Analysis by Mass Spectrometry, A.J. Aheard, ed. Academic Press, NY (1977).

D.L. Donohue, J.A. Carter and J.C. Franklin, Anal. Lèters, $10(5)$ 37i-379 (7979).

\section{Equipment:}

Spark Source Mass Spectrometer

Remarks: 1. Replicate determinations must be made for adequate accuracy and precision.

2. Spark source mass spectrometry provides simultaneous, multi-element analysis for selected metals and ion-metals.

Edition: 
Method: Sample containing aluminum is exposed to a neutron source (e.g. nuclear reactor) and radioactive aluminum isotopes formed are identified by their beta and gamma spectra using a multi-channel analyzer. The amount of aluminum present is proportional to the measured activity.

Sample Handling: Use RA or FA brine. Evaporate samples to dryness before neutron irradiation.

Range:

Precision:

Accuracy:

\section{Cross Reference:}

Appendix 2

Sampling Methods: 11-S, 29-S
Literature Reference:

Robertson and Carpenter, "Neutron Activation Techniques for the Measurement of Trace Metals in Environmental Samples", NAS-NS-3114, Jan. 1974.

Reagents:

\section{Equipment:}

1. Neutron Source (nuclear reactor)

2. Multichannel analyzer.

Remarks: 1. Sufficient time must be allowed for decay of sodium species where sodium spectrum masks Al peaks.

2. Neutron activation provides simultaneous multi-element analysis for selected metals and non-metals. 
Aluminum

Analysis:

Emission Spectrometry

$10-A$

Method: The sample containing aluminum in either solid or liquid state is vaporized using a flame, $A C$ spark or DC arc and the intensity of the selected emission line is measured against standards.

Sample Handling: Use $R A$ or FA brine. Evaporation to dryness may be required.

Range: $\quad 0.3-2 \mathrm{mg} / 1 \quad$ Precision: $\pm 10 \% \quad$ Accuracy:

Cross Reference:

Appendix 2

Sampling Methods: 11-S, 29-S

Reagents:

Aluminum standards

Vanadium internal standard

\section{Literature Reference:}

Instrument Manufacturer's Literature

\section{Equipment:}

Emission spectrometer

Photo processor

Microphotometer

Remarks: 1. Use matrix matching, standard additions and background correction whenever possible.

2. Emission spectrometry provides simultaneous, multi-element determinations for metals.

3. Larne differences in matrix effects will be observed deponding on the type of excitation source (flame, AC spark, or DS arc).

Edition: 
Ammonia

Analysis: Distillation Procedure

\begin{tabular}{|l|l|}
\hline No. & $11-\mathrm{A}$ \\
\hline
\end{tabular}

Method: Ammonia is distilled from the sample buffered with a borate buffer at $\mathrm{pH}$ 9.5. The distilled ammonia is captured in a solution of boric acid or sulfuric acid and then analyzed by desired procedure.

Sample Handling: Use RA or FA brine.

Range:

Precision:

Accuracy:

Cross Reference:

Appendix 2

Sampling Methods: 11-S, 29-S

Analysis Methods: 12-A, 13-A, 14-A,

\section{Reagents:}

$\mathrm{Na}_{2} \mathrm{BH}_{4} \mathrm{O}_{7}$

Dechlorinating agent (any of the

following):

Phenylarsine oxide

Sodium arsenite

Sodium sulfite

Sodium thiosulfate

Sulfuric acid

Ammonia-free $\mathrm{H}_{2} \mathrm{O}$

Remarks: 1. Procedure is necessary to get rid of most interferences, especially from the nesslerization and titration procedures; distiliation may be desirable before any ammonia analysis.

2. Hydrolyzable and/or volatile amines and cyanide will interfere, but these are usually absent from geothermal fluids.
Literature Reference:

APHA 418 A (75)

ASTM 1426-74 (77)

EPA $00610(76)$

\section{Equipment:}

800-2000 mi pyrex flask

vertical condenser

$500 \mathrm{ml}$ receiving flask

(Micro-distillation equipment may also be used)

\section{Edition:}


Ammonia

Analysis: Titration

No.

$12-A$

Method: Distillation of ammonia from alkaline solution and collection in known amount sulfuric acid and subsequent back titration with sodium hydroxide.

Sample Handling: Distill RA or FA brine per the distillation procedure for ammonia.

Range:

$1-5,29-5$
$1-A$

Cross Reference:

Appendix 2

Sampling Methods: 11-S, 29-S

Analys is Methods: 11-A

\section{Reagents:}

standardized sodium hydroxide and sulfuric acid, and a solution of: 675 grams sodium hydroxide and 80 grams sodium thiosulfate/L, methyl red.

\section{Precision: $₫ 2 \% \quad$ Accuracy: unknown}

\section{Literature Reference:}

\section{Equipment:}

KJELDAHL apparatus with flasks, burets.

Remarks: Distillation required before analysis. 
Method: A basic solution of $\mathrm{HgI}_{2}+\mathrm{KI}$ is added to the sample to form $\mathrm{NH}_{2} \mathrm{Hg}_{2} \mathrm{I}_{3}$ which has a yellow to brown hue that is measured between 450 and $500 \mathrm{~nm}$.

Sample Handling: Use RA or FA brine. Distillation recommended.

Range: $0.05-5 \mathrm{mg} / 1$

Precision: $\pm 10 \%$

Accuracy: $\pm 20 \%$

\section{Cross Reference:}

Appendix 2

Sampling Methods: 11-S, 29-S

Analys is Methods: 11-A

\section{Reagents:}

$\mathrm{ZnSO}_{4} \cdot 7 \mathrm{H}_{2} \mathrm{O}$

EDTA ${ }^{4}$ or Rochelle salt solution

Nessler reagent $\left(\mathrm{HgI}_{2}+\mathrm{KI}\right)$

$\mathrm{NaOH}$

Ammonia standards

Ammonia free $\mathrm{H}_{2} \mathrm{O}$

\section{Literature Reference:}

APHA 418B (75)

ASTM 1426-74A, B (77)

EPA $00610(76)$

\section{Equipment:}

Spectrophotometer or filter photometer at 45J-500 nm

Matched absorbance cells or Nessler tubes $\mathrm{pH}$ meter

Remarks: 1. Interferences: many interferences eliminated by distillation; others (in nondistilled samples) eliminated by addition of basic $\mathrm{ZnSO}_{4}$ to precipitate $\mathrm{Ca}^{2+}$, $\mathrm{Fe}, \mathrm{Mg}_{+}^{2+}$, and $\mathrm{H}_{\mathcal{T}} \mathrm{S}$; addition of EDTA or Rochelle salts prevents $\mathrm{Ca}^{2+}$ and $\mathrm{Mg}^{2 Z^{2}}$ from precipitating during determinations; $S^{2-}$, hydrazine, urea, and other hydrolyzable organic amides and amino acids will interfere.

2. Ammonia standards must be prepared fresh daily. 
Ammonia

Analysis: Automated Colorimetric Phenate

\begin{tabular}{|l|l|}
\hline No. & $14-\mathrm{A}$ \\
\hline
\end{tabular}

Method: The blue indophenol species is formed when alkaline phenol, hypochlorite, and ammonia react together. The blue color is proportional to the ammonia concentration and is measured in a 15 or $50 \mathrm{~mm}$ flow cell at 630-660 nm.

Sample Handling: Use RA or FA brine. Distillation may be desirable.

Range: $\quad 0.01-10 \mathrm{mg} / 1$

Precision: $\quad \pm 3 \%$

Accuracy: $\pm 10 \%$

Cross Reference: Appendix 2

Sampling Methods: 11-S, 29-S

Analysis Methods: 17-A

\section{Reagents:}

Ammonia free water

Sulfuric acid

Sodium phenolate

Sodium hypochlorite

Disodium EDTA

Sodium nitroprusside

Ammonia standards

\section{Literature Reference:}

EPA 00610 (76)

Technicon Auto Analyzer Industrial Method 98-70W Revised.

Bolleter, W.T., Bushman, C.J. and Tidwell, P.H., Ana T. Chem., 33, 592, T96T.

\section{Equipment:}

Technicon Auto Analyzer with:

Sampler

Manifold (AAI) or Analytical Cartridge (AAII)

Proportioning pump

Heating bath w/ double delay coil (AAI)

Colorimeter $w / 15 \mathrm{~mm}$ or $50 \mathrm{~mm}$ tubular cell

630-660 nm color filter

Recorder or digital printer

Remarks: 1. Distillation may be desirable.

2. Interferences in non-distilled samples: $\mathrm{Ca}$ and $\mathrm{Mg}$ (eliminated by adding EDTA), large amounts of $\mathrm{Hg}^{2+}$, turbidity (removed by filtration), color absorbing from 630-660 $\mathrm{nm}$.

Edition:

$7 / 78$ 
Ammonia

Analysis: Ammonia Selective Electrode

No. $\quad 15-\mathrm{A}$

Method: Ammonia is determined with a pIon or millivolt meter and an ammonia selective electrone after raising sample $\mathrm{pH}$ to $10-14$.

Sample Handling: Use raw or filtered acidified brine. Distillation usually not required, but may be done if so desired.

Range: $1-17,000 \mathrm{mg} \mathrm{NH} / \mathrm{H} \quad$ Precision: $\pm 3 \% \quad$ Accuracy: $\pm 3 \%$

Cross Reference:

Appendix 2

Sampling Methods: 11-S, 29-S

Analys is Methods: 11-A

Reagents:

$\mathrm{NaOH}$

Ammonia standards

Ammonia free water

\section{Literature Reference:}

Presser and Barnes USGS, WRI-22-74

EPA 00610 (76)

Electrode Manufacturer's Literature

\section{Equipment:}

Ammonia gas electrode

pIon or millivolt meter with expanded scale Magnetic stirring apparatus

Remarks: 1. Interferences: volatile amines, $\mathrm{s}^{2-}, \mathrm{Hg}$ (II).

2. Fresh ammonia standards required daily.

3. Use of standard additions recommended to check accuracy of analysis, especially if distillation not performed.

Edition: 
Ammonia

Analysis: Ion-Exchange Chromatography

\begin{tabular}{|l|l|}
\hline No. & $16-\mathrm{A}$ \\
\hline
\end{tabular}

Method: Ionic components are separated on sulfonated polymer-based column. A dilute nitric acid solution is used as the eluting solvent. The separation column is followed by a suppressor column to remove highly concentrated background components, and ammonium ion is detected by a conductivity detector.

Sample Handling: Use RA or FA brine. Distillation not required.

Range:

Cross Reference:

Appendix 2

Sampling Methods: 11-S, 29-S

Reagents:

Nitric acid

Ammonia standard solutions

\section{Precision: $\pm 1.83 \% \quad$ Accuracy: $\pm 5 \%$}

\section{Literature Reference:}

Dionex Corp., Sunnyvale, CA, Literature Ana.1. Chem, 47, 11, (1975).

Microchem. Jour. 22, (45-49) (1977).

Ana T. Chem. 49, 401" (1977).

\section{Equipment:}

Dionex ion chromatograph

72-120 psi air supply

Remarks: . Ammonia may be determined simultaneously with lithium by this method.

2. Additional reference: Smal1, H., T. S. Stevens, and W. C. Bauman, Ana 1. Chem. 47 180? (1975). 
Analysis: Atomic Absorption (Direct)

$17-A$

Method: Sample containing antimony is aspirated directly into an air-acetylene flame and the absorbance at $217.6 \mathrm{~nm}$ is compared to a standard curve.

Sample Handling: Use RA or FA brine.

\section{Range: (1 inear) $0.2-30 \mathrm{mg} / 1$ Precision: $\pm 5 \%$ Accuracy: $\pm 10 \%$}

\section{Cross Reference:}

Appendix 2

Sampling Methods: 11-S, 29-S

Analys is Methods: 18-A

\section{Reagents:}

Antimony standards

(Potassium antimony tartrate

Hemihydrate may be used)

\section{Literature Reference:}

Instrument Manufacturer's Method's Manual, Dean \& Rains III (192).

\section{Equipment:}

Atomic Absorption Spectrophotometer

Air-Acetylene burner head

Antimony electrodeless discharge lamp (optional)

Remarks: 1. Spectral interferences from non-absorbing wavelengths may be compensated by using a narrow slit-width or a different wavelength.

2. $\mathrm{Cu}$ and $\mathrm{Pb}$ in significant amounts compared to antimony interfere: use 206.8 or $231.2 \mathrm{~nm}$ antimony resonance lines.

3. Acid concentration must be matched between standards and sample.

4. Use of the more intense antimony electrodeless discharge lamo will aive better detection Timits.

Edition:

5. Background correction, matrix matching and standard additions recommended. 
6. Use of a graphite furnace will increase sensitivity. 
Analysis: Atomic Absorption (Hydride Evolution)

\begin{tabular}{|l|l|}
\hline No. & $18-\mathrm{A}$
\end{tabular}

Method: Sb is determined by atomic absorption at $217.6 \mathrm{~nm}$ in a nitrogen or arçonhydrogen flame after evolution as its hydride by addition at $\mathrm{IaBl}_{4}{ }_{4}$ to an acid solution of sample containing $\mathrm{SnC}_{-} \mathrm{I}_{2}$ and $\mathrm{KI}$.

Sample Handling: Use raw or filtered acidified brine.

Range: $>0.1 \mu \mathrm{g}$

Precision: $+2 \%$

Accuracy:

Cross Reference:

Appendix 2

Sampling Methods: 11-S, 29-S

Analysis Methods: 17-A

\section{Reagents:}

KI solution

$\mathrm{SnCl}_{2}$ solution

$\mathrm{NaBH}_{4}^{2}$ solution

$\mathrm{HC} 7$

Nitrogen or argon bottled gas

Hydrogen bottled gas

\section{Literature Reference:}

Instrument Manufacturer's Methods Manual

\section{Equipment:}

Atomic absorption spectrophotometer Hydride evolution unit

Remarks: Use of matrix matching, standard additions and background correction recommended.

Edition: 


\section{Sb}

Antimony

Analysis: $X$-ray Fluorescence

$19-A$

Method: The sample containing antimony is caused to fluoresce by $X$-ray bombardment.

The fluorescent radiation is dispersed by a crystal and detected by a scintillation counter and/or a flow proportional counter.

Sample Handling: Use RA or FA brine; sample may be run as is or evaporated to dryness depending upon instrumentztion. Sariple may be stabilized by adding $5 \mathrm{ml} \mathrm{HNO}_{3}$ per liter.

Range: $10-100 \mathrm{mg} / 1 \quad$ Precision: $\pm 10 \mathrm{mg} / 1 \quad$ Accuracy: $\pm 10 \mathrm{mg} / 1$

Cross Reference:

Appendix 2

Sampling Methods: 11-S, 29-S

\section{Literature Reference:}

Cooper. Nuc. Inst. and Methods, Vol. 106, pp. $525-\overline{538,} 1973$.
Reagents:

Antimony standards

\section{Equipment:}

$X$-ray fluorescence spectrophotometer

Remarks: 1. Computer program usually required to interpret data.

2. Standardization of instrument with antimony standards required.

3. X-ray fluorescence provides simultaneous, mult-element determinations for selected metals and non-metals.

4. Use standard additions for quantification.

Edition: 5. Detectability and accuracy limited by presence of antimony (as fire $7 / 78$ retardant?) in plastic films used to contain liquid sample. 


\section{Sb}

Antimony

Analysis: Inductively Coupled Plasma - Atomic Emission

Spectroscopy

\begin{tabular}{|l|l|}
\hline No. & $20-\mathrm{A}$ \\
\hline
\end{tabular}

Method: The brine sample is aspirated into a radiofrequency generated, inductively coupled argon plasma and the intensity of the emission spectrum of antimony is measured by the instrument and compared with standards. Intensity is measured at $217.59 \mathrm{~nm}$ or alternate wavelength.

\section{Sample Handling: Use RA or FA brine.}

3-5 orders of magnitude from

Range: a single spectral line Precision: $\pm 1-10 \%$

Accuracy:

\section{Cross Reference:}

Append ix 2

Sampling Methods: 11-S, 29-S

\section{Literature Reference:}

"Evaluation of an Inductively Coupled Plasma Multichannel Spectrometric Analys is System", EPA-600/4-77-032, June 1977.

\section{Equipment:}

Inductively coupled plasma

Atomic emission spectrometer

Remarks: 1. $\mathrm{HaCl}$ matrix of samples and standards should be matched to minimize differences in solution properties which cäin affect vaporizationi characteristics. Background correction and standard additions recommended.

2. Inductively coupled plasma technique provides simultaneous multi-element analysis of metals.

3. Additional references: R.H. Scott and M.L. Kokot, "Application of Edition: Inductively Coupled Plasmas to the Analysis of Geochemical Samples", Anal. Chim. Acta 75, 257-270 (1975).

(cont. on back) 


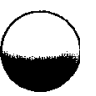




\section{Sb}

Antimony

Analysis: Spark Source Mass Spectrometry

No. 27-A

Method: Dehydrated brine sample is vaporized and ionized by an arc source and enters an evacuated chamber. Antimony is separated and detected by its mass/charge ratio and determined quantitatively by comparison with standards.

Sample Handling: Use RA or FA brine, evaporate to dryness.

Range: $\quad 0.1-1000 \mathrm{mg} / 1 \quad$ Precision: $\pm 25 \% \quad$ Accuracy: $\pm 25 \%$

Cross Reference:

Appendix 2

Sampling Methods: 11-s, 29-S

\section{Reagents:}

Antimony standards

\section{Literature Reference:}

Trace Analysis by Mass Spectrometry, A.J. Aheard, ed., Academic Press, NY (1977).

D.L. Donohue, J.A. Carter and J.C. Franklin, Anal. Letters, $10(5) \quad 371-379$ (1977).

\section{Equipment:}

Spark source mass spectrometer

Remarks: Spark source mass spectrometry provides simultaneous, multi-element determination for selected metals and non-metals.

Edition:

$7 / 78$ 
Analysis: Neutron Activation

\begin{tabular}{|l|l|}
\hline No. & $22-\mathrm{A}$ \\
\hline
\end{tabular}

Method: Dehydrated sample is irradiated by neutron bombardment to form radioactive antimony isotopes. The beta and gamma spectra are analyzed by a multichannel analyzer; peak heights are proportional to the amount isotope present.

Sample Handling: Use RA or FA brine and evaporate sample to dryness.

Range:

Precision:

Accuracy:

Cross Reference:

Appendix 2

Sampling Methods: 11-S, 29-S

\section{Literature Reference:}

Robertson \& Carpenter, "Neutron Activation Techniques for the Measurements of Trace Metals in Environmental Samples", NAS-NS-3114, Jan. 1974.

Reagents:

\section{Equipment:}

Neutron source (nuclear reactor)

Multichannel analyzer

Remarks: 1. Sufficient time (several days) must be allowed for sodium decay if the sodium spectrum masks the element of interest.

2. Neutron activation provides simultaneous, multi-element determination for metals and non-metals.

Edition:

$7 / 78$ 
Analysis: Emission Spectrometry

\begin{tabular}{|l|l|l|l|l|}
\hline No. & $23-\mathrm{A}$ \\
\hline
\end{tabular}

Method: The sample containing antimony is either solid or liquid state is vaporized using a flame, AC spark or DC arc and the intensity of the selected emission line is measured against standards.

Sample Handling: Use RA or FA brine. Evaporation to dryness may be requirea. (Ash filter and mix with graphite.)

\begin{tabular}{|c|c|}
\hline Range: $\quad 0-40 \mathrm{mg} / 1$ & Precision: $\pm 20 \%$ \\
\hline $\begin{array}{l}\text { Cross Reference: } \\
\text { Appendix } 2 \\
\text { Sampling Methods: } 11-\mathrm{S}, 29-\mathrm{S}\end{array}$ & $\begin{array}{l}\text { Literature Reference: } \\
\text { Instrument Manufacturer's Literature }\end{array}$ \\
\hline $\begin{array}{l}\text { Reagents: } \\
\text { Antimony standards } \\
\mathrm{HNO}_{3} \text { or } \mathrm{HClO}_{4} \\
\text { Graphite }\end{array}$ & $\begin{array}{l}\text { Equipment: } \\
\text { Emission spectrometer } \\
\text { Muffle furnace } \\
\text { Photo processor } \\
\text { Microphotometer }\end{array}$ \\
\hline
\end{tabular}

Remarks: 1. Use matrix matching, standard additions and background correction whenever possitle.

2. Emission spectrometry provides simultaneous, multi-element determinations for metals.

3. Antimony precipited along with $\mathrm{SiO}_{2}$ in $\mathrm{HNO}_{3}$ dehydration procedure.

Edition: 4. Alternatively antimony may be precipitated with $\mathrm{HClO}_{\text {during de- }}$

$7 / 78$ hydration procedure. This method is not applicable where high levels of alkali metals form difficultly dissolved perchlorate salts. (over) $\quad C-27$ 
5. Large differences in matrix effects will be observed depending on the tvpe of excitation source (flame, AC spark, or DC arC). 


\section{As}

Arsenic

Analysis: Silver Diethyldithiocarbamate

\begin{tabular}{|l|l|l|}
\hline No. $24-A$ \\
\hline
\end{tabular}

Method: Arsenic is reduced to arsine by zinc in an arsine generator. The arsine gas is passed through a glass plug impregnated with lead acetate and into a chamber containing silver diethyldithiocarbamate dissolved in pyridine where the gas forms a red solution which is measured spectrophotometrically at $535 \mathrm{~nm}$.

Sample Handling: Use RA or FA brine. Nitric acid will give a negative interference if used for acidification.

Range: $>0.005 \mathrm{mg} / 1$

Precision: $\pm 0.002 \mathrm{mg}$

Accuracy: $\pm 0.002 \mathrm{mg}$

Cross Reference:

Appendix 2

Sampling Methods: 11-S, 29-S

\section{Literature Reference:}

APHA 404 A(75)

EPA 01002 (76)

ASTM D2972-74 (77)

\section{Reagents:}

Hydrochloric acid

Potassium iodide

Stannous chloride

Lead acetate

Silver diethyldithiocarbamate

Pyridine

Arsenic standards

\section{Equipment:}

Arsine generator and absorption tube

Spectrophotometer at $535 \mathrm{~nm}$

Remarks: 1 . Interferences: $\mathrm{Cr}, \mathrm{Co}, \mathrm{Cu}, \mathrm{Hg}, \mathrm{Mo}, \mathrm{Ni}, \mathrm{Pt}, \mathrm{Ag}$ interfer if in large enough concentrations. Antimony interferes by forming stibine. Sulfide is trapped in the lead acetate trap.

2. Standard additions should be used to establish recoveries.

Edition:

3. Generator system must be tightly closed to avoid losses of arsine during analys is.

$7 / 78$

4. 1-Ephedrine in chloroform is

a suitable solvent substitute for pyridine. 


\section{As}

Arsenic

Analysis: Atomic Absorption (Direct)

\begin{tabular}{|l|l|}
\hline No. & $25-\mathrm{A}$ \\
\hline
\end{tabular}

Method: Sample containing arsenic is aspirated into an air acetylene flame and the absorbance of the 193.7 arsenic resonance line is measured and compared to standards.

Sample Handling: Use RA or FA brine.

(1 inear)

Range: $0.7-20 \mathrm{mg} / 1$

Cross Reference:

Appendix 2

Sampling Methods: 11-S, 29-S

Analys is Methods: 26-A

Reagents:

Arsenic standards
Precision:

Accuracy:

\section{Literature Reference:}

Dean \& Rains, Flame Emission and Atomic Absorption Spectrometry, Vol III, 1975. pp. 205-208.

Instrument Manufacturer's Standard Methods Manual.

\section{Equipment:}

Atomic absorption spectrophotometer. Arsenic electrodeless discharge lamp (optional)

Remarks: 1. Interferences: main interference is the absorption of the hollow cathode radiation by air-acetylene flame. In the direct air-acetylene flame

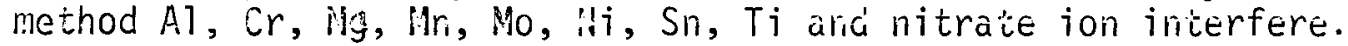

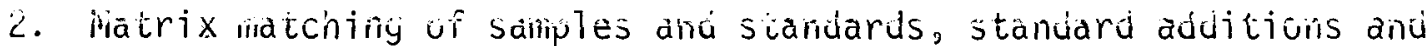
backyround correction recommended.

3. Use of an arsenic electrodeless discharge lamp gives lower detecticn Edition: limits. 

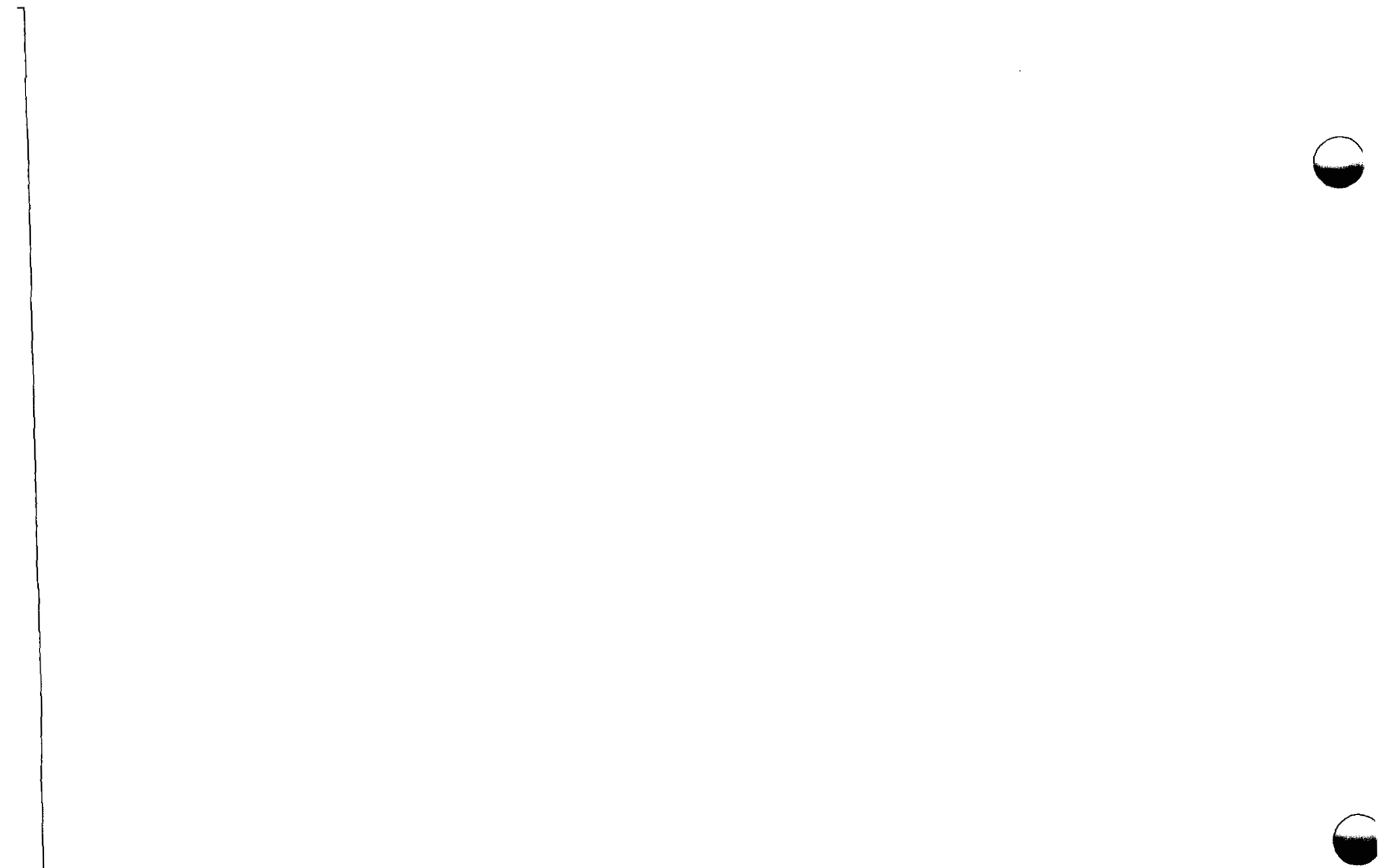

4. Use of a granhite furnace will incroase sonsitivity. 
Arsenic

Analysis: Atomic Absorption (Hydride Evolution)

No. $\quad 26-\mathrm{A}$

Method: Arsenic is determined as its hydride by atomic absorption at $193.7 \mathrm{~nm}$ in an argon or nitrogen-hydrogen flame after reduction with $\mathrm{SnCl}_{2}$ - KI and conversion to its hydride by addition of $\mathrm{Zn}$ to the acid solution.

Sample Handling: Use RA or FA brine.

Range: $0.5-50 \mu \mathrm{g} / 1$

Cross Reference:

Appendix 2

Sampling Methods: 11-S, 29-S

Analys is Methods: 25-A

\section{Reagents:}

KI

$\mathrm{SnCl}$

Zn sturry (200 mesh Zn)

$\mathrm{HCl}$

Nitrogen or argon bottled gas

Hydrogen bottled gas

$\mathrm{NaBH}_{4}$ pellets 10/32 in. (option)

\section{Precision: $\quad \pm 10 \% \quad$ Accuracy: $\quad \pm 10 \%$}

\section{Literature Reference:}

Instrument Manufacturer's Methods Manual

APHA 301 A (1975)

\section{Equipment:}

Atomic absorption spectrophotometer Hydride evolution unit

Remarks: 1 . Use of matrix matching, standard additions and background correction recommended.

2. Use of an electrodeless discharge lamp will increase sensitivity.

3. Arsenic can also be generated by the action of $\mathrm{NaBH}_{4}$ and hydrochloric

Edition: acid on the sample. The arsenic may be stored in a 4 balloon prior to $7 / 78$ $A A$ analysis instead of being flushed directly into the burner. 


\section{As}

Arsenic

Analysis: Inductively Coupled Plasma-Atomic Emicsion Spectroscopy

\begin{tabular}{|l|l|}
\hline No. & $27-\mathrm{A}$ \\
\hline
\end{tabular}

Method: The brine sample is aspirated into a radiofrequency generated, inductivelv coupled argon plasma and the intensity of the emission spectrum of arsenic is measured by the instrument and compared with standards. Intensity is measured at $193.76 \mathrm{~nm}$ or alternate wavelengths.

Sample Handling: Use KA or $F$ A brine.

3-5 orders of magnitude from a

Range: single spectral 1ine. Precision: $\pm 1-10 \%$

Accuracy:

\section{Cross Reference:}

Apperiuix?

Sanpling Methods: 11-S, 29-S

\section{Literature Reference:}

Evaluation of an Inductively Coupled Plasma Multichannel Spectrometric Analys is System EPA-600/4-77-032, June 1977.

\section{Equipment:}

Inductively coupled plasma

Atomic emission spectrometer

Remarks: 1. NaCl matrix of samples and standards should be matched to minimize differences in solution properties which can affect vaporization characteristics. Background correction and standard additions recommended.

2. Additional references: R. H. Scott and M. L. Kokot, "Application of

Edition: Inductively Coupled Plasmas to the Analysis of Geochemical Samples",

$7 / 78$ Ana1. Chim. Acta 75, 257-270 (1975).

(cont. on back) 
3. Probable spectral interference from manganese and iron at arsenic $193.76 \mathrm{~nm}$ line when analyzing concentrated brines.

4. Upper limit of concentration range may be extended by using alternate spectral lines. 


\section{As}

Arsenic

Analysis: Neutron Activation

No. $29-A$

Method: Dehydrated sample is irradiated by neutron bombardment to form radioactive arsenic isotopes. The beta and gamma spectra are analyzed by a multichannel analyzer; peak heights are proportional to the amount of isotope present.

Sample Handling: Use RA or FA brine and evaporate sample to dryness.

Range:

Cross Reference:

Appendix 2

Sampling Methods: 11-S, 29-S
Precision:

Accuracy:

\section{Literature Reference:}

Robertson \& Carpenter, "Neutron Activation Techniques for the Measurement of Trace Metals in Environmental Samples", NAS-NS-3114, Jan. 1974.

\section{Equipment:}

Reactor

Multichannel analyzer

Remarks: 1. Sufficient time (several days) must be allowed for sodium decay if the sodium spectrum masks the element of interest.

2. Neutron activation provides simultaneous, multi-element determination for selected metals and non-metals.

Edition: 3. Since arsenic is a volatile element, evaporation to complete dryness

$7 / 78$ may volatilize arsenic (Rowe, Fournier, and Morey, 1973, USGS Bulletin \#1303). 
Arsenic

Analysis: Emission Spectrometry

\begin{tabular}{|l|l|}
\hline No. & $30-\mathrm{A}$
\end{tabular}

Method: The sample containing arsenic in either solid or liquid state is vaporized using a flame, AC spark or DC arc and the intensity of the selected emission line is measured against standards.

Sample Handling: Use RA or FA brine. Evaporation to dryness may be required. (Ash filter and mix witr. graphite.)

Range: $\quad 0-40 \mathrm{mg} / \mathrm{T}$ Cross Reference:

Appendix 2

Sampling Methods; 11-S, 29-S

\section{Accuracy:}

\section{Literature Reference:}

Instrument Manufacturer's Literature

\section{Equipment:}

Fmission Spectrometer

$\mathrm{pH}$ meter

Magnetic stirrer

Photo processor

Microphotometer

Muffle furnace

Remarks: 1. Use matrix matching, standard additions and background correction whenever possit?e.

2. Emission spectrometry provides simultaneous, multi-element determination for metals.

3. Arsenic precipitated by Zno addition to final pH of 5.3 , using iron

Edition; as the collector.

$7 / 78$

4. Large differences in matrix cffects will be observed depending on the type of excitation source (flame, $A C$ spark, or DC arc). 
Barium

Analysis: Turbidimetric (Absorptometric)

No. $31-\mathrm{A}$

Method: Barium is measured turbidimetrically at $420 \mathrm{~nm}$ as its sulfate.

Sample Handling: Use filtered acidified brine.

Range: Precision: Accuracy:

Cross Reference:

Appendix 2

Sampling Methods: 11-S, 29-S

Analys is Methods: 197-A, 198-A

\section{Reagents:}

Magnesium chloride

Barium chloride

Sodium citrate dihydrate

Dioctyl ester of sodium sulfosuccinic acid (Aerosol OT)

Hydrochloric acid

Magnesium sulfate

\section{Literature Reference:}

API 3.32 (1968).

\section{Equipment:}

Spectrophotometer to measure at $420 \mathrm{~nm}$.

Remarks: 1. Calcium interferes when $>100 \mathrm{mg} / 1 \mathrm{CaCO}_{3}$.

2. Strontium interferes directly and is read as barium.

3. Polyphosphate $>2 \mathrm{mg} / 1$ can inhibit the formation or turbidity. Boiling with concentrated hydrochloric acid and subsequent neutralization with sodium hydroxide can overcome this effect.

Edition:

4. Interference can also be expected from high concentrations of organic $7 / 78$ 
Barium

Analysis: Atomic Absorption

No. $32-A$

Method: The sample containing barium is aspirated directly into a $\mathrm{N}_{2} \mathrm{O}$-acetylene flame and the absorbance of the Ba resonance line at $553.6 \mathrm{~nm}$ is measured.

Sample Handling: Use RA or FA brine.

Range: $1-20 \mathrm{mg} / \mathrm{l}$

Precision: $\pm 5 \%$

Accuracy: $\pm 10 \%$

Cross Reference:

Appendix 2

Sampling Methods: 11-S, 29-S

\section{Literature Reference:}

APHA 303 (75) USGS Book 5, Chapter Al (1974)

EPA 01007 (76)

Instrument Manufacturer's Standard Methods Manual

\section{Reagents:}

Barium standards

KCl

Nitrous oxide gas cylinder

\section{Equipment:}

Atomic absorption spectrophotometer

Nitrous oxide burner head

Remarks: 1. The ionization of barium in the nitrous oxide-acetylene flame is reduced by adding $\mathrm{KCl}$ until a $1000-2000 \mathrm{mg} / 1 \mathrm{~K}$ background is obtained in both standards and samples.

2. Graphite furnace atomization may be used in the place of the nitrous

Edition: oxide flame.

$7 / 78$ 3. Use of standard additions and matrix matching of alkali and alkaline earth metals recommended.

(cont. on back) 
4. If sample shows Tyndall effect, filter through $0.45 \mu$ membrane filter.

5. Some high salinity brines generate spectral interference around the $553.6 \mathrm{~nm}$ line. A window of $40 \mu \mathrm{m}$ is recommended. 
Barium

Analysis: Flame Emission

$33-A$

Method: Barium is determined by aspirating the sample into a nitrous oxide-acetylene flame and the emission intensity at $553.6 \mathrm{~nm}$ from barium is measured by a spectrophotometer.

Sample Handling: Use filtered acidified or raw acidified brine. Sample may be stabilized by diluting with 9 parts distilled water and $5 \mathrm{ml} \mathrm{HNO} 3$ per liter of sample.

\begin{tabular}{l} 
Range: $>0.05 \mathrm{mg} / 1$ \\
\hline Cross Reference: \\
Appendix 2 \\
Sampling Methods: $11-\mathrm{S}, 29-\mathrm{S}$ \\
Analysis Methods: $32-\mathrm{A}$
\end{tabular}

$<0.5 \mathrm{mg} / 1+25 \%$ Precision: $>0.5 \mathrm{mg} / 1 \mp 5 \%$

\section{Literature Reference:}

Dean and Rains, Flame Emission and Atomic Absorption Spectrometry, Vol. III, 1975, pp. 33-65.

W. Snelleman, Spectrochim. Acta, 23B, 403 (1968).

\section{Reagents:}

Barium atomic absorption standard solution or barium chloride Nitrous oxide gas cylinder Potassium chloride or potassium nitrat申

\section{Equipment:}

Atomic absorption spectrophotometer with emission mode or flame emission spectrophotometer. Nitrous oxide burner head.

Remarks: 1. The ionization of barium in the nitrous oxide-acetylene flame is reduced by adding $\mathrm{KCl}$ or $\mathrm{KNO}_{3}$ until a 1000-2000 mg/l K background is obtained in both standards and samples.

2. Use of standard additions and matrix matching of alkali and alkalir earth metals recommended.

Edition:

$7 / 78$

3. Precipitated $\mathrm{BaSO}_{4}$ may be determined by filtration of brine through 0.45 filter ashing paper dissolution of $\mathrm{BaSO}_{4}$ with EDTA and ammonia
and measurement via FAE.

(cont. on back) 


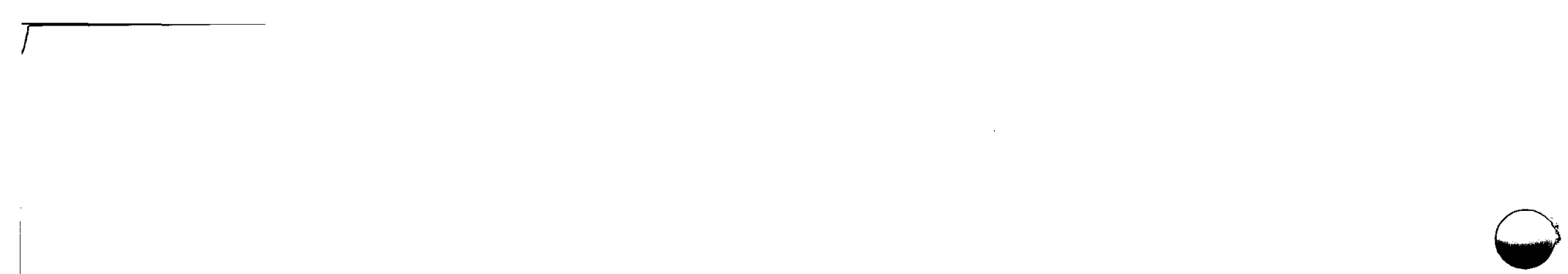

4. Some high salinity brines generate spectral interference around the $553.6 \mathrm{~nm}$ 1ine. A window of $40 \mu \mathrm{m}$ is recommended. 
Barium

Analysis: Inductively Coupled Plasma - Atomic Emission Spectroscopy

\begin{tabular}{|l|l|}
\hline No. & $34-A$ \\
\hline
\end{tabular}

Method: The brine sample is aspirated into a radiofrequency generated, inductively coupled argon plasma and the intensity of the emission spectrum of barium is measured ty the instrument and compared with standards. Intensity is measured at $233.53 \mathrm{~nm}$ or alternate wavelength.

Sample Handling: Use RA or FA brine.

3-5 orders of magnitude from

Range: a single spectral line Precision: $\pm 1-10 \% \quad$ Accuracy:

Cross Reference:

Appendix 2

Sampling Methods: $11-5,29-5$
Literature Reference:

"Evaluation of an Inductively Coupled Plasma Multichannel Spectrometric Analys is System" EPA-600/4-77-032, June, 1977.

\section{Equipment:}

Inductively coupled plasma-

Atomic emission spectrometer

Remarks: 1. $\mathrm{NaCl}$ matrix of samples and standards should be matched to minimize differences in solution properties which can affect vaporization characteristics. Background correction and standard additions recommended.

Edition:

2. Inductively coupled plasma technique provides simultaneous, multi-

$7 / 78$ element determination for metals.

3. Additional references: R. H. Scott and M. L. Kokot, "Application of Inductively Coupled Plasmas to the Analysis of Geochemical Sampies", Anal. Chim. Acta 75, 257-270 (1975).

$$
\text { (cant. on hack) C-38 }
$$


4. Upper limit of concentration range may be extended by using alternate spectral lines. 
Barium

Analysis: Spark Source Mass Spectrometry

\begin{tabular}{|l|l|}
\hline No. & $35-\mathrm{A}$ \\
\hline
\end{tabular}

Method: The dehydrated brine sample is vaporized and ionized by an arc source and enters an evacuated chamber where barium is separated and detected by its mass to charge ratio; quantitative analysis require comparison to standard barium samples.

Sample Handling: Use RA or FA brine, evaporate to dryness.

Range: $0.1-1000 \mathrm{mg} / 1$

Precision: $\begin{gathered} \pm 5 \% \\ \pm 25 \%\end{gathered}$

$+5 \%$ (isotope dil.)

Cross Reference:

Appendix 2

Sampling Methods: 11-S, 29-5

\section{Literature Reference:}

Trace Analysis by Mass Spectrometry, A.J. Aheard, ed., Academic Press, NY (1977).

D.L. Donohue, J.A. Carter and J.C. Franklin, Anal. Letters, 10(5) 37i-379 (1977).

Reagents:

Barium standards

\section{Equipment:}

Spark source mass spectrometer

Remarks: 1. Spark source mass spectrometry provides simultaneous, multi-element determination for selected metals and non-metals.

2. Additional references: J. A. Carter, D. L. Donohue, and J. C. Franklin, Trace Substances in Environmental Health-IX. U. of Missouri, 303 (1975).

Edition! J. C. Franklin, J. A. Carter, D. L. Donohue, and R. W. Stelzner, $7 / 78 \quad 354$ (1975).

R. Alvarez, B. J. Paulsen, and D. E. Kelleher, Anal. Chem. 41955 $(1969)$. 
Barium

Analysis: Neutron Activation

\begin{tabular}{|l|l|}
\hline No. & $36-\mathrm{A}$ \\
\hline
\end{tabular}

Method: Dehydrated sample is irradiated by neutron bombardment to form radioactive barium isotopes. The beta and gamma spectra are analyzed by a multichannel analyzer; peak heights are proportional to the amount of isotope present.

Sample Handling: Use RA or FA brine; evaporate sample to dryness.

Range:

Precision:

Accuracy:

\section{Cross Reference:}

Appendix 2

Sampling Methods: $11-\mathrm{S}, 29-\mathrm{S}$

\section{Literature Reference:}

Robertson \& Carpenter, "Neutron Activation Techniques for the Measurement of Trace Metals in Environmental Samples", NAS-NS-3114, Jan. 1974.

\section{Equipment:}

Neutron source (e.g. nuclear reactor)

Multichannel analyzer

Remarks: 1. Sufficient time (several days) must be allowed for sodium decay if the sôdium spectruim masks the element of interest.

2. Neutron activation provides simultaneous; rilti-element determination of selected metals and non-metals.

Edition:

$7 / 78$ 
Barium

Analysis: $\quad$ Emission Spectrometry

\begin{tabular}{|l|l|}
\hline No. & $37-A$ \\
\hline
\end{tabular}

Method: The sample containing barium in either solid or liquid state is vaporized using a flame, AC spark or DC arc and the intensity of the selected emission line is measured against standards.

Sample Handling: Use RA or FA brine. Evaporation to dryness may be required.

Range: $0.25-7.5 \mathrm{mg} / 1$ Cross Reference: Appendix 2

Sampling Methods; 11-S, 29-S

\section{Reagents:}

Barium standards

Vanadium internal standard
Precision: $\quad+10 \%$

Accuracy:

\section{Literature Reference:}

Instrument Manufacturer's Literature

\section{Equipment:}

Emission spectrometer

Photo processor

Microphotometer

Remarks: 1. Use matrix matching, standard additions and background correction whenever possible.

2. Emission spectrometry provides simultaneous, multi-element determination for metals.

Edition:

$7 / 78$

3. Larae differences in matrix effects wi?? te observed depending on the type of excitation source (flame, AC spark, or DC arc). 


\section{$\mathrm{HCO}_{3}$, $\mathrm{CO}_{3}$}

Bicarbonate, Carbonate

Analysis: Acid Titration

No.

$38-A$

Method: The bicarbonate and carbonate species concentrations are determined from the sample $\mathrm{pH}$, and the titration of the sample to $\mathrm{pH} 8.3$ (if the sample $\mathrm{pH}$ is $>8.3$ ) then to a $\mathrm{pH}$ of 4.5 with standard $\mathrm{HCl}$. Specie concentrations are then calculated from the equilibrium reactions of carbonate and bicarbonate.

Sample Handling: Use RU or FU brine.

\section{Range: $>10 \mathrm{mg} / 1$}

Precision: $\pm 0.5 \%$

Accuracy: $\pm 0.5 \%$

Cross Reference:

Appendix 2

Sampling Methods: 11-S, 29-S

Analys is Methods: 1-A, 39-A, 61-A, 62-A, 63-A, 64-A, 65-A, 141-A

\section{Reagents:}

Standard $\mathrm{HCl}$, Phenolphthalien indicator

Methyl red - bromocresol green

indicator or methyl orange indicator

\section{Literature Reference:}

APHA 407 B(75)

ASTM D513-71C (77)

USGS Book 5, Chapter AT (1974)

\section{Equipment:}

$\mathrm{pH}$ meter

Remarks: 1. Interferences: Large deviations from $25^{\circ} \mathrm{C}$ (unless equilibrium constants are used that reflect the temperature of the sample); variable ionic strength of sample, (activity coefficients may be used to correct for sample ionic strength).

Edition: 2. $\mathrm{CO}_{3}^{2-}, \mathrm{HCO}_{3}^{-}$, and $\mathrm{H}_{2} \mathrm{CO}_{3}$ concentrations may be determined by this method.

$7 / 78$ 3. Determine bicarbonate and carbonate on site whenever possible on fresh raw unacidified brine.

$$
\text { (cont. on back) }
$$





\section{$\mathrm{HCO}_{3}$, $\mathrm{CO}_{3}$}

Bicarbonate, Carbonate

Analysis: Calcium Carbonate Saturation Calculation

No.

$39-A$

Method: By determining the sample $\mathrm{pH}$ and calcium ion concentration and with the values of the solubility product of $\mathrm{CaCO}_{3}\left(\mathrm{~K}_{\mathrm{S}}\right)$ and the second proton dissociation constant of $\mathrm{H}_{2} \mathrm{CO}_{3}\left(\mathrm{~K}_{2}\right)$, bicarbonate may be determined from the equation: $\log \left(\mathrm{HCO}_{3}^{-}\right)=-\log \left(\mathrm{Ca}^{2+}\right)-\log \left(\mathrm{K}_{2} / \mathrm{K}_{\mathrm{S}}\right)-\mathrm{pH}$ and carbonate from the equation: $\left(\mathrm{CO}_{3}^{2-}\right)=\frac{\mathrm{K}_{2}\left(\mathrm{HCO}_{3}^{-}\right)}{\left(\mathrm{H}^{+}\right)^{-}}$

Sample Handling: Use RU brine for $\mathrm{PH}$ measurement and RA or FA brine for $\mathrm{Ca}^{2+}$ determination.

Range:

Precision:

Accuracy:

Cross Reference:

Appendix 2

Sampling Methods: $11-S, 29-5$

Analys is Methods: $1-A, 38-A, 61-A$, 62-A, 63-A, 64-A, 65-A, 141-A

Reagents:

Use appropriate reagents for $\mathrm{pH}$ and $\mathrm{Ca}^{2}+$ determinations.

Literature Reference:

APHA 203 (75)

\section{Equipment:}

Use equipment appropriate to $\mathrm{pH}, \mathrm{Ca}^{2+}$, and TDS determinations.

Remarks: 1. $\mathrm{pH}, \mathrm{Ca}^{2+}$ concentration, and total dissolved solids (TDS) must be determined before using this method.

2. Interferences: differences in temperature and sample ionic strength may cause inaccuracies in results; use activity coefficients and equilibrium

Edition; constants for temperature of measurement when possible.

$7 / 78$ 
Boron

Analysis: Carmine Colorimetric No. $\quad 40-A$

Method: Carmine in concentrated $\mathrm{H}_{2} \mathrm{SO}_{4}$ changes from bright red to bluish-red in the presence of boron. Color is measured at $585 \mathrm{~nm}$.

Sample Handling: Use RA or FA brine.

$4 \mu g \pm 10 \%$

Range: $2-20 \mu \mathrm{g}$

Precision:

higher conc.

\section{Literature Reference:}

APHA 405B (1975)

ASTM D3082-74A (77)

USGS Book 5, Chapter A1 (1974)

\section{Equipment:}

UV-Vis spectrophotometer at $585 \mathrm{~nm}$.

Sampling Methods: 11-S, 29-S

Reagents:

Boron standards $41-\mathrm{A}$

$\mathrm{HCl}$

$\mathrm{H}_{2} \mathrm{SO}_{4}$

Carmine N.F. or carminic acid $\mathrm{NaOH}$

Remarks: 1. Interferences: $\mathrm{F}^{-}, \mathrm{SiO}_{2}$ and $\mathrm{PO}_{4}^{3-}$ create slight interference.

2. Range may be expanded by dilution or evaporation of sample.

\section{Edition:}


Boron

Analysis: Curcumin Colorimetric

No.

$41-A$

Method: An acidified sample containing boron is evaporated in the presence of curcumin to produce rosocyanine which is measured colorimetrically at $540 \mathrm{~nm}$.

Sample Handling: Use RA or FA brine.

Range: $0.1-1 \mathrm{mg} / 1$

Precision: $\pm 5 \%$

Accuracy: $\pm 5 \%$

\section{Cross Reference:}

Appendix 2

Sampling Methods: 11-S, 29-S

Analys is Methods: 40-A

\section{Reagents:}

Boron standards

Curcumin reagent

Ethyl or isopropyl alcohol

$\mathrm{HCl}$

Oxalic acid

$\mathrm{NaOH}$ or $\mathrm{Na}_{2} \mathrm{CO}_{3}$

\section{Literature Reference:}

APHA 405A (75)

EPA $01022(76)$

\section{Equipment:}

UV-Visible spectrophotometer to measure at $540 \mathrm{~nm}$ Evaporation dishes

Heat source (e.g. hot water bath or infrared lamp)

Remarks: 1. Interferences: $>20 \mathrm{mg} / 1 \mathrm{NO}_{3}^{-} ;>100 \mathrm{mg} / 1 \mathrm{Ca}^{2+}$ and $\mathrm{Mg}^{2+}$ may be removed by precipitating with $\mathrm{NaOH}$ or $\mathrm{Na}_{2} \mathrm{CO}_{3}$ and filtering.

2. Close control of evaporating times, volumes and other variables required.

Edition: $7 / 78$

3. Range may be expanded by sample dilution or concentration. 
Boron

Analysis: Frame Emission

No. $42-A$

Method: Boron is determined by aspirating the sample into a nitrous oxide-acetylene flame and the emission intensity at $249.8 \mathrm{~nm}$ from boron is measured by a spectrophotometer.

Sample Handling: Use raw unacidified or filtered unacidified brine. Stabilization not necessary.

Range: $>20 \mathrm{mg} / 1$ high brine Precision: $\pm 10-25 \%$

\section{Cross Reference:}

Appendix 2

Sampling Methods: 11-S, 29-S

\section{Literature Reference:}

Dean and Rains, Flame Emission and Atomic Absorption Spectrometry, Vol. III, 1975, pp. 95-116.

W.Snelleman, Spectrochim. Acta, 23B, 403 (1968).

\section{Equipment:}

Atomic absorption spectrophotometer with emission mode or flame emission spectrophotometer.

Nitrous oxide burner head.

Nitrous oxide gas cylinder

Hydrochloric acid

Isopropanol

Remarks: 1. $1 \%(\mathrm{v} / \mathrm{v})$ hydrochloric acid added to standards.

2. Use of standard additions and matrix matching of alkali and alkaline earth metals recommended.

Edition:

3. Dilute samples with distilled water, acidify with $1 \%(v / v) \mathrm{HCl}$, add $10 \%(v / v)$ ispropana?. 
Boron

Analysis: Inductively Coupled Plasma - Atomic. Emission spectroscipy

No. $\quad 43-\mathrm{A}$

Method: The brine sample is aspirated into the radiofrequency generated inductively coupled argon plasma and the intensity of the emission spectrum of boron is analyzed by the instrument and compared with standards. Intensity is measured at $249.68 \mathrm{~nm}$ or alternate wavelength.

Sample Handling: Use RA or FA brine.

3-5 orders of magnitude from

Range: a single spectral line. Precision: $\pm 1-10 \% \quad$ Accuracy:

Cross Reference:

Appendix 2

Sampling Methods: 11-S, 29-S
Literature Reference:

"Evaluation of an Inductively Coupled Plasma Multichannel Spectrometric Analys is System", EPA-600/4-77-032, June, 1977.
Reagents:

Boron standards
Equipment:

Inductively coupled plasma-atomic emission spectrometer

Remarks: 1. NaCl matrix of samples and standards should be matched to minimize differences in solution properties which can affect vanorization characteristics. Use standard additions and background correction whenever possible.

Edition 2, Inductively counled plasma technique provides simultaneous, multielement determination for metals.

$7 / 78$

3. Additional references: R. H. Scott and M. L. Kokot, "Application of Inductively Coupled Plasmas to the Analys is of Geochemical Samples", Ana 1. Chim. Acta 75, 257-270 (1975).

$$
\text { (cont. on back) C-4.7 }
$$




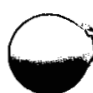

4. Upper limit of concentration range may be extended by using alternate spectral 1 ines. 
Analysis: Spark Source Mass Spectrometry

\begin{tabular}{l|l|}
\hline No. & $44-A$ \\
\hline
\end{tabular}

Method: Dehydrated brine sample is vaporized and ionized by an arc source and enters an evacuated chamber. Boron is separated and detected by its mass/charge ratio and determined quantitatively by comparison with standards.

Sample Handling: Use RA or FA brine. Evaporate to dryness for analysis.

Range: $\quad 0.1-1000 \mathrm{mg} / 1$

$\pm 5 \%$ (isotope dil.) Precision: $\pm 5 \%(15$ $\pm 5 \%$ (isotope dil.) Cross Reference: Appendix 2 Sampling Methods: 11-S, 29-5

\section{Literature Reference:}

Trace Analys is by Mass Spectrometry, A.J. Aheard, ed., Academic Press, NY (1977).

D.L. Donohue, J.A. Carter and J.C. Franklin, Anal. Letters, $10(5)$ 371-379 (1977).

Reagents:

Equipment:

Boron standards

Spark source mass spectrometer

Remarks: 1. Spark source mass spectrometry provides simultaneous, multi-element determination for selected metals and non-metals.

2. Additional references: J. A. Carter, D. L. Donohue, and J. C. Franklin, Trace Substances in Environmental Health-IX. U. of Missouri, 303 (1975).

Edition: J. C. Franklin, J. A. Carter, D. L. Donohue, and R. W. Stelzner, 23d

$7 / 78$ Conf. on Mass Spectrometry and Allied Topics, Houston, TX 354 (1975). R. Alvarez, B. J. Paulsen, and D. E. Kelleher, Anal. Chem. 41955 (1969).

3. Since boron is a volatile element, evaporation to complete dryness may volatilize boron (Rowe, Fournier, and Morey, 1973, USGS Bulletin \#1303). 
Boron

Analysis:

Emission Spectrometry

\begin{tabular}{|l|l|}
\hline No. & $45-\mathrm{A}$ \\
\hline
\end{tabular}

Method: The sample containing boron in either solid or liquid state is vaporized using a flame, AC spark or DC arc and the intensity of the selected emission line is measured against standards.

Sample Handling: Use RA or FA brine. Evaporation to dryness may be required.

Range: $\quad 2-10 \mathrm{mg} / \mathrm{l}$

Cross Reference:

Appendix 2

Sampling Methods: 11-S, 29-5

\section{Literature Reference:}

Instrument Manufacturer's Literature

\section{Reagents:}

Boron standards

Vanadium internal standard

\section{Equipment:}

Emission spectrometer

Photo processor

Microphotometer

Remarks: 1. Use matrix matching, standard additions and background correction whenever possible.

2. Emission spectrometry provides simultaneous, multi-element determination for selected metals.

Edition; 3, Largc differences in matrix effects will be observed depending on the $7 / 78$ type of excitation source (flame, AC spark, or DC arc). 
Bromide

Analysis: Hypochlorite 0xidation - Titration

\begin{tabular}{|l|l}
\hline No. & $46-\mathrm{A}$ \\
\hline
\end{tabular}

Method: Iodide in a sample is oxidized with bromide to iodate; the excess bromide is then destroyed. Iodine is then formed by oxidizing iodide with the iodate and the resulting iodine is determined by titration with thiosulfate. Iodide and bromide are then determined together by oxidizing both with $\mathrm{ClO}^{-}$to iodate and bromate. Excess $\mathrm{ClO}^{-}$is destroyed; the iodine is $1 \mathrm{ib}-$ erated and determined with thiosulfate. The bromide content is taken as the difference between the iodide and bromide content and the iodide content.

Sample Handling: Use RU or FU brine.

Range: $\quad 2-20 \mathrm{mg} / 1$

Precision: $\pm 12 \%$

Accuracy: $\pm 10 \%$

Cross Reference:

Appendix 2

Sampling Methods: 11-S, 29-S

Analysis Methods: $96-\mathrm{A}$

\section{Literature Reference:}

ASTM D 1246-77C (1977)

EPA 71870 (76)

USüS Book 5, Chapter A7 (1974)

\section{Equipment:}

Hotplate

Magnetic stirrer

Sodium Formate

Sodium molybdate

Bromine

Sodium thiosulfate or

Common lab glassware (burets, pipets, etc.) phenyl arsine oxide titrant Starch indicator Sulfuric acid

Chlorine gas (bromine free)

Calcium oxide

Methyl red indicator

Potassium fluoride

Potassium hydroxide

Potassium Iodide

Sodium acetate

Remarks: Interferences: $\mathrm{Fe}, \mathrm{Mg}$ and organic material (removed prior to determination with $\mathrm{CaO}$ ).

Edition:

$7 / 78$ 
Bromide

Analysis: Chromic Acid Oxidation - Extraction

No. $47-A$

Method: Bromide is oxidized by chromic acid to bromine, then extracted from the aqueous phase with $\mathrm{CCl}_{4}$. The $\mathrm{CCl}_{4}$ solution is then measured at 417 $\mathrm{nm}$ for bromine content.

Sample Handling: Use RU or FU brine.

$\pm 4-5 \%$ a $200-400 \mathrm{mg} / 1$ Precision: $\pm 75 \%$ a $4.0 \mathrm{mg} / 7$ Accuracy $\pm 3-4 \%$ \& $200-40$

Range: $8-400 \mathrm{mg} / 1$ Literature Reference:

Cross Reference:

Appendix? Sampling Methods: 11-S, 29-S

Analysis Methods: $48-1,49-\mathrm{A}$
API 3.14 (68)

\section{Equipment:}

UV-Vis spectrophotometer at $417 \mathrm{~nm}$

Separatory funnels

Filtering apparatus

Remarks: 1 .Chloride and iodide do not interfere in this method.

2. Large precipitates may form upon addition of $\mathrm{H}_{2} \mathrm{SO}_{4}$ to high solids brine. Dilution with $21: 1$ water/sulfuric acid reduces the amount of precipitate

Edition: prior to the extraction step.

$7 / 78$

3. Longer gelling times for phase separation our required for high solids brines during the extraction step. 
Bromide

Analysis: Colorimetric (Iodine-Permanganate)

\begin{tabular}{|l|l|}
\hline No. & $48-\mathrm{A}$ \\
\hline
\end{tabular}

Method: Bromide catalyzes the oxidation of $\mathrm{I}_{2}$ to periodate by permanganate and hence affects the reaction rate. For a given time, $\mathrm{pH}$, temperature and reactant concentrations, the concentration of bromide is inversely proportional to the unreacted $\mathrm{I}_{2}$. The $\mathrm{I}_{2}$ is extracted with $\mathrm{CCl}_{4}$ and measured colorimetricaliy at $515 \mathrm{~nm}$.

Sample Handling: Use raw unacidified or filtered unacidified brine.

Range: $\quad 0.001-0.1 \mathrm{mg} / 1 \quad$ Precision: $\pm 19 \% \quad$ Accuracy:

Cross Reference:

Appendix 2

Sampling Methods: 11-S, 29-S

Ana Tys is Methods: $47-A, 49-A$

Literature Reference:

ASTM D 1246-77B (1977)

USGS Book 5, Chapter A1 (1974)

\section{Reagents:}

Carbon tetrachioride Potassium bromide

Potassium iodide

Sulfuric acid

Potassium permanganate

\section{Equipment:}

Spectrophotometer to measure at $575 \mathrm{~nm}$. Separatory funnels Water bath $\left(0^{\circ} \mathrm{C}\right)$

Timer

Remarks: 1. Following ions interfere: $\mathrm{I}_{2}>10 \mathrm{mg} / 1, \mathrm{Ag}_{-3}^{+1}>3 \mathrm{mg} / 1, \mathrm{Zn}_{+2}^{+2}>3 \mathrm{mg} / 1$, $\mathrm{Mn}^{+2}>3 \mathrm{mg} / 1, \mathrm{Fe}>3 \mathrm{mg} / 1, \mathrm{NO}_{2}^{2}>1 \mathrm{mg} / 1, \mathrm{~S}_{2} \mathrm{O}_{3}^{-3}>3 \mathrm{mg} / 1, \mathrm{Co}>3 \mathrm{mg} / 1$,
$\mathrm{Ni}$

2. Any substance that oxidizes iodine or reduces iodate or permanganate will interfere.

Edition:

$7 / 78$

3. Free chlorine cannot be tolerated or nitrite. 
Analysis: Phenor Red - Colorimetric

Method: Bromide reacts with phenol red in the presence of chloramine $T$ at $p H$ 5.0-5.4 to form a reddish-violet complex which is measured colorimetrically at $590 \mathrm{~nm}$.

Sample Handling: Use RU or FU brine.

Range:

Precision:

Accuracy:

Cross Reference:

Appendix 2

Sampling Methods: 11-S, 29-S

Anatys is Methods: 47-A, 48-A

\section{Reagents:}

Acetic acid

Sodium acetate

Phenol red (sodium salt)

Chloramine $T$

Sodium thiosulfate

Bromide standards

\section{Literature Reference:}

APHA 406 (75)

\section{Equipment:}

UV-V is spectrophotometer to measure at $590 \mathrm{~nm}$.

Remarks: 1 . Interferences: $\mathrm{Cl}_{2}$ forms during reaction, may be removed by addition of $\mathrm{Na}_{2} \mathrm{~S}_{2} \mathrm{O}_{3}$.

2. Glassware must be cleaned using dilute $\mathrm{HNO}_{3}$ to remove traces of bromide.

Edition: 3. High salinity may affect consistency of results.

$7 / 78$ 
Bromide

Analysis: Bromide Specific Electrode

No.

$50-A$

Method: Bromide activity is measured using a bromide specific electrode containing a silver bromide crystal which responds to bromide ion in solution. The potential response of the electrode is proportional to the log of the bromide activity.

Sample Handling: Use RU or FU brine.

Range: $0.1-100 \mathrm{mg} / 1$

Precision: $\quad{ }_{-2} \%$

Accuracy:

Cross Reference:

Appendix 2

Samp1ing Methods: 11-S, 29-S

Analys is Methods: 74-A, 89-A, $101-A$

Reagents:

Ionic strength adjustor $\left(\mathrm{NaNO}_{3}\right)$

Bromide standards

Electrode filling solutions

\section{Literature Reference:}

Electrode Manufacturer's Literature

\section{Equipment:}

$\mathrm{pH}$ or millivolt meter with expanded scale Bromide specific electrode

Reference electrode (double junction $\mathrm{Ag} / \mathrm{AgCl}$ recommended)

Remarks: 1.Chloride and iodide interfere severely with this method.

2 . Ionic strength adjustor solution consisted of the addition of

$2 \mathrm{ml} 5 \mathrm{M} \mathrm{NaNO}_{3}$ per $100 \mathrm{ml}$ solution.

Edition:

$7 / 78$ 
Bromide

Analysis: X-Ray Fluorescence

\begin{tabular}{|l|l|l|l|}
\hline No. & $51-\mathrm{A}$ \\
\hline
\end{tabular}

Method: The sample containing bromide is caused to fluoresce by $X$-ray bombardment. The fluorescent radiation is dispersed by a crystal and detected by a scintillation counter and/or a flow proportional counter.

Sample Handling: Use RA or FA brine; sample may be run as is or evaporated to dryness depending upon instrumentation.

Range: $2-100 \mathrm{mg} / 1$

Cross Reference:

Appendix 2

Sampling Methods: 11-S, 29-S

\section{Literature Reference:}

Cooper, J.A. , Nuc. Inst. and Methods., Vol. 106, pp. 525-538, $19 \overline{73}$.

\section{Equipment:}

$X$-ray fluorescence spectrophotometer

Remarks: 1. Computer program usually required to interpret data.

2. Standardization of instrument required.

3. Bromide is usually determined with metal cations in this

Edition: multi-element technique.

4. Use standard additions for quantification. 
Method: Anion components are separated on sulfonated cation exchange columns coated with finely ground anion resin. A dilute sodium carbonate/bicarbonate solution is used as the eluting solvent. The separation column is followed by a suppressor column to remove highly concentrated background components, and bromide is detected by a conductivity detector.

Sample Handling: Use RU or FU brine.

Range:

Cross Reference:

Appendix 2

Sampling Methods: 11-S, 29-S

\section{Reagents:}

$\mathrm{Na}_{2} \mathrm{CO}_{3}$

$\mathrm{NaHCO}_{3}$

Standard bromide solutions

\section{Precision: $\pm 2 \% \quad$ Accuracy: $+5 \%$}

Literature Reference:

Dionex Corp., Sunnyvale, CA, Literature Ana1. Chem. $47,11,(1975)$

Microchem. Jour. 22, (45-49) (1977)

Ana 1. Chem. 49, 2, 3, $401(1977)$.

\section{Equipment:}

Dionex Ion Chromatograph

75-120 psi air supply

Remarks: 1. Bromide may be determined simultaneously with fluoride, nitrate, and sulfate by this method.

2. Additional reference: Smal1, H., T. S. Stevens and W. C. Bauman,

Edition: Anal. Chem. 47, 1801 (1975).

$7 / 78$ 


\section{$\mathrm{Br}$}

Bromide

Analysis: Spark Source Mass spectrometry

No. $53-\mathrm{A}$

Method: The dehydrated brine sample is vaporized and ionized by an arc source and enters an evacuated chamber where bromide is separated and detected by its mass to charge ratio; quantitative analysis requires comparison to standard bromide samples.

Sample Handling: Use RA or FA brine, evaporate to dryness.

Range: $0.1-1000 \mathrm{mg} / \mathrm{l}$

Precision: $\pm 25 \%$

Accuracy: $\pm 25 \%$

Cross Reference:

Appendix 2

Sampling Methods: 11-5, 29-5
Literature Reference:

Trace Analysis by Mass Spectrometry, A.J. Aheard, ed., Academic Press, NY (1977).

D.L. Donohue, J.A. Carter and J.C. Franklin, Anal. Letters, 10(5) 371-379 (1977).

\section{Equipment:}

Spark source mass spectrometer

Remarks: 1. Acidified brine is recommended for this analysis because bromide is usually determined concurrently with the metal constituents of the brine.

Edition:

2. Spark source mass spectrometry provides simultaneous, multi-element determination of selected metals and non-metals. 
Bromide

Analysis: Neutron Activation

No.

$54-A$

Method: A dehydrated brine sample is irradiated by neutron bombardment to form radioactive bromine isotopes. The beta and gamma spectra are analyzed by a multichannel analyzer; peak heights are proportional to the amount of isotope present.

Sample Handling: Use RU or FU brine. Evaporate to dryness.

Range:

Precision:

Accuracy:

Cross Reference:

Appendix 2

Sampling Methods; 11-S, 29-S

\section{Literature Reference:}

Robertson \& Carpenter, "Neutron Activation Techniques for the Measurement of Trace Metals in Environmental Samples", NAS-NS-3114, Jan. 1974.

\section{Equipment:}

Neutron source (e.g. nuclear reactor)

Multichannel analyzer

Remarks: 1. Sufficient time (several days) must be allowed for soaium aecay if the sodium spectrum masks the element of intcrest.

2. iveutron activation provides simultaneous, multi-element determination of selected metals and non-metals.

Edition:

$7 / 78$ 
Calcium

Analysis: EDTA Titrimetric

\begin{tabular}{|l|l|l|}
\hline No. & $55-\mathrm{A}$ \\
\hline
\end{tabular}

Method: Titrimetric using murexide and EDTA titrant. $\mathrm{pH}$ is adjusted to 12-13 with sodium hydroxide and approximately 0.2 gms murexide is added and titrated with EDTA.

Sample Handling: Use raw acidified or filtered acidified brine.

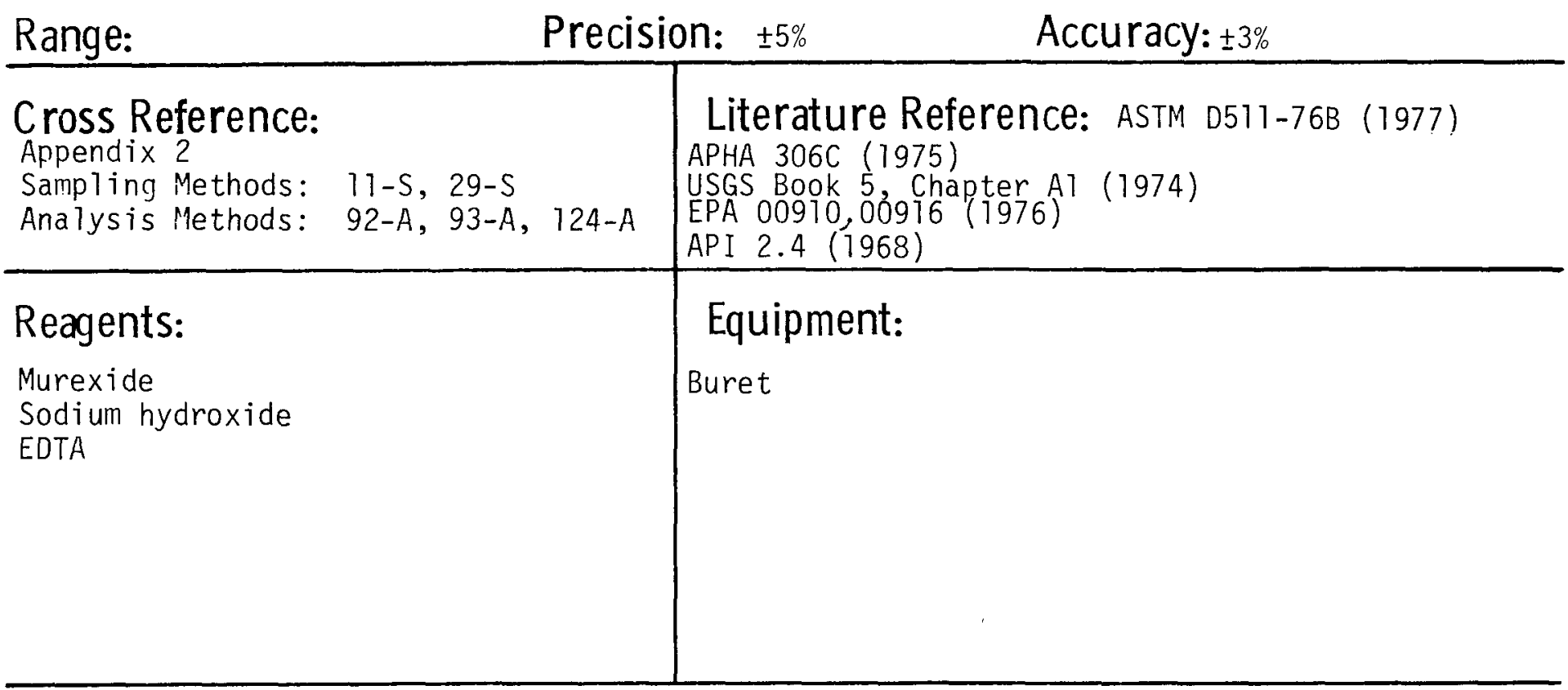

Remarks: Barium and strontium interfere when present in quantities greater than $30 \mathrm{mg} / \mathrm{l}$.

Edition:

$7 / 78$ 


\section{Ca}

Calcium

Analysis: Atomic Absorption

$56-A$

Method: Samples containing calcium are aspirated into an air-acetylene or nitrous oxide-acetylene flame and determined by the absorption of the calcium resonance 7 ine at $422,7 \mathrm{~nm}$.

\section{Sample Handling: Use raw or filtered acidified brine.}

Range: $0.01-3 \mathrm{mg} / 1$

Cross Reference:

Appendix 2

Sampling Methods: 11-S, 29-S

Analysis Methods: $57-A$

\section{Precision: $\pm 5 \%$}

Accuracy: $\pm 10 \%$

Literature Reference: EPA 00916 (1976)

APHA 301 A (1975) (1974).

ASTM D2576-70 D511-76C (7977).

Flame Emission and Atomic Absorption Spectrometry, Dean and Rains; 1975, Vol. III, pp. 33-64.

\section{Equipment:}

AA Spectrophotometer

Nitrous oxide burner head

Ca stock solution, $1000 \mathrm{ppm}$
prepared from $\mathrm{CaCO}_{3}$ and $\mathrm{HC}$ ?

Nitrous oxide gas cylinder

Lanthanum chloride or strontium

nitrate

Potassium chloride or strontium

nitrate

Remarks: 1. Interferences occur from $\mathrm{Al}, \mathrm{Si}, \mathrm{Fe}, \mathrm{SO}_{4}{ }^{2}$, et al:, removed by using a nitrous oxide flame (use hottest section of flame, just above red crown). Ionization interferences must be depressed by addition of $2000 \mathrm{mg} / 1 \mathrm{~K}^{+}$, or $1 \%(\mathrm{w} / \mathrm{v}) \mathrm{Sr}$.

Edition:

2. When using an air-acetylene flame standards, samples, and blanks

$7 / 78$ should contain $0.1-1 \%(\mathrm{~W} / \mathrm{V}) \mathrm{La}^{+3}$ or $\mathrm{Sr}^{+2}$ to minimize interferences from $\mathrm{Si}, \mathrm{Al}, \mathrm{PO}_{4}, \mathrm{SO}_{4}, \mathrm{Ti}$, and $\mathrm{Zr}$.

3. If sample shows Tyndall effect, filter through a 0.45 membrane filter.

$$
\text { (cont. cn back' } \mathrm{C}-60
$$


4. Matrix matching (using equivalent amounts of alkali and alkaline earth metals) in standards important. Use of standard additions recommended.

5. Alternatively, the $239.9 \mathrm{~nm}$ line and $\mathrm{D}_{2}$ background correction may be used. 


\section{Calcium}

Analysis: Flame Emission

No. $57-A$

Method: Calcium is determined by aspirating the sample into a nitrous oxide-acetylene flame and the emission intensity at $422.7 \mathrm{~nm}$ from calcium is measured by a spectrophotometer.

Sample Handling: Use raw acidified or filtered acidified brine. Sample may be stabilized by diluting with 9 parts distilled water and adding $5 \mathrm{ml} \mathrm{HNO} 3$ per liter of sample.

Range: $>0.05 \mathrm{mg} / 1$

$<0.5 \mathrm{mg} / 1 \pm 25 \%$

Precision: \begin{tabular}{ll}
$<0.5 \mathrm{mg} / 1 \pm 25 \%$ \\
\hline
\end{tabular}

Accuracy: $\begin{aligned} & <0.5 \mathrm{mg} / 1 \pm 25 \% \\ & >0.5 \mathrm{mg} / \mathrm{l} \pm 5 \%\end{aligned}$

Cross Reference: Append ix 2

Sampling Methods: 11-S, 29-S

Analys is Methods: $56-\mathrm{A}$

Reagents:

Calcium atomic absorption standard solution or calcium carbonate Hydrochloric acid (to dissolve calcium carbonate)

Nitrous oxide gas cylinders

Potassium chloride or potassium nitrate

Remarks: 1. Addition of potassium chloride or potassium nitrate to give a final concentration of $2000 \mathrm{mg} / \mathrm{l} \mathrm{K}$ is necessary to suppress ionization.

2. Slightly higher height of observation in flame reduces potential chemical interferences.

Edition:

3. Use of standard additions and matrix matching of alkali and alkaline earth metal ions recommended.

\section{Literature Reference:}

Dean and Rains, Flame Emission and Atomic Absorption Spectrometry, Vol. III, 1975, pp. 33-65. W. Snelleman, Spectrochim. Acta, 23B, 403 (1968).

\section{Equipment:}

Atomic absorption spectrophotometer with emission mode or flame emission spectrophotometer.

Nitrous oxide burner head. 


\section{$\mathrm{Ca}$}

Calcium

\begin{tabular}{l|l|l}
\cline { 2 - 2 } Analysis: Inductively Coupled Plasma- & Nomic Emission Spectroscopy & $58-A$ \\
\hline
\end{tabular}

Method: A sample containing calcium is aspirated into a radiofrequency generater: argon plasma and the intensity of the emission spectrum is analyzed and compared with standards. Intensity is measured at $315.89 \mathrm{~nm}$ or alternate wavelength.

Sample Handling: Use raw or filtered acidified brine.

3-5 orders of magnitude from

Range: a single spectral line Precision: $+1-10 \%$

Accuracy:

Cross Reference:

Appendix 2

Sampling Methods: 11-S, 29-S
Literature Reference:

Evaluation of an Inductively Coupled Plasma, Multichannel Spectrometric Analys is System, EPA 600/4-77-032, June 1977.

\section{Reagents:}

Calcium standard solution; prepared from $\mathrm{CaCO}_{3}$ and $\mathrm{HCl}$

\section{Equipment:}

Inductively coupled plasmaatomic emission spectrometer

Remarks: 1. NaCl matrix of samples and standards should be matched to minimize differences in solution properties which affect vaporization characteristics. Background correction and standard additions method recommended. ICP-AES is a simultaneous multi-element technique for metal ions.

Edition: 2. Additional references: R. H. Scott and M. L. Kokot, "Application of 7/78 Inductively Coupled Plasmas to the Analys is of Geochemical Samples", Anal. Chim. Aicta 75, 257-270 (1975). 
3. Upper limit of concentration range may be extended by using alternate spectral lines. 


\section{$\mathrm{Ca}$}

Calcium

Analysis: Neutron Activation

No.

$59-A$

Method: Dehydrated sample is irradiated by neutron bombardment to form radioactive calcium isotopes. The beta and gamma spectra are arialyzed by a multichannel analyzer; peak heignts are proportional to the amount of calcium present.

Sample Handling: Filter brine on site. Evaporate sample and irradiated residue with neutron source.

Range:

Precision:

Accuracy:

Cross Reference: Appendix 2

Sampling Methods: 11-S, 29-S

\section{Literature Reference:}

Robertson, D.E. \& Carpenter, R., "Neutron Activation Techniques for the Measurement of Trace Metals in Environmental Samples", NAS-NS-3114, Jan. 1974.

\section{Equipment:}

Reactor

Multichannel analyzer

Remarks: 1-Sufficient time (several days) must be allowed for sodium decay if the sodium spectrum masks the element of interest. 2-Calcium may be measured simultaneously with other elements of interest.

Edition:

$7 / 78$ 


\section{Calcium}

Analysis: Emission Spectrometry

No. $60-A$

Method: The brine sample in either solid or liquid state is vaporized using a flame, d-c arc, or a-c spark and the intensity of the selected emission line is measured against standards.

Sample Handling: Use raw or filtered acidified brine. Evaporation to dryness may be required.

Range: $2-20 \mathrm{mg} / 1 \quad$ Precision: $\pm 10 \%$ Accuracy:

Cross Reference:

Appendix 2

Sampling Methods: 11-S, 29-S

\section{Reagents:}

Calcium standards

Vanadium internal standard

\section{Literature Reference:}

Instrument Manufacturer's Literature

\section{Equipment:}

Emission Spectrometer

Photo processor

Microphotometer

Remarks: 1. Use matrix matching, standard additions and background corrections whenever possible.

2. Large differences in matrix effects will be observed depending on the type of excitation source (flame, AC spark, or DC arc).

Edition:

$7 / 78$ 
Carbon Dioxide

Analysis: Titrimetric

No.

$61-A$

Method: The sample is titrated with a strong acid $\left(\mathrm{H}_{2} \mathrm{SO}_{4}\right.$ or $\left.\mathrm{HCl}\right)$ to separate equivalence points for $\mathrm{CO}_{3}^{2-}, \mathrm{HCO}_{3}^{-}$, and $\mathrm{OH}^{-}$. Equivalence points are determined either potentiometrically or with visual indicators. The molar concentration of $\mathrm{CO}_{2}$ is equal to the molar concentration of carbonate.

Sample Handling: Carbon dioxide is trapped by passing raw or filtered brine through a fritted glass bubbler which is submerged in sodium hydroxide solution (forming carbonate). The sodium hydroxide solution is diluted to a preselected concentration with brine (usually 1:1).

Range:

Cross Reference:

Appendix 2

Samnling Methods:

$12-S, 13-S, 14-S, 19-S, 20-S, 29-S, 34-5$

Analysis Methods: $1-\AA, 38-n, 39-\AA, 62-$

$63-A, 64-A, 65 A, 747 \AA$

\section{Reagents:}

Hydrochloric or sulfuric acid Sodium carbonate or sodium hydroxide Bromcresol green-methyl red indicator Phenolphthalein indicator

\section{Equipment:}

Buret

$\mathrm{pH}$ meter

Remarks: 1. Cations or anions which affect the carbonate equilibriuni or precipitate or consume the reactant $(\mathrm{NaOH})$ preferentially affect the accuracy, as do colors and turbidity which obscure colorimetric end parts.

Edition;

$7 / 78$

2. Aluminum, iron, chromium, and copper will affect precipitation.

3. Abnormal results also obtained in the presence of high concentrations of ammonia, amines, phosphate, borate, sulfide and nitrate.

4. Excessive dissolved solids introduce error.

(cont. on back) 
5. The endpoints can be detected more easily by titrating the excess caustic first with strong acid followed by titration with weak acid to the precise endpoints.

6. Sharper endpoints are obtained if the titration is blanketed with nitrogen. 


\section{$\mathrm{CO}_{2}$}

Carbon Dioxide

Analysis: Strontium Gravimetric

No. $62-\mathrm{A}$

Method: Sample is pretreated with phosphoric acid in a glass bubbler apparatus using a nitrogen atmosphere and boiled to remove all the $\mathrm{CO}_{2}$ from sample. The $\mathrm{CO}_{2}$ is trapped in a sodium hydroxide solution and is then determined gravimetrically by adding strontium nitrate solution, filtering, ashing and weighing the $\mathrm{SrCO}_{3}$ precipitate.

Sample Handling: Carbon dioxide is trapped by passing raw or filtered brine through a fritted glass bubbler which is submerged in sodium hydroxide solution (forming carbonate). The sodium hydroxide solution is diluted to a preselected concentration with brine (usualiy $1: 1$ ).

Range:

Precision: $\pm 10 \%$

Accuracy:

Cross Reference: Appendix 2

Sampling i.te thods: 4-S, 5-S, 8-S, 17-S,

\section{Literature Reference:}

12-S, 13-S, 14-S, 19-S, 20-S, 29-S, 34-S

Analys is Methods. 1-A, 38-A, 39-A,61-A

63-A, 64-A, 65-A, 141-A

\section{Reagents:}

Phosphoric acid

Sodium hydroxide

Strontium nitrate

Sodium carbonate

$\mathrm{Nitrogen}$ gas $-\mathrm{CO}_{2}$ free

\section{Equipment:}

Hot plate

Gas bubbler with reflux condenser

Remarks: 1. Phosphoric acid treatment eliminates interferences due to compounds that react with strontium or the sodium hydroxide to produce a precipitate. Problem in this method is the availability of $\mathrm{CO}_{2}$ free nitrogen gas. Other gases might be tried.

Edition:

2. Alternatively, strontium chloride dissolved in ammonium hydroxide may be $7 / 78$ substituted as the trapping solution (USGS method). 
Carbon Dioxide

Analysis: Precise Evolution

\begin{tabular}{|l|l|}
\hline No. & $63-\mathrm{A}$ \\
\hline
\end{tabular}

Method: $\mathrm{CO}_{2}$ is liberated by acidifying and boiling the sample in a closed system. The liberated $\mathrm{CO}_{2}$ is trapped by bubbling into a $\mathrm{Ba}(\mathrm{OH})_{2}$ solution; excess $\mathrm{Ba}(\mathrm{OH})_{2}$ is then titrated with standard $\mathrm{HCl}$ and the $\mathrm{CO}_{2}$ species content determined by calculation from the titration and the $\mathrm{pH}$ of the sample.

Sample Handling: Carbon dioxide is trapped by passing raw or filtered brine through a fritted glass bubbler which is submerged in sodium hydroxide solution (forming carbonate). The sodium hydroxide solution is diluted to a preselected concentration with brine (usually $1: 1$ ).

Range: $\quad>10 \mathrm{mg} / 1$

Precision: $\quad \pm 1 \%$

Accuracy: $\pm 5 \%$

Cross Reference: Appendix 2 $4-S, 5-S, 8-5,11-S, 12-5,13-5,14-S$,

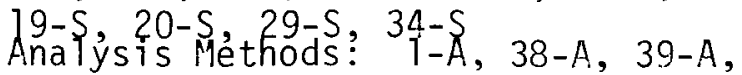
61-A, 62-A, 64-A, 65-A, 147-A

\section{Reagents:}

Barium hydroxide Hydrochloric acid Methyl orange indicator

Phenolphthalein indicator

Chromic acid

Sulfuric acid

Ascarite (option)

Anhydrone (option)

\section{Literature Reference:}

ASTM D513-71A, B (1977)

\section{Equipment:}

Evolution flask

Absorption flask

Pump

$\mathrm{pH}$ meter

Burets

Heating mantle

Remarks: 1. Any volatile acid, base, or barium precipitant not removed by scrubbing solution will interfere.

2. See remarks under "Carbon Dioxide - Titrimetric".

Edition: 3. Alternatively, the $\mathrm{CO}_{2}$ gas may be passed through a scrubbing train, $7 / 78$ collected as ascarite and weighed. ("Determination of Carbon Dioxide in Carbonates", Scott's Standard Methods of Chemical Analysis, 6 th ed., New York, 1962.) 


\section{$\mathrm{CO}_{2}$}

Carbon Dioxide

Analysis: Carculation

No.

$64-A$

Method: By determining the sample $\mathrm{pH}$ and calcium ion concentration and with the values of the solubility product of $\mathrm{CaCO}_{3}\left(\mathrm{~K}_{\mathrm{S}}\right)$ and the second proton dissociation constant of $\mathrm{H}_{2} \mathrm{CO}_{3}\left(\mathrm{~K}_{2}\right)_{3}$ bicarbonate may be determined from the equation: $\log \left(\mathrm{HCO}_{3}{ }^{-}\right) \stackrel{-}{=} \log \left(\mathrm{Ca}^{2+}\right)-\log \left(\mathrm{K}_{2} / \mathrm{K}_{\mathrm{S}}\right)-\mathrm{pH}$ and carbonate from the equation: $\left(\mathrm{CO}_{3}^{2-}\right)^{3}=\frac{\mathrm{K}_{2}\left(\mathrm{HCO}_{3}^{-}\right)}{\left(\mathrm{H}^{+}\right)}$. The amount of $\mathrm{CO}_{2}$ is determined by the relation $\mathrm{mg} / 1$ total $\mathrm{CO}_{2}=\mathrm{mg} / 1$ free $\mathrm{CO}_{2}+0.88(\mathrm{~A}+\mathrm{B})$ where $\mathrm{A}=\mathrm{mg} / 1$ bicarbonate alkalinity and $B=1 / 2\left(\mathrm{mg} / 1\right.$ carbonate alkalinity). Free $\mathrm{CO}_{2}$ is determined titrimetrically or nomographically.

Sample Handling: Use RU or FU brine for $\mathrm{pH}$ and alkalinity measurements and RA or FA brine for $\mathrm{Ca}^{2+}$ determination.

Range:

Precision:

Accuracy:

Appendix 2

Cross Reference: Sampling Methods: Literature Reference:

4-S, 5-S, 8-S, 11-S, 12-S, 13-S, 14-S

$19-S, 20-S, 29-S, 34-S$

Analysis Methods: 1-A, 38-A, 39-A,

61-A, 62-A, 63-A, 65-A, 141-A

\section{Reagents:}

Use appropriate reagents for $\mathrm{pH}$, alkalinity, and $\mathrm{Ca}^{2+}$ determinations.

\section{Equipment:}

Use equipment appropriate to $\mathrm{pH}, \mathrm{Ca}^{2+}$, and titrimetric determinations.

Remarks: 1. $\mathrm{pH} \mathrm{Ca}^{2+}$, and alkalinity concentrations must be determined before using this method.

2. Interferences: differences in temperature and sample ionic strength may cause inaccuracies in results; use activity coefficients and

Edition; equilibrium constants for temperature of measurement when possible.

$7 / 78$ 
Carbon Dioxide

Analysis: Carbon Analyzer (Infrared)

\begin{tabular}{|l|l|}
\hline No. & $65-\mathrm{A}$ \\
\hline
\end{tabular}

Method: Sample containing carbonate is acidified to convert carbonate back to carbon dioxide. Carbon dioxide is measured by a carbon analyzer using an infrared detector.

Sample Handling: Carbon dioxide is trapped by passing raw or filtered brine through a fritted glass bubbler which is submerged in sodium hydroxide solution (forming carbonate). The sodium hydroxide solution is diluted to a preselected concentration with brine (usually $1: 1$ ).

Range: Precision:

Accuracy:

Appendix 2

Cross Reference: Sampling Methods: Literature Reference:

4-S, 5-S, 8-S, 11-S, 12-S, 13-S, 14-S, 19-S, 20-S, 29-S, 34-S

Analysis Methods: I-A, 38-A, 39-A, 61-A, 62-A, 63-A, 64-A, 141-A

\section{Reagents:}

Potassium hydrogen phthalate Sodium bicarbonate Sodium carbonate
EPA 00680 (1976)

\section{Equipment:}

Total carbon analyzer

Syringes

Remarks: 1. Procedure applicable only to homogeneous samples which can be injected into the apparatus reproducibly by means of a microliter type syringe or pipette. Particles in the sample may block the opening of the syringe or pipette.

Edition:

$7 / 78$

2. See remarks under "Carbon Dioxide - Titrimetric". 
Analysis: Atomic Absorption

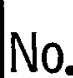

$66-A$

Method: Samples containing Cs are directly aspirated into an air-acetylene flame and determined by absorption of the Cs resonance line at $894.4 \mathrm{~nm}$ or $852.1 \mathrm{~nm}$.

Sample Handling: Use raw or filtered acidified brine.

Range: $0.02-10 \mathrm{mg} / 1$

Cross Reference:

Appendix 2

Sampling :lethods: 11-S, 29-S

Ana Tysis Methods: $67-\mathrm{A}$
Precision: $\pm 5 \%$

Literature Reference:

Flame Emission and Atomic Absorption Spectrometry, Dean and Rains; 1975, Vol. III, pp. 2-32.

\section{Equipment:}

AA Spectrophotometer

Red filter, required for some spectrometer models at high wavelengths

Remarks: 1. Interference due to ionization should be suppressed by addition of $\mathrm{KCl}$ to a final $\mathrm{K}^{+}$concentration of $5000 \mathrm{mg} / \mathrm{l}$. Standard additions technique and use of Deuterium background lamp recommended.

2. If sample shows Tyndall effect, filter through $0.45 \mu$ membrane filter.

Edition!

3. Use of electrodeless discharge lamp increases sensitivity.

$7 / 73$ 4. Matrix matching (equivalent amounts of alkali and alkaline earth metals) in standards important.

(cont. on back) 


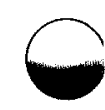




\section{Cs}

Cesium

Analysis: Flame Emission

\begin{tabular}{|l|l|}
\hline No. & $67-\mathrm{A}$ \\
\hline
\end{tabular}

Method: Cesium is determined by aspirating the sample into an air-acetylene flame and the emission intensity at $852.1 \mathrm{~nm}$ from cesium is measured by a spectrophotometer.

Sample Handling: Use raw acidified or filtered acidified brine. Sample may be stabilized by diluting with 9 parts distilled water and adding $5 \mathrm{mi} \mathrm{HNO}_{3}$ per liter of sample.

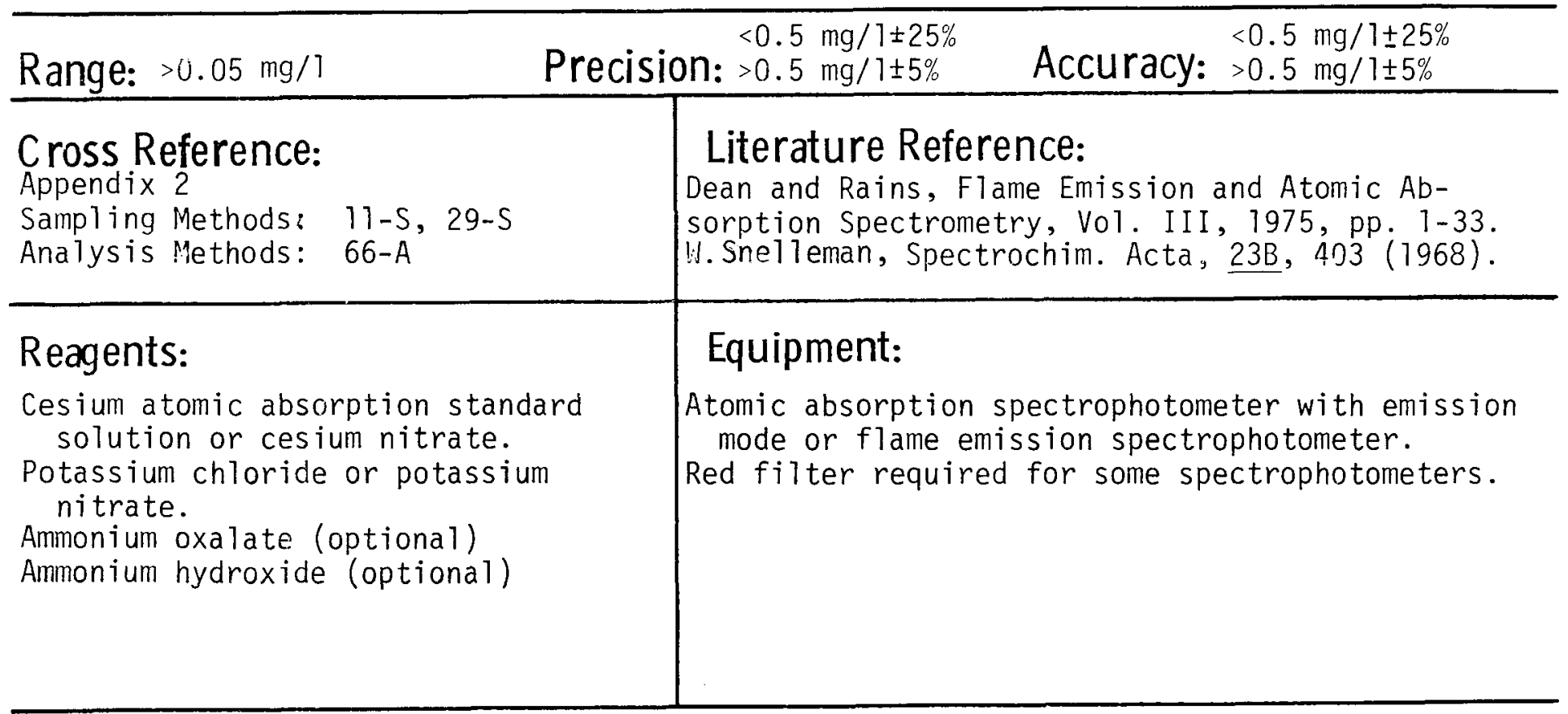

Remarks: 1. Ionization is suppressed by the addition of potassium chloride or potassium nitrate to give a potassium concentration of $5000 \mathrm{mg} / 1$.

2. Use of standard additions and matrix matching of aikali and alkaline earth metal ions recommended.

Edition: 3. Deuterium background correction system enhances response.

$7 / 78$ 4. Use of an air-hydrogen flame has also been reported.

(cont. on back) 



\section{Cs}

Cesium

Analysis: Neutron Activation

$68-A$

Method: Dehydrated sample is irradiated by neutron bombardment to form radioactive cesium isotopes. The beta and gamma spectra are analyzed by a multichannel analyzer; peak heights are proportional to the amount of cesium present.

Sample Handling: Filter brine on site. Evaporate sample and irradiated residue with neutron source.

\begin{tabular}{l|l}
\hline \multicolumn{2}{c}{ Precision: } \\
\hline $\begin{array}{l}\text { Crange: } \\
\text { Appendix 2 } \\
\text { Sampling Methods: 11-S, 29-S }\end{array}$ & $\begin{array}{l}\text { Literature Reference: } \\
\text { Robertson, D.E. \& Carpenter, R., "Neutron Activa- } \\
\text { tion Techniques for the Measurement of Trace Metals } \\
\text { in Environmental Samples", NAS-NS-3114, Jan. 1974. }\end{array}$ \\
\hline $\begin{array}{l}\text { Reagents: } \\
\text { Standards containing cesium }\end{array}$ & $\begin{array}{l}\text { Equipment: } \\
\text { Reactor } \\
\text { Multichannel analyzer }\end{array}$ \\
\hline
\end{tabular}

Remarks:l-Sufficient time (several days) must be allowed for sodium decay if the sodium spectrum masks the element of interest.

2- Several elements may be measured simultaneously with this method.

Edition:

$7 / 78$ 
Analysis: Emission Spectrometry

No. $69-\mathrm{A}$

Method: Sample is vaporized using a flame, d-c arc, or a-c spark and the intensity of the selected cesium emission line is measured against standards.

Sample Handling: Use raw or filtered acidified brine. Evaporation to dryness may by required.

Range:

Precision:

Accuracy:

\section{Cross Reference:}

Appendix 2

Sampling Methods: 11-S, 29-S

\section{Literature Reference:}

Flame Emission and Atomic Absorption Spectrometry, Dean and Rains;1975, Vol. III, pp. 2-32.

Instrument Manufacturer's Literature.

\section{Equipment:}

Emission spectrometer

Remarks: 1. Use matrix matching, standard additions and background correction whenever possible.

2. Large differences in matrix effects will be observed depending on the type of excitation source (flame, AC spark, or DC arc).

Edition:

$7 / 78$ 


\section{$\mathrm{Cl}$}

Chloride

Analysis: Silver Nitrate Titration

No. $70-A$

Method: Silver chloride precipitates quantitatively as silver nitrate titrant is added to the sample. The endpoint is marked by the formation of red silver chromate. The $\mathrm{pH}$ range of the solution must be 7-70.

Sample Handling: Use unacidified brine

Range: $>5 \mathrm{mg} / \mathrm{l}$

Precision: $\pm 4 \%$

Accuracy: $\pm 4 \%$

Cross Reference:

Appendix 2

Sampling Methods: $11-\mathrm{S}, 29-\mathrm{S}$

Analysis Methods: 71-A, 72-A

Reagents:

Potassium chromate indicator

Standardized $\mathrm{NaCl}$ solution

Standardized $\mathrm{AgNO}_{3}$ titrant solution
Literature Reference: USGS Book 5, Chapter A1, APHA 408A (1975)

ASTM D512-678 (1977)

Fischer and Peters, Quantitative Chemical Analysis, p. 375.

\section{Equipment:}

Burette

Magnetic stirrer and teflon-coated stirbar

Remarks:

Possible interferences: 1. Bromide, iodide, $\mathrm{CN}^{-}$, and $\mathrm{S}^{\mathbf{0}}$ will interfere as equivalent chloride concentrations, 2 . Iron greater than $10 \mathrm{mg} / 1$ will mask endpoint; may be removed with $\mathrm{Al}(\mathrm{OH})_{2}$ suspension (see

Edition: APHA ref.). 3. High $\mathrm{Ca}+2$ anü/or $\mathrm{Mg}^{+2}$ content samples may form ppt. When $\mathrm{pH}$ is raised to 8.3. Dilution or separation of $\mathrm{Ca}$ and/or Ma mav ho 
4. Alternatively, 2,4 dichlorofluorescein may be used as the indicator with the endpoint detected as a change from yellow to pink. Dextrin may have to be added to disperse AgCl crystals. A back titration with $\mathrm{KCl}$ (1000 ppm) is recommended. If on ly 1-2 drops are needed to reach yellow color, then end point is accurate. 
Chloride

Analysis: Mercuric Nitrate Titration

No.

$71-A$

Method: The chloride sample is titrated with mercuric nitrate titrant; the endpoint is detected by diphenylcarbazone which forms a purple complex with excess $\mathrm{Hg}$ (II).

Sample Handling: Use unacidified brine sample.

\begin{tabular}{|c|c|}
\hline Range: $\quad 0.2-100 \mathrm{mg} / 1$ & Accuracy: $\pm 5 \%$ \\
\hline $\begin{array}{l}\text { Cross Reference: } \\
\text { Append ix } 2 \\
\text { Sampling ilethods: } 11-5,29-\mathrm{S} \\
\text { Analysis Methods: } 70-\mathrm{A}, 72-\mathrm{A}\end{array}$ & $\begin{array}{l}\text { Literature Reference: } \text { EPA } 00940 \text { (1976) } \\
\text { APHA 408B (1975) } \\
\text { ASTM D512-67A (1977) } \\
\text { USGS Book 5, Chapter A1 (1974) }\end{array}$ \\
\hline $\begin{array}{l}\text { Reagents: } \\
\text { Sodium chioride standard solution } \\
\text { Nitric acid, } 1 . \mathrm{N} \\
\text { Sodium hydroxide, .1 N } \\
\text { Indicator reagent: } \\
\text { diphenyl carbazone powder } \\
\text { brompheny blue powder } \\
95 \% \text { ethyl alcohol } \\
\text { Mercuric nitrate titrant }\end{array}$ & $\begin{array}{l}\text { Equipment: } \\
\text { Burette } \\
\text { Magnetic stirrer and teflon-coated stirbar }\end{array}$ \\
\hline
\end{tabular}

Remarks: 1. Ferric ion $\left(\mathrm{Fe}^{3+}\right)$ must be reduced if greater than $10 \mathrm{ppm}$. Highly colored or turbid samples not suitable unless color or turbidity eliminated.

Edition; 2. Other halides are also titrated by this method.

$7 / 78$ 
Chloride

Analysis: Titrimetric (Conductometric)

No. $72-\mathrm{A}$

Method: $A g C l$ precipitates quantitatively as silver nitrate titrant is added; the endpoint is indicated by plotting conductance data versus volume increments of silver nitrate added. The intersection of the two lines on the plot indicates the endpoint.

Sample Handling: No preservatives.

Range:

Precision:

Accuracy:

Cross Reference:

Sampling Methods: 11-S, 29-S

Analys is Methods: 70-A, 71-A, 73-A, $74-A$

\section{Reagents:}

Sodium chloride standard solution

Silver nitrate standard solution

\section{Literature Reference:}

Fischer and Peters, Quantitative Chemical Analysis;

p. 742 .

\section{Equipment:}

Conductivity cell

Remarks: 1. A variation of this procedure involves plotting volume of $\mathrm{AgNO}_{3}$ added vs potential using an Ag electrode and reference electrode (U.S. Geological Survey Method).

Edition:

$7 / 78$ 
Chloride

Analysis: Gravimetric

$73-\wedge$

Method: The chloride content of a soluble chloride is determined gravimetrically by precipitation as silver chloride by the addition of an excess of silver nitrate solution to the chloride solution containing nitric acid. The precipitate is filtered, washed, dried, and weighed as $\mathrm{AgCl}$.

Sample Handling: Use unacidified brine sample.

\begin{tabular}{lll}
\hline Range: $\quad 2100 \mathrm{mg} / 1$ & Precision: $\pm 1 \%$ & Accuracy: $\pm 2 \%$ \\
\hline
\end{tabular}

Cross Reference:

Appendix 2

Sampling Methods: 11-S, 29-S

Analysis Methods: 70-A, 72-A

\section{Reagents:}

$\mathrm{AgNO}_{3}$ standard solution

Nitric acid

Hydrochloric acid

\section{Literature Reference:}

Fischer and Peters, Quantitative Chemical Analysis;

p. 181.

"Determination of Chloride in Soluble Chlorides",

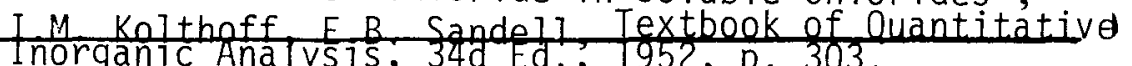
Equipment:

Filtration apparatus

Drying oven

Analytical balance

Remarks: 1. Interferences: anions which form insoluble salts with $\mathrm{Ag}^{+}$, e.g., $\mathrm{S}^{2-}, \mathrm{Br}^{-}, \mathrm{I}^{-}, \mathrm{S}_{2} \mathrm{O}_{3}=, \mathrm{SCN}^{-}, \mathrm{CN}^{-}$, precipitate may contain occluded materials from mother liquor; AgCl precipitate subject to photodecomposition (procedure must be done in darkened room with incandescent lamp); peptization of precipitate may occur during washing.

Edition: $7 / 70$

2. Presence of nitric acid prevents precipitation of silver salts insoluble in neutral media. 


\section{$\mathrm{Cl}$}

Chloride

Analysis: Chloride-Specific Electrode

No. $74-A$

Method: The chloride electrode is a selective ion sensor which allows free chloride ions in aqueous solutinrs to be measured. The chloride electrode consists of a silver chloride/silver sulfide membrane bonded into the tip of an epoxy electrode bcdy. When the membrane is in contact with the chloride solution, silver ions dissolve from membrane surface and electrode develops potential due to silver ion concentration. Potential measurements of chloride standards vs concentration are plotted on four-cycle semilog paper.

Sample Handling: Analyses were made on filtered unacidified samples. Ionic strength adjustor solution was added to samples and standards in order to keep a constant background.

Range: $1-100 \mathrm{mg} / 1$

Precision: $\pm 2 \%$

Accuracy:

\section{Cross Reference:}

Appendix 2

Sampling Methods: 11-S, 29-S

Analys is Methods: 50-A, 72-A, 89-A

$101-A$

\section{Reagents:}

Standard chloride solutions, prepared from $\mathrm{NaCl}$

Reference electrode filling solution

Sodium nitrate, reagent grade

\section{Literature Reference:}

Silver Halide Electrode Instruction Manual, Form 94H1678, Orion Research Inc., Cambridge, MA (1976).

\section{Equipment:}

Silver cinloricie electrode, Orion model 94-17 or $36-17$

Vagnetic stirrer

Jouble-Junction reference electrode

$\mathrm{pH}$ meter with expanded $\mathrm{mV}$ scale or specific

ion meter

Remarks: 1 . Bromide ratio above $2 \times 10^{-3}$ and iodide ratio above $5 \times 10^{-7}$ will interfere.

2. The ionic strength adjustor solution consisted of the addition of $2 \mathrm{ml}$ of $5 \mathrm{M} \mathrm{NaNO}_{3}$ per $100 \mathrm{ml}$ of solution.

Edition;

$7 / 78$ 


\section{$\mathrm{Cl}$}

Chloride

Analysis: $\quad X$-Ray Fluorescence

No. $75-\mathrm{A}$

Method: The sample containing chloride is caused to fluoresce by $X$-ray bombardment. The fluorescent radiation is dispersed by a crystal and detected by a scintillation counter and/or a flow proportional counter.

Sample Handling: Use raw or filtered acidified brine; sample may be run as is or evaporated to dryness depending upon instrumentation.

Range: $1000-50,000 \mathrm{mg} / 7 \quad$ Precision: $\pm 3 \%$ @ 9 95\% level Accuracy: $\pm 3 \%$

\section{Cross Reference:}

Appendix 2

Sampling Methods: 11-S, 29-S

\section{Literature Reference:}

Cooper, J.A., Nuc. Inst. and Methods., Vol. 106, pp. 525-538, $1 \overline{973 .}$

\section{Equipment:}

$X$-ray fluorescence spectrophotometer

Chloride standards

Cadmium nitrate

$x$-ray fluorescence spectrophotometer

Remarks: 1. Computer program usually required to interpret data.

2. Standardization of instrument required.

3. Several elements may be measured simultaneously with this method.

Edition:

4. Cadmium nitrate added, $C D L \propto$ radiation used as internal standard for matrix compensation.

$7 / 78$

5. For liquid samples, $\mathrm{CdNO}_{3}$ solution added: sample first freed of any free $\mathrm{H}_{2} \mathrm{~S}$ by bubbling argon through liquid. Sample may be diluted to extend ${ }^{2}$ range. 
Chloride

Analysis: Ion-Exchange Chromatography No. $76-\mathrm{A}$

Method: Anion components are separated on sulfonated cation exchange columns coated with finely ground anion resin. Sodium carbonate/sodium bicarbonate solution is used as the eluting solvent. The separation column is followed by a suppressor column to remove highly concentrated background components, and chloride is detected by a conductivitv detector.

Sample Handling: Use unacidified brine.

Range:

Precision:

Accuracy: $\pm 5 \%$

\section{Cross Reference:}

Appendix 2

Sampling Methods: 11-S, 29-5
Literature Reference:

Dionex Corp., Sunnyvale, CA, Literature

Anal. Chem. 47, $11,(1975)$

Microchem. Jour. 22, (45-49) (1977)

Anal. Chem. 49, 2, 3, 401 (1977)

\section{Equipment:}

Dionex Ion Chromatograph, Model 10 or 14

75-120 psi air supply

Anion separator column, $3 \mathrm{~mm} \times 500 \mathrm{~mm}$

Anion precolumn, $3 \mathrm{~mm} \times 150 \mathrm{~mm}$

Anion suppressor column, $6 \mathrm{~mm} \times 250 \mathrm{~mm}$

Remarks: 1. Due to typically high $\mathrm{Cl}^{-}$concentrations in brines, this anion generally cannot be analyzed simultaneously with other anions.

2. Additional reference: Sma 17, H., T. S. Stevens and W. C. Bauman, Anal. Chem., 47, 1801 (1975).

Edition: 


\section{Cl}

Chloride

Analysis: Neutron Activation

No.

$77-A$

Method: Dehydrated sample is irradiated by neutron bombardinent to form radioactive chloride isotopes. The beta and gamma spectra are analyzed by a multichannel analyzer; peak heights are proportional to the amount of chtoride present.

Sample Handling: Filter brine on site. Evaporate sample and irradiated residue with neutron source.

Range: Precision: Accuracy:

Cross Reference:

Appendix 2

Sampling Methods: 11-S, 29-S

Reagents:

Standards containing chloride
Literature Reference:

Robertson, D.E. \& Carpenter, R., "Neutron Activation Techniques for the Measurement of Trace Metals in Enviromental Samples", NAS-NS-3114, Jan. 1974.

\section{Equipment:}

Reactor

Multichannel analyzer

Remarks:1-Sufficient time (several days) must be allowed for sodium decay if the sodium spectrum masks the element of interest. 2-Several elements may be measured simultaneously with this method.

Edition:

$7 / 78$ 
Analysis: Conductivity Meter

No. $78-\mathrm{A}$

Method: Conductivity is measured with a platinum electrode cell of known cell constant and a conductivity bridge.

Sample Handling: Use RU brine stored in plastic, determine $<6$ hours after collecting. Record sample temperature at time of conductivity measurement.

Range: $10-500,000 \mu \mathrm{mhos} / \mathrm{cm} \quad$ Precision: $\pm 3 \% \quad$ Accuracy: $\pm 5 \%$ \begin{tabular}{l|l} 
Cross Reference: & Literature Reference:
\end{tabular}

Appendix 2

Sampling Methods: 11-S, 29-S

USGS Book 5, Chapter A1

(1974).

APHA 205 (75)

API $2.91(68)$

ASTM D1125-77A, B, C, (1977)

Reagents:

Standard $\mathrm{KC} 1$ solutions

Equipment:

Conductivity meter, conductivity cell

Remarks: 1. Interferences: temp. dependent, oil and residue foul electrodes.

2. Cell constant at different temp. must be determined with standard

$\mathrm{KCl}$ solutions or samples must be measured at constant temp. (e.g., $25^{\circ} \mathrm{C}$ ).

3. Cell constant should be measured with standard $\mathrm{KCl}$ solutions.

4. Field analysis on fresh raw brine strongly recommended; commercial

Edition: field conductivity meters available.

$7 / 78$

5. Record sample temperature at time of conductivity measurement.

(cont. on back) 
6. Specific conductivity will change as sample ages according to $\mathrm{CO}_{2}$ concentration and oxidation of ion's (iron and manganese) and $\mathrm{H}_{2} \mathrm{~S}$ occurs. 


\section{$\mathrm{Cu}$}

Copper

Analysis: Atomic Absorption

No. $79-1$

Method: Samples containing Cu are directly aspirated into an air-acetylene flame and determined by absorption of the $\mathrm{Cu}$ resonance line at $324.7 \mathrm{~nm}$.

Sample Handling: Use raw or filtered acidified brine. Samble may be stabilized by adding $5 \mathrm{ml} \mathrm{HNO}_{3}$ per liter at sample.

Range: $0.01-4 \mathrm{mg} / 1$

Precision: $\pm 5 \%$

Accuracy: $\pm 10 \%$

\section{Cross Reference:}

Appendix 2

Sampling Methods: 11-S, 29-S

Analysis Methods: $80-A$

\section{Reagents:}

Cu stock solution, (purchased or prepared from metallic copper in $1: 1 \mathrm{HNO}_{3}$ )
Literature Reference. EPA 01042 (1976)

APHA 30 Y (1975)

ASTM D2576-70, D1688D (1977)

USGS Book 5, Chapter Al, (1974)

Flame Emission and Atomic Absorption Spectrometry, Dean and Rains: 975 Vol. DII $00.65-94$.

\section{Equipment:}

Atomic absorption

Spectrophotometer

Remarks: 1. Standards should be matched to brine for major cations, so that physical properties such as viscosity are similar. Deuterium arc background lamp may be used for matrix background correction at a nearby wavelength. Graphite furnace has also been used in place of flame for atomization.

2. If samples show Tyndall effect, filter through $0.45 \mu$ membrane filter.

Edition:

3. With high $\mathrm{Zn} / \mathrm{Cu}$ ratios use a lean air-acetylene flame.

$7 / 78$

4. Spectral interferences due to $\mathrm{Na}$ and $\mathrm{Ca}$ in high brine samples at low copper concentration must be corrected.

(cont. on back)

C -83 


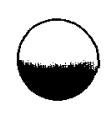


Copper

Analysis: Atomic Absorption (MIBK Extraction)

$80-A$

Method: Copper is extracted from the aqueous phase with ammonium pyrrolidine dithiocarbamate in MIBK. The extraction is then aspirated into an air-acetylene flame and the absorbance of the resonance 1 ine at $324.7 \mathrm{~nm}$.

Sample Handling: Use raw or filtered acitified brine.

\begin{tabular}{l|l} 
Range: & \multicolumn{2}{c}{ Precision: $\mp 10 \%$} \\
\hline $\begin{array}{l}\text { Cross Reference: } \\
\text { Appendix 2 }\end{array}$ & Literature Reference: \\
Sampling Methods: 11-S, 29-S & USGS Book 5 Chapter A1 (1974). \\
Analysis Methods: 79-A & \\
\hline $\begin{array}{l}\text { Reagents: } \\
\text { Ammonium pyrrolidine dithiocarbamate }\end{array}$ & Equipment: \\
$\begin{array}{l}\text { Methyl isobytyl ketone } \\
\text { Copper standard solutions, prepared } \\
\text { from metallic copper and nitric } \\
\text { acid }\end{array}$ & Separatory funnels \\
& \\
&
\end{tabular}

Remarks: 1. Extraction is useful for increased sensitivity.

2. Alternatively, chloroform can be used as the extraction solvent (ASTM 01688 -77E (1977)). 
Copper

Analysis: $\quad X$-ray Fluorescence

No. $81-A$

Method: Liquid samples are made to fluoresce by $X$-ray bombardment. Secondary fluorescence is separated into wavelengths by a crystal and the radiation is detected by a scintillation counter or a flow proportional counter. A vacuum is required for the lighter elements. Standardization of instrument required.

Sample Handling: Use filtered acidified, raw unacidified or filtered unacidified brine.

\section{Range:}

Precision:

Accuracy:

Cross Reference:

Appendix 2

Sampling Methods: 11-5, 29-S

Reagents:

Copper metal or other copper standard Nitric acid (to dissolve copper)

\section{Literature Reference:}

Nuc. Inst. and Methods, Vo . 106, pp. 525-538 $(1973)$.

\section{Equipment:}

$X$-ray fluorescence spectrophotometer

\section{Remarks:}




\section{$\mathrm{Cu}$}

Copper

Analysis: Inductively Coupled Plasma-

Atomic Emission Spectroscopy

No. $\quad 32-\mathrm{A}$

Method: Sample is aspirated into the argon plasma and the intensity of the emission spectrum is analyzed and compared with standards. Intensity is measured at $324.75 \mathrm{~nm}$ or alternate wavelength.

Sample Handling: Use filtered acidified or raw acidified brine.

3-5 orders of magnitude from

Range: a single spectral line Precision: $\pm 1-10 \%$

Cross Reference:

Appendix 2

Sampling Methods: 11-S, 29-S

\section{Literature Reference:}

Evaluation of an Inductively Coupled Plasma, Multichannel Spectrometric Analys is System, EPA-600/4-77-032, June 1977.

\section{Reagents:}

Copper atomic absorption standard solutions or copper metal

Nitric acid (to dissolve copper metal)

\section{Equipment:}

Inductively coupled plasma-atomic emission spectrometer.

Remarks: 1. External standards using $\mathrm{NaCl}$ concentrations equivalent to sample concentrations of $\mathrm{NaCl}$ are required.

2. Additional references:

R. H. Scott and M. L. Kokot, "Application of Inductively Coupled Plasmas

to the Analysis of Geochemical Samples", Anal. Chim. Acta 75, 257-270 (1975).

Edition:

(cont. on back) 



\section{$\mathrm{Cu}$}

Copper

Analysis: Spark Source Mass Spectrometry

\begin{tabular}{l|l|}
\hline No. & $83-\mathrm{A}$ \\
\hline
\end{tabular}

Method: Dehydrated brine sample is vaporized and ionized by an arc source and enters an evacuated chamber. Copper is separated and detected by its mass/charge ratio and determined quantitatively by comparison with standards.

Sample Handling: use raw or filtered acidified brine.

Range: $\quad 0.1-1000 \mathrm{mg} / 1 \quad$ Precision: $\pm 25 \%$

Accuracy: $\pm 25 \%$

Cross Reference:

Appendix 2

Sampling Methods: 11-S, 29-S

Reagents:

Solid copper

standard sample

\section{Literature Reference:}

Trace Analysis by Mass Spectrometry, A.J. Aheard, ed. Academic Press, NY (1977).

D.L. Donohue, J.A. Carter and J.C. Franklin, Ana 1. Letters, 10(5) 371-379 (1977).

\section{Equipment:}

Spark source mass spectrometer

Remarks: May be analyzed simultaneously with other elements of interest.

Edition: 
Copper

Analysis: Neutron Activation No. $84-A$

Method: Dehydrated sample is irradiated by neutron bombardment to form radioactive copper isotopes. The beta and gamma spectra are analyzed by a multicinannel analyzer; peak heights are proportional to the ariount of copper present.

Sample Handling: Filter brine on site. Evaporate sample and irradiated residue with neutron source.

Range: Precision: Accuracy:

Cross Reference:

Appendix 2

Sampling Methods: 11-S, 29-S

Reagents:

Standards containing copper
Literature Reference:

Robertson, D.E. \& Carpenter, R., "Neutron Activation Techniques for the Measurement of Trace Metals in Environmental Samples", NAS-NS-3114, Jan. 1974.

\section{Equipment:}

Reactor

Multichannel analyzer

Remarks:1-Sufficient time (several days) must be allowed for sodium decay if the sodium spectrum masks the element of interest.

2-Copper may be measured simultaneously with other elements of interest.

Edition: 


\section{$\mathrm{Cu}$}

Copper

Analysis: Emission Spectrometry

$85-A$

Method: The brine sample in either solid or liquid state is vaporized using a flare, $d-c$ arc, or a-c spark and the intensity of the selected copper emission line is measured against standards.

Sample Handling: Use raw or filtered acidified brine. Evaporation to dryness may be required.

Range: $0.04-0.2 \mathrm{mg} / 1$ Precision: $\pm 10 \% \quad$ Accuracy:

Cross Reference:

Literature Reference:

Appendix 2

Instrument Manufacturer's Literature

Sampling Methods: 11-S, 29-S

Reagents:

Copper standards

Vanadium internal standard
Equipment:

Emission spectrometer

Photo processor

Microphotometer

Remarks: 1. Use matrix matching, standard additions, and background correction whenever possible.

2. Large differences in matrix effects will be observed depending on the type of excitation source (flame, AC spark, or DC arc).

Edition: 
Fluoride

Analysis: Alizarin (Pre-distillation)

\begin{tabular}{|l|l}
\hline No. & 86-A \\
\hline
\end{tabular}

Method: Fluoride is distilled away from chemical interferences in the sample by acidifying the sample with concentrated sulfuric acid and distilling off the volatile $\mathrm{HF}$ which is formed at $180^{\circ} \mathrm{C}$. Silver sulfate is added to samples of high chloride content during distillation. 3-alizarinsulfuric acid, a yellow dye, is added to sample containing fluoride, to form a colorless zirconium hexafluoride species. Increasing fluoride concentration yields lighter sample color. Sample is matched visually to standards.

Sample Handling: Use unacidified brine sample.

Range: $0.05-1.4 \mathrm{mg} / 1$

Precision: $\pm 15 \%$

Accuracy: $\pm 5 \%$

Cross Reference:

Appendix 2

Sampling Methods: 11-S, 29-S

Analys is Methods: 87-A, 88-A, 89-A

\section{Literature Reference:}

Distillatiun: APHA 414A (1975)

Alizarin method: APHA 414D (1975)

\section{Equipment:}

Nessler tubes for visual comparison

Sulfuric acid; cone

Hydrochloric acid; cone

Fluoride standard solutions; prepared from $\mathrm{KF}$

Zirconyl-alizarin reagent; Zirconyl chloride $\left(\mathrm{ZrOCl}_{2} \cdot 8 \mathrm{H}_{2} \mathrm{O}\right)$

3-alizarinsulfuriz acid (alizarin red $S$ )

Sodium arsenite

Remarks: Interferences from $\mathrm{Al}(\mathrm{III}), \mathrm{Cl}^{-}$, $\mathrm{Fe}(\mathrm{III})$, hexametaphosphate, $\mathrm{PO}_{4}^{3-}, \mathrm{SO}_{4}^{2-}$, color and turbidity removed by distillation, which is quantitative within the accuracy and nrecision of the Alizarin method.

Procedure is time consuming. The still must be flushed by distilling with pure $\mathrm{H}_{2} \mathrm{O}$ before and after distilling $\mathrm{HF}$. One hour is required

Edition: for development of zirconium hexafluoride species. 


\section{Fluoride}

Analysis: Colorimetric (Spadns)

No. $37-\mathrm{A}$

Method: Fluoride reacts with zirconium dye lake to produce a colorless zirconium hexafluoride species. The dye becomes lighter in color with the increasing concentration of fluoride. The color is measured at $570 \mathrm{~nm}$.

Sample Handling: Use unacidified brine.

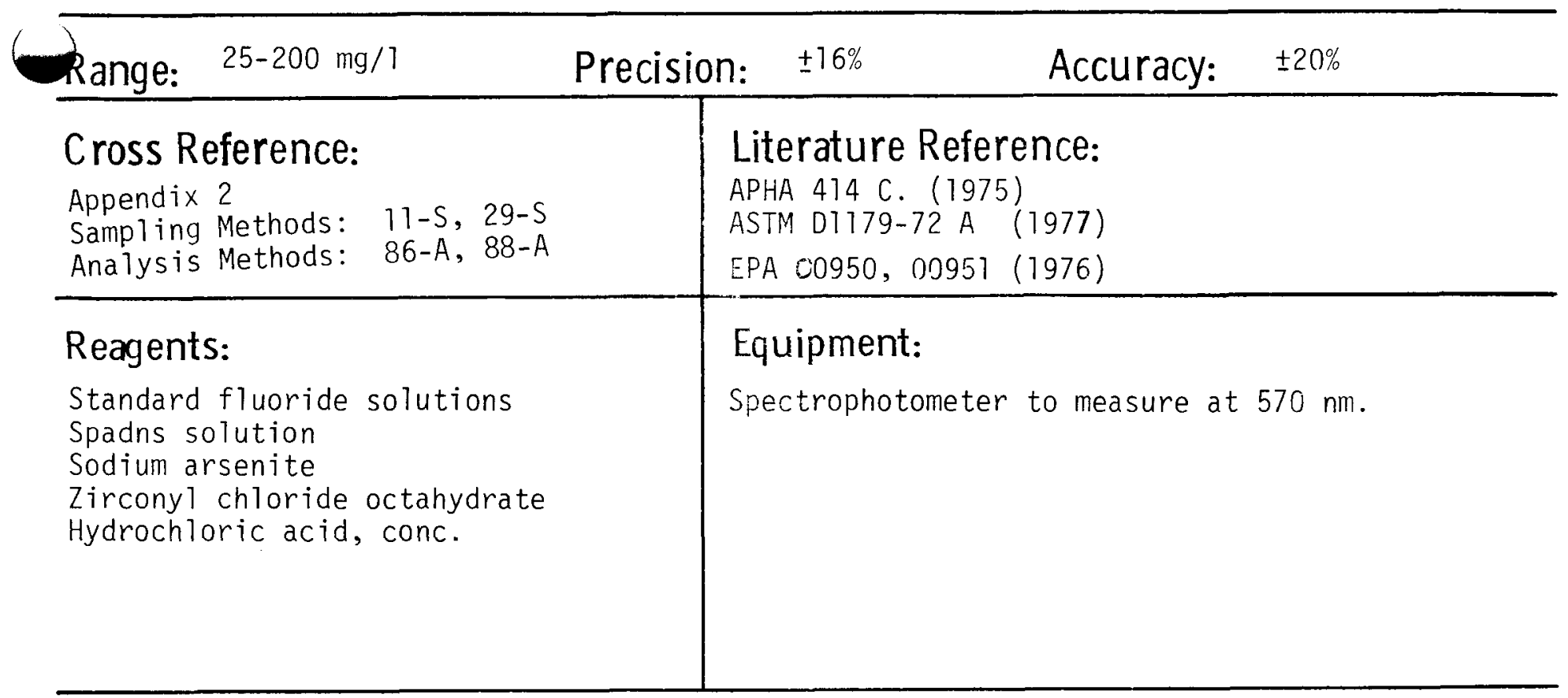

Remarks: 1. No known interferences. 
Analysis: Amadac F Colorimetric No. $88-\mathrm{A}$

Method: Amadac F, followed by distillation; sample is distilled using excess silver sulfate in sulfuric acid media. Distillation is stopped at $180^{\circ} \mathrm{C}$. The distillate is neutralized with sodium hydroxide and diluted to known volume. A portion of the distillate is reacted with $5 \mathrm{ml}$ Amadac $\mathrm{F}$ solution in a $25 \mathrm{ml}$ volumetric flask and read on spectrophotometer.

Sample Handling: Use raw unacidified or filtered unacidified brine.

Range:

Precision: $\pm 15 \%$ Accuracy:

Cross Reference:

Appendix 2 Sampling Methods: 11-S, 29-S Analysis Methods: $86-\mathrm{A}, 87-\mathrm{A}$

\section{Reagents:}

Amadac F, (trade mark of a mixture of chelated Tanthanum and organic dyes), Isopropyl Alcohol, Silver Sulfate, Sulfuric Acid, Reagent Sodium Hydroxide.
Literature Reference:

Burdick and Jackson Labs, Inc.

Muskegon, MI Literature

\section{Equipment:}

Distillation apparatus

Spectrophotometer to measure at $620 \mathrm{~nm}$

Remarks: In concentrated brines, interferences have been observed.

Edition: 
Fluoride

Analysis: Fluoride Specific Electrode

No. $89-\mathrm{A}$

Method: Fluoride concentration is measured with a fluoride specific electrode containing a lanthanum fluoride crystal and an electrometer or pIon meter.

Sample Handling: Use unacidified brine sample.

Range: $0.1-1000 \mathrm{mg} / 1$

Precision: $\pm 5 \%$

Accuracy: $+15 \%$

Cross Reference: Appendix 2

$11-5,29-5$

Analysis Methods: $50-A, 74-A, 101-A$

Reagents:

Stock fluoride solution

Fluoride standards: $1-10 \mu \mathrm{g} / \mathrm{m} 1$

Total ionic strength adjustment

buffer (TISAB)

Literature Reference:

APHA 474B (1975)

ASTM D1179-72B (1977)

USGS Book 5, Chapter AT (1974)

\section{Equipment:}

Fluoride electrode

Calamel reference electrode

Magnetic stirrer and teflon stirbar

Specific ion meter or $\mathrm{pH}$ meter with millivolt scale

Remarks: 1. Aluminum interference (up to $2 \mathrm{mg} / 1$ ) removed by complexation with citrate in TISAB solution.

2. Fluoride also forms complexes with $\mathrm{Si}, \mathrm{Fe}^{+3}$, and other polyvalent cations as well as hydrogen. Extent of complexation depends on the concentrations, $\mathrm{pH}$ of the solution, and total ionic strength of the solution. TISAB also compensates for these effects.

Edition:

$7 / 78$

(cont. on back) 


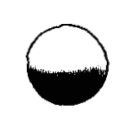

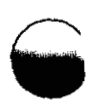

3. Recovery values from spiked samples may be high. 
Analysis: Ion-Exchange Chromatography No. $90-A$

Method: Anion components are separated on sulfonated cation exchange colums coated with finely ground anion resin. A sodium bicarbonate/carbonate solution is used as the eluting solvent. The separation column is followed by a suppressor column to remove highly concentrated background components, and fluoride is detected by a conductivity detector.

Sample Handling: Use unacidified brine

Range:

Precision: $\pm 0.55 \%$

Accuracy: $\pm 5 \%$

\section{Cross Reference:}

Appendix 2

Sampling Methods: 11-S, 29-S

\section{Reagents:}

Standard fluoride solution

Sodium carbonate/sodium bicarbonate eluent

\section{Literature Reference:}

Dionex Corp., Sunnyvale, CA, Literature Ana 1. Chem. 47, 11, (1975)

Microchem. Jour. 22, (45-49) (1977)

Ana 1. Chem. 49, 2, 3, 401 (1977)

\section{Equipment:}

Dionex Ion Chromatograph

75-120 psi air supply

Remarks: 1. May be analyzed simultaneously with bromide, nitrate, and sulfate.

2. Additional reference: Small, H., T. S. Stevens, and W. C. Bauman, Anal. Chem. 47, 1801 (1975).

Edition:

$7 / 78$ 


\section{Fluoride}

Analysis: Spark Source Mass Spectrometry

No. $91-\Lambda$

Method: Dehydrated sample is vaporized and ionized by an arc source and enters an evacuated chamber. Fluoride is separated and detected by its mass/ charge ratio, and determined quantitatively by comparison with standards.

Sample Handling: Use filtered unacidified or raw unacidified brine. Evaporate samples and analyze residue.

Range: $0.1-1000 \mathrm{mg} / 1$

Precision: $\pm 25 \%$

Accuracy: $\pm 25 \%$

\section{Cross Reference:}

\section{Appendix 2}

Sampling Methods: 11-S, 29-5

\section{Reagents:}

Sodium fluoride or other fluoride std. Spark source mass spectrometer

\section{Literature Reference:}

D. L. Donohue, J. A. Carter and J. C. Franki in Anal. Letters, 10(5) 371-379 (1977).

Trace Analys is by Mass Spectrometry, A. J. Aheard, ed., Academic Press, NY (1977).

\section{Equipment:}

\section{Remarks:}


Hardness

Analysis: EDTA Titration

No. $92-A$

Method: A buffered aliquot of the sample is titrated with a standard solution of disodium - EDTA. Magnesium and calcium react with the EDTA to form chelated complexes. In the presence of a dye such as Eriochrome $B l a c k T$ the solution changes from wine red to blue at the end point.

Sample Handling: Use raw acidified or filtered acidified brine.

Range: $1-1200 \mathrm{mg} / \mathrm{l}$

Cross Reference:

Append ix 2

Sampling Methods: $11-5,29-5$

Analys is Methods: 55-A, 93-A, 124-A

Reagents:

Ammonium chloride

Ammonium hydroxide

EDTA-Mg salt or

EDTA-disodium salt

Sodium cyanide

Sodium sulfide

Hydroxylamine hydrochloride

Ethanol or isopropanol

Eriochrome Black T dye

Calcium carbonate
Precision: $\pm 3 \%$

Accuracy: $\pm 5 \%$

Literature Reference:

APHA 309B (1975)

USGS Book 5, Chapter A1 (1974)

ASTM D 1126-67B (1977)

EPA 00900 (1976)

Hydrochioric acid Equipment:

Burets

Remarks: 1. Highly colored and strong brines interfere $\left(\mathrm{Al}>20 \mathrm{ppm}, \mathrm{CO}_{3}>1000 \mathrm{ppm}\right.$, $\left.\mathrm{Cl}>10,000 \mathrm{ppm}, \mathrm{SO}_{4}>10,000 \mathrm{ppm}, \mathrm{Fe}>30 \mathrm{ppm}\right)$. Inhibitors can usual1y be used to overcome these effects.

2. In high calcium solution, addition of ammonium hydroxide can cause precipitation.

3. Maintain $\mathrm{Mg}^{+2}$ and $\mathrm{Na}_{2}$-EDTA in approximate equivalence for best results,

Edition: 
Hardness

Analysis: Calculation

No.

93-A

Method: Hardness is determined as $\mathrm{mg} / \mathrm{l} \mathrm{CaCO}_{3}$ by determining the concentrations of $\mathrm{Ca}, \mathrm{Mg}, \mathrm{Sr}, \mathrm{Fe}, \mathrm{Al}, \mathrm{Zn}$, and $\mathrm{Mn}$, multiplying the $\mathrm{mg} / 1$ concentrations of these metals by the appropriate factors and summing the products to obtain hardness in $\mathrm{mg} / \mathrm{l}$ as $\mathrm{CaCO}_{3}$.

Sample Handling: Use RA or FA brine for the metal determinations.

Range:

Precision:

Accuracy:

Cross Reference:

Appendix 2

Sampling Methods: 11-S, 29-S

Analysis Methods: 55-A, 92-A, 105-A,

124-A

Reagents:

Use reacents required for metais determinations

\section{Literature Reference:}

APHA 309 (75)

USGS Book 5, Chapter AI (1974)

\section{Equipment:}

Use equipment required for metals determinations

Remarks: 1. This method considered more accurate than hardness by EDTA.

2. Method requires those metals in highest concentration be determined.

\section{Edition:}


Analysis: Titrimetric (Iodine) No. $94-A$

Method: Hydrogen sulfide is collected in zinc acetate solution. Excess iodine in water is added. The solution is acidified to allow sulfide to react with the iodine to form sulfur. Excess iodine is titrated with thiosulfate.

Sample Handling:

Sulfide from Hydrogen Sulfide is precipitated as zinc sulfide by passing raw or filtered brine through a fritted glass bubbler which is submerged in a zinc acetate solution. The zinc acetate solution is diluted to a preselected concentration with brine (usua11y 1:1).

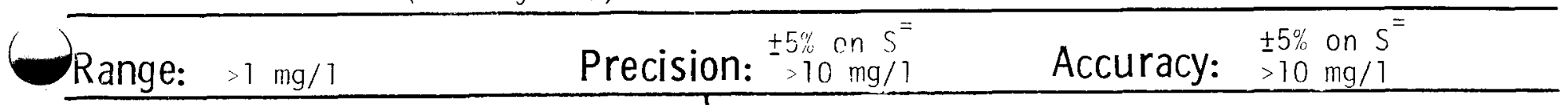

Cross Reference Appendix 2

Cross Reference: Sampling Methods: $4-S, 11-S, 12-S, 29-5,34-S$

Analysis Methods: 202-A

\section{Literature Reference:}

APHA 428 D (1975)

API $3.10 .1(1968)$

USGS Book 5 , Chapter A1 (1974)

EPA 00746 (1976)

\section{Reagents:}

Zinc acetate

Sodium thiosulfate

Starch

Iodine

Hydrochloric acid

\section{Equipment:}

Burets

Remarks: 1. Reducing substances such as heavy metal ions, sulfite, thiosulfate and hydrosulfite will use up iodine and contribute positive errors.

2. Oxygen and other oxidants react with hydriodic acid and contribute negative errors.

3. Field analysis for sulfide is advised. 
4. $H_{2} S$ may be evolved from sample by boiling with phosphoric acid and recapturing in a glass bubbler apparatus containing zinc acetate solution. This procedure frees sulfide from heavy metals. Use $\mathrm{N}_{2}$ gas free of $\mathrm{H}_{2} \mathrm{~S}$ for purging $\mathrm{H}_{2} \mathrm{~S}$ out of original trapping solution. 


\section{$\mathrm{H}_{2} \mathrm{~S}$}

Hydrogen Sulfide

Analysis: Colorimetric (Methylene Blue)

\begin{tabular}{|l|l|}
\hline No. & $95-\Lambda$ \\
\hline
\end{tabular}

Method: Methylene blue is formed when sulfide is reacted with 4-amino-N, Ndimethylaniline in the presence of ferric chloride. Ammonium phosphate is then added to destroy excess Fe(III). The color is measured at $600 \mathrm{~nm}$.

Sample Handling: Sulfide from Hydrogen Sulfide is precipitated as zinc sulfide by passing raw or filtered brine through a fritted glass bubbler which is submerged in a zinc acetate solution. The zinc acetate solution is diluted to a preselected concentration with brine (usually $1: 1$ ).

Range: $0.01-1.0 \mathrm{mg} / 1$

Precision:

Accuracy:

$\pm 10 \%$

Cross Reference: Appendix 2

4-S, 11-S, 12-S, 29-S, 34-S

Analysis Methods: 204-A

Literature Reference:

APHA 428 C (1975)

API $3.10 .2(1968)$

\section{Reagents:}

Zinc acetate

Sodium carbonate

$\mathrm{N}, \mathrm{N}$-dimethyl-phenylene-diamine

oxalate (also called p-amino-

dimethylariline oxalate)

Sulfuric acid

Ferric chloride

Diammonium hydrogen phosphate

Sodium sulfide Sodium Hydroxide

Iodine Starch

Remarks: 1. Reducing substances such as heavy metal ions, sulfite, thiosulfate and hydrosulfite inhibit color formation.

2. Field analysis for sulfide is advised.

3. A modification of this method using Lauth's violet dye instead of methylene blue gives more consistent color development with brine samples (Strickland and Parsons, "A Practical Handbook of Seawater Analys is",

Edition: Fisheries Research Board of Canada, Ottawa, 1968, p. 41-44).

\section{Equipment:}

Spectrophotometer to measure at $600 \mathrm{~nm}$ Burets 
4. Field samples should be collected with all air srace excluded from bottle.

5. Interferences due to sulfite, thiosulfate, iodide, and many other soluble substances, but not ferrocyanide may be removed by first precipitating sulfide as ZnS, decanting, and washing the precipitate with distilled water. The $\mathrm{ZnS}$ is then treated using the standard procedure [APHA 4?8B (1975)]. 
\begin{tabular}{l|l|l|} 
Analysis: Titrimetric (For Bromide and Iodide) & No. & $96-\Lambda$ \\
\hline
\end{tabular}

Method: Iodide in a sample is oxidized with bromine to iodate; the excess bromine is then destroyed. Iodine is then formed by oxidizing iodide in $k^{\prime} I$ with the iodate and the resulting iodine is determined by titration with thiosulfate.

Sample Handling: Acidified or unacidified brine may be used.

Range: $>50 \mathrm{mg} / 7 \quad$ Precision: $\pm 10 \% \quad$ Accuracy: $\pm 10 \%$

Cross Reference:

Appendix 2 Sampling Methods: 11-S, 29-S AnaTys is Methods: $46-\mathrm{A}$

\section{Reagents:}

Acetic acid

Bromine water

Calcium carbonate

Calcium oxide

Hydrochloric acid Methyl red indicator Potassium fluoride Hypochlorite solution Potassium iodide
Sodium acetate

Sodium formate

Sodium chloride

Sodium molybdate

Sodium thiosulfate

standard solution

Sulfuric acid
Literature Reference:

ASTM $01246-77 \mathrm{C}$ (1977)

API 3.16 (1968)

USGS Book 5, Chapter AT (1974)
EPA $71865(1976)$

\section{Equipment:}

Iodide flasks, $250 \mathrm{ml}$

Burette

Remarks: 1. Bromide and iodide are determined together similarly, by oxidation with hypochlorite ion. Bromide may then be determined by difference. (See Bromide, Titrimetric).

2. Iron, magnesium, and organic matter interfere, but are removed prior to determination with CaO.

Edition: 
\begin{tabular}{l|l|l|l|}
\cline { 2 - 3 } Analysis:Colorimetric (Arsenious-Ceric-Ferric thiocyanate) & No. & $97-A$ \\
\hline
\end{tabular}

Method: Procedure is similar to the arsenious-ceric colorimetric method, except the reaction of $\mathrm{Ce}$ (IV) with the arsenious ion is quenched with ferric alum and thiocyanate to form the red Fe(III) thiocyanate complex which is measured at 510 or $525 \mathrm{~nm}$.

Sample Handling: Use raw unacidified or filtered unacidified brine.

Range:

Precision:

Accuracy:

\section{Cross Reference:}

Appendix 2

Sampling Methods: 11-S, 29-S

Analys is Methods: 98-A, 99-A, 100-A

\section{Reagents:}

Sodium chloride

Arsenious acid

Sulfuric acid

Ceric ammonium sulfate

Ferrous ammonium sulfate

Potassium thiocyanate

Potassium iodide

\section{Literature Reference:}

APHA 415B (1975).

\section{Equipment:}

water bath

Spectrophotometer to measure at 510 or $525 \mathrm{~nm}$

Timer

Remarks: 1. Excess of sodium chloride added to sample eliminates interference from chloride already present by attaining a stable maximum chloride concentration that sensitizes the reaction. Formation of noncatalytic forms of iodine and inhibitory effects of silver and mercury are reduced by $\mathrm{NaCl}$ addition.

Edition: 
Iodide

Analysis: Leuco Crystal Violet Method

$98-A$

Method: Iodide is selectively oxidized to iodine which then reacts with leuco crystal violet to form the highly colored leuco crystal violet dye. The color is measured spectrophotometricaliy.

Sample Handling: Use raw unacidified or filter unacidified brine. Determine within 1 day after collection.

Range: $>0.6 \mathrm{mg} / 1$

Precision: $\pm 10 \%$

Accuracy:

Cross Reference:

Appendix 2

Sampling Methods: 11-S, 29-S

Analysis Methods: 97-A, 99-A, 100-A

\section{Literature Reference:}

APHA 475A (1975)

Reagents:

Potassium iodide Calcium oxide

Equipment:

Citric acid

Ammonium hydroxide

Ammonium dihydrogen phosphate

Leuco crystal violet indicator

Mercuric chloride

Sulfuric acid

Potassium peroxymonosulfate

Sodium thiosulfate

Oxone

Remarks: 1. Chloride above $200 \mathrm{mg} / 1$ causes inhibition of the color formation.

2. Oxidized forms of manganese cause apparent high iodide results.

3. Color development time must be carefully watched.

4. Calcium oxide used to pretreat sample to remove various metal interferences. This treatment is followed by sulfuric acid neutralization.

Edition: 
Analysis: Colorimetric (Arsenious-Ceric)

No. $99-\Lambda$

Method: The iodide concentration affects the first order reaction rate of $\mathrm{AsO}_{3}$ with Ce(IV) in acid solutions. Samples and standards are reacted in a constant temperature bath at $30^{\circ} \mathrm{C}$ for 30 minutes and the remaining yellow $\mathrm{Ce}$ (IV) ion is measured at $450 \mathrm{~nm}$.

Sample Handling: Use unacidified brine.

Range: $0.001-0.1 \mathrm{mg} / 1 \quad$ Precision: $\pm 5 \%$ Accuracy:

Cross Reference:

Appendix 2

Sampling Methods: 11-S, 29-S

Analys is Methods: $97-A, 98-A, 100-A$

\section{Reagents:}

Arsenious acid solution Ceric sulfate solution Silver nitrate solution Sulfuric acid

\section{Literature Reference:}

ASTM D1246-77A (1977)

USGS Book 5, Chapter AT (1974)

\section{Equipment:}

Spectrophotometer to measure at $450 \mathrm{~nm}$

Timer

Water bath $30 \pm .5^{\circ} \mathrm{C}$

Remarks: 1. Reducing agents that react rapidly with ceric ion cause positive errors, but are removed by a preliminary treatment with dilute permanganate solution.

2. Oxidizing agents cause negative results by lowering the concentration of arsenious acid. The magnitude of the error is proportional to the iodide concentration.

Edition:

7/78 
Iodide

Analysis: Photometric

No. $100-A$

Method: Iodide is oxidized to iodine by nitrous acid and extracted into carbon tetrachloride. The purple color of iodide is measured versus standards at $517 \mathrm{~nm}$.

Sample Handling: Use unacidified or acidified brine.

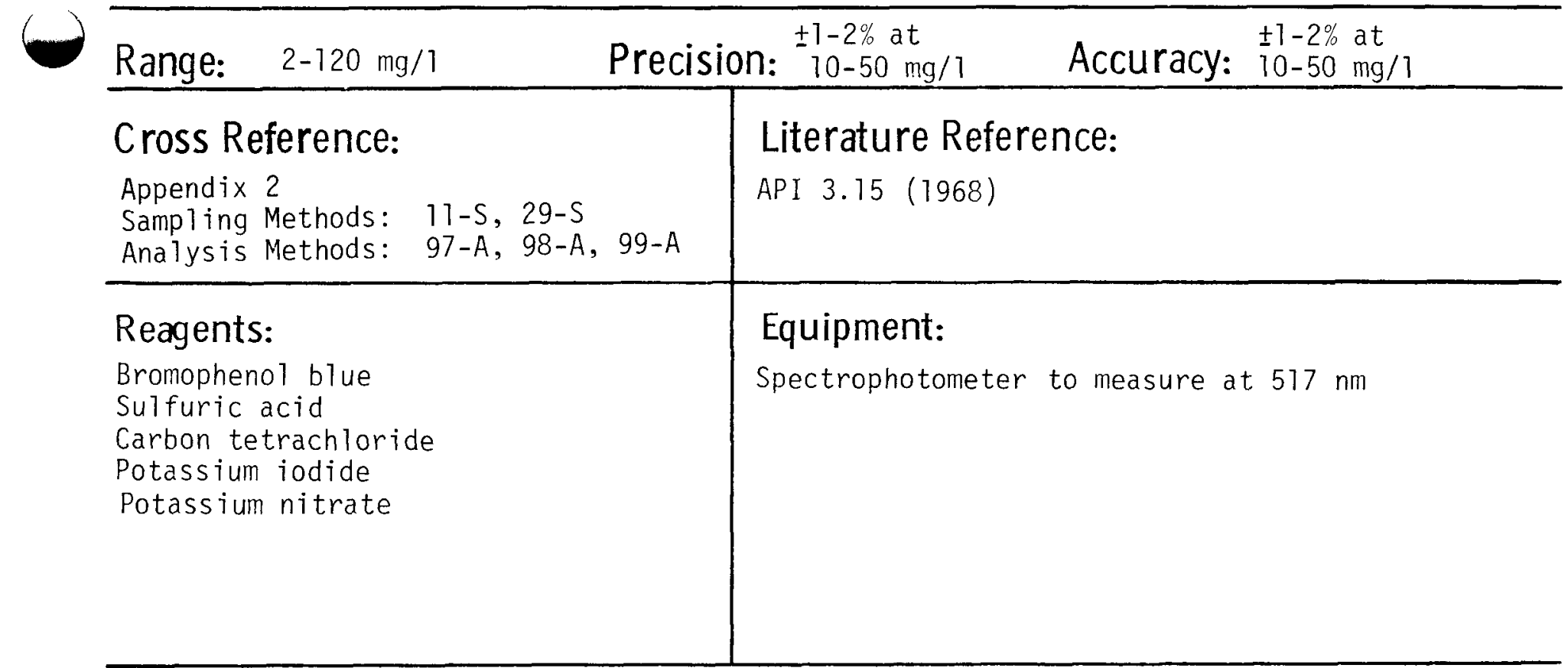

Remarks: Hydrogen sulfide can interfere. May be removed by boiling acidified brine.

Edition: 


\section{Iodide}

Analysis: Iodide-Specific Electrode

\begin{tabular}{|l|l|l}
\hline No. & $101-A$
\end{tabular}

Method: Iodide concentration is measured directly using a silver iodide electrode and an electrometer

Sample Handling: Use unacidified brine sample

Range: $0.1-100 \mathrm{mg} / 1 \quad$ Precision: $\pm 2 \% \quad$ Accuracy:

Cross Reference:

Appendix 2

Sampling Methods: 11-S,29-S

Analysis Methods: 50-A, 74-A, 89-A

Reagents:

Iodide standard solutions; prepared

from potassium iodide

Sodium nitrate, reagent grade

\section{Literature Reference:}

"Instruction Manual; Halide Electrode", Orion Research Co., 1976.

\section{Equipment:}

Silver iodide electrode, Orion model 94-53

Specific ion meter or $\mathrm{pH}$ meter with millivolt scale

Magnetic stirrer and stirbar

Reference electrode

Remarks: 1. Sulfide interference at $10^{-6}$ ratio level.'

2. Ionic strength adjuster solution added to samples and standards in order to keep constant background. Ionic strength adjuster consists of addition of $2 \mathrm{ml}$ of $5 \mathrm{M} \mathrm{NaNO}_{3}$ per $100 \mathrm{ml}$ of solution. 
Iodide

Analysis: $\quad x$-Ray Fluorescence

No.

$102-\Lambda$

Method: The sample containing iodide is caused to fluoresce by $X$-ray bombardment. The fifuorescent radiation is dispersed by a crystal and detected by a scintillation counter and/or a flow proportional counter.

Sample Handling: Use raw or filtered acidified brine; sample may be run as is or evaporated to dryness depending upon instrumentation.

Range: $10-100 \mathrm{mg} / 1 \quad$ Precision: $\pm 10 \mathrm{mg} / 1 \quad$ Accuracy: $\pm 10 \mathrm{mg} / \mathrm{l}$

Cross Reference:

Appendix 2

Sampling Methods: 11-S, 29-S

Literature Reference:

Cooper, J. A., Nuc. Inst. and Methods., Vol. 106, pp. 525-538, 1973.

Reagents:

Iodide standards

\section{Equipment:}

$x$-ray fluorescence spectrophotometer

Remarks: 1. Computer program usually required to interpret data.

2. Standardization of instrument required.

3. Iodide may be determined simultaneously with other elements of interest.

4. Use standard additions for quantification.

Edition: 


\section{Iodide}

Analysis: Spark Source Mass Spectrometry

\begin{tabular}{l|l}
\hline No. $103-\Lambda$ \\
\hline
\end{tabular}

Method: Dehydrated brine sample is vaporized and ionized by an arc source and enters an evacuated chamber. Iodide is separated and detected by its mass/charge ratio and determined quantitatively by comparison with standards.

Sample Handling: Use filtered or raw unacidified brine.

Range: $\quad 0.1-1000 \mathrm{mg} / 7 \quad$ Precision: $+25 \% \quad$ Accuracy: $\pm 25 \%$

\section{Cross Reference:}

Appendix 2

Sampling Methods: 11-S, 29-S

\section{Literature Reference:}

Trace Analys is by Mass Spectrometry, A.J. Aheard, ed., Academic Press, NY (1977).

D.L. Donohue, J.A. Carter and J.C. Franklin, Anal. Letters, 10(5) 371-379 (1977).

Reagents:

\section{Equipment:}

Solid iodide

standard sample

$$
\text { Spark source mass spectrometer }
$$

Remarks: other elements may be determined simultaneously with iodide.

Edition: 


\section{Iodide}

Analysis: Neutron Activation

No. $104-\mathrm{A}$

Method: Dehydrated sample is irradiated by neutron bombardment to form radioactive iodide isotopes. The beta and gamma spectra are analyzed by a multichannel analyzer; peak heights are proportional to the amount of iodide present.

Sample Handling: Filter brine on site. Evaporate sample and irradiate residue with neutron source.

Range: Precision: Accuracy:

Cross Reference:

Appendix 2

Sampling Methods: 11-S, 29-S

Reagents:

Standards containing iodide
Literature Reference:

Robertson, D.E. \& Carpenter, R., "Neutron Activation Techniques for the Measurement of Trace Metals in Environmental Samples", NAS-NS-3114, Jan. 1974.

\section{Equipment:}

Reactor

Multichannel analyzer

Remarks: Sufficient time (several days) must be allowed for sodium decay if the sodium spectrum masks the element of interest. Iodine may be analyzed simultaneously with other elements of interest. 


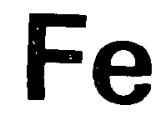

Iron

Analysis: Phenanthroline Colorimetric

$105-A$

Method: Iron is reduced to Fe(II) with hydroxylamine hydrochloride and complexed with 1, 10-phenanthroline between $\mathrm{pH}$ 2.9-3.5 to give an orange-red complex which is measured at $510 \mathrm{~nm}$.

Sample Handling: Use raw acidified or filtered acidified brine.

Range: $0.05-3 \mathrm{mg} / 1$

Precision:

Accuracy:

Cross Reference:

Appendix 2

Sampling Methods: 11-S, 29-S

Literature Reference:

APHA 310A (1975)

ASTM D1068-77A (1977)

Reagents:

Hydrochloric acid

Hydroxylamine hydrochloride

Ammonium acetate

Sodium acetate

1, 10-phenanthroline monohydrate

Iron standard

Diisopropyl or isopropyl ether

Remarks: 1. Interferences include strong oxidizing agents; cyanide; nitrite; phosphates; chromium and zinc > 10 times concentration of iron; cobalt and copper > $5 \mathrm{mg} / \mathrm{l}$; and nickel $>2 \mathrm{mg} / \mathrm{l}$.

2. Bismuth, cadmium, mercury, molybdate and silver precipitate phenanthroline.

3. In the presence of interfering metal ions an excess of phenanthroline is required to complex metal ions.

Edition: 4. Extraction step may be necessary if large amounts of interfering metals $7 / 78$

(cont. on back)

C-109 
5. If noticeable color is present evaporate sample, gently ash residue and redissolve in acid. 


\section{$\mathrm{Fe}$}

Iron

Analysis: Atomic Absorption

No. 106-A

Method: Aqueous samples of iron are aspirated directly into an air-acetylene

flame and the absorbance of the Fe resonance line at $248.3 \mathrm{~nm}$ is measured.

Sample Handling: Use raw or filtered acidified brine.

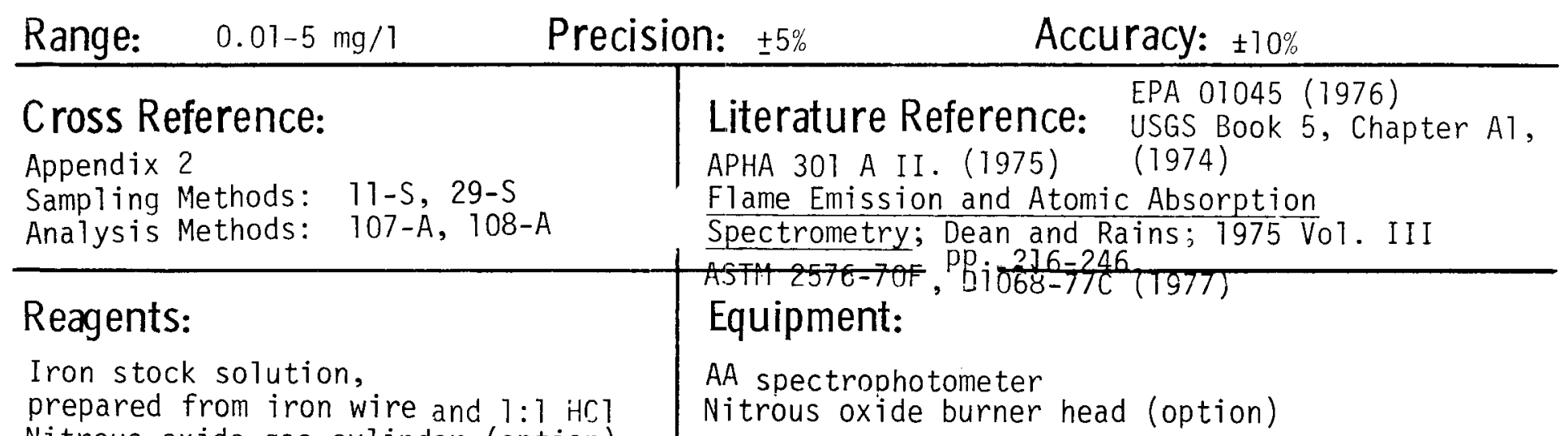

Remarks: 1. Major cations and acidity of brine should be simulated in standards, to liken physical properties such as viscosity. Interferences observed in air-acetylene flame (ref. 2) include aluminum, silica, sulfate, phosphate, et al. Standard additions technique is therefore recommended, significant ionization occurs if a nitrous oxide/acetylene flame is used, and $1000 \mathrm{\mu g} / \mathrm{ml}$ total $\mathrm{K}^{+}$should be added to solution for this flame.

Edition:

2. If samples show Tyndall effect, filter through $0.45 \mu$ membrane filter.

3. Background correction at $247.2 \mathrm{~nm}$ has been observed to be advantageous ( $n_{2}$ lamp).

(over) $\quad$ C-110 
4. A reduction in sensitivity has been observed when iron is determined in the presence of nitric acid and nickel. This effect can be minimized ty using a very lean flarrie. Tir use of a nitrous oxide/acetylene flame has been found to remove all interferences. 
Analysis: Atomic Absorption (MIBK Extraction)

No. $107-\Lambda$

Method: Iron is extracted from the aqueous phase with ammonium pyrrolidine dithiocarbamate in MIBK. The extraction is then aspirated into an air-acetylene flame and the absorbance of the resonance line at $248.3 \mathrm{~nm}$ measured.

Sample Handling: Use raw or filtered acidified brine.

Range:

Cross Reference:

Appendix 2

Sampling Methods: 11-S, 29-S

Analys is Methods: 106-A, 108-A

\section{Reagents:}

Ammonium pyrrolidine dithiocarbamate Methyl isobutyl ketone

Iron standard solutions, prepared

from iron and hydrochloric acid

\section{Literature Reference:}

APHA 301-A-III (1975)

Accuracy: $\pm 10 \%$

Precision: $\pm 14 \% \quad$ Accuracy: $\pm 10 \%$

Equipment:

AA spectrophotometer

Separatory funnels

Remarks:1. Improved sensitivity; useful for sub-ppm levels of iron.

2. Use of standard additions recommended.

3. Alternatively, chloroform may be used as the extraction solvent (ASTM D1068-77D (1977)). 


\section{$\mathrm{Fe}$}

Iron

Analysis: Flame Emission

No. $108-A$

Method: Iron is determined by aspirating the sample into a nitrous oxide acetylene flame and the emission intensity at $372.0 \mathrm{~nm}$ from iron is measured by a spectrophotometer.

Sample Handling: Use filtered acidified or raw acidified brine. Sample may be stabilized by adding $5 \mathrm{ml} \mathrm{HNO}_{3}$ per liter of sample.

$>0.05 \mathrm{mg} / 1$ low brine

Range: $>0.5 \mathrm{mg} / 7$ high brine

Cross Reference:

Appendix 2

Sampling Methods: $11-S, 29-S$

Analys is Methods: 106-A, 107-A

\section{Reagents:}

Iron atomic absorption standard solution or iron metal

Hydrochloric acid (to dissolve iron metal)

Nitrous oxide gas cylinder
$<0.5 \mathrm{mg} / 1 \pm 25 \%$

Precision:
$<0.5 \mathrm{mg} / 1 \pm 25 \%$

Accuracy: $>0.5 \mathrm{mg} / 1 \pm 5 \%$

\section{Literature Reference:}

Dean and Rains, Flame Emission and Atomic Absorption Spectrometry, Vol. III, $1975 \mathrm{pp}$.

W. Snelleman, Spectrochim. Acta, 23B, 403 (1968).

\section{Equipment:}

Atomic absorption spectrophotometer with emission mode or flame emission spectrophotometer Nitrous oxide burner head

Remarks: 1. Iron often coprecipitates with silica and must be recovered by acid digestion of brine residue.

2. Careful matrix matching (i.e. using same amounts of $\mathrm{NaCl}$, other alkali metal and alkaline earth metal ions) between sample and standards must be made.

3. Use of standard additions recommended.

Edition: 


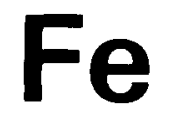

Iron

Analysis: $X$-ray Fluorescence

\begin{tabular}{|l|l|}
\hline No. & $109-A$ \\
\hline
\end{tabular}

Method: Liquid samples are made to fluoresce by X-ray bombardment. Secondary fluorescence is separated into wavelengths by a crystal and the radiation is detected by a scintillation counter or a flow proportional counter. A vacuum is required for the lighter elements. Standardization of instrument required.

Sample Handling: Use filtered acidified, raw unacidified or filtered unacidified brine.

\section{Range: \\ Precision: \\ Accuracy:}

\section{Cross Reference:}

Appendix 2

Sampling Methods: 11-S, 29-S

\section{Literature Reference:}

Nuc. Inst. and Methods, Vol. 106, pp. 525-538 (1973).

\section{Equipment:}

$x$-ray fluorescence spectrophotometer

Remarks:

Edition: 


\section{$\mathrm{Fe}$}

Iron

Analysis: Inductively Coupled Plasma-

\begin{tabular}{l|l}
\hline No. & $110-A$ \\
\hline
\end{tabular}

Method: The brine sample is aspirated into a radiofrequency generated argon plasma and the intensity of the emission spectrum of iron is analyzed by the instrument and compared with standards. Intensity is measured at $261.19 \mathrm{~nm}$ or al ternate wavelengths.

Sample Handling: Use raw or filtered acidified brine.

3-5 orders of magnitude from

Range: a single spectral line Precision: $\pm 1-10 \%$

Accuracy:

Cross Reference:

Literature Reference:

Appendix 2

Sampling Methods: 11-S, 29-S

"Evaluation of an Inductively Coupled Plasma

Multichannel Spectrometric Analys is System", EPA-600/4-77-032, June 1977.

\section{Reagents:}

Iron standard solution, prepared

from iron wire and hydrochloric acid

\section{Equipment:}

Inductively coupled plasma-

Atomic emission spectrometer

Remarks: 1. NaCl matrix of samples and standards should be matched to minimize differences in solution properties which can affect vaporization characteristics. Background correction and standard additions method recommended.

2. ICP-AES is a simultaneous multi-element technique for metal ions.

3. Upper limit of concentration range may be extended by using alternate spectral lines.

Edition:

(cont. on back) 
4. Additional references: R. H. Scott and M. L. Kokot, "Application of Inductively Coupled Plasmas to the Analysis of Geochemical Samples", Ana 1. Chim. Acta 75, 257-270 (1975). 
Iron

Analysis: Spark Source Mass Spectrometry

No. $111-A$

Method: Dehydrated sample is vaporized and ionized by an arc source and enters an evacuated chamber. Iron is separated and detected by its mass/charge ratio, and determined quantitatively by comparison with standards.

Sample Handling: Use filtered acidified, raw acidified, filtered unacidified, or raw unacidified brine. Evaporate samples and analyze residue.

Range: $0.7-1000 \mathrm{mg} / \mathrm{l}$

Precision: $\pm 5 \%$

$\pm 5 \%$ (isotope

Aiccuracy: $\quad \pm 5 \%$

(isotope Di1.)

Cross Reference:

Appendix 2

Sampling Methods: 11-S, 29-S

\section{Literature Reference:}

D.L. Donohue, J.A. Carter and J.C.Frankl in

Anaj. Letters, 10(5) $371-379$ (1977).

Trace Analys is by Mass Spectrometry, A.J. Aheard, ed., Academic Press, NY (1977).

\section{Equipment:}

Spark source mass spectrometer

Reagents:
Iron standards

Remarks: 1. Additional References:

J. A. Carter, D. L. Donohue, and J. C. Franklin, Trace Substances in Environmental Health-IX. U. of Missouri, 303 (1975).

J. D. Franklin, J. A. Carter, D. L. Donohue, and R. W. Stelzner, 23d Conf. on Mass Spectrometry and Allied Topics, Houston, TX 345 (1975).

R. Alvarez, B. J. Paulsen, and D. E. Kelleher, Anal. Chem. 41955 (1969).

Edition: 
Iron

Analysis: Neutron Activation

No. $112-A$

Method: Sample is exposed to neutron source (reactor) and radioactive iron isotopes are formed. The isotopes and their associated beta and gamma spectra are identified by multichannel analyzers. The amount of iron is proportional to the measured activity.

Sample Handling: Use raw acidified or filtered acidified brine. Evaporate samples and irradiate residue with neutron source.

Range:

Precision:

Accuracy:

\section{Cross Reference:}

Appendix 2

Samplinq Methods: 11-S, 29-S

\section{Literature Reference:}

Robertson and Carpenter, "Neutron Activation Techniques for the Measurement of Trace Metals in Environmenta1 Samples", NAS-NS-3114, Jan. 1974.

\section{Reagents:}

\section{Equipment:}

Reactor (neutron source)

Multichannel analyzer

Remarks: Sufficient time must be allowed for sodium decay if the sodium spectrum masks the element of interest.

Edition: 
Iron

Analysis:

Emission Spectrometry

No. $113-\mathrm{A}$

Method: The brine sample in either solid or liquid state is vaporized using a flame, d-c arc, or a-c spark and the intensity of the selected iron emission iine is measured against standards.

Sample Handling: Use raw or filtered acidified brine. Evaporation to dryness may be required.

\begin{tabular}{|c|c|}
\hline $0.5-2 \mathrm{mg} / \mathrm{T}$ & Precision: \\
\hline $\begin{array}{l}\text { Cross Reference: } \\
\text { Appendix } 2 \\
\text { Sampling Methods: } 11-5,29-5\end{array}$ & $\begin{array}{l}\text { Literature Reference: } \\
\text { Instrument Manufacturer's Literature }\end{array}$ \\
\hline Reagents: & Equipment: \\
\hline $\begin{array}{l}\text { Iron standards } \\
\text { Vanadium internal standard }\end{array}$ & $\begin{array}{l}\text { Emission spectrometer } \\
\text { Photo orncessnr } \\
\text { Microphotometer }\end{array}$ \\
\hline
\end{tabular}

Remarks: 1. Use matrix matching, standard additions and background correction whenever pussible.

2. Large differences in matrix effects will be observed depending on the type of excitation source (flame, AC spar, or DC arc).

Edition:

7/78 


\section{$\mathrm{Pb}$}

Lead

Analysis: Atomic Absorption

$114-A$

Method: Aqueous sample containing lead is aspirated directly into an air-acetylene flame and the absorption of the resonance line at $217.0 \mathrm{~nm}$ or $283.3 \mathrm{~nm}$ is analyzed.

Sample Handling:Use raw or filtered acidified brine. Sample may be stabilized by adding $5 \mathrm{ml} \mathrm{HNO}$ per liter of sample.

Range: $\quad 0.02-15 \mathrm{mg} / \mathrm{l}$

Cross Reference:

Appendix 2

Sampling Methods: 11-S, 29-S

Analysis Methods: 115-A
Precision: $\pm 5 \%$

Literature Reference:

) APHA 301A II (1975)

) Flame Emission and Atomic Absorption Spectrometry,

Dean and Rains; 1975 Vol. II I pp. 183-202.

\section{Equipment:}

\section{Accuracy: $\pm 10 \%$}

EPA 01051 (1976)

ASTM D2576-70, D3559-77A

(1977)
Lead standard solutions; prepared from metallic lead and nitric acid. EDTA

\section{Reagents:}

AA spectrophotometer

Remarks: 1. Anions which precipitate with lead may interfere. Making solutions $0.1 \mathrm{M}$ in EDTA will largely eliminate these interferences (ref. 2 above). (These anions include $\mathrm{PO}_{4}, \mathrm{CO}_{3}, \mathrm{I}, \mathrm{F}$, and acetate when present in concentrations ten times greater than $\mathrm{Pb}$.)

2. Use of a graphite furnace will increase sensitivity.

3. If samples show Tyndall effect, filter through a $0.45 \mu$ filter.

Edition:

$7 / 78$
4. Spectral interferences from sodium and calcium must be corrected at low $\mathrm{Pb}$ concentrations.

(cont'd. on back)

C-118 
5. Matrix matching (use of equivalent concentrations of alkali and alkaline earth metals) recommended.

6. Use of standard additions recommended.

7. Matrix interference may be removed by using a non-absorbing line at $282.5 \mathrm{~nm}$ for background correction.

8. Background correction using the $282.0 \mathrm{~nm}$ line has been shown to be advantageous. 
Analysis: Atomic Absorption (MIBK Extraction)

No. $115-\mathrm{A}$

Method: Lead is extracted from the aqueous phase with ammonium pyrrolidine dithiocarbamate in MIBK. The extraction is then aspirated into an air-acetylene flame and the absorbance of the resonance line at $283.3 \mathrm{~nm}$ measured.

Sample Handling: Use raw or filtered acidified brine.

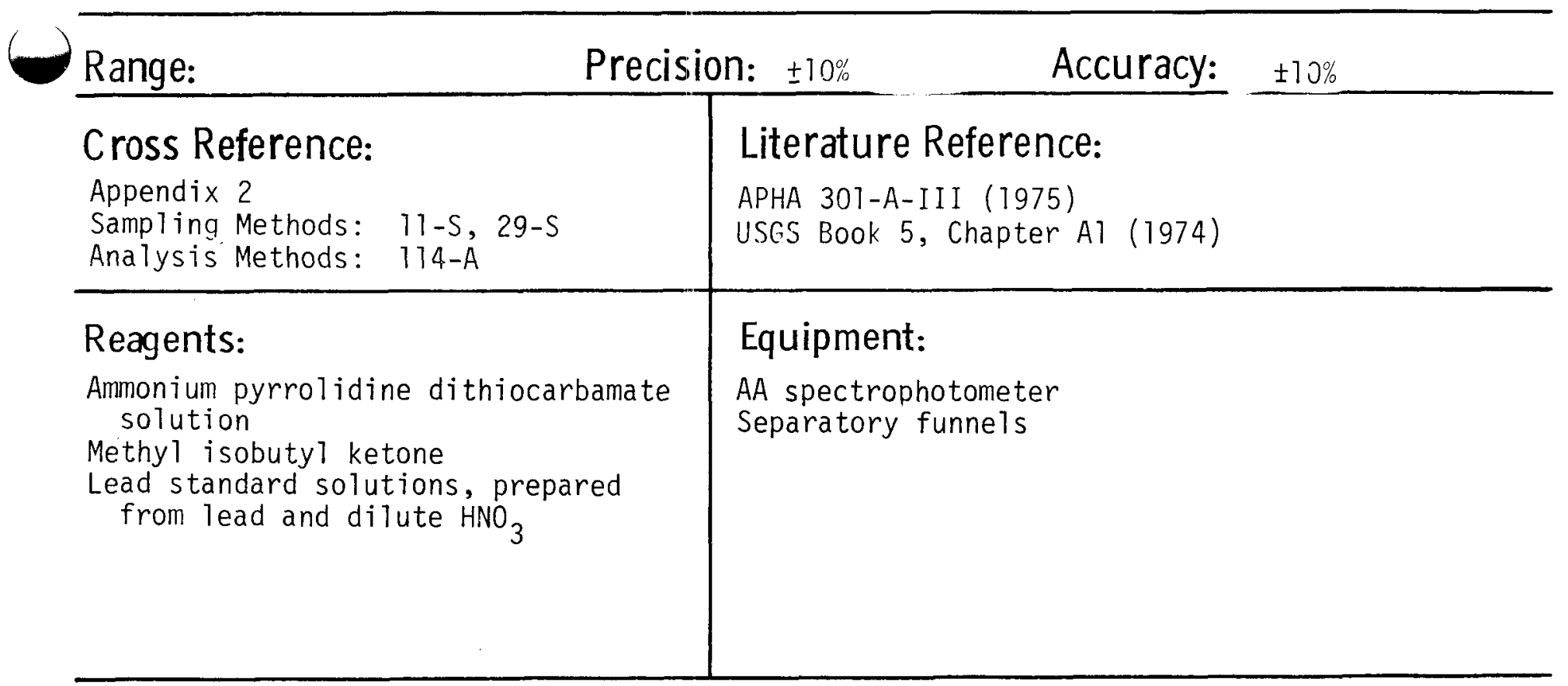

Remarks:1.Improves sensitivity, for very low concentrations of lead.

2. Use of standard additions recommended.

3. Alternatively, chloroform may be used as the extraction solvent (ASTM 3559-77B (1977)).

Edition:

$7 / 78$ 
Lead

Analysis: Inductively Coupled Plasma-

Analysis: Atomic Emission spect

No. $116-\mathrm{A}$

Method: The brine sample is aspirated into a radiofrequency generated argon plasma and the intensity of the emission spectrum of lead is analyzed by the instrument and compared with standards. Intensity is measured at $220.35 \mathrm{~nm}$ or alternate wavelength.

Sample Handling: Use raw or filtered acidified brine.

3-5 orders of magnitude from

Range: a single spectral line. Precision: $\pm 1-10 \%$

\section{Cross Reference:}

Appendix 2

Sampling Methods: 11-S, 29-S

\section{Accuracy:}

\section{Literature Reference:}

"Evaluation of an Inductively Coupled Plasma, Multichannel Spectrometric Analysis System" EPA-600/4-77-032, June 1977.

\section{Equipment:}

Inductively coupled plasmaatomic emission spectrometer

from metallic lead and dilute nitric acid

Remarks: 1. NaCl matrix of samples and standards should be matched to minimize differences in solution properties which can affect vaporization characteristics. Background correction and standard addition recommended. other metal ions may be measured simultaneously.

2. Upper limit of concentration range may be extended by using alternate spectral lines.

Edition:

3. Additional references: R. H. Scott and M. L. Kokot, "Application of Inductively Coupled Plasmas to the Analysis of Geochemical Samples", Anal. Chim. Acta 75, 257-270 (1975). 
Lead

Analysis: Spark Source Mass Spectrometry

No. $117-\mathrm{A}$

Method: Dehydrated brine sample is vaporized and ionized by an arc source and enters an evacuated chamber. Lead is separated and detected by its mass/charge ratio and determined quantitatively by comparison with standards.

Sample Handling: Use raw or filtered acidified brine.

Sange: $0.1-1000 \mathrm{mg} / 1 \quad$ Precision: $\pm 5 \%$ (isotope di Áccuracy: $\pm 25 \%$ (isotope dil.)

Cross Reference:

Appendix 2

Sampling Methods: 11-S, 29-S

Reagents:

Solid lead

standard sample
Literature Reference:

Trace Analys is by Mass Spectrometry, A.J. Aheard, ed., Academic Press, NY (1977).

D.L. Donohue, J.A. Carter and J.C. Frank1 in, Anal. Letters, 10(5) 371-379 (1977).

Equipment:

Spark source mass spectrometer

Remarks:1. Other elements may be determined simultaneously with lead.

2. Additional references:

J. A. Carter, D. L. Donohue, and J. C. Franklin, Trace Substances in Environmental Health-IX. U. of Missouri, 303 (1975).

J. C. Franklin, J. A. Carter, D. L. Donohue, and R. W. Stelzner, 23d Conf. on Mass Spectrometry and Allied Topics, Houston, TX 354 (1975).

R. Alvarez, B. J. Paulsen, and D. E. Kelleher, Ana1. Chem. 41955 (1969).

$7 / 78$ 
Analysis:

Emission Spectrometry

No. $118-\mathrm{A}$

Method: The brine sample in either solid or liquid state is vaporized using a flame, d-c arc, or a-c spark, and the intensity of the selected leac emission line is measured ayainst stanciarus.

Sample Handling: Use raw or filtered acidified brine. Evaporation to dryness may be required.

Range:

Precision:

Accuracy:

Cross Reference:

Appendix 2

Sampling Methods: 11-S, 29-5

\section{Literature Reference:}

Instrument Manufacturer's Literature

\section{Equipment:}

Lead standards
Emission spectrometer

Remarks: 1. Use matrix matching, standard additions, and background correction whenever jossible.

2. Large differences in matrix effects will be observed depending on the type of excitation source (flame, AC spark, or DC arC).

Edition: 
Lithium

Analysis: Atomic Absorption

No. $119-\mathrm{A}$

Method: Sample is aspirated directly into an air-acetylene flame and lithium is determined from the degree of absorption of the $L i$ resonance $l$ ine at $670.8 \mathrm{~nm}$.

Sample Handling: Use raw or filtered acidified brine.

Range: $\quad 0.05-2 \mathrm{mg} / 1$ Cross Reference:

Appendix 2

Sampling Methods: 11-S, 29-S

Analys is Methods: $120-A$

\section{Reagents:}

Lithium standard solutions; prepared from $\mathrm{Li}_{2} \mathrm{CO}_{3}$ and hydrochloric acid Potassium chloride
Precision: $\pm 5 \%$

\section{Accuracy: $\pm 10 \%$}

\section{Literature Reference:}

Flame Emission and Atomic Absorption Spectrometry, Dean and Rains, 1975, Vol. III, pp. 2-32.

USGS Book 5, Chapter A1 (1974)

ASTM D3567-77 (1977)

\section{Equipment:}

AA spectrophotometer

Remarks: 1. Interference by ionization of $\mathrm{Li}$ in flame can be suppressed by matching matrix of standards and samples for alkali and alkali earths metals. Addition of $\mathrm{KCl}$ to a final $\mathrm{K}^{+}$concentration of $2000 \mu \mathrm{g} / 7$ recommended. Standard additions method also compensates for matrix effects.

2. If sample shows Tyndall effect, filter through a $0.45 \mu$ membrane filter.

3. On same instruments a red filter is used. 
Lithium

Analysis: Flame Emission

$120-A$

Method: Lithium is determined by aspirating the sample into an air-acetylene flame and the emission intensity at $670.8 \mathrm{~nm}$ from lithium is measured by a spectrophotometer.

Sample Handling: Use filtered acidified or raw acidified brine. Sample may be stabilized by dilution with 9 parts distilled water and adding $5 \mathrm{ml} \mathrm{HNO}_{3}$ per liter of sample.

Range: $>0.05 \mathrm{mg} / \mathrm{l}$

$<0.5 \mathrm{mg} / 1 \pm 25 \%$

Precision: $>0.5 \mathrm{mg} / 1 \pm 5 \%$

Accuracy:

$<0.5 \mathrm{mg} / 1 \pm 25 \%$

Cross Reference:

Appendix 2

Sampling Methods: 11-S, 29-S

Analys is Methods: 119-A

Literature Reference:

Dean and Rains, Flame Emission and Atomic Absorp-

tion Spectrometry, Vol. III, 1975.

W. Snelleman, Spectrochim. Acta, 23B, 403 (1968).

Reagents:

Lithium atomic absorption standard solutions or lithium carbonate

Hydrochloric acid (to dissolve lithium carbonate)

Potassium chloride or potassium nitrat申

\section{Equipment:}

Atomic absorption spectrophotometer with emission mode or flame emission spectrophotometer

Remarks: 1. Lithium is partially ionized in an air-acetylene flame. This ionization may be suppressed by adding either potassium nitrate or potassium chloride to give a potassium concentration of $2000 \mathrm{ppm}$ potassium.

2. Careful matrix matching between sample and standards must be made

(i.e. use same amounts of alkali metal and alkaline earth metal ions).

3. High concentrations of sulfate interfere.

Edition: 4. Use of standard additions recommended. 
Analysis: Ion-Exchange Chromatography

No. $121-$ A

Method: Ionic components are separated on sulfonated polymer-based column. Dilute nitric acid solution is used as the eluting solvent. The separation column is followed by a suppressor column to remove highly concentrated background components, and lithium is detected by a conductivity detector.

Sample Handling: Use raw or filtered acidified brine.

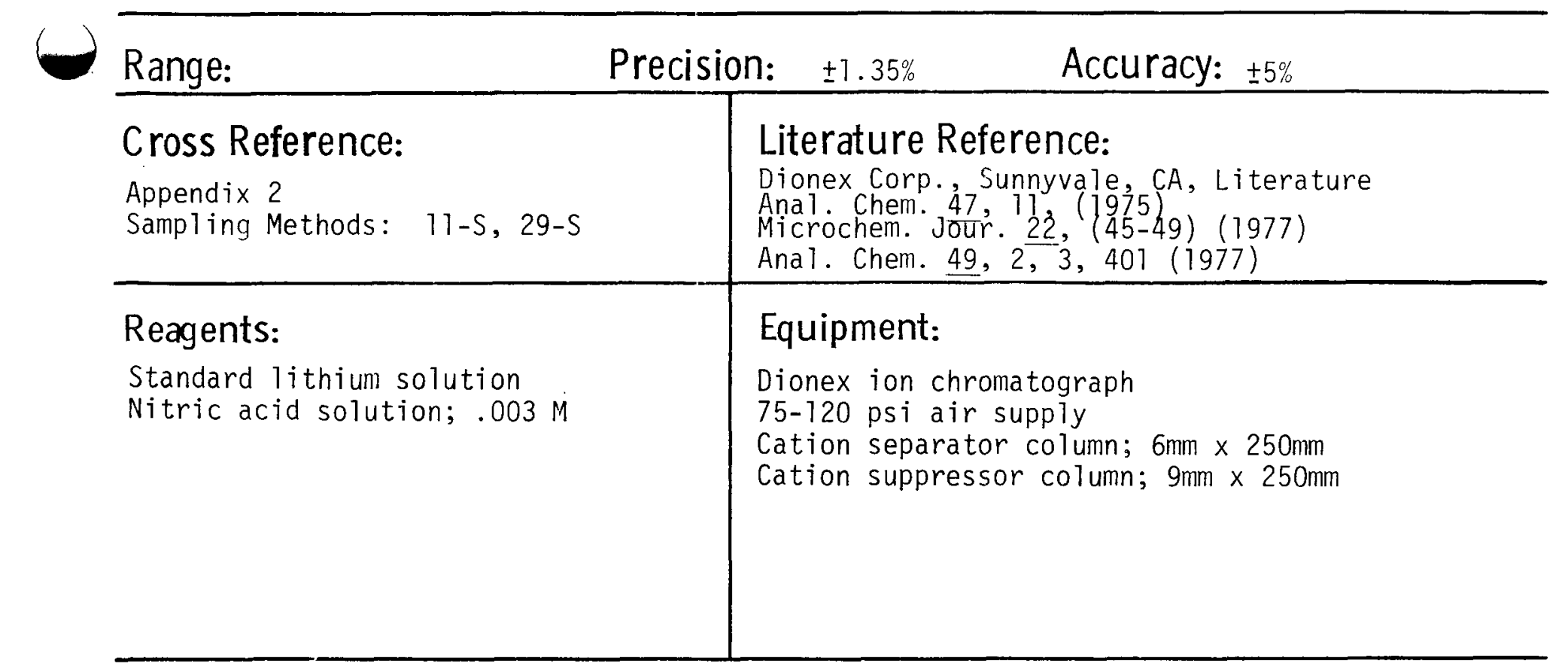

Remarks: 1. May be determined simultaneously with potassium, sodium, and ammonium cations.

2. Additional reference: Sma11, H., T. S. Stevens and W. C. Bauman, Anal. Chem., 471801 (1975).

Edition:

$7 / 78$ 
Lithium

\begin{tabular}{l|l|l}
\cline { 2 - 2 } Analysis: Spark Source Mass Spectrometry & No. & 122-A \\
\hline
\end{tabular}

Method: Dehydrated brine sample is vaporized and ionized by an arc source and enters an evacuated chamber. Lithium is separated and detected by its mass/charge ratio and determined quantitatively by comparison with standards.

Sample Handling: Use raw or filtered acidified brine.

Range: $0.1-1000 \mathrm{mg} / 1$

Precision: $\quad \pm 25 \%$

Accuracy: $\pm 25 \%$

Cross Reference:

Appendix 2

Sampling Methods: 11-S, 29-5

\section{Reagents:}

Solid lithium standard sample

\section{Literature Reference:}

Trace Analys is by Mass Spectrometry, A.J. Aheard, ed. Academic Press, NY (1977).

D.L. Donohue, J.A. Carter, and J.C. Franklin, Anal. Letters, 10(5) 371-379 (1977).

\section{Equipment:}

Spark source mass spectrometer

\section{Remarks:}

Edition:

$7 / 78$ 
Analysis: Emission Spectrometry

$123-A$

Method: Sample is vaporized using a flame, $d-c$ arc, or a-c spark and the intensity of the selected lithium emission line is measured against standards.

Sample Handling: Use raw or filtered acidified brine. Evaporation to dryness may be required.

Dilute to

Range: $\leq 1.0 \mathrm{mg} / 1$

Precision:

Accuracy:

Cross Reference:

Literature Reference:

Appendix 2

Sampling Methods: 11-S, 29-5

\section{Reagents:}

Lithium stock solution; may be prepared from $\mathrm{Li}_{2} \mathrm{CO}_{3}$ and $\mathrm{HCl}$
Instrument Manufacturer's Literature

\section{Equipment:}

Emission spectrometer

Remarks: 1. Some flames (e.g. $\mathrm{O}_{2}-\mathrm{H}_{2}-\mathrm{N}_{2}$ ) may not be hot enough to vaporize completely the aerosols from solutions with high solids contents.

2. Reference standards should contain as high a salt content as unknowns.

3. Large differences in matrix effects will be observed depending on the type of excitation source (flame, AC spark, or DC arc).

Edition:

$7 / 78$ 
Method: Magnesium is determined volumetrically by titrating with EDTA in the presence of a compleximetric indicator dye at $\mathrm{pH}$ 10. A sample aliqunt is first buffered and titrated with EDTA to a blue endpoint using Eriochrome indicator. This gives the $\mathrm{Ca}+\mathrm{Mg}$ concentration. A second sample aliquot is treated with $4 \mathrm{~N} \mathrm{NaOH}$ and titrated with EDTA to a purple endpoint using murexide indicator. This gives the Ca concentration. The magnesium concentration is calculated by difference.

Sample Handling: Use raw acidified or filtered acidified brine.

Range:

Precision:

Accuracy:

\section{Cross Reference:}

Appendix 2

Sampling Methods: $11-5,29-S$

Analys is Methods: 55-A, 92-A, 93-A

\section{Reagents:}

Murexide (ammonium purpurate)

Sodium hydroxide (4N)

EDTA

Ammonium chloride-ammonium hydroxide buffer

Calcium standard

Magnesium standard

Eriochrome Black T

Hydroxylamine hydrochloride

Remarks: Barium and strontium interfere when present in quantities greater than $30 \mathrm{mg} / 1$.
Literature Reference:

APHA 373C (1975)

ASTM D $511^{-} 76 B(1977)$

API 2.4 (1968)

USGS Book 5, Chapter AT (1974)

\section{Equipment:}

Buret

\section{Edition:}


Magnes ium

Analysis: Atomic Absorption

$125-A$

Method: Solutions containing magnesium are aspirated directly into an air-acetylene flame and the absorbance of the resonance line at $285.2 \mathrm{~nm}$ is measured.

Sample Handling: Use raw or filtered acidified brine. Sample may be stabilized by dilution with 9 parts distilled water and adding $5 \mathrm{ml} \mathrm{HNO}$ per liter of sample.

Range: $0.01-0.4 \mathrm{mg} / 1 \quad$ Precision: $\pm 5 \% \quad$ Accuracy: $\pm 10 \%$

Cross Reference:

Literature Reference: USA O0927 (1976)

Appendix 2

Sampling Methods: 11-S, 29-S

APHA 301 A. II (1975) (1974)

ASTM D2576-70, D517-76C (1977)

Flame Emission and Atomic Absorption Spectrometry, Dean and Rains, 1975,Vol. III, pp. 33-64.

\section{Reagents:}

Magnesium stock solution, may be prepared by dissolving magnesium ribbon in $1: 1 \mathrm{HCl}$

Potassium chloride

Nitrous oxide gas cylinder (option)

Lanthanum chloride

\section{Equipment:}

Atomic Absorption spectrophotometer

Nitrous oxide burner head (option)

Remarks: 1. Aluminum and silicon interfere; effect may be largely removed by addition of $0.1-1 \%(\mathrm{w} / \mathrm{v})$ La or use of nitrous oxide/acetylene flame. Ionization interference also occurs. Matrix of samples and standards should be matched for alkali salts and/or a final $\mathrm{K}^{+}$concentration of $2000 \mathrm{mg} / \mathrm{l}$ should be added to all solutions. Standard additions technique recommended.

2. If sample shows a Tyndall effect, filter through a $0.45 \mu$ membrane filter. 


\section{Mg}

Magnesium

Analysis: Inductively Coupled Plasma-

Atomic Emission Spectroscopy

$126-A$

Method: The brine sample is aspirated into a radiofrequency generated argon

plasma and the intensity of the emission spectrum of magnesium is

analyzed by the instrument and compared with standards. Intensity is

measured at $279.55 \mathrm{~nm}$ or alternate wavelength.

Sample Handling: Use raw or filtered acidified brine.

3-5 orders of magnitude from a

Range: single spectral line. Precision

Cross Reference:

Appendix 2

Sampling Methods: 11-S, 29-S

\section{Reagents:}

Magnesium standard solution, prepared

from magnesium ribbon and dilute $\mathrm{HCl}$

\section{Literature Reference:}

"Evaluation of an Inductively Coupled Plasma, Multichannel Spectrometric Analys is System", EPA-600/4-77-032, June 1977.

\section{Equipment:}

Inductively coupled plasma-

atomic emission spectrometer

Remarks: 1. NaCl matrix of samples and standards should be matched to minimize differences in solution properties which can affect vaporization characteristics.

2. This instrument allows simultaneous measurement of several metal cations.

3. Background correction and standard additions method recommended.

4. Upper limit of concentration range may be extended by using alternate

Edition: spectral 1 ines. 
5. Additional references: R. H. Scott and M. L. Kokot, "Application of Inductively Coupled Plasmas to the Analys is of Geochemical Samples", Anal. Chim. Acta 75, 257-270 (1975). 


\section{Mg}

Magnesium

Analysis: Spark Source Mass Spectrometry

No. $127-\mathrm{A}$

Method: Dehydrated sample is vaporized and ionized by an arc source and enters an evacuated chamber. Magnesium is separated and detected by its mass/charge ratio, and determined quantitatively by comparison with standards.

Sample Handling: Use filtered acidified, raw acidified, filtered unacidified, or raw unacidified brine. Evaporate samples and analyze residue.

Range: $0.1-1000 \mathrm{mg} / 1 \quad$ Precision: $\pm 25 \% \quad$ Accuracy: $\pm 25 \%$

Cross Reference:

Appendix 2

Sampling Methods: 11-S, 29-S

Reagents:

Magnesium standards
Literature Reference:

D.L. Donohue, J.A. Carter and J.C. Franklin Anal. Letters, 10(5) 371-379 (1977).

Trace Analyș is by Mass Spectrometry, A.J. Aheard, ed., Academic Press, NY (1977).

\section{Equipment:}

Spark source mass spectrometer

\section{Remarks:}


Analysis: Neutron Activation

No. $128-\mathrm{A}$

Method: Dehydrated sample is irradiated by neutron bombardment to form radioactive magnesium isotopes. The beta and gamma spectra are analyzed by a multichannel analyzer; peak heights are proportional to the amount of magnesium present.

Sample Handling: Filter brine on site. Evaporate sample and irradiated residue with neutron source.

Range:

Precision:

Accuracy:

\section{Cross Reference:}

\section{Appendix 2}

Sampling Methods: 11-S, 29-5

\section{Reagents:}

Standards containing magnesium

\section{Literature Reference:}

Robertson, D.E. \& Carpenter, R., "Neutron Activation Techniques for the Measurement of Trace Metals in Environmental Samples", NAS-NS-3114, Jan. 1974.

\section{Equipment:}

\section{Reactor}

Multichannel analyzer

Remarks: Sufficient time (several days) must be allowed for sodium decay if the sodium spectrum masks the element of interest.

other elements may be analyzed simultaneously with magnesium.

Edition:

$7 / 78$ 
Analysis: Emission Spectrometry

$129-A$

Method: The brine sample in either solid or liquid state is vaporized using a flame, d-c arc, or a-c spark and the intensity of the selected magnesium emission line is measured against standards.

Sample Handling: Use raw or filtered acidified brine. Evaporation to dryness may be required.

\section{Range: $\quad 0.1-1 \mathrm{mg} / 1 \quad$ Precision: $\pm 10 \% \quad$ Accuracy:}

\section{Cross Reference:}

Appendix 2

Sampling Methods: $11-5,29-5$

\section{Literature Reference:}

Instrument Manufacturer's Literature

\section{Reagents:}

\section{Magnesium standards}

Vanadium internal standard

\section{Equipment:}

Emission spectrometer

Photo processor

Microphotometer

Remarks: 1. Use matrix matching, standard additions, and background correction whenever possible.

2. Large differences in matrix effects will be observed depending on the type of excitation source (flame, AC spark, or DC arc).

Edition: 
Manganese

Analysis: Atomic Absorption

\begin{tabular}{l|l|l|l}
\hline No. & $130-A$
\end{tabular}

Method: Manganese may be determined by aspirating the aqueous sample directly into an air-acetylene flame and measuring the absorbance of the resonance 7 ine at $279.4 \mathrm{~nm}$.

Sample Handling: Use raw or filtered acidified brine. Sample may be stabilized with $5 \mathrm{ml} \mathrm{HNO}_{3}$ per liter of sample.

Range: $0.07-3 \mathrm{mg} / 1$

Precision: $\pm 5 \%$

Accuracy: $\pm 10 \%$ Cross Reference:

Appendix 2

Sampling Methods: 11-S, 29-S

Analys is Methods: 131-A

\section{Reagents:}

Mn stock solution, $1000 \mathrm{ppm}$ purchased or prepared from metallic manganese in 1:1 nitric acid Nitrous oxide gas cylinder (option)

Literature Reference: EPA 01055 (1976) APHA 129 (1975) (1974) ASTM D2576-70, D858-77B (1977)

Flame Emission and Atomic Absorption Spectrometry, Dean and Rains, 1975, Vol. III.

\section{Equipment:}

Atomic Absorption Spectrophotometer

Nitrous oxide burner head (option)

Remarks: 1. Interferences by silica, iron and phosphate, nickel, and cobalt have been reported in the literature, and the use of a nitrous oxide/acetylene flame or oxidizing air-acetylene flame suggested. Alkali salt content of samples and standard should be matched. Standard additions technique also recommended. Use of a background correction lamp at a nearby wavelength also suggested.

2. If sample shows Tyndall effect, filter through a $0.45 \mu$ membrane filter. 
3. Manganese absorbance is also depressed in the presence of perchlorate, when usina a reducina air/acetylene flame. In an oxidizing air/acetylene flame or a nitrous oxide/acetylene flame, this interference is not present. 
Manganese

Analysis: Atomic Absorption (MIBK Extraction) \begin{tabular}{|l|l|}
\hline No. & $131-\mathrm{A}$ \\
\hline
\end{tabular}

Method: Manganese is chelated with ammonium pyrrolidine dithiocarbamate (APDC) and extracted into methyl isobutyl keton (MIBK). The extraction is aspirated into an air-acetylene flame and the absorbance of the resonance line at $279.5 \mathrm{~nm}$ is measured.

Sample Handling: use raw or fiitered acidified brine.

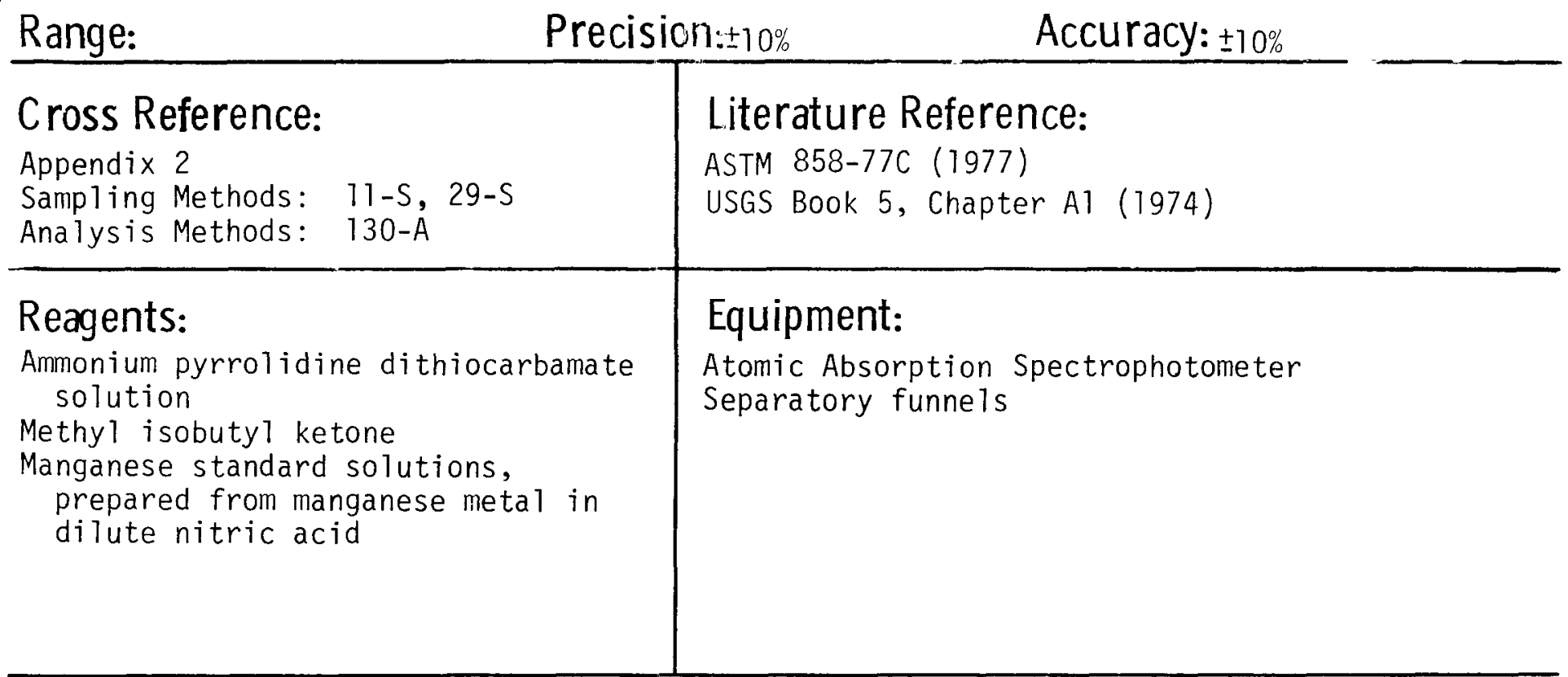

Remarks: 1. Extraction procedure improves sensitivity and helps to eliminate background interferences.

2. Use of standard additions recommended.

3. Alternatively, chloroform may be used as the extraction solvent, (ASTM D858-77C (1977)).

Edition: 
Manganese

Analysis: $X$-ray Fluorescence

$132-A$

Method: Liquid samples are made to fluoresce by $X$-ray bombardment. Secondary fluorescence is separated into wavelengths by a crystal and the radiation is detected by a scintillation counter or a flow proportional counter. A vacuum is required for the lighter elements. Standardization of instrument required.

Sample Handling: Use filtered acidified, raw unacidified or filtered unacidified brine.

Range:

Precision:

Accuracy:

Cross Reference:

Appendix 2

Sampling Methods: 11-S, 29-S

Reagents:

Manganese standards
Literature Reference:

Nuc. Inst. and Methods, Vol. 106, pp. 525-538

$(1973)$.

Equipment:

$X$-ray fluorescence spectrophotometer

\section{Remarks:}

\section{Edition:}


Manganese

Analysis: Inductively Coupled Plasma-

Atomic Emission Spectroscopy

No. $133-\mathrm{A}$

Method: The brine sample is aspirated into a radiofrequency generated argon plasma and the intensity of the emission spectrum of manganese is analyzed by the instrument and compared with standards. Intensity is measured at $257.61 \mathrm{~nm}$ or alternate wavelength.

Sample Handling: Use raw or filtered acidified brine.

3-5 orders of magnitude from a

Range: single spectral line. Precision: $\pm 1-10 \%$ Accuracy:

Cross Reference:

Literature Reference:

"Evaluation of an Inductively Coupled Plasma,

Appendix 2

Sampling Methods: 11-\$, 29-S

Multichannel Spectrometric Analys is System", EPA-600/4-77-032, June 1977.

\section{Reagents:}

Manganese standard solution, prepared

from metaliic manganese and dilute nitric acid

\section{Equipment:}

Inductively coupled plasma-

atomic emission spectrometer

Remarks: 1. NaCl matrix of samples and standards should be matched to minimize differences in solution properties which can affect vaporization characteristics.

2. This spectrometer allows simultaneous analys is of several metal cations.

3. Background correction and standard additions method recommended.

4. Upper limit of concentration range may be extended by using alternate spectral lines. 
5. Additional references: R. H. Scott and M. L. Kokot, "Application of Inductively Coupled Plasmas to the Analysis of Geochemical Samples", Ana 1. Chim. Acta 75, 257-270 (1975). 
Manganese

Analysis: Spark Source Mass Spectrometry

No. $134-\mathrm{A}$

Method: Dehydrated brine sample is vaporized and ionized by an arc source and enters an evacuated chamber. Manganese is separated and detected by its massicharge ratio and determined quantitatively by comparison with standards.

Sample Handling: Use raw or filtered acidified brine.

Range: $\quad 0.1-1000 \mathrm{mg} / 1 \quad$ Precision: $\pm 25 \%$ Accuracy: $\pm 25 \%$

\section{Cross Reference:}

\section{Appendix 2}

Sampling Methods: 11-5, 29-5

\section{Reagents:}

Solid manganese standard sample
Literature Reference:

Trace Analys is by Mass Spectrometry, A.J. Aheard, ed. Academic Press, NY (1977).

D.L. Donohue, J.A. Carter and J.C. Frankiin, Anal. Letters, 10(5) 371-379 (1977).

\section{Equipment:}

Spark source mass spectrometer

Remarks: Several elements of interest may be analyzed simultaneously with this instrumentation.

Edition: 
Analysis: Neutron Activation

No. $135-\mathrm{A}$

Method: Dehydrated sample is irradiated by neutron bombardment to form radioactive manganese isotopes. The beta and gamma spectra are analyzed by a multichannel analyzer; peak heights are proportional to the amount of manganese present.

Sample Handling: Filter brine on site. Evaporate sample and irradiated residue with neutron source.

Range:

Precision:

Accuracy:

\section{Cross Reference:}

Appendix 2

Sampling Methods: 11-S, 29-S

Reagents:

Standards containing manganese
Literature Reference:

Robertson, D.E. \& Carpenter, R., "Neutron Activation Techniques for the Measurement of Trace Metals in Environmental Samples", NAS-NS-3114, Jan. 1974.

\section{Equipment:}

Reactor

Multichannel analyzer

Remarks: Sufficient time (several days) must be allowed for sodium decay if the sodium spectrum masks the element of interest. other elements may be determined simultaneously with manganese. 
Manganese

Analysis: Emission Spectrometry

136-A

Method: The brine sample in either solid or liquid state is vaporized using a flame, $d-c$ arc, or a-c spark and the intensity of the selected manganese emission line is measured agairist standards .

Sample Handling: Use raw or filtered acidified brine. Evaporation to dryness may be required.

Range: $\quad 0.06-2 \mathrm{mg} / 1 \quad$ Precision: $\pm 10 \% \quad$ Accuracy:

\section{Cross Reference:}

Appendix 2

Sampling Methods: 11-5, 29-S

\section{Reagents:}

Manganese standards

Vanadium internal standard

\section{Literature Reference:}

Instrument Manufacturer's Literature

\section{Equipment:}

Emission spectrometer

Photo processor

Microphotometer

Remarks: 1. Use matrix matching, standard additions, and background correction whenever possible.

2. Large differences in matrix effects will be observed depending on the type of excitation source (flame, AC spark, or DC arc).

Edition: 
Mercury

Analysis: Cold Vapor Atomic Absorption

\begin{tabular}{l|l}
\hline No. & $137-\mathrm{A}$ \\
\hline
\end{tabular}

Method: Mercury is oxidized to its $\mathrm{Hg}$ (II) state, then reduced to elemental mercury. The mercury vapor is circulated through a cell in an atomic absorption instrument and the absorption of the mercury resonance 1 ine at $253.7 \mathrm{~nm}$ is measured.

Sample Handling: Use filtered acidified or raw acidified brine.

Range: $0.05-10 \mu \mathrm{g} / 7$

Precision: $\pm 70 \%$

Accuracy:

$\pm 10 \%$

\section{Cross Reference:}

Appendix 2

Sampling Methods: 11-S, 18-S, 29-5

\section{Reagents:}

Nitric acid

Hydrochloric acid

Potassium permanganate

Sodium chloride

Hydroxylamine sulfate

Stannous chloride

Mercuric chloride

Potassium persulfate

Sulfuric acid
Literature Reference:

ASTM D3223-73 (1977)

EPA 71900 (?:276)

APHA 301 A (1976)

\section{Equipment:}

Atomic absorption spectrophotometer or equivalent cold vapor mercury analyzer to measure at $253.7 \mathrm{~nm}$. Woodr iff Furnace (option)

Remarks: 1. Certain volatile organic materials absorb at $253.7 \mathrm{~nm}$. If this is suspected the sample should be analyzed without addition of stannous chloride (under oxidizing conditions). Obtain true value by difference between this value and reducing condition (with stannous chloride).

2. Additional permanganate (up to $25 \mathrm{ml}$ ) may be needed to overcome high chloride and sulfide values in brines.

3. High copper concentrations can cause interference. 
4. When using Woodriff Furnace an organic vapor trap apparatus is used due to high salt content. This allows for volatilization of any $\mathrm{Hg}$ in the sample without salt carryover to the graphite sample collection cup where the $\mathrm{Hg}$ is collected on a gold substrate. 
Analysis: X-Ray Fluorescence \begin{tabular}{|l|l|l}
\hline No. & $138-A$
\end{tabular}

Method: Liquid samples are made to fluoresce by $X$-ray bombardment. Secondary fluorescence is separated into wavelengths by a crystal and the radiation is detected by a scintillation counter or a flow proportional counter. A vacuum is required for the lighter elements. Standardization of instrument required.

Sample Handling: Use filtered acidified, raw unacidified, or filtered unacidified brine.

Range:

Precision:

Accuracy:

Cross Reference:

Appendix 2

Sampling Methods: 11-S, 18-5, 29-5

\section{Reagents:}

Mercuric chloride or other mercury s.tandard.

\section{Literature Reference:}

Nuc. Inst. and Methods, Vol. 106, pp. 525-538 $(1973)$.

\section{Equipment:}

$X$-ray fluorescence spectrophotometer

Remarks: Detection 1imit 1-5 ppm not sensitive for water samples without much preconcentration, sample would have to be evaporated or ion exchanged. 
Mercury

Analysis: Neutron Activation

139-A

Method: Sample is exposed to neutron source (reactor) and radioactive mercury isotopes are formed. The isotopes and their associated beta and gamma spectra are identified by multichannel analyzers. The amount of mercury present is proportional to the measured activity.

Sample Handling: Use raw acidified or filtered acidified brine. Evaporate samples and irradiate residue with neutron source.

Range:

Precision:

Accuracy:

\section{Cross Reference:}

Appendix 2

Sampling Methods: 11-S, 18-S, 29-S

\section{Literature Reference:}

Robertson and Carpenter, "Neutron Activation Techniques for the Measurement of Trace Metals in Environmental Samples", NAS-NA-3114, Jan. 1974.

\section{Reagents:}

\section{Equipment:}

Reactor (neutron source)

Multichannel analyzer

Remarks: 1. Sufficient time must be allowed for sodium decay if the sodium spectrum masks the element of interest.

2. Since mercury is a volatile element, evaporation to complete dryness may volatilize mercury (Rowe, Fournier, and Morey, 1973, USGS Bulletin \#1303).

Edition: 


\section{$\mathrm{Hg}$}

Mercury

Analysis: Emission Spectrometry

No. $140-A$

Method: The sample containing mercury in either solid or liquid state is vaporized by a flame, $d-c$ arc, or a-c spark and the intensity of the selected emission line is measured against standards.

Sample Handling: Use filtered acidified or raw acidified brine.

Range:

Cross Reference:

Appendix 2

Sampling Methods: 11-S, 18-5, 29-S
Precision:

Accuracy:

\section{Literature Reference:}

Instrument Manufacturer's Literature

Equipment:

Emission spectrometer

Mercury standards

Remarks: 1. Large differences in matrix effects will be observed depending on the type of excitation source (flame, AC spark, or DC arC).

Edition: 


\section{$\mathrm{pH}$}

$\mathrm{pH}$

Analysis: $\mathrm{pH}$ meter

No. $141-\mathrm{A}$

Method: The pH of a solution is determined by measuring the potential of the solution between glass and reference electrodes. The $\mathrm{pH}$ may be determined in batch form with dip type electrodes or flow-through form using flowthrough cells.

Sample Handling: Use RU. Analyze within 6 hours of sampling. Record temperature of sample at time of $\mathrm{pH}$ measurement.

Range: $0-14 \mathrm{pH}$ units Precision: $\pm 1 \%$ Accuracy: $\pm 1 \%$

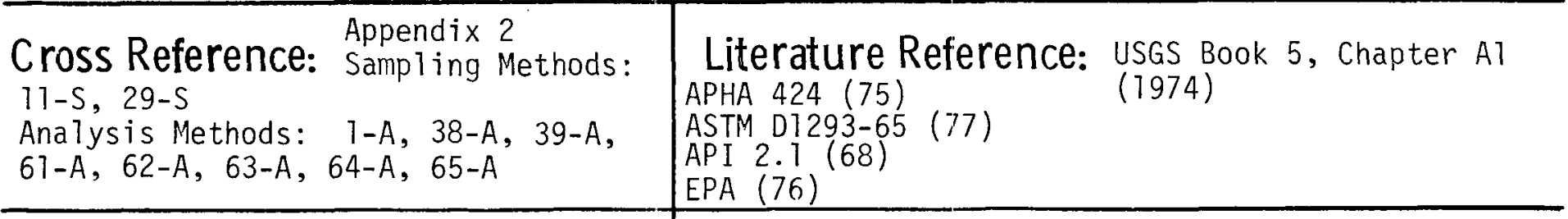

Reagents:

Distilled water $\mathrm{pH}$ buffers

\section{Equipment:}

$\mathrm{pH}$ meter

Glass electrode

Reference electrode

Remarks: 1. Interferences: temperature must be controlled, glass electrode suffers from $\mathrm{Na}$ ion interference at high $\mathrm{pH}$ and acid interference at low $\mathrm{pH}$, poorly buffered sample difficult to analyze (unless flow-through is used), oil and grease coat electrodes, no interferences from color, turbidity, oxidants, reductants or colloidal matter.

2. Field analysis on fresh raw brine strongly recommended; commercial field

Edition: $\mathrm{pH}$ meters available. Avoid loss or interchanges of gases.

3. Record sample temperature at time of $\mathrm{pH}$ measurement.

(cont. on back) 
4. Oxidation of various ions such as iron or manganese can influence $\mathrm{pH}$.

5. The reaction $2 \mathrm{HCO}_{3}^{-} \rightarrow \mathrm{H}_{2} \mathrm{O}+\mathrm{CO}_{2}+\mathrm{CO}_{3}{ }^{-}$increases $\mathrm{pH}$. 
Phosphate

Analysis: Colorimetric (Stannous Chloride)

$142-A$

Method: In acid solution molybdate is added to form molybdophosphoric acid which

is reduced to the molybdenum blue complex by stannous chloride.

Sample Handling: Use filtered unacidified or raw unacidified brine.

Range: $2-25 \mathrm{mg} / 1 \quad$ Precision: $\pm 26 \% \quad$ Accuracy: $\pm 29 \%$

Cross Reference:

Appendix 2

Sampling Methods: $11-\mathrm{S}, 29-\mathrm{S}$

Analysis Methods: 143-A, 144-A

\section{Reagents:}

Sulfuric acid

Phenolphthalein indicator

Ammonium molybdate

Potassium dihydrogen phosphate

Nitric acid

Stannous chloride

\section{Literature Reference:}

APHA 425 E (1975)

\section{Equipment:}

Spectrophotometer to measure at $690 \mathrm{~nm}$.

Remarks: 1. Increased sensitivity can be achieved or interferences can be overcome by benzene-isobutanol solvent - molybdate reagent extraction and further treatment as described in APHA $425 \mathrm{E}$ (1975).

2. A preliminary digestion with ammonium persulfate allows for conversion of other phosphate forms to ortho phosphates which allows analyst to use this test for total phosphates (APHA $425 \mathrm{C}$ (1975)). A precipitate may form during this digestion but it will not interfere with the analysis.

$$
\text { (cont. on back) C-146 }
$$


3. Alternatively the orthophosphate phosphorous is extracted selectively as phosphomolybdic acid into methyl isobutyl ketone from a $2 \mathrm{M} \mathrm{HClO}$ medium. The yellow complex is then reduced to the molybdenum blue complex and measured at $625 \mathrm{~nm}$.

4. Arsenic can be a significant interference unless it is reduced first. 
Phosphate

Analysis: Colorimetric (Ascorbic Acid Reduction)

No. $143-\mathrm{A}$

Method: Orthophosphate reacts with ammonium molybdate and Sb-K tartrate to form an antimony phosphate tartrate complex which is reduced by ascorbic acid to a blue molybdenum complex. The complex is measured colorimetrically at 880 or $625-650 \mathrm{~nm}$.

Sample Handling: Use filtered unacidified or raw unacidified brine.

Range: $\quad 0.03-40 \mathrm{mg} / \mathrm{l}$ Precision: $\pm 10 \% \quad$ Accuracy: $\pm 70 \%$

Cross Reference:

Appendix 2 Sampling Methods: 11-S, 29-S

Analysis Methods: 142-A, 144-A

Reagents:

Sulfuric acid

Antimony potassium tartrate

Ammonium molybdate

Ascorbic acid

Potassium di.hydrogen phosphate

Literature Reference:

APHA $425 \mathrm{~F}$ (1975)

ASTM D515-72 A (1977)

EPA 70507 (1976)

USGS Book 5, Chapter A1 (1974)

\section{Equipment:}

Spectrophotometer or auto analyzer to measure at $880 \mathrm{~nm}$ or $625-650 \mathrm{~nm}$.

Remarks: 1. A preliminary digestion with ammonium persulfate allows for conversion of other phosphate forms to ortho phosphates which allows analyst to use this test for total phosphates (APHA 425 C (1975)).

2. A modification using an amino reduction in place of ascorbic acid (ASTM D515-72B) allows for a fourfold increase in color intensity.

3. Silica, arsenic and ferric ions cause interference.

4. Alternatively the reduction may be accomplished using amino-naphthotsulfuric acid (Anal. Chem. 32824 (1960)).

$$
\text { (cont, on back) C-147 }
$$


Analysis: Modified Molybdophosphoric Acid Analysis: Spectrophotometric Method

$144-A$

Method: Orthophosphate and molybdate react in acidic solution to give a yellow color of molybdophosphoric acid. The molybdophosphoric acid is extracted with $20 \%$ by volume of 1-butanol in chloroform and the resultant extract measured at a wave length of $310 \mathrm{~nm}$.

Sample Handling: Use filtered unacidified brine.

\begin{tabular}{|c|c|c|}
\hline \multicolumn{2}{|c|}{ Precisiol } & \multirow{2}{*}{$\begin{array}{l}\mathrm{n}: \quad \pm 30 \% \text { Accuracy: } \quad \pm 30 \% \\
\text { Literature Reference: } \\
\text { D. F. B01tz, "Colorimetric Determination of Non- } \\
\text { Metals", Interscience Publishers, Inc., New York, } \\
1958, \text { pp. 38-39. }\end{array}$} \\
\hline $\begin{array}{l}\text { Cross } F \\
\text { Appendi } \\
\text { Samp lin } \\
\text { Ana Tysi }\end{array}$ & $\begin{array}{l}\text { Reference: } \\
2 \\
\text { Methods: } 11-S, 29-\mathrm{S} \\
\text { Methods: } 142-\mathrm{A}, 143-\mathrm{A}\end{array}$ & \\
\hline \multicolumn{2}{|c|}{ Reagents: } & Equipment: \\
\hline \multicolumn{2}{|c|}{$\begin{array}{l}\text { Potassium dihydrogen phosphate reagent } \\
\text { grade } \mathrm{KH}_{2} \mathrm{PO}_{4} \\
\text { Sodium mo } \mathrm{mobdate} \text { ybagent grade } \\
\mathrm{Na}_{2} \mathrm{MoO}_{4} \cdot 2 \mathrm{H}_{2} \mathrm{O} \\
\text { l-Butanol - reagent grade } \\
\text { Chloroform reagent grade }\end{array}$} & $\begin{array}{l}\text { Spectrophotometer for use at } 310 \mathrm{~nm} \\
\text { Absorption cells } 1 \mathrm{~cm} \text { light path }\end{array}$ \\
\hline
\end{tabular}

Remarks: The selective extraction of molybdophosphoric acid eliminates interference due to silicate, arsenate, and germanate.

Edition: 
Analysis:

$X$-Ray Fluorescence

$145-A$

Method: Liquid samples are made to fluoresce by $X$-ray bombardment. Secondary fluorescence is separated into wavelengths by a crystal and the radiation is detected by a scintillation counter or a flow proportional counter. A vacuum is required for the iighter elements. Standardization of instrument required.

Sample Handling: Use filtered acidified, raw unacidified or filtered unacidified brine.

Range:

Precision:

Accuracy:

\section{Cross Reference:}

Append $\mathrm{ix} 2$

Sampling Methods: 11-S, 18-S, 29-S

\section{Reagents:}

Potassium dihydrogen phosphate or other phosphate standard

\section{Literature Reference:}

Nuc. Inst. and Methods, Vol. 106, pp. 525-538, (1973).

\section{Equipment:}

$X$-ray fluorescence spectrophotometer

Remarks: 1. Analysis gives result as phosphorous concentration. To obtain the phosphate concentration multiply by the gravimetric factor $\frac{\mathrm{PO}_{4}}{\mathrm{P}}$
(i.e., $\left[\mathrm{PO}_{4}{ }^{-3}\right]=[\mathrm{P}] \times 3.07$ ).

\section{Edition:}


Phosphate

Analysis: Inductively Coupled Plasma-Atomic Emission Spectroscopy $146-A$

Method: Sample is aspirated into the argon plasma and the intensity of the emission spectrum is analyzed and compared with standards. Intensity is measured at $213.62 \mathrm{~nm}$.

Sample Handling: Use filtered acidified or raw acidified brine.

3-5 orders of magnitude from

Range: a single spectra? 1ine. Precision: $\pm 1-10 \%$

Accuracy:

\section{Cross Reference:}

Appendix 2

Sampling Methods: 11-S, 29-S

\section{Literature Reference:}

Evaluation of an Inductively Coupled Plasma, Multichannel Spectrometric Analys is System, EPA-600/4-77-032, June 1977.

\section{Reagents:}

\section{Equipment:}

Potassium dihydrogen phosphate or other Inductively coupled plasma-atomic emission phosphate standard spectrometer

Remarks: 1. External standards using $\mathrm{NaCl}$ concentrations equivalent to sample concentrations of $\mathrm{NaCl}$ are required.

2. Additional references: R. H. Scott and M. L. Kokot, "Application of Inductively Coupled Plasmas to the Analys is of Geochemical Samples", Ana7. Chim. Acta 75, 257-270 (1975).

Edition:

3. Background correction and standard additions method recommended.

(over) 
4. Analysis gives result as phosphorous concentration. To obtain the phosphate corcentration multiply by the gravimetric factor $\frac{\mathrm{PO}_{4}}{\mathrm{p}}$ (i.e., $\left[\mathrm{PO}_{4}^{-3}\right]=[\mathrm{P}] \times 3.07$ ). 
Phosphate

Analysis: Spark Source Mass Spectrometry

\begin{tabular}{|l|l|l|}
\hline No. & $147-\mathrm{A}$
\end{tabular}

Method: Dehydrated sample is vaporized and ionized by an arc source and enters an evacuated chamber. Phosphorous is separated and detected by its mass/charge ratio, and determined quantitatively by comparison with standards.

Sample Handling: Use filtered acidified, raw acidified, filtered unacidified, or raw unacidified brine. Evaporate brine samples and analyze residue.

Range: $0.1-1000 \mathrm{mg} / 1$

Precision: $\pm 25 \%$

Accuracy: $\pm 25 \%$

\section{Cross Reference:}

Appendix 2

Sampling Methods: $11-5,29-5$
Literature Reference:

Trace Analys is by Mass Spectrometry, A.J. Aheard, ed., Academic Press, NY (1977).

D.L. Donohue, J.A. Carter and J.C. Franklin, Anal. Letters, 10(5) 377-379 (1977).

\section{Equipment:}

Spark source mass spectrometer

Potassium dihydrogen phosphate or other phosphate standard

Remarks: 1. Analysis gives result as phosphorous concentration. To obtain the phosphate concentration multiply by the gravimetric factor $\frac{\mathrm{PO}_{4}}{\mathrm{P}}$
(i.e., $\left.\left[\mathrm{PO}_{4}{ }^{-3}\right]=[\mathrm{P}] \times 3.07\right)$.

Edition:

$7 / 78$ 
Potassium

Analysis: Specific Ion Electrode $148-A$

Method: A potassium specific electrode is used to measure potassium ion activity in a solution of $\mathrm{pH} \mathrm{1-12.}$

Sample Handling: Use raw unacidified, filtered unacidified, raw acidified or filtered acidified brine.

Range: $>0.04 \mathrm{mg} / 1 \quad$ Precision:

Accuracy:

Cross Reference:

Appendix 2

Sampling Methods: 11-S, 29-S

Analysis Methods: 182-A

\section{Reagents:}

Potassium standard solutions or potassium chloride Sodium chloride
Literature Reference:

orion Research Inc., Literature

Equipment:

Potassium specific ion electrode Specific ion meter

Magnetic stirrer

Reference electrode compatible with potassium electrode.

Remarks: 1. Easily adapted for field measurement.

\section{Edition:}


Potassium

Analysis: Atomic Absorption

No. $149-\mathrm{A}$

Method: Potassium is determined by aspirating the sample into an air-acetylene flame of an atomic absorption spectrophotometer. The intensity of the potassium absorbance at $766.5 \mathrm{~nm}$ is measured and is proportional to the potassium concentration.

Sample Handling: Use filtered acidified or raw acidified brine.

Range: (1inear) $0.05-2 \mathrm{mg} / 1$ Precision: $\pm 5 \%$

Accuracy: $\pm 10 \%$

Cross Reference:

Appendix 2

Sampling Methods: 11-S, 29-S

Analys is Methods: $150-A$

Reagents:

Potassium atomic absorption

standard solution or potassium

chloride

Sodium chloride

Cesium chloride or cesium nitrate

\section{Literature Reference:}

Instrument Manufacturer's Std. Methods Manual EPA 00937 (1976)

USGS Book 5 , Chapter A 1 (1974)

ASTM D3567-77 (7977)

\section{Equipment:}

Atomic absorption spectrophotometer

Remarks: 1. Ionization in air-acetylene flame can be suppressed by the addition of cesium nitrate or cesium chloride to give $1000 \mathrm{ppm}$ Cs in all solutions.

2. Careful matrix matching between sample and standards must be made (i.e. using same amounts of $\mathrm{NaCl}$, other alkali metal and alkaline earth metal ions).

Edition:

3. On some AA spectrophotometers a red filter is used to reduce background radiation. 
4. If sample shows Tyndall effect, filter through $0.45 \mu \mathrm{m}$ membrane filter.

5. $1 \%$ strontium $w t / v o l$ is also effective in suppressing ionization.

6. Us̄e of standard additions recommended. 
Potassium

Analysis: Flame Emission

No. $150-A$

Method: Potassium is determined by aspirating the sample into an air-acetylene

flame and the emission intensity at $766.5 \mathrm{~nm}$ from potassium is measured

by a spectrophotometer. Alternatively, the intensity at $4.04 .4 \mathrm{~nm}$ may

be measured.

Sample Handling: Use filtered acidified or raw acidified brine. Sample may be stabilized by diluting with 9 parts distilled water and adding $5 \mathrm{ml} \mathrm{HNO}_{3}$ per liter of sample.

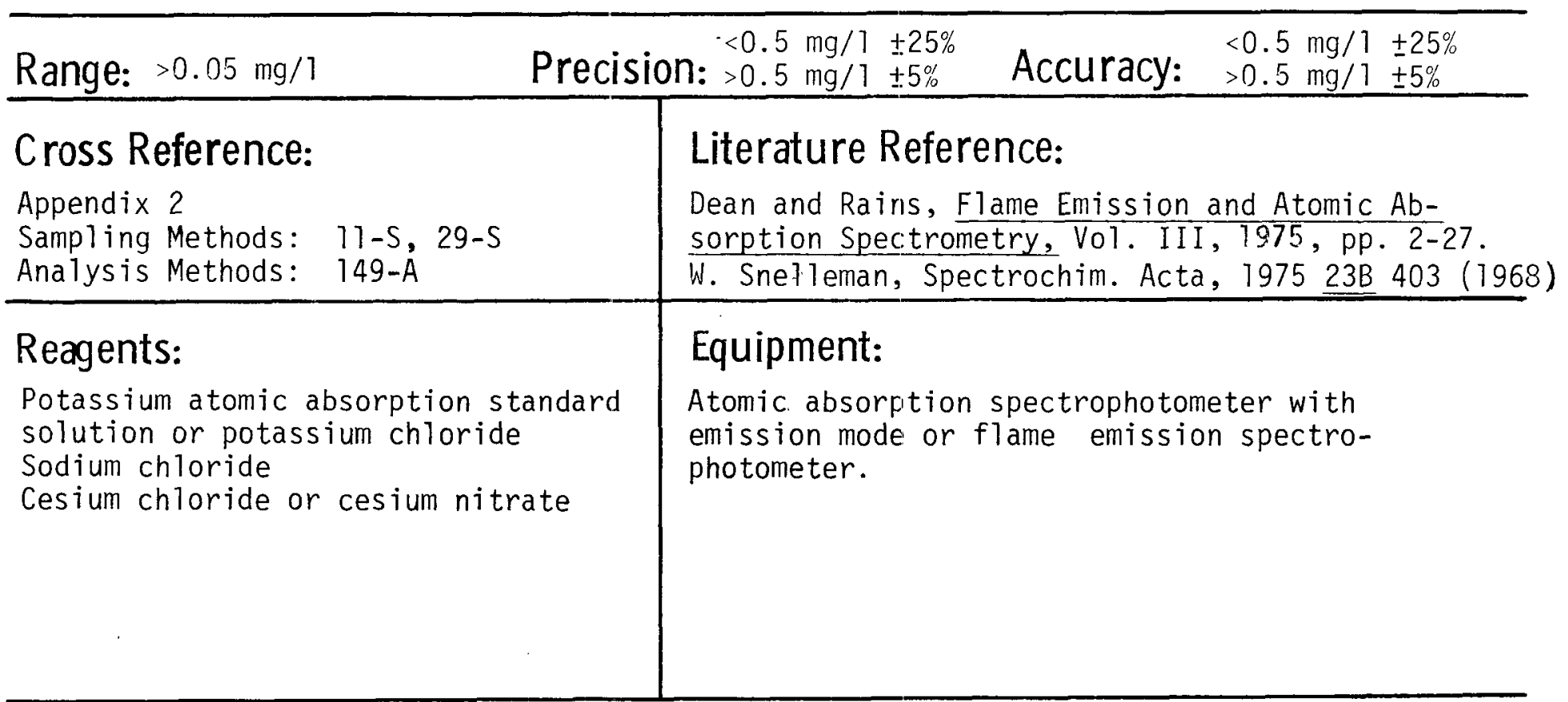

Remarks: 1. Ionization of potassium in an air-acetylene flame is suppressed by the addition of $1000 \mathrm{ppm}$ cesium.

2. Careful matrix matching between sample and standards is necessary (especially sodium chloride).

3. On some AA spectrophotometers a red filter is used to reduce background radiation.

Edition:

$7 / 78$

4. $1 \%$ strontium wt/vol is also effective in suppressing ionization.

5. Use of standard additions recommended. 


\section{K}

Potassium

Analysis: X-Ray Fluorescence

No. $151-\mathrm{A}$

Method: Liquid samples are made to fluoresce by $X$-ray bombardment. Secondary

fluorescence is separated into wavelengths by a crystal and the radiation

is detected by a scintillation counter or a flow proportional counter.

A vacuum is required for the lighter elements. Standardization of

instrument required.

Sample Handling: Use filtered acidified, raw unacidified, or filtered unacidified brine.

Range:

Precision:

Accuracy:

Cross Reference:

Appendix 2

Sampling Methods: 11-S, 29-S

Reagents:

Potassium chloride or other potassium standard

\section{Literature Reference:}

Nuc. Inst. and Methods, Vo1. 106, pp. 525-538 $(1973)$.

\section{Equipment:}

$X$-ray fluorescence spectrophotometer

\section{Remarks:}


Analysis: Inductively Coupled Plasma-Atomic Analysis: Emission Spectroscopy

No. $152-\mathrm{A}$

Method: Sample is aspirated into the argon plasma and the intensity of the emission spectrum is analyzed and compared with standards.

Sample Handling: Use filtered acidified or raw acidified brine.

Range: Precision:

Accuracy:

Cross Reference:

Appendix 2

Sampling Methods: 11-S, 29-5

\section{Reagents:}

Potassium chloride or other potassium standard
Literature Reference:

Evaluation of an Inductively Coupled Plasma, Multichannel Spectrometric Analys is System, EPA-600/4-77-032, June 1977.

\section{Equipment:}

Inductively coupled plasma-atomic emission spectrometer.

Remarks: 1. External standards using $\mathrm{NaCl}$ concentrations equivalent to sample concentrations of $\mathrm{NaCl}$ are required.

2. Additional references: R. H. Scott and M. L. Kokot, "Application of Inductively Coupled Plasmas to the Analysis of Geochemical

Samples", Ana 7. Chim. Acta 75, 257-270 (1975).

Edition:

3. Background correction and standard additions method recommended.

$7 / 78$ 
Potassium

Analysis: Ion Exchange Chromatography

No. $153-\mathrm{A}$

Method: Ion components are separated on sulfonated polymer based columns. A solution of nitric acid is used to elute potassium from the column.

The separation column is followed by a suppressor column which removes high background conductivity due to the solvent. Ions are detected with a conductivity detector.

Sample Handling: Use raw unacidified, filtered unacidified, or filtered acidified brine.

Range:

Precision: $\pm 7.24 \%$

Accuracy: $\pm 5 \%$

\section{Cross Reference:}

Appendix 2

Sampling Methods: 11-S, 29-S

\section{Reagents:}

Potassium chloride or other potassium standard

Nitric acid

\section{Literature Reference:}

Dionex Corp., Sunnyvale, CA, Literature

Ana 1. Chem., 47 (11), 1801 (1975).

Microchem. J., 22, 45 (1977).

Anal. Chem., $49(3), 401$ (1977).

\section{Equipment:}

Ion exchange chromatograph

Remarks: 1. High rubidium concentrations cause interference because rubidium elutes at the same time as potassium.

2. Additional reference: Sma11, H., T. S. Stevens and W. C. Bauman, Anal. Chem., 471801 (1975). 
Analysis: Spark Source Mass Spectrometry $154-\mathrm{A}$

Method: Dehydrated sample is vaporized and ionized by an arc source and enters an evacuated chamber. Potassium is separated and detected by its mass/charge ratio, and determined quantitatively by comparison with standards.

Sample Handling: Use filtered acidified, raw acidified, filtered unacidified or raw unacidified brine. Evaporate samples and analyze residue.

Range: $\quad 0.1-1000 \mathrm{mg} / 1$ Precision: $\stackrel{ \pm 2 \% \%}{ \pm 25 \%}$ (isotope dil. Accuracy: $\underset{ \pm 25 \%}{ \pm 2 \%}$ (isotope dil.)

\section{Cross Reference:}

Appendix 2

Sampling Methods: $11-5,29-5$

\section{Reagents:}

Potassium chloride or other potassium standard.

\section{Literature Reference:}

Trace Analys is by Mass Spectrometry, A.J. Aheard, ed., Academic Press, NY (1977).

D.L. Donohue, J.A. Carter and J.C. Frank1in, Ana1. Letters, 10(5) 37i-379 (1977).

\section{Equipment:}

Spark source mass spectrometer

Remarks: 1. Additional references: J. A. Carter, D. L. Donohue, and J. C. Franklin, Trace Substances in Environmental Health-IX. U. of Missouri, 303 (1975). J. C. Franklin, J. A. Carter, D. L. Donohue, and R. W. Stelzner, 23d Conf. on Mass Spectrometry and Allied Topics, Houston, TX 354 (1975). R. Alvarez, B.J. Paulsen, and D.E. Kelleher, Anal. Chem. 41955 (1969).

Edition: 
Potassium

Analysis: Neutron Activation

$155-A$

Method: Sample is exposed to neutron source (reactor) and radioactive potassium isotopes are formed. The isotopes and their associated beta and gamma spectra are identified by multichannel analyzers. The amount of potassium present is proportional to the measured activity.

Sample Handling: Use raw acidified or filtered acidified brine. Evaporate samples and irradiate residue with neutron source.

Range:

Precision:

Accuracy:

\section{Cross Reference:}

Appendix 2

Sampling Methods: 11-S, 29-S

\section{Literature Reference:}

Robertson and Carpenter, "Neutron Activation Techniques for the Measurement of Trace Metals in Environmenta1 Samples", NAS-NS-3114, Jan. 1974.

\section{Reagents:}

\section{Equipment:}

Reactor (neutron source)

Multichannel analyzer

Remarks: Sufficient time must be allowed for sodium decay if the sodium spectrum masks the element of interest. 
Potassium

Analysis: Emission Spectrometry

$156-A$

Method: The sample containing potassium in either solid or liquid state is vaporized by a flame, $d-c$ arc, or a-c spark and the intensity of the selected emission line is measured against standards.

Sample Handling: Use filtered acidified or raw acidified brine.

Range: $\begin{aligned} & \text { Dilute to } \\ & \text { s } 7.0 \mathrm{mg} / 1\end{aligned}$

Precision:

Accuracy:

Cross Reference:

Literature Reference:

Appendix 2

Sampling Methods: 11-S, 29-S

Instrument Manufacturer's Literature

Reagents:

Equipment:

Potassium chloride or other potassium standard

Emission spectrometer

Remarks: 1. Some flames (e.g. $\mathrm{O}_{2}-\mathrm{H}_{2}-\mathrm{N}_{2}$ ) may not be hot enough to vaporize completely the aerosols from solutions with high solids contents.

2. Reference standards should contain as high a salt content as unknowns.

3. Large differences in matrix effects will be observed depending on the type of excitation source (flame, AC spark, or DC arc).

Edition:

$7 / 78$ 


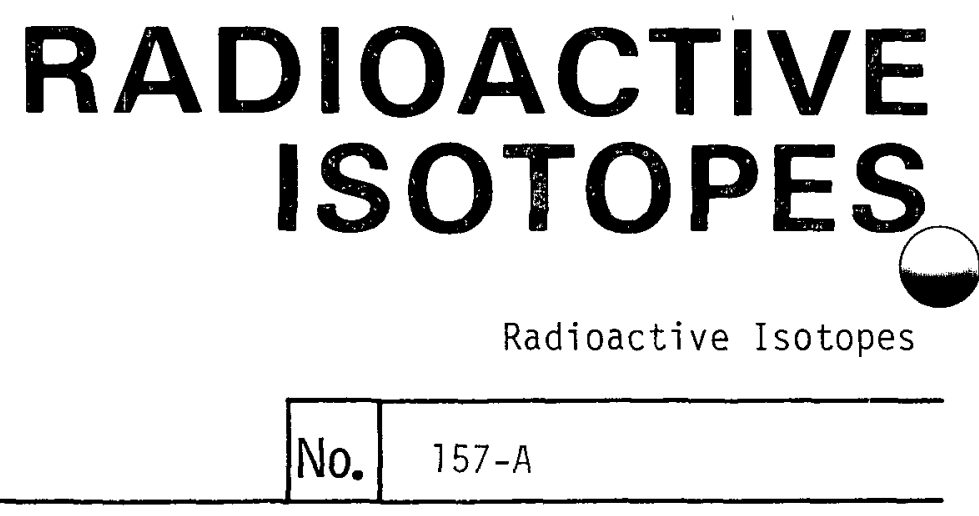

Analysis: Gamma Spectrometry

No. 157-A

Method: Raw unacidified brine is put in a Merinelli flask which is placed on a gamma detector. Peak energies and areas are analyzed by a computer program and compared with values obtained with radioactive standards.

Sample Handling: Use raw unacidified brine.

Range: Precision:

Accuracy:

Cross Reference:

Appendix 2

Sampling Methods: 11-S, 29-5

Reagents:

Nuclear reference solutions

\section{Literature Reference:}

Procedures Manual

Health and Safety Lab, ERDA-NY HASL-300

\section{Equipment:}

Gamma detector system [Ge(Li)-semiconductor]

Multichannel analyzer

Merinelli flask

Planchet for solid residue

Remarks: Precipitates are analyzed by filtering the samples and analyzing the residue on planchets.

Edition: 


\section{RADIOACTIVE \\ ISOTOPES}

Radioactive Isotopes

Analysis: Lead-210

No. $158-\mathrm{A}$

Method: $\quad \mathrm{Bi}-210$ daughter is chemically separated from the $\mathrm{Pb}-210$ parent and other contaminants and is measured by beta counting on a low-background beta counter.

Sample Handling: Use raw unacidified brine. Solutions are made acid to a $\mathrm{pH}$ of 1 with $\mathrm{HNO}_{3}$ and allowed to equilibrate with stable carriers.

Range: $>0.1$ (1 iter sample)

Range: $>0.1 \mathrm{pci} / \mathrm{ml} \quad$ Precision: $\pm 10 \% \quad$ Accuracy: $\pm 20 \%$

Cross Reference:

Literature Reference: 1. "Collected Radiochem-

Appendix 2

Sampling Methods: 11-S, 29-S

ical Procedures", edited by Helen L. Smith; LA-172T, 4th Ed.; UC-4, Chemistry Issued: April 1975.

2. W. M. Gibson, "The Radiochemistry of Lead", NAS-NS 3040, Auqust 1961.

Reagents:

Standardized $\mathrm{Bi}$ carrier

Pb carrier $(10 \mathrm{mg} / \mathrm{ml})$

Thioacetamide

Normal acids and bases of varying molarities

\section{Equipment:}

Normal glassware

Hot water bath

Centrifuge

Filtering apparatus

Low-background beta proportional counter

\section{Remarks:}

\section{Edition:}




\section{RADIOACTIVE \\ ISOTOPES}

Radioactive Isotopes

Analysis: Ra-226 (Radon Emanation Method)

No. $159-\mathrm{A}$

Method: Radium is concentrated and separated by coprecipitation with barium sulfate.

Precipitate is treated to remove silicates, to decompose insoluble radium compounds, and treated to remove $\mathrm{SO}_{3}$. Precipitate is dissolved in $\mathrm{HCl}$ and placed in a bubbler to allow for racion growth. $\mathrm{Rn}-222$ is removed from the solution by aeration, transferred to a scintillation cell and counted with an alpha scintillation counter. The amount of $\mathrm{Rn}-222$ counted is proportional to the original amount of $\mathrm{Ra}-226$.

Sample Handling: Use fittered acidified, raw acidified, or raw unacidified brine.

Range: $>0.1 \mathrm{pCi} / 1$

Precision: $\pm 5 \%$

Accuracy: $\quad \pm 8 \%$

Cross Reference:

Appendix 2

Sampling Methods: 11-S, 17-5, 29-S

Analys is Methods: 160-A
Literature Reference:

APHA 705 (1975)

ASTM D3454-75T (1977)

Procedures Manual HASL-300 (1974)
Reagents:

Barium chloride

Hydrochloric acid

Stock Ra-226 sol' $n$.

Sulfuric acid

Hydrofluoric acid

Ammonium sulfate

Phosphoric acid

Ascarite

Magnesium perchlorate

EDTA-sodium salt
Potassium carbonate

Sodium carbonate

Sodium tetraborate

Hydrogen peroxide

Silicone grease

Sealing wax

Helium, nitrogen or air
Equipment:

Scintillation counter

Scintillation cells

Radon bubblers

Manometer

Gas purification tube

Sample bottles

Membrane filters

Platinum crucibles or dishes

Remarks: 1. Barium chloride should be checked for Ra-226 content (requires blank correction).

2. Alpha-emitting radionuclides $\mathrm{Rn}-219$ and $\mathrm{Rn}-220$ interfere.

3. An equilibration time of 4 hours must be allowed after Rn-222 transfer to the scintillation cell before the sample is counted.

Edition: 
Analysis: $\mathrm{Ra}-226$

No. $160-\mathrm{A}$

Method: Radium is carried on $\mathrm{Pb}$ and Ba carriers as the nitrates and sulfates; the $B a$ and $\mathrm{Ra}$ are selectively precipitated as the sulfate from EDTA solution; finally the Ba-Ra sulfate is dried on stainless steel and counted for alpha activity using disposable $\mathrm{Zn}-\mathrm{S}$ phosphors and a photo-multiplier counting system. Ba-133 is used for yield correction and decay counting is used for purity checks.

Sample Handling: Use raw unacidified brine. Solutions are made acid to $\mathrm{pH} 1$ using $\mathrm{HNO}_{3}$ and allowed to equilibrate with carriers and tracer.

Range: $>1 \times 10^{-3} \mathrm{pci} / \mathrm{ml}$ (1iter sample) Precision: $\pm 10 \% \quad$ Accuracy: $\pm 20 \%$

Cross Reference:

Appendix 2

Sampiing Methods: $11-5,29-5$

Analys is Methods: 159-A

\section{Reagents:}

$\mathrm{Ba}-133$ tracer

Ba carrier, $10 \mathrm{mg} / \mathrm{ml}$

$\mathrm{Pb}$ carrier, $10 \mathrm{mg} / \mathrm{ml}$

0.25 EDTA solution

$98 \% \mathrm{HNO}_{3}$

Normal 3 acids

\section{Literature Reference:}

(See remarks)

\section{Equipment:}

Hot water bath

Centrifuge

$15 \mathrm{ml}$ centrifuge cones

Gamma detection system (spectrometer or other)

Disposable $\mathrm{Zn}-\mathrm{S}$ phosphors

Ludlum-type alpha counter

Remarks: References

1. Radium-226 Analysis Principles, Interference and Practice, National Lead Co., Inc. WIN-112 February 1, 1960.

2. P. E. Trujillo, Jr., "Analytical Procedures for the Determination of Radionuclides in Air Filters, Water, and Soils", Los Alamos Scientific Laboratory, H8-MR-72-3 May, 1972.

ition: 3. Harley, J. R..Editor, "HASL Procedures Manual", Health and Safety Laboratory, HASL-

1/78 4. APHA 705 (1975), ASTM D2460-70 (1977).

$$
\text { (cont. on back) } \quad \text { - }-764
$$




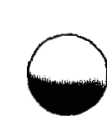

5. Large precipitates may form upon $\mathrm{H}_{2} \mathrm{SO}_{4}$ addition and may not completely dissolve in EDTA, This material should be analyzed separately for activity. 
Analysis: Thorium Isotopes

No. $161-\mathrm{A}$

Method: Thorium-234 tracer is equilibrated with thorium isotopes in the sample. All the thorium isotopes are carried on $\operatorname{Pr}$ as a fluoride and hydroxide and finally extracted into thenoyltrifluoro-acetene-xylene. The organic complex is dried on stainless steel plate and the thorium evaluated by absolute alpha measurement using solid-state, surface barrier detectors and alpha spectroscopy.

Sample Handling: Use raw unacidified brine. Solutions are made acid to a pH of 1 using $\mathrm{HNO}_{3}$ and allowed to equilibrate with carriers and tracers.

\begin{tabular}{|c|c|}
\hline $\begin{array}{l}\text { Cross Reference: } \\
\text { Appendix } 2 \\
\text { Sampling Methods: } 11-5,29-5\end{array}$ & $\begin{array}{l}\text { Literature Reference: } \\
\text { F. L. Moore, "Radiochemical Determination of } \\
\text { Ionium in Uranium Fluorination Ash", Ana 1. Chem. } \\
\underline{30}, 1020 \text { (1958). }\end{array}$ \\
\hline $\begin{array}{l}\text { Reagents: } \\
\text { Thorium- } 234 \text { tracer } \\
\text { Praseodymium, } 5 \mathrm{mg} / \mathrm{ml} \\
0.5 \text { Mthenoyltrifluoreacetone in xylene } \\
0.4 \mathrm{M} \mathrm{K}_{2} \mathrm{Cr}_{2} \mathrm{O}_{7} \\
2 \mathrm{MAl}\left(\mathrm{NO}_{3}\right)_{3} \\
\text { Normal acids and bases }\end{array}$ & $\begin{array}{l}\text { Equipment: } \\
\text { Vortex mixer } \\
40 \mathrm{ml} \text { screw-cap } \\
50 \mathrm{ml} \text { plastic centrifuge tubes } \\
\text { Centrifuge } \\
\text { Stainless steel plates } \\
\text { Surface barrier detectors and alpha spectrometer }\end{array}$ \\
\hline
\end{tabular}

\section{Remarks:}

Edition: 


\section{RADIOACTIVE ISOTOPES}

Radioactive Isotopes

Analysis: Uranium Isotopes

$162-A$

Method: Uranium-332 tracer is equilibrated with the isotopes of uranium in the sample. All of the uranium isotopes are chemically purified by anion exchange and extraction into hexone (methyl isobutyl ketone) which is dried on stainless steel. The uranium isotopes are measured by alpha spectroscopy using surface barrier detectors, and the sample activities evaluated by ratio to the tracer activity.

Sample Handling: Use raw unacidified brine. Solutions are made acid to a pH of 1 using $\mathrm{HNO}_{3}$ and allowed to equilibrate with the tracer.

Range $\times 1 \times 10^{-3}$ (liter sample)

Range: $>1 \times 10^{-3} \mathrm{pci} / \mathrm{ml}$ Precision: $\pm 10 \%$ Accuracy: $\pm 20 \%$

\section{Cross Reference:}

Appendix 2

Sampling Methods: 11-S, 29-S
Literature Reference: 1 . James E. Grindler, "The Radiochemistry of Uranium", NAS-NS 3050, March 1962. 2. Editor, Frederick D. Johns, "Handbook of Radiochemical Methods", EPA-680/4-75001 , February 1975.

\section{Equipment:}

Resin column

Vortex mixer

Centrifuge

Normal glass ware

$40 \mathrm{ml}$ screw-cap vials

Remarks:

Edition: 
Analysis: Atomic Absorption

$163-A$

Method: Rubidium is determined by aspirating the sample into an air-acetylene flame of an atomic absorption spectrophotometer. The intensity of the rubidium absorbance at $780 \mathrm{~nm}$ is measured and is proportional to the rubidium concentration.

Sample Handling: Use filtered acidified or raw acidified brine.

Range: (1 inear) $0.07-2 \mathrm{mg} / 1$

Cross Reference:

Appendix 2

Sampling Methods: 11-S, 29-S

Analysis Methods: 164-A
Precision: $\pm 5 \%$

\section{Literature Reference:}

Instrument Manufacturer's Std. Methods Manual

Dean \& Rains, Flame Emission and Atomic Absorp-

tion Spectrometry, Vol. III, 1975 pp. 2-27.

\section{Equipment:}

Atomic absorption spectrophotometer
Accuracy: $\quad+10 \%$
Rubidium atomic absorption standard

solution or rubidium chloride

Sodium chloride

Potassium chloride or potassium

nitrate

Ammonium oxalate (option)

Ammonium hydroxide (option) 
5. If sample shows Tyndall effect, filter through $0.45 \mu \mathrm{m}$ membrane filter.

6. Use of a graphite furnace wili increase sensitivity.

7. Use of standard additions recommended.

8. Potassium and calcium can interfere and give slightly higher results if background correction at $779.0 \mathrm{~nm}$ is not used. Calcium may be removed as an oxalate with ammonium oxalate and ammonium hydroxide. 
Rubidium

Analysis: Flame Emission

No. $164-A$

Method: Rubidium is determined by aspirating the sample into an air-acetylene flame and the emission intensity at $780 \mathrm{~nm}$ from rubidium is measured by a spectrophotometer.

Sample Handling: Use filtered acidified or raw acidified brine. Sample may be stabilized by diluting with 9 parts distilled water and adding $5 \mathrm{ml} \mathrm{HNO}_{3}$ per liter of sample.

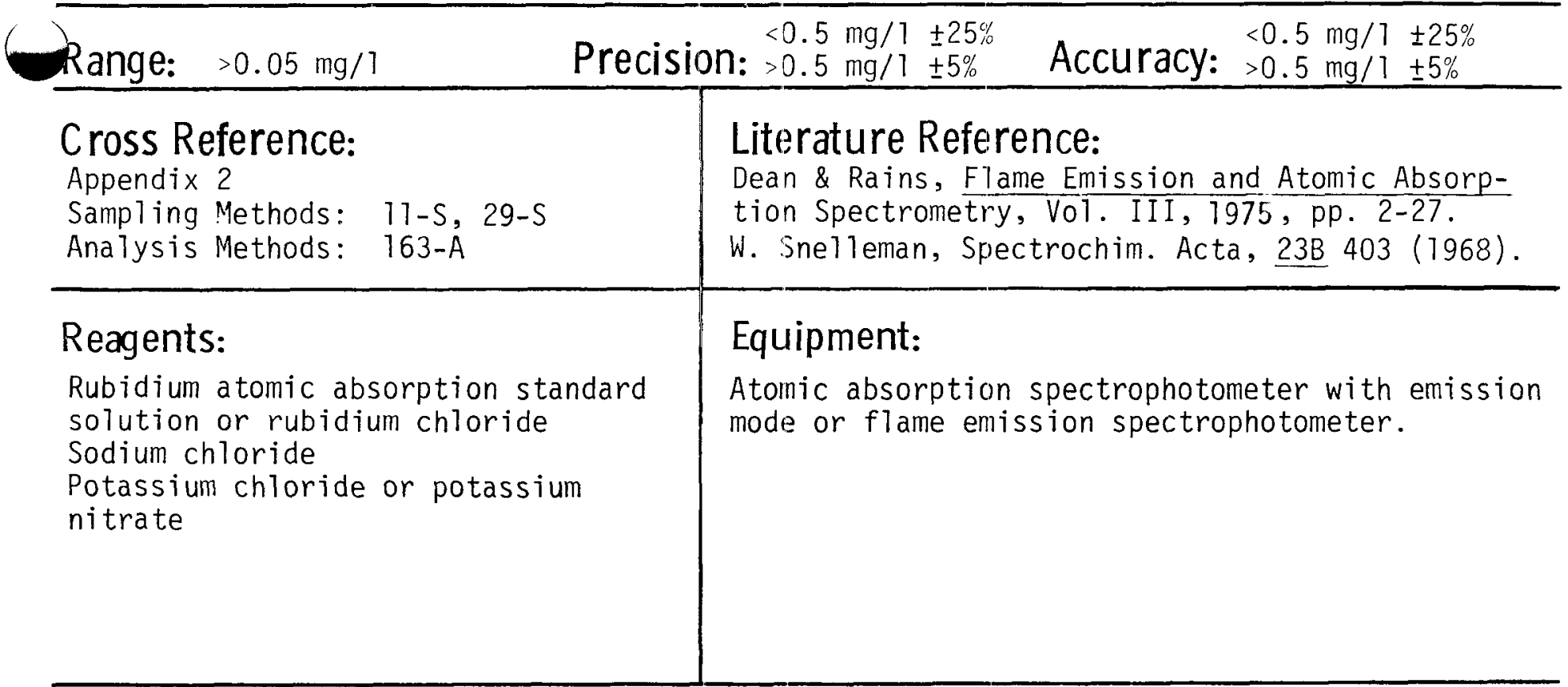

Remarks: 1. Ionization of rubidium in an air-acetylene flame is suppressed by the addition of $2000 \mathrm{ppm}$ potassium.

2. Carefur matrix matching between sample and standards is necessary (especially sodium chloride).

3. On some AA spectrophotometer's a red filter is used to reduce background radiation.

Edition:

4. Use of standard additions recommended. 
Rubidium

Analysis: Spark Source Mass Spectrometry

\begin{tabular}{l|l}
\hline No. & $165-\mathrm{A}$
\end{tabular}

Method: Dehydrated sample is vaporized and ionized by an arc source and enters an evacuated chamber. Rubidium is separated and detected by its mass/charge ratio, and determined quantitatively by comparison with standards.

Sample Handling: Use filtered acidified, raw acidified, filtered unacidified, or raw unacidified brine. Evaporate samples and analyze residue.

Range: $0.1-1000 \mathrm{mg} / 1 \quad$ Precision: $\pm 25 \%$ (isotope di7.) Accuracy: $\pm 2 \%$ (isotope di

\section{Cross Reference:}

Appendix 2

Sampling Methods: 11-S, 29-5

\section{Reagents:}

Rubidium chioride or other rubidium standard

\section{Literature Reference:}

Trace Analysis by Mass Spectrometry, A.J. Aheard, ed., Academic Press, NY (1977).

D.L. Donohue, J.A. Carter and J.C. Franklin, Anal. Letters, 10(5) 371-379 (1977).

\section{Equipment:}

Spark source mass spectrometer

Remarks: 1. Additional references: J. A. Carter, D. L. Donohue, and J. C. Frank7in, Trace Substances in Environmental Health-IX. U. of Missouri, 303 (1975). J. C. Franklin, J. A. Carter, D. L. Donohue, and R. W. Stelzner, 23d Conf. on Mass Spectrometry and Allied Topics, Houston, TX 354 (1975). R. Alvarez, B. J. Paulsen, and D. E. Kelleher, Anal. Chem. 41955 (1969) 
Rubidium

Analysis: Neutron Activation $166-A$

Method: Sample is exposed to neutron source (reactor) and radioactive rubidium isotopes are formed. The isotopes and their associated beta and gamma spectra are identified by multichannel analyzers. The amount of rubidium present is proportional to the measured activity.

Sample Handling: Use raw acidified or filtered acidified brine. Evaporate samples and irradiate residue with neutron source.

Range:

Cross Reference:

Appendix 2

Sampling Methods: 11-S, 29-S
Precision:

Accuracy:

\section{Literature Reference:}

Robertson and Carpenter, "Neutron Activation

Techniques for the Measurement of Trace Metals

in Environmental Samples", NAS-NS-3114, Jan. 1974.

\section{Equipment:}

Reactor (neutron source)

Multichannel Analyzer

Remarks: Sufficient time must be allowed for sodium decay if the sodium spectrum masks the element of interest. 
Analysis: Emission Spectrometry

\begin{tabular}{|l|l|}
\hline No. & $167-A$
\end{tabular}

Method: The sample containing rubidium in either solid or liquid state is vaporized by a flame, $d-c$ arc, or a-c spark and the intensity of the selected emission line is measured against standards.

Sample Handling: Use filtered acidified or raw acidified brine.

Range:

Cross Reference:

Appendix 2

Sampling Methods: 11-S, 29-S

\section{Reagents:}

Rubidium chloride or other rubidium standard

\section{Precision:}

Accuracy:

\section{Literature Reference:}

Instrument Manufacturer's Literature

Equipment:

Emission spectrometer

Remarks: 1. Large differences in matrix effects will be observed depending on the type of excitation source (flame, AC spark, or DC arc).

\section{Edition:}

$7 / 78$ 


\section{$\mathrm{SiO}_{2}$}

Silica

Analysis: Gravimetric

$168-A$

Method: Silica in water is concentrated and precipitated as partially dehydrated silica by evaporation with $\mathrm{HCl}$. The residue is ignited at $1000-1200^{\circ} \mathrm{C}$ and weighed; subsequently the silica present is converted to volatile silicon tetrafluoride by addition of HF. The silicon tetrafluoride is driven off by a second ignition and the difference between the weights of the remaining residue and the residue before HF treatment is considered to be the silica content.

Sample Handling: Use raw unacidified or filtered unacidified brine.

Range:

Accuracy:

Cross Reference:

Appendix 2

Sampling Methods: 11-S, 29-5
Literature Reference:

ASTM D859-68A (1977)

APHA 426A (1975)

\section{Reagents:}

Hydrochloric acid

Sulfuric acid

Hydrofluoric acid

Perchloric acid

\section{Equipment:}

Platinum crucibles with covers

Platinum evaporating dishes

Muffle furnace

Drying oven

Analytical balance

Remarks: 1. Avoid use of glassware as much as possible to avoid introducing $\mathrm{SiO}_{2}$.

Edition: 
Analysis: Colorimetric (Heteropoly Blue)

\begin{tabular}{l|l|l|l|l|}
\hline No. & $169-\mathrm{A}$ \\
\hline
\end{tabular}

Method: Soluble silica reacts with molybdate ion to produce a greenish-yellow complex which is then reduced by 1-amino-2-naphthol-4-sulfonic acid to produce a blue complex which is measured at (preferably) $815 \mathrm{~nm}$ or, with reduced sensitivity, at $640-700 \mathrm{~nm}$.

Sample Handling: Use raw uncaidified brine, dilute on site if $\mathrm{SiO}_{2}>100 \mathrm{ppm}$.

\begin{tabular}{|c|c|c|c|}
\hline \multicolumn{2}{|l|}{ Range: $>1 \mathrm{mg} / 1$} & Precision: & Accuracy: $\pm 15 \%$ \\
\hline $\begin{array}{l}\text { Cross Reference: } \\
\text { Appendix } 2 \\
\text { Sampling Methods: } \\
\text { Analysis Methods: }\end{array}$ & $\begin{array}{l}11-S, 29-S \\
170-A\end{array}$ & $\begin{array}{l}\text { Literature Reference: } \\
\text { APHA } 426 \text { C (1975) } \\
\text { ASTM D859-68 B, C (1977) } \\
\text { EPA 00955 (1976) }\end{array}$ & $\begin{array}{l}\text { USGS Book 5, Chapter } \\
\text { AT (1974) }\end{array}$ \\
\hline $\begin{array}{l}\text { Reagents: } \\
\text { 1-amino-2-naphthol } \\
\text { Sodium sulfite } \\
\text { Sodium bisulfite } \\
\text { Sodium bicarbonate } \\
\text { Sulfuric acid } \\
\text { Hydrochloric acid } \\
\text { Sodium or ammoniun } \\
\text { Ammonium molybdate } \\
\text { Oxalic acid } \\
\text { Sodium meta silica }\end{array}$ & -4-sulfonic acid & $\begin{array}{l}\text { Equipment: } \\
\text { Spectrophotometer to measur } \\
640-700 \mathrm{~nm} \text {. }\end{array}$ & at $815 \mathrm{~nm}$ or \\
\hline
\end{tabular}

Remarks: 1. If $\mathrm{SiO}_{2}>100 \mathrm{ppm}$ dilute $1 / 10$ with distilled water.

2. Avoid use of glassware or reagents which may contain silica.

3. Turbidity, iron, sulfide, color interfere; phosphate removed by oxalic acid.

Edition:

$7 / 78$ 
Analysis: Colorimetric (Molybdosilicate) \begin{tabular}{|l|l|}
\hline No. & $170-A$
\end{tabular}

Method: Soluble silica reacts with molybdate ion to produce a greenish-yellow complex. The yellow silica-molybdate complex is measured directly at $410 \mathrm{~nm}$ with a spectrophotometer.

Sample Handling: Use raw unacidified brine, dilute on site if $\mathrm{SiO}_{2}>100 \mathrm{ppm}$.

Range: $10-100 \mathrm{mg} / 1$

Precision: $\quad \pm 10 \%$

Accuracy: $\pm 20 \%$

Cross Reference:

Appendix 2

Sampling Methods: 11-S, 29-S

Analysis Methods: 169-A

Reagents:

Sodium bicarbonate

Sulfuric acid

Hydrochloric acid

Sodium or ammonium hydroxide

Ammonium molybdate

Oxalic acid

Sodium meta silicate

Sodium bicarbonate

Literature Reference:

APHA 426 B (1975)

EPA 00955 (1976)

ASTM D859-68 B, C (1977)

\section{Equipment:}

Spectrophotometer to measure at $410 \mathrm{~nm}$.

Remarks: 1. If $\mathrm{SiO}_{2}>100$ dilute $1 / 10$ with distilled water.

2. Avoid use of glassware or reagents which may contain silica.

3. Iron, color, turbidity, sulfide interfere. Phosphate removed by oxalic acid.

4. Any silica present as "molybdate-unreactive" silica must be pretreated

Edition: by digesting with $\mathrm{NaHCO}_{3}$ on a steam bath for one hour. 
Silica

Analysis: Atomic Absorption

\begin{tabular}{|l|l|l|l|l|}
\hline No. & $171-\mathrm{A}$ \\
\hline
\end{tabular}

Method: Silicon (Si) is determined by aspirating the sample into a nitrous oxideacetylene flame of an atomic absorption spectrophotometer. The intensity of the silicon absorbance at $251.6 \mathrm{~nm}$ is measured and is proportional to the silicon concentration. Silica concentration is calculated by multiplying the silicon value by the gravimetric factor $-\mathrm{SiO}_{2} / \mathrm{Si}=2.14$.

Sample Handling: Use filtered acidified or raw acidified brine. Sample should be diluted in field if $\mathrm{SiO}_{2}>250 \mathrm{mg} / 1$, otherwise precipitation may occur before analysis (10:1 dilution suggested).

Range: (1 inear) $3-150 \mathrm{mg} / 1 \quad$ Precision: $\pm 5-25 \% \quad$ Accuracy: $\pm 5-25 \%$

Cross Reference:

Appendix 2

Sampling Methods: 11-S, 29-S

Analysis Methods: 172-A

Reagents:

Silicon atomic absorption standard solution or sodium metasilicate Nitrous oxide gas cylinder

\section{Literature Reference:}

APHA 301-A (1975)

Instrument Manufacturer's Std. Methods Manual USGS Book 5, Chapter AT (1974).

\section{Equipment:}

Atomic absorption spectrophotometer Nitrous oxide burner head

Remarks: 1. HF, boric acid and potassium at a level of $1 \%$ or greater cause severe depression in silicon absorbance. Use of a slightly reducing flame with red feather height of $5 \mathrm{~mm}$ minimizes this effect.

2. Burner height position is very important since there is a narrow region of nitrous oxide-acetylene flame where Si absorbs. Burner height of $7 \mathrm{~mm}$ is recommended.

ition:

$7 / 78$
3. Low-acetylene tank pressure can cause acetone to be aspirated (with commercial grade acetylene). This will result in complete lack of sensitivity being observed on absorbance.

(Cont. on back) 
4. Careful matrix matching between sample and standards must be made (i.e. using same amounts of $\mathrm{NaCl}$, other alkali metal and alkaline earth metal ions).

5. Use of standard additions recommended.

6. If samples show Tyndall effect filter through $0.45 \mu$ membrane filter. 
Silica

Analysis: Flame Emission

\begin{tabular}{|l|l|l|}
\hline No. & $172-\mathrm{A}$ \\
\hline
\end{tabular}

Method: Silicon is determined by aspirating the sample into a nitrous oxide-acetylene flame and the emission intensity at $251.6 \mathrm{~nm}$ from silicon is measured by a spectrophotometer. Silica concentration is calculated by multiplying the silicon value by the gravimetric factor $\mathrm{SiO}_{2} / \mathrm{Si}=2.14$.

Sample Handling: Use filtered acidified or raw acidified brine. Sample should be diluted in field if $\mathrm{SiO}_{2}>100 \mathrm{mg} / 1$ (10:1 dilution suggested).

Range:

Precision:

Accuracy:

\section{Cross Reference:}

Appendix 2

Sampling Methods: 11-S, 29-S

Analys is Methods: 171-A

\section{Reagents:}

Silicon atomic absorption standard solution or sodium metasilicate Nitrous oxide cylinder

\section{Literature Reference:}

Dean \& Rains, Flame Emission and Atomic Absorption Spectrometry, Vol. III, 1975, pp. 136-154.

W. Snelleman, Spectrochim. Acta, 23B 403 (1968).

\section{Equipment:}

Atomic absorption spectrophotometer with emission mode or flame emission spectrophotometer. Nitrous oxide burner head

Remarks: 1. HF, boric acid and potassium at a level of $1 \%$ or greater cause severe depression in silicon absorbance. Use of a slightly reducing flame with red feather height of $5 \mathrm{~mm}$ minimizes this effect.

2. Burner height position is very important since there is a narrow region of nitrous oxide-acetylene flame where Si absorbs. Burner height of $7 \mathrm{~mm}$ is recommended.

Edition:

$7 / 78$

3. Careful matrix matching between sample and standards must be made (i.e. using same amounts of $\mathrm{NaCl}$, other alkali metal and alkaline earth metal ions. 
Analysis: Inductively coupled Plasma-Atomic

Emission Spectroscopy

$173-A$

Method: Sample is aspirated into the argon plasma and the intensity of the emission spectrum is analyzed and compared with standards. Intensity is measured at $288.16 \mathrm{~nm}$ or alternate wavelength.

Sample Handling: Use filtered acidified or raw acidified brine. Sample should be diluted in field if $\mathrm{SiO}_{2}>100 \mathrm{mg} / 1$ (10:1 dilution suggested).

3-5 orders of magnitude from

Range: a single spectral line Precision: $\pm 1-10 \%$

Accuracy:

\section{Cross Reference:}

Appendix 2

Sampling Methods: 11-S, 29-S

\section{Literature Reference:}

Evaluation of an Inductively Coupled Plasma, Multichannel Spectrometric Analys is System, EPA-600/4-77-032, June 1977.

\section{Equipment:}

Inductively coupled plasma-atomic emission spectrometer

Sodium met
standard

silica

Remarks: 1. External standards using $\mathrm{NaCl}$ concentrations equivalent to sample concentrations of $\mathrm{NaCl}$ are required.

2. Additional references: R. H. Scott and M. L. Kokot, "Application of Inductively Coupled Plasmas to the Analysis of Geochemical Samples", Anal. Chim. Acta 75, 257-270 (1975).

Edition: 
3. Background correction and standard additions method recommended.

4. Upper limit of concentration range may be extended by using alternate spectral 1ines.

5. To convert from silicon to silica concentration multiply by the gravimetric factor $\frac{\mathrm{SiO}_{2}}{\mathrm{Si}}\left(\mathrm{i} . \mathrm{e} .,\left[\mathrm{SiO}_{2}\right]=[\mathrm{Si}] \times 2.14\right)$. 


\section{$\mathrm{SiO}_{2}$}

Silica

Analysis: Spark Source Mass Spectrometry

No. $174-A$

Method: Dehydrated sample is vaporized and ionized by an arc source and enters an evacuated chamber. Silicon is separated and detected by its mass/charge ratio, and determined quantitatively by comparison with standards.

Sample Handling: Use filtered acidified, raw acidified, filtered unacidified or raw unacidified brine. Evaporate samples and analyze residue.

Range: $0.1-1000 \mathrm{mg} / 1 \quad$ Precision: $\pm 25 \% \quad$ Accuracy: $\pm 25 \%$

Cross Reference:

Appendix 2

Sampling Methods: 11-S, 29-S

\section{Reagents:}

Sodium metasilicate or other silica standard

\section{Literature Reference:}

Trace Analys is by Mass Spectrometry, A.J. Aheard, ed., Academic Press, NY (1977).

D.L. Donohue, J.A. Carter and J.C. Franklin, Anal. Letters, $10(5) 37 i-379$ (1977).

\section{Equipment:}

Spark source mass spectrometer

Remarks: 1. If $\mathrm{SiO}_{2}>100 \mathrm{mg} / 1$ field dilution is recommended. (10:1 dilution suggested.)

2. To convert from silicon to silica concentration multiply by the gravimetric factor $\frac{\mathrm{SiO}_{2}}{\mathrm{Si}}$ (i.e., $\left[\mathrm{SiO}_{2}\right]=[\mathrm{Si}] \times 2.14$ ).

Edition:

$7 / 78$ 
Analysis: Emission Spectrometry

No. $175-\mathrm{A}$

Method: The sample containing silica in either solid or liquid state is vaporized by a flame, d-c arc, or a-c spark and the intensity of the selected emission line is measured against standards.

Sample Handling: Use filtered acidified or raw acidified brine. Sample should be diluted in field if $\mathrm{SiO}_{2}>100 \mathrm{mg} / 1$ (10:1 dilution suggested).

Range: $0.2-2 \mathrm{mg} / 1$ (as $\mathrm{Si}$ ) Precision: $\pm 10 \% \quad$ Accuracy:

Cross Reference:

Appendix 2

Sampling Methods: 11-S, 29-5

\section{Reagents:}

Sodium metasilicate or other silica standard

Vanadium internal standard

\section{Literature Reference:}

Instrument Manufacturer's Literature

\section{Equipment:}

Emission spectrometer

Photo processor

Microphotometer

Remarks: 1. Matrix matching (use of equivalent amounts of alkali and alkaline earth metals) in standards important.

2. Large differences in matrix effects will be observed depending on the type of excitation source (flame, AC spark, or DC arc).

Edition:

$7 / 78$ 
Analysis: Atomic Absorption

No. $176-\mathrm{A}$

Method: Silver is determined by aspirating the sample into an air-acetylene flame of an atomic absorption spectrophotometer. The intensity of the silver absorbance at $328.1 \mathrm{~nm}$ is measured and is proportional to the silver concentration.

Sample Handling: Use filtered acidified or raw acidified brine. Sample may be stabilized by adding $5 \mathrm{ml} \mathrm{HNO}_{3}$ per liter.

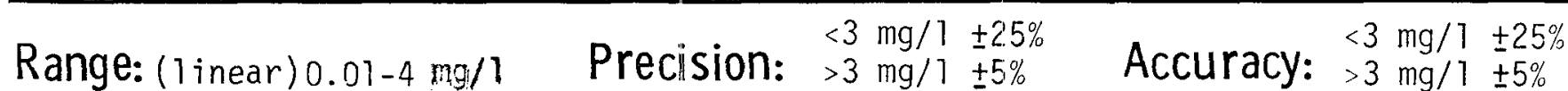
Cross Reference:

Appendix 2

Sampling Methods: 11-S, 29-S

Analysis Methods: 177-A

Literature Reference:

EPA 01077 (1976)

APHA 301-A (1975)

Instrument Manufacturer's Std. Methods Manual

\section{Reagents:}

Silver Atomic Absorption standard Solution or silver nitrate

Sodium chloride

\section{Equipment:}

Atomic absorption spectrophotometer

Remarks: 1. No known interferences with AA method.

2. Careful matrix matching between sample and standards must be made (i.e. using same amounts of $\mathrm{NaCl}$, other alkali metal and alkaline earth metal ions).

3. Graphite furnace atomization may be used to detect low concentrations.

Edition:

4. Some matrix interferences can be eliminated by using a deuterium arc background correction system.

$7 / 78$ (Cont. on back) 


\section{Ag}

Silver

Atomic Absorption using APDC and

Analysis: MIBK Extraction

No. $177-A$

Method: Silver is chelated with ammonium pyrrolidine dithiocarbamate (APDC) and extracted with methyl isobutyl ketone (MIBK). The extract is then aspirated directly into an air-acetylene flame of an atomic absorption spectrophotometer. The intensity of the silver absorbance at $328.1 \mathrm{~nm}$ is measured and is proportional to the silver concentration.

Sample Handling: Use filtered acidified or raw acidified brine.

Range:

Precision:

Accuracy: $\pm 15 \%$

Cross Reference:

Literature Reference:

APHA 301 A (1975)

Appendix 2

Sampling Methods: 11-2, 29-S

USGS Book 5, Chapter A1 (1974)

Analysis Methods: 176-A

Reagents:

Silver atomic absorption standard solution or silver nitrate

Methyl isobutyl ketone

Ammonium pyrrolidine dithiocarbamate

\section{Equipment:}

Atomic absorption spectrophotometer

Separatory funnels

Remarks: 1. No known interferences with AA method.

2. Careful matrix matching between sample and standards must be made (i.e. using same amounts of $\mathrm{NaCl}$, other alkali metal and alkaline earth metal ions).

3. Some matrix interferences can be elminated by using a deuterium arc background correction system.

Edition:

4. Use of standard additions recommended. 


\section{$\mathrm{Ag}$}

Silver

Inductively Coupled Plasma-Atomic

Analysis: Emission Spectroscopy

No. $178-A$

Method: Sample is aspirated into the argon plasma and the intensity of the emission spectrum is analyzed and compared with standards. Intensity is measured at $328.07 \mathrm{~nm}$ or at alternate spectral line.

Sample Handling: Use filtered acidified or raw acidified brine.

3-5 orders of magnitude from

Range: a single spectral line Precision: $\pm 7-70 \%$

Accuracy:

Cross Reference:

Literature Reference:

Appendix 2

Sampling Methods: $11-5,29-5$

Evaluation of an Inductively Coupled Plasma, Multichannel Spectrometric Analysis System, EPA-600/4-77-032, June 1977.

Reagents:

Silver nitrate or other silver standar

\section{Equipment:}

Inductively coupled plasma-atomic emission spectrometer.

Remarks: 1. External standards using $\mathrm{NaCl}$ concentrations equivalent to sample concentrations of $\mathrm{NaCl}$ are required.

2. Additional reference: R. H. Scott and M. L. Kokot, "Application of Inductively Coupled Plasmas to the Analysis of Geochemical Samples", Anal. Chim. Acta 75, 257-270 (1975).

Edition:

$7 / 78$

(cont. on back) 
3. Probable spectral interference from iron at silver $328.07 \mathrm{~nm}$ line when analyzing concentrated brines.

4. Use of standard additions and background correction recommended.

5. Upper limit of concentration range may be extended by using alternate spectral lines. 
Silver

Analysis: Spark Source Mass Spectrometry

\begin{tabular}{l|ll} 
No. & 179-A \\
\hline
\end{tabular}

Method: Dehydrated sample is vaporized and ionized by an arc source and enters an evacuated chamber. Silver is separated and detected by its mass/charge ratio, and determined quarititatively by comparison with standards.

Sample Handling: Use filtered acidified, raw acidified, filtered unacidified, or raw unacidified brine. Evaporate brine samples and analyze residue.

\section{Range: $0.1-1000 \mathrm{mg} / 1 \quad$ Precision: $\pm 25 \% \quad$ Accuracy: $\pm 25 \%$}

\section{Cross Reference:}

Appendix 2

Sampling Methods: $11-5,29-5$

\section{Reagents:}

Silver nitrate or other silver standard

\section{Literature Reference:}

Trace Analysis by Mass Spectrometry, A. J. Aheard, ed., Academic Press, NY (1977).

D. L. Donohue, J. A. Carter and J. C. Frank in Anal. Letters, 10(5) 371-379 (1977).

\section{Equipment:}

Spark source mass spectrometer

\section{Remarks:}

Edition:

$7 / 78$ 


\section{$\mathrm{Ag}$}

Silver

Analysis: Neutron Activation

$18 n-A$

Method: Sample is exposed to neutron source (reactor) and radioactive silver isotopes are formed. The isotopes and their associated beta and gamma spectra are identified by multichannel analyzers. The amount of silver present is proportional to the measured activity.

Sample Handling: Use raw acidified or filtered acidified brine. Evaporate samples and irradiate residue with neutron source.

Range:

Precision:

Accuracy:

\section{Cross Reference:}

Appendix 2

Sampling Methods: 11-S, 29-S

\section{Literature Reference:}

Robertson and Carpenter, "Neutron Activation Techniques for the Measurement of Trace Metals in Environmental Samples", NAS-NS-3114, Jan. 1974.

Reagents:

\section{Equipment:}

Reactor (neutron source)

Multichannel analyzer

Remarks: Sufficient time must be allowed for sodium decay if the sodium spectrum masks the element of interest.

Edition: 


\section{$\mathrm{Ag}$}

Silver

Analysis: Emission Spectrometry

\begin{tabular}{|l|l|}
\hline No. & $181-\mathrm{A}$ \\
\hline
\end{tabular}

Method: The sample containing silver in either solid or liquid state is vaporized by a flame, d-c arc, or a-c spark and the intensity of the selected emission line is measured against standards.

Sample Handling: Use filtered acidified or raw acidified brine.

Range: $\quad 0.04-0.2 \mathrm{mg} / 1 \quad$ Precision: $\pm 10 \% \quad$ Accuracy:

Cross Reference:

Literature Reference:

Appendix 2

Sampling Methods: 11-S, 29-S

Instrument Manufacturer's Literature

\section{Reagents:}

Silver nitrate or other silver standard

Vanadium internal standard

\section{Equipment:}

Emission spectrometer

Photo processor

Microphotometer

Remarks: 1. Use of matrix matching (equivalent amounts of alkali and alkaline earth metals) in standards important.

2. Large differences in matrix effects will be observed depending on the type of excitation source (flame, AC spark, or DC arc).

Edition: 
Method: A sodium specific electrode is used to measure sodium ion activity in a solution with the pH buffered at 11.0.

Sample Handling: Use raw unacidified or filtered unacidified brine.

Range: $>0.02 \mathrm{mg} / 7 \quad$ Precision: $\pm 5 \% \quad$ Accuracy:

\section{Cross Reference:}

Appendix 2

Sampling Methods: $11-5,29-5$

Analys is Methods: 148-A

\section{Reagents:}

Sodium standard solutions or sodium chloride

Ammonium chloride

Ammonium hydroxide

\section{Literature Reference:}

ASTM D2791-77A (1977)

Orion Research Inc., Literature

\section{Equipment:}

Sodium specific ion electrode

Specific ion meter

Magnetic stirrer

Remarks: 1. Interferences are from $\mathrm{Ag}^{+}, \mathrm{Li}^{+}, \mathrm{H}^{+}, \mathrm{K}^{+}, \mathrm{NH}_{4}^{+}$. Elevation of $\mathrm{pH}$ so that $\mathrm{H}^{+}$concentration is 3-4 orders of magnitude lower than that for sodium makes electrode response independent of $\mathrm{H}^{+}$concentration.

2. Easily adapted for field measurement. 
Analysis: Atomic Absorption $183-A$

Method: Sodium is determined by aspirating the sample into an air-acetylene flame of an atomic absorption spectrophotometer. The intensity of the sodium absorbance at $589 \mathrm{~nm}$ is measured and is proportional to the sodium concentration.

Sample Handling: Use filtered acidified or raw acidified brine.

Range: (1 inear) $0.02-1 \mathrm{mg} / 1$ Precision: $\pm 5 \%$

Accuracy: $\pm 10 \%$

\section{Cross Reference:}

Appendix 2

Sampling Methods: 11-S, 29-S

Analysis Methods: 184-A

\section{Literature Reference:}

EPA 00929 (1976)

USGS Book 5, Chapter AT (1974).

Instrument Manufacturer's Std. Methods. Manual ASTM D3561-77 (1977)

\section{Equipment:}

Atomic absorption spectrophotometer

solution or sodium chloride

Potassium chloride or potassium

nitrate

Remarks: 1. Sodium is partially ionized in an air-acetylene flame. This ionization may be suppressed by adding either potassium nitrate or potassium chloride to give a potassium concentration of $2000 \mathrm{ppm}$ potassium.

2. Careful matrix matching between sample and standards must be made (i.e. use same amounts of alkali metal and alkaline earth metal ions).

Edition:

3. If sample shows Tyndall effect, filter through $0.45 \mu \mathrm{m}$ membrane filter.

$7 / 78$

(cont. on back) 
4. Use of standard additions recommended.

5. All glass and plasticware should be acid washed and thoroughly rinsed to prevent sodium contamination. 
Analysis: Flame Emission

\begin{tabular}{|l|l|}
\hline No. & 184-A \\
\hline
\end{tabular}

Method: Sodium is determined by aspirating the sample into an air-acetyiene flame and the emission intensity at $589 \mathrm{~nm}$ from sodium is measured by a spectrophotometer. Alternatively the emission at $330.3 \mathrm{~nm}$ may be measured.

Sample Handling: Use filtered acidified or raw acidified brine. Sample may be stabilized by dilution with 9 parts distilled water and adding $5 \mathrm{ml} \mathrm{HNO}_{3}$ per liter.

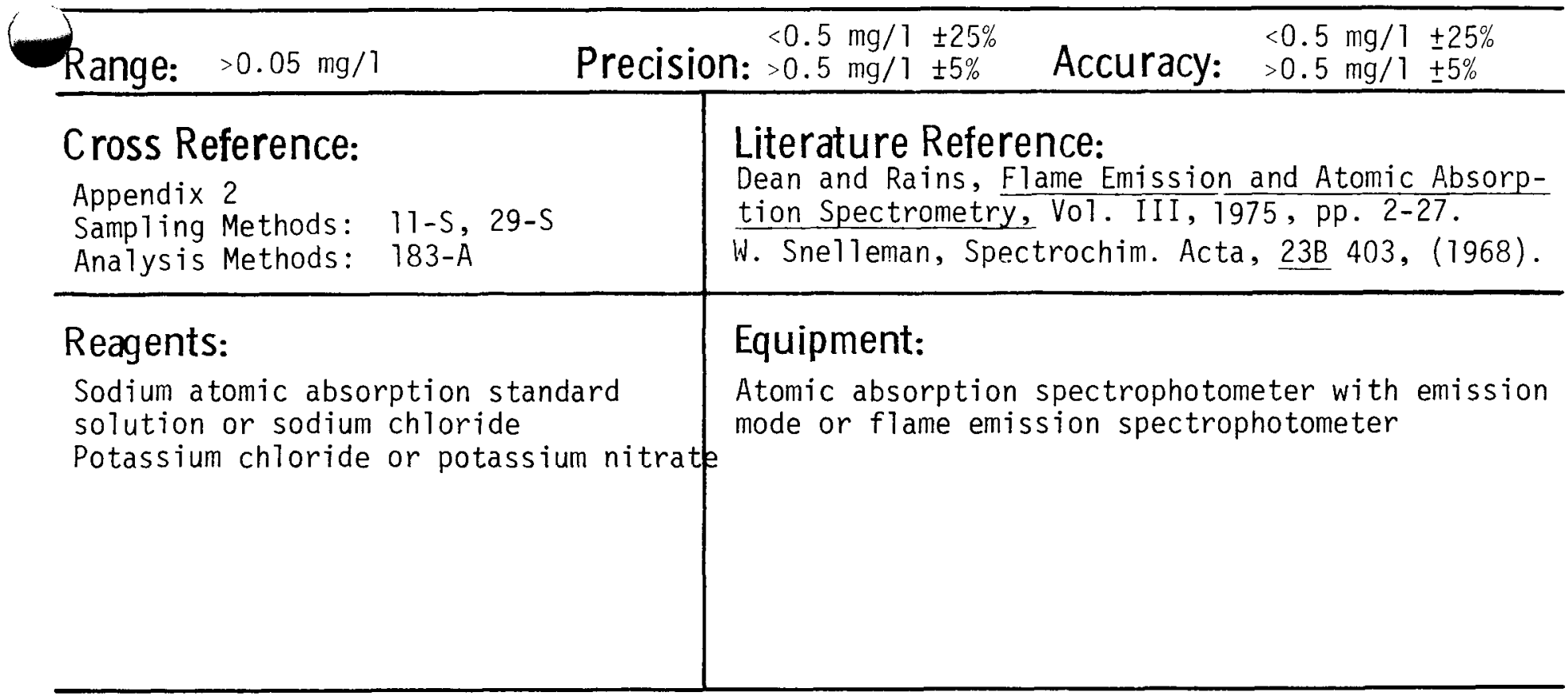

Remarks: 1. Sodium is partially ionized in an air-acetylene flame. This ionization may be suppressed by adding either potassium nitrate or potassium chloride to give a potassium concentration of $2000 \mathrm{ppm}$ potassium.

2. Careful matrix matching between sample and standards must be made (i.e. use same amounts of alkali metal and alkaline earth metal ions).

Edition:

$7 / 78$ 
Analysis: Inductively Coupled Plasma-Atomic Analysis: Emission Spectroscopy

No. $\quad 185-\mathrm{A}$

Method: Sample is aspirated into the argon plasma and the intensity of the emission spectrum is analyzed and compared with standards.

Sample Handling: Use filtered acidified or raw acidified brine.

Range:

Precision:

Accuracy:

Cross Reference:

Literature Reference:

Appendix 2

Sampling Methods: 11-S, 29-S

Evaluation of an Inductively Coupled Plasma,

Multichannel Spectrometric Analys is System,

EPA-600/4-77-032, June 1977.

Reagents:

Sodium chloride or other sodium standard

\section{Equipment:}

Inductively coupled plasma-atomic emission spectrometer

Remarks: 1. Additional reference: R. H. Scott and M. L. Kokot, "Application of Inductively Coupled Plasmas to the Analys is of Geochemical Samples", Anal. Chim. Acta 75, 257-270 (7975).

2. Background correction and standard additions method recommended.

Edition: 
Sodium

Analysis: Ion Exchange Chromatography

$186-A$

Method: Ion components are separated on sulfonated polymer based columns. A solution of nitric acid is used to elute sodium from the column. The separation column is followed by a suppressor column which removes high background conductivity due to the solvent. Ions are detected with a conductivity detector.

Sample Handling: Use raw or filtered unacidified brine or filtered acidified brine.

\section{Reagents:}

Sodium chloride or other sodium standard

Nitric acid

\section{Precision: $\pm 0.40 \% \quad$ Accuracy: $\pm 5 \%$}

Literature Reference:

Dionex Corp., Sunnyvale, CA, Literature

Ana 1. Chem., 47 (11), 1801 (1975).

Microchem. J., 22, 45 (1977).

Ana 1. Chem., 49 (3), 401 (1977).

Equipment:

Ion exchange chromatograph

RemarkS: 1. Additional reference: Sma 11, H., T. S. Stevens, and W. C. Bauman, Anal. Chem. 47, 1807 (1975). 
Analysis: Spark Source Mass Spectrometry \begin{tabular}{l|l}
\hline No. & $187-\mathrm{A}$
\end{tabular}

Method: Dehydrated sample is vaporized and ionized by an arc source and enters an evacuated chamber. Sodium is separated and detected by its mass/charge ratio, and determined quantitatively by comparison with standards.

Sample Handling: Use filtered acidified, raw acidified, filtered unacidified or raw uncaidified brine. Evaporate samples and analyze residue.

Range: $0.7-1000$

Appendix 2

Sampling Methods: 11-S, 29-S

\section{Reagents:}

Sodium chloride or other sodium standard
Precision: $\pm 25 \%$

Accuracy: $\pm 25 \%$

\section{Literature Reference:}

Trace Analys is by Mass Spectrometry, A. J. Aheard, ed., Academic Press, NY (1977).

D. L. Donohue, J.A. Carter and J. C. Franklin, Ana 7 . Letters, $10(5) 377-379$ (1977).

\section{Equipment:}

Spark source mass spectrometer

\section{Remarks:}

Edition:

$7 / 78$ 
Sodium

Analysis: Neutron Activation

$188-A$

Method: Sample is exposed to neutron source (reactor) and radioactive sodium isotopes are formed. The isotopes and their associated beta and gamma spectra are identified by multichannel analyzers. The amount of sodium present is proportional to the measured activity.

Sample Handling: Use raw acidified or filtered acidified brine. Evaporate samples and irradiate residue with neutron source.

Range:

Precision:

Accuracy:

Cross Reference:

Appendix 2

Sampling Methods: 11-S, 29-5
Literature Reference:

Robertson and Carpenter, "Neutron Activation Techniques for the Measurement of Trace Metals in Environmental Samples", NAS-NS-3114. Jan. 1974.

\section{Reagents:}

\section{Equipment:}

Reactor (neutron source)

Multichannel analyzer

\section{Remarks:}

Edition: 
Analysis: Emission Spectrometry

Method: The sample containing sodium in either solid or liquid state is vaporized by a flame, $d-c$ arc, or a-c spark and the intensity of the selected emission line is measured against standards.

Sample Handling: Use filtered acidified or raw acidified brine.

Ditute to

Range: $\quad \leq 1.0 \mathrm{mg} / 1$

Cross Reference:

Sampling Methods: 11-S, 29-S
Appendix 2

Precision:

Accuracy:

\section{Literature Reference:}

Instrument Manufacturer's Literature

\section{Equipment:}

Sodium chloride or other sodium standard
Emission spectrometer

Remarks: 1 . Some flames (e.g. $\mathrm{O}_{2}-\mathrm{H}_{2}-\mathrm{N}_{2}$ ) may not be hot enough to vaporize completely the aerosols from solutions with high solids contents.

2. Reference standards should contain as high a salt content as unknowns.

3. Large differences in matrix effects will be observed depending on the type of excitation source (flame, AC spark, or DC arc).

Edition: 
Analysis: Atomic Absorption

No. $190-A$

Method: Strontium is determined by aspirating the sample into an air-acetylene $f$ lame of an atomic absorption spectrophotometer. The intensity of the strontium absorbance at $460.7 \mathrm{~nm}$ is measured and is proportional to the strontium concentration.

Sample Handling: Use filtered acidified of raw acidified brine.

Range: (1 inear) $0.02-5 \mathrm{mg} / 1$ Precision Cross Reference:

Appendix 2 Sampling Methods: 11-S, 29-S Analys is Methods: 191-A

\section{Reagents:}

Strontium atomic absorption standard solution or strontium nitrate Potassium chloride or potassium nitrate Nitrous oxide gas cylinder (option) Lanthanum chloride

\section{Literature Reference:}

USGS Book 5, Chapter A7 (1974)

Instrument Manufacturer's Std. Methods Manual ASTM D3352-74 (1977)

\section{Equipment:}

Atomic absorption spectrophotometer

Nitrous oxide burner head (option)

Remarks: 1. Strontium is partially ionized in an air-acetylene flame. Ionization is suppressed by adding $2000 \mathrm{ppm}$ potassium to the standards and samples.

2. Silica, aluminum, titanium, zirconium, phosphate and sulfate depress $\mathrm{Sr}$ absorbance in an air-acetylene flame. These effects can be eliminated by adding $1 \%(\mathrm{w} / \mathrm{v})$ lanthanum or $0.01 \mathrm{M}$ EDTA with $2000 \mathrm{ppm}$ Tanthanum also being present. These effects can also be removed by using a nitrous oxide-acetylene flame and adding $2000 \mathrm{ppm} \mathrm{K}$.

ition:

3. Careful matrix matching between sample and standards must be made (i.e. using same amounts of $\mathrm{NaCl}$, other alkali metal and alkaline earth metal ions).

(Cont. on back) C-194 


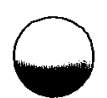


Analysis: Flame Emission $191-A$

Method: Strontium is determined by aspirating the sample into an air-acetylene flame and the emission intensity at $460.7 \mathrm{~nm}$ from strontium is measured by a spectrophotometer.

Sample Handling: Use filtered acidified or raw acidified brine. Sample may be stabilized by dilution with 9 parts distilled water and adding $5 \mathrm{ml} \mathrm{HNO}_{3}$ per liter.

Range: $\quad>0.05 \mathrm{mg} / \mathrm{l}$

Cross Reference:

Appendix 2

Sampling Methods: 11-S, 29-S

Analys is Methods: 190-A
Precision: $\begin{array}{ll}<0.5 \mathrm{mg} / 1 \pm 25 \% \\ >0.5 \mathrm{mg} / 1 \pm 5 \%\end{array}$
Accuracy: $\begin{array}{ll}<0.5 \mathrm{mg} / 1 & +25 \% \\ > & 0.5 \mathrm{mg} / 1 \pm 5 \%\end{array}$

\section{Literature Reference:}

Dean and Rains, Flame Emission and Atomic Absorption Spectrometry, Vol. I I , 1375, p. 33-65.
Reagents:

Strontium atomic absorption standard solution or strontium nitrate Potassium chloride or potassium nitrate

Nitrous oxide gas cylinder (option)

\section{Equipment:}

Atomic absorption spectrophotometer with emission mode or flame emission spectrophotometer Nitrous oxide burner head (option)

Remarks: 1. Strontium is partially ionized in an air-acetylene flame. Ionization is suppressed by adding $2000 \mathrm{ppm}$ potassium to the standards and samples.

2. Silica, aluminum, titanium, zirconium, phosphate and sulfate depress Sr absorbance in an air-acetylene flame. These effects can be eliminated. by adding $1 \%(\mathrm{~W} / \mathrm{V})$ lanthanum or 0.01 M EDTA with 2000 ppm lanthanum

ition: also being present. These effects can also be removed by using a

$7 / 78$ nitrous oxide-acetylene flame and adding $2000 \mathrm{ppm} \mathrm{K}$.

3. Careful matrix matching between sample and standards must be made (i.e. using same amounts of $\mathrm{NaCl}$, other alkali metal and alkaline earth metal ions).

$$
\text { (cont. on back) C-195 }
$$


4. Use of standard additions recommended.

5. Background determined by reading donor solution blank at $460.7 \mathrm{~nm}$ instead of at $454.0 \mathrm{~nm}$ as specified on same instruments. 
Analysis: X-Ray Fluorescence No. $192-$ A

Method: Liquid samples are made to fluoresce by $X$-ray bombardment. Secondary fluorescence is separated into wavelengths by a crystal and the radiation is detected by a scintillation counter or a flow proportional counter. A vacuum is required for the lighter elements. Standardization of instrument required.

Sample Handling: Use filtered acidified, raw unacidified or filtered unacidified brine.

Range:

Precision:

Accuracy:

\section{Cross Reference:}

Appendix 2

Sampling Methods: 11-5, 29-5

\section{Reagents:}

Strontium nitrate or other strontium standard

\section{Literature Reference:}

Nuc. Inst. and Methods, Vol. 106, pp. 525-538 (1973).

\section{Equipment:}

$X$-ray fluorescence spectrophotometer

\section{Remarks:}


Strontium

Analysis. Inductively Coupled Plasma-Atomic

Analysis: Emission Spectroscopy

\begin{tabular}{|l|l|l|l|}
\hline No. & $193-\mathrm{A}$
\end{tabular}

Method: Sample is aspirated into the argon plasma and the intensity of the emission spectrum is analyzed and compared with standards. Intensity is measured at $338.07 \mathrm{~nm}$ or alternate wavelength.

Sample Handling: Use filtered acidified or raw acidified brine.

3-5 orders of magnitude from

Range: a single spectral line Precision: $\pm 1-10 \%$

Accuracy:

\section{Cross Reference:}

Appendix 2

Sampling Methods: 11-S, 29-S

\section{Literature Reference:}

Evaluation of an Inductively Coupled Plasma,

Multichannel Spectrometric Analys is System, EPA-600/4-77-032, June 1977.

\section{Reagents:}

Strontium nitrate or other strontium standard

\section{Equipment:}

Inductively coupled plasma-atomic emission spectrometer

Remarks: 1. External standards using $\mathrm{NaCl}$ concentrations equivalent to sample concentrations of $\mathrm{NaCl}$ are required.

2. Additional reference: R. H. Scott and M. L. Kokot, "Application of Inductively Coupled Plasmas to the Analysis of Geochemical Samples", Ana 1. Chim. Acta 75, 257-270 (1975).

Edition:

7/78

(cont. on back) 
3. Background correction and standard additions method recommended.

4. Upper limit of concentration ragne may be exțended by using alternate spectral lines. 
Strontium

Analysis: Spark Source Mass Spectrometry

\begin{tabular}{|l|l|l|l}
\hline No. & $194-\mathrm{A}$ \\
\hline
\end{tabular}

Method: Dehydrated sample is vaporized and ionized by an arc source and enters an evacuated chamber. Strontium is separated and detected by its mass/charge ratio, and determined quantitatively by comparison with standards.

Sample Handling: Use filtered acidified, raw acidified, filtered unacidified, or raw unacidified brine. Evaporate samples and analyze residue.

Range: $0.1-1000 \mathrm{mg} / \mathrm{l}$

Precision: $\pm 5 \%$ (isotope dil Accuracy: $\pm 5 \%$ (isotope dil.)

Cross Reference:

Appendix 2

Sampling Methods: 11-S, 29-5

Reagents:

Strontium nitrate or other strontium standard

\section{Literature Reference:}

J. A. Carter, D. L. Donohue, and J. C. Frankling, Trace Substances in Environmental Heaith-IX, U. of Missouri, 303 (1975).

\section{Equipment:}

Spark source mass spectrometer

Remarks: 1. Additional references: J. C. Franklin, J. A. Carter, D. L. Donohue, and R. W. Stelzner, 23d Conf. on Mass Spectrometry and Allied Topics, Houston, TX 354 (1975).

R. Alvarez, B. J. Paulsen, and D. E. Kelleher, Anal, Chem. 41955 (1969).

Edition: 


\section{Sr}

Strontium

Analysis: Neutron Activation

195-A.

Method: Sample is exposed to neutron source (reactor) and radioactive strontium isotopes are formed. The isotopes and their associated beta and gamma spectra are identified by multichannel analyzers. The amount of strontium is proportional to the measured activity.

Sample Handling: Use raw acidified or filtered acidified brine. Evaporate samples and irradiate residue with neutron source.

Range:

Precision:

Accuracy:

Cross Reference:

Appendix 2

Sampling Methods: $11-5,29-5$

\section{Literature Reference:}

Robertson and Carpenter, "Neutron Activation Techniques for the Measurement of Trace Metals in Environmental Samples", NAS-NS-3114, Jan. 1974.

\section{Equipment:}

Reactor (neutron source)

Multichannel analyzer

Remarks: Sufficient time must be allowed for sodium decay if the sodium spectrum masks the element of interest.

Edition: 


\section{Sr}

Strontium

Analysis: Emission Spectrometry

$196-A$

Method: The sample containing strontium in either solid or liquid state is vaporized by a flame, $d-c$ arc, or a-c spark and the intensity of the selected emission line is measured against standards.

Sample Handling: Use filtered acidified or raw acidified brine.

Range: $10-100 \mathrm{mg} / 1 \quad$ Precision: $\pm 10 \% \quad$ Accuracy:

Cross Reference:

Appendix 2

Sampling Methods: 11-S, 29-S

\section{Literature Reference:}

Instrument Manufacturer's Literature

\section{Reagents:}

Strontium nitrate or other strontium standard

Vanadium internal standard

\section{Equipment:}

Emission spectrometer

Photo processor

Microphotometer

Remarks: 1. Matrix matching (using equivalent amounts of alkali and alkaline earth metals) in standards important.

2. Large differences in matrix effects will be observed depending on the type of excitation source (flame, AC spark, or DC arc).

Edition:

$7 / 78$ 
Sulfate

Analysis: Gravimetric

\begin{tabular}{|l|l|}
\hline No. & 197-A \\
\hline
\end{tabular}

Method: Sulfate is precipitated as barium sulfate in a hydrochloric acid medium by the addition of barium chloride. After a period of digestion, the precipitate is filtered, washed with hot water until free of chloride, ignited, and weighed as $\mathrm{BaSO}_{4}$.

Sample Handling: Use fittered unacidified or raw unacidified brine.

Range: $\quad>10 \mathrm{mg} / \mathrm{l}$

Cross Reference:

Apjendix 2

Sainpling Methods: 11-S, 29-S

Analysis Methods: $31-\mathrm{A}$, 198-A

\section{Reagents:}

Methyl red indicator

Hydrochloric acid

Barium chloride

Silver nitrate

Nitric acid

Silicone fluid

Anticreep fluid
Precision: $\pm 2 \% \quad$ Accuracy: $\pm 2 \%$

\section{Literature Reference:}

APHA 427 A, B (1975) EPA 00945 (1976)

ASTM D516-68A (1977)

API 2.71 (1968)

\section{Equipment:}

Steam bath

Drying oven

Muffle furnace

Dessicator

Analytical balance

Porous bottom silica or porcelain crucible

Fritted glass filter or membrane filter

Filtering apparatus appropriate to filter selected

Remarks: 1. Interferences leading to high results are suspended matter, silica, barium chloride precipitant, nitrate, sulfite and water.

2. Interferences leading to low results are alkali metal sulfates, hydrogen sulfates of alkali metals, chromium and iron.

Edition:

(cont. on back)

$7 / 78$ 
3. A modification to this procedure for high $\mathrm{SiO}_{2}$ brines involves addition of $\mathrm{BaCl}_{2}$ to a hot $\mathrm{HCl}$ acidified ( $\mathrm{pH}$ adjusted to 1-2) sample. After this the solution is allowed to boil and the solid produced allowed to floculate and settle. The precipitate is filtered and ashed. The material is then fused witn iva ${ }_{2} \mathrm{CO}_{3}$ and $\mathrm{Na}_{2} \mathrm{O}_{2}$. The melt is then leached with water, cooled and filtered. Filtrate is acidified slowly with $\mathrm{HCl}$. Filtrate is evaporated and residue baked until dry. Residue is redissolved with water and filtered. Filtrate is acidified with $\mathrm{HCl}$ and boiled followed by treatment with $\mathrm{BaCl}_{2}$. Precipitate is filtered and ashed at $800^{\circ} \mathrm{C}$ and resulting solid weighed as $\mathrm{BaSO}_{4}$. (John Bricarello, Westec Services, Inc., Calipatria, CA).

4. Samples containing suspended or insoluble material must be filtered before analyses.

5. A cleanup procedure when large amounts of calcium are present is presented below:

Sulfate analysis by $\mathrm{BaCl}_{2}$ - thorin titration can be done after running sample through cation exchange resin mainly to remove calcium. An alternative cleanup technique would be to run sample through an ammonium exchanger on an aluminum support. 
Analysis: Turbidimetric

\begin{tabular}{|l|l|}
\hline No. & $198-\mathrm{A}$ \\
\hline
\end{tabular}

Method: Sulfate is converted to a barium sulfate colloidal suspension under controlled conditions. The concentration of the sulfate is then determined turbidimetricaliy.

Sample Handling: Use filtered unacidified or raw unacidified brine.

\begin{tabular}{l|l} 
Range: $500-1500 \mathrm{mg} / 1$ & \multicolumn{1}{c}{ Precision: $\pm 9 \%$} \\
\hline Cross Reference: & Literature Reference: \\
Appendix 2 & APHA 427-C (1975) \\
Sampling Methods: 11-S, 29-S & ASTM D516-68 B (1977) \\
Analysis Methods: 31-A, 197-A & API 2.72 (1968) \\
& EPA 00945 (1976) \\
\hline Reagents: & Equipment: \\
Glycerol & Magnetic stirrer \\
Hydrochloric acid & Nephelometer or spectrophotometer to measure at \\
Ethyl alcohol (95\%) or isopropyl & 420 nm or filter photometer with violet \\
alcohol & filter having maximum transmittance at $420 \mathrm{~nm}$. \\
Sodium chloride & Stopwatch \\
Barium chloride & Measuring spoon 0.2-0.3 ml. capacity \\
Sulfuric acid & \\
Sodium sulfate & \\
Gylcerol (option) & \\
\hline
\end{tabular}

Remarks: 1 . Color or suspended matter in large amounts interferes. Suspended matter may be removed by filtration.

2. Silica in excess of $500 \mathrm{mg} / 1$ interferes.

3. Precision and accuracy may be influence by the ionic strength of some brines. 
4. A conditioning reagent of glycerol-sodium chloride solution can be added to stabilize the suspension and minimize interferences.

5. All parameters of the method must be closely controlled in order to obtain reproducible results, i.e. acid concentration, crystal size of $\mathrm{BaCl}_{2}$, stirring time, and loose time between adding $\mathrm{BaCl}_{2}$ crystals and spectrophotometric reading. 


\section{$\mathrm{SO}_{4}$}

Sulfate

Analysis: Atomic Absorption

No. 199-A

Method: The sample containing sulfate is treated with a quantitative excess of barium chloride. The amount of barium remaining in solution following precipitation of barium sulfate is determined by atomic absorption, using a nitrous oxide-acetylene flame and measuring the absorbance at $553.6 \mathrm{~nm}$.

Sample Handling: Use filtered unacidified or raw unacidified brine.

Range:

Precision:

Accuracy:

Cross Reference:

Appendix 2

Sampling Methods: 11-S, 29-S

Analys is Methods: 32-A, 200-A

\section{Reagents:}

Barium chloride

Barium atomic absorption standard

solution

Nitrous oxide gas cylinder

Potassium chloride or potassium

nitrate

\section{Literature Reference:}

Instrument Manufacturer's Std. Methods Manua 1

\section{Equipment:}

Atomic absorption spectrophotometer

Filtration apparatus

Nitrous oxide burner head

Remarks: 1. Barium is partially ionized in the nitrous oxide-acetylene flame. This ionization can be suppressed by adding $2000 \mathrm{ppm} \mathrm{K}$.

2. Careful matrix matching between sample and standards must be made (i.e. use same amounts of $\mathrm{NaCl}$, alkali metal and alkaline earth metal ions).

3. Graphite furnace atomization may be used for barium instead of the nitrous oxide-acetylene flame.

Edition; 


\section{$\mathrm{SO}_{4}$}

Sulfate

Analysis: Flame Emission - Indirect

$200-A$

Method: Sulfate is determined by precipitation of the sulfate in acid solution with barium chloride. The barium sulfate is removed by centrifugation, washed with acetone and water and dissolved in warm EDTA at pH of 10.5. The solution is aspirated into a nitrous oxide-acetylene flame and the emission intensity at $553.5 \mathrm{~nm}$ is measured using a spectrophotometer.

Sample Handling: Use filtered unacidified or raw unacidified brine.

Range: $\quad 40-1000 \mathrm{mg} / 1$

Precision: $\pm 2 \%$

Accuracy: $\pm 2 \%$

\section{Cross Reference:}

Appendix 2

Sampling Methods: 11-S, 29-S

Analys is Methods: 33-A, 199-A

\section{Reagents:}

Barium chloride

Barium atomic absorption standard solution

Nitrous oxide gas cylinder

Potassium chloride or potassium

nitrate

Acetone

EDTA

Thymol blue indicator

Leconal wetting agent

\section{Literature Reference:}

Cullum, D. C., and D. B. Thomas, Analyst 85, 1960, 668.

\section{Equipment:}

Atomic absorption spectrophotometer with emission mode or flame emission spectrophotometer

Vitrous oxide burner head

Centrifuge

Remarks: 1. Barium is partially ionized in the nitrous oxide-acetylene flame. This ionization can be suppressed by adding $2000 \mathrm{ppm} \mathrm{K}$.

2. Careful matrix matching between sample and standards must be made (i.e. use same amounts of $\mathrm{NaCl}$, alkali metal and alkaline earth metal ions).

Edition: 
Sulfate

Analysis: Ion Exchange Chromatography

No. $201-\mathrm{A}$

Method: Anion components are separated on sulfonated cation exchange columns coated with finely ground anion resin. A solution of sodium bicarbonate-sodium carbonate is used to elute sulfate from the column. The separation column is followed by a suppressor column which removes high background conductivity due to the solvent. Ions areidetected with a conductivitv detectonr.

Sample Handling: Use raw or filtered unacidified brine or filtered acidified brine.

Range:

Precision: $\pm 0.06 \%$

Accuracy: $\quad \pm 5 \%$

Cross Reference:

Literature Reference:

Appendix 2

Sampling Methods: 11-S, 29-S

Dionex Corp., Sunnyvale, CA Literature.

Ana 1. Chem., 47 (17), 1801 (1975).

Microchem. J., 22, 45 (1977).

Anal. Chem., 49 (3), 401 (1977).

Reagents:

Equipment:

Sulfuric acid, sodium sulfate, or other sulfate standard

Ion exchange chromatograph

$\mathrm{NaHCO}_{3}$

$\mathrm{Na}_{2} \mathrm{CO}_{3}$

Remarks: 1. Additional reference: Sma11, H., T. S. Stevens, and W. C. Bauman, Anal. Chem., 47, 1801 (1975).

Edition:

$7 / 78$ 
Analysis: Titrimetric (Iodine)

\begin{tabular}{|l|l|}
\hline No. & $202-\mathrm{A}$ \\
\hline
\end{tabular}

Method: Sulfide is indirectly determined by stripping hydrogen sulfide from an acidified sample with an inert gas. Hydrogen sulfide is collected in zinc acetate solution to which excess iodine in water is added to oxidize sulfide to elemental sulfur. Excess iodine is titrated with thiosulfate.

Sample Handling: Use filtered unacidified or raw unacidified brine.

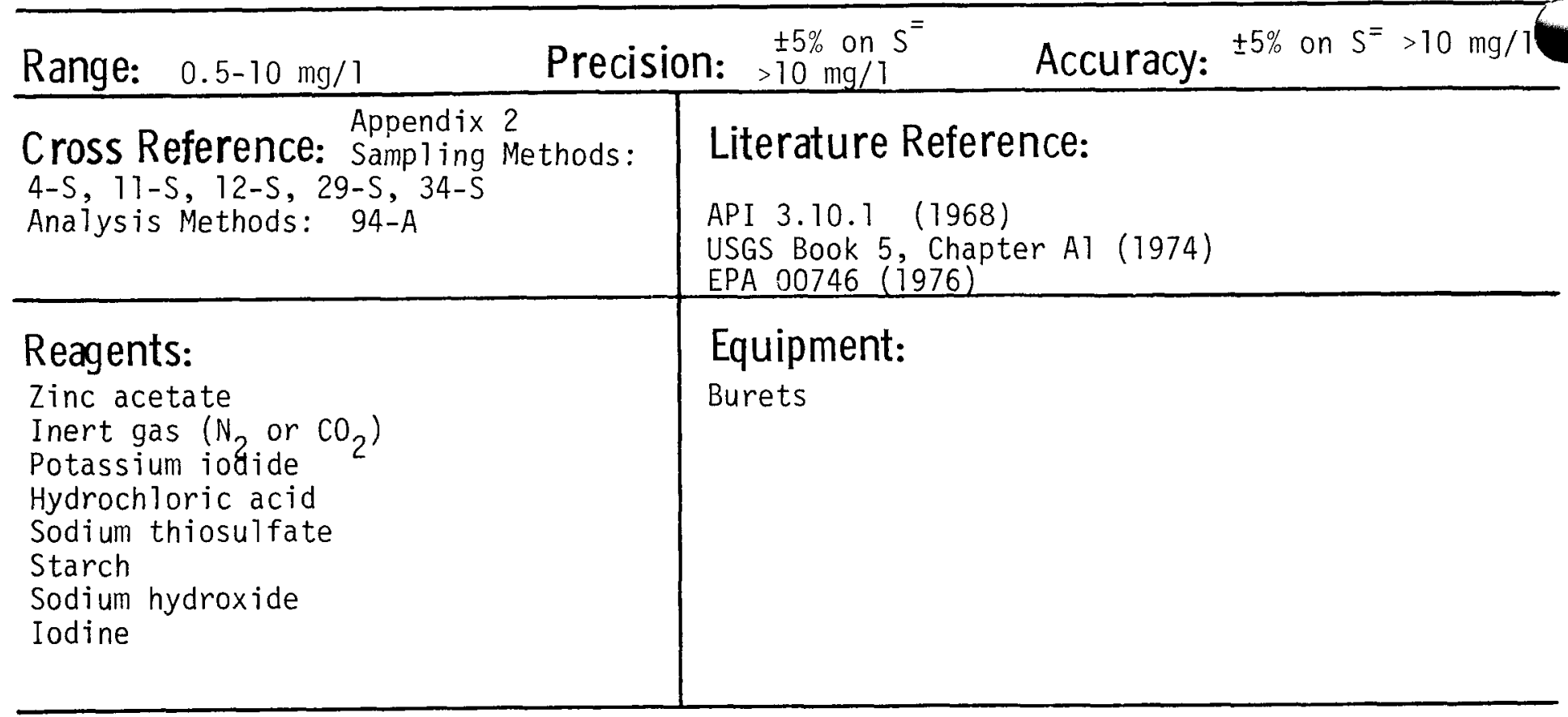

Remarks: 1. Reducing substances such as heavy metal ions, sulfite, thiosulfate and hydrosulfite will use up iodine and contribute positive errors.

2. Oxygen and other oxidants react with hydriodic acid and contribute negative errors.

3. Field analysis for sulfide is advised.

Edition:

4. Alternatively $\mathrm{ZnS}$ is decanted, distilled water washed and returned the

$7 / 78$ contents acidified to the original container. Iodine standard solution is added with hydrochloric acid and the test proceeds as before [APHA 428D (1975)]. 
Sulfide

Analysis: Antimony Test (Qualitative)

203-A

Method: The sample is treated with potassium antimony tartrate in the presence of hydrochloric acid. Yellow antimony sulfide, $\mathrm{Sb}_{2} \mathrm{~S}_{3}$, is discernible at sulfide concentrations greater than $0.5 \mathrm{mg} / 1$.

Sample Handling: Use raw unacidified or filtered unacidified brine.

Range: $>0.5 \mathrm{mg} / 1$ Precision: Accuracy:

Cross Reference:

Appendix 2

Sampling Methods: 4-S, 11-5, 12-5, 29-S, 34-S

\section{Reagents:}

Potassium antimony tartrate Hydrochloric acid

\section{Literature Reference:}

APHA 428 (1975)

\section{Equipment:}

Remarks: 1. Metallic ions such as lead interfere because the sulfide is held so firmly that it does not produce antimony sulfide.

2. Dithonite, which decomposes in acid solution to produce sulfide, interferes.

Edition:

$7 / 78$ 
Sulfide

Analysis: Colorimetric (Methylene Blue)

\begin{tabular}{|l|l|}
\hline No. & $204-\mathrm{A}$ \\
\hline
\end{tabular}

Method: Methylene blue is formed when sulfide is reacted with 4-amino-N, Ndimethylaniline in the presence of ferric chloride. Ammonium phosphate is then added to destroy excess Fe(III). The color is measured at $600 \mathrm{~nm}$.

Sample Handling: Use filtered unacidified or raw unacidified brine.

Range. $0.01-1.0 \mathrm{mg} / \mathrm{l}$

Range: $0.2-400 \mu \mathrm{g} / 1$ (Lauth's Precision:

Accuracy:

Violet)

Cross Reference: Appendix 2

Sampling Methods: 4-A, 11-S, 12-A, 29-S, 34-S

Analysis Methods: $95-\mathrm{A}$

\section{Literature Reference:}

APHA 428 C (1975)

API $3.10 .2(1968)$
Reagents:

Zinc acetate

Sodium carbonate

$\mathrm{N}, \mathrm{N}$-dimethy $\mathrm{l}$-phenylene-diamine

Potassium Iodide

Sodium Thiosulfate

Hydrochloric acid

Equipment:

Spectrophotometer to measure at $600 \mathrm{~nm}$

Burets

oxalate (also called p-amino-

dimethylamiline oxalate)

Sulfuric acid

Ferric chloride

Diammonium hydrogen phosphate

Sodium sulfide

Iodine

Sodium Hydroxide Starch

Remarks: 1. Reducing substances such as heavy metal ions, sulfite, thiosulfate and hydrosulfite inhibit color formation.

2. Field analysis for sulfide is advised.

3. A modification of this method using Lauth's violet dye instead of methylene blue gives more consistent color development with brine samples

Edition: (Strickland and Parsons, "A Practical Handbook of Seawater Analys is",

$7 / 78$ Fisheries Research Board of Canada, Ottawa, 1968, p. 41-44.) 
Sulfide

Analysis: Specific Ion Electrode

No. $205-\mathrm{A}$

Method: The potential of a silver sulfide-silver electrode relative to a reference electrode is measured in the sample. A series of sulfide standards is used to determined the potential-concentration relationship.

Sample Handling: Use filtered unacidified or raw unacidified brine.

Range:

Precision:

Accuracy:

Cross Reference:

Appendix 2

Sampling Methods: 4-S, 11-S, 12-S, $29-\mathrm{S}, 34-\mathrm{S}$

\section{Reagents:}

Sodium sulfide or other sulfide standard

EDTA

Sodium hydroxide

Ascorbic acid

\section{Literature Reference:}

Analytical Letters, I (13), 825 (1968).

Anal. Chem., 44 (5), 270 (1972).

Orion Res. Inc., Cambridge, MA Literature

\section{Equipment:}

Sulfide specific ion electrode

Remarks:1. Antioxidant buffer should be added in the field to avoid negative errors from oxidation.

2.Field analysis for sulfide is advised.

3.Standard additions should be made to verify results.

Edition: 


\section{Sulfide}

Analysis: X-Ray Fluorescence

$206-\mathrm{A}$

Method: Liquid samples are made to fluoresce by $x$-ray bombardment. Secondary

fluorescence is separated into wavelengths by a crystal and the

radiation is detected by a scintillation counter or a flow proportional

counter. A vacuum is required for the lighter elements. Standardization

of instrument required.

Sample Handling: Use filtered unacidified or raw unacidified brine.

Range: Precision: Accuracy:

\section{Cross Reference:}

Appendix 2 Sampling Methods: 4-S, $11-5,12-5$, 29-S, 34-S

\section{Reagents:}

Sodium sulfide or other sulfide standard
Literature Reference:

Nuc. Inst. and Methods, Vol. 106, pp. 525-538 (7973).

\section{Equipment:}

$X$-ray fluorescence spectrophotometer

\section{Remarks:}


Sulfide

Analysis:

Spark Source Mass Spectrometry

\begin{tabular}{|l|l|l|l|}
\hline No. & $207-A$ \\
\hline
\end{tabular}

Method: Dehydrated sample is vaporized and ionized by an arc source and enters an evacuated chamber. Sulfur is separated and detected by its mass/charge ratio, and determined quantitatively by comparison with standards,

Sample Handling: Use filtered unacidified or raw unacidified brine. Evaporate samples and analyze residue.

Range: $0.1-1000 \mathrm{mg} / 1 \quad$ Precision: $\pm 25 \% \quad$ Accuracy: $\pm 2.5 \%$

Cross Reference:

Appendix 2

Literature Reference:

Sampling Methods: 4-S, 11-S, 12-S, 29-S, 34-S

Trace Analysis by Mass Spectrometry, A. J. Aheard, ed., Academic Press, NY (1977).

D. L. Donohue, J. A. Carter and J. C. Franklin, Ana 1. Letters, 10(5) 371-379 (1977).

\section{Reagents:}

Sodium sulfide or other sulfide standard

\section{Equipment:}

Spark source mass spectrometer

\section{Remarks:}

Edition:

$7 / 78$ 
Analysis: Neutron Activation

No. $208-\mathrm{A}$

Method: Sample is exposed to neutron source (reactor) and radioactive sulfur isotopes are formed. The isotopes and their associated beta and gamma spectra are identified by multichannel analyzers. The amount of sulfide present is proportional to the measured activity.

Sample Handling: Use raw acidified or filtered acidified brine. Evaporate samples and irradiate residue with neutron source.

Range: Precision: Accuracy:

\section{Cross Reference:}

Appendix 2

Sampling Methods: 4-S, 11-S, 12-S, 29-S, 34-S
Literature Reference:

Robertson and Carpenter, "Neutron Activation Techniques for the Measurement of Trace Metals in Environmental Samples", NAS-NS-3114, Jan. 1974.

Reagents:

\section{Equipment:}

Reactor (neutron source)

Multichannel analyzer

Remarks: Sufficient time must be allowed for sodium decay if the sodium spectrum masks the element of interest.

Edition: 


\section{SUSPENDED
SOLIDS}

Suspended Solids

Analysis: Gravimetric

No. 209-A

Method: Suspended solids (nonfiltrable residue) are usually determined in conjunction with filtrable solids and total solids content. Suspended solids are determined directly by filtering sample through a tared filter, drying at $103-105^{\circ} \mathrm{C}$ and veighing.

Sample Handling: Use raw unacidified brine. Analyze as soon as possible.

Range: $5-10,000 \mathrm{mg} / 1$

Precision: $\pm 25 \%$

Accuracy:

Cross Reference:

Sampling Methods:

Analys is Methods:

213-A

Appendix 2

$11-S, 29-S$

210-Ä, 211-A, 212-A,

Literature Reference:

APHA 208 D (1975)

EPA $00530(1976)$

USGS Book 5, Chapter A1 (1974)

ASTM D1888-67A (1977)

Reagents:

None

\section{Equipment:}

Gooch crucible or membrane filter apparatus

Suction flash and appropriate crucible holder

Glass fiber filter inats or inieibrane filters

Drying oven

Desiccator

Analytical balance

Remarks: 1. Accuracy cannot be obtained since the true concentration of suspended matter is unknown.

2. Too much residue on filter will crust over and entrap water that will not be driven off during drying. Total residue should be limited to about $200 \mathrm{mg}$.

3. Filtration into pre-weighed crucibles on-site would be a preferred method. 
4. Precipitation of iron, manganese, and silica in highly concentrated brines causes higher results than would be obtained on site. 
Analysis: Gravimetric

No. $210-\mathrm{A}$

Method: A sample is filtered through a membrane filter, evaporated in a tared drying dish, oven dried and weighed for nonfilterable residue.

Sample Handling: Use filtered unacidified brine.

\begin{tabular}{|c|c|c|}
\hline \multicolumn{3}{|c|}{ Precision: $\begin{array}{ll} \pm 10 \% \text { Below } 25 \mathrm{mg} / \text { Accuracy: } & \pm 10 \% \text { Be low } 25 \mathrm{mg} / 1 \\
\pm 5 \% \text { Higher } & \text { Higher }\end{array}$} \\
\hline $\begin{array}{l}\text { Cross Reference: } \\
\text { Appendix } 2 \\
\text { Sampling Methods: } 1 \\
\text { Analysis Methods: } 2 \\
\end{array}$ & $\begin{array}{l}11-S, 29-S \\
209-A\end{array}$ & $\begin{array}{l}\text { Literature Reference: } \\
\text { APHA } 208 \text { B, C (1975) } \\
\text { ASTM D1888-67A (1977) } \\
\text { EPA 70300 (1976) } \\
\text { USGS Book 5, Chapter Al (1974) }\end{array}$ \\
\hline $\begin{array}{l}\text { Reagents: } \\
\text { Drierite }^{R} \text { or silica }\end{array}$ & ge 7 & $\begin{array}{l}\text { Equipment: } \\
\text { Evaporating dishes } \\
\text { Drying oven } \\
\text { Desiccator } \\
\text { Analytical balance }\end{array}$ \\
\hline
\end{tabular}

Remarks: 1. Highly mineralized waters with considerable calcium, magnesium, chloride, and/or sulfate content may be hygroscopic and require prolonged drying, proper desiccation and rapid weighing.

2. Samples high in bicarbonate require careful and possibly prolonged drying at $180^{\circ} \mathrm{C}$ to insure complete conversion of bicarbonate to carbonate.

Edition: $\quad 3$. Too much residue in evaporating dish will crust over and entrap water $7 / 78$ that will not be driven off during drying. Total residue should be limited to about $200 \mathrm{mg}$.

$$
\text { (cont, on back) C-214 }
$$


4. Under certain conditions $\mathrm{SiO}_{2}$ will settle out of brine solution upon standing. Better results should be obtainable using the suspended solids filtrate (filtered on site) and then include any further precipitation with TDS. 
Turbidity

Analysis: Absorptometric

\begin{tabular}{|l|l|l|}
\hline No. & $211-\mathrm{A}$ \\
\hline
\end{tabular}

Method: Sample is inserted into a spectrophotometer and the amount of light not attenuated by the sample is detected. Results are determined in formazin turbidity units (= Jackson candle units).

Sample Handling: Use RU brine, determine as quickly after collection as possible.

Range: $0.7-1000$ FTU

Cross Reference:

Sampling Methods:

Analys is Methods:

Appendix 2

$11-S, 29-S$

$209-A, 212-A, 213-A$

Precision: $\quad \pm 1 \%$

Accuracy: $\pm 1 \%$

\section{Literature Reference:}

Hach manua 1

\section{Equipment:}

Spectrophotometer or filter photometer

Remarks:1-Interferences: true color, air bubbles, settleable matter, dirty glassware.

2-Unstable brines will yield changes in turbidity with time; field analysis of turbidity recommended.

Edition:

7/78 
Analysis: Visual Matching

No. $212-\mathrm{A}$

Method: Turbidity of sample is visually measured against turbidity standards made of Kaolin, formazin, or similar material.

Sample Handling: Use RU brine; determine as quicklv after collection as possible.

Range:

Precision:

Accuracy:

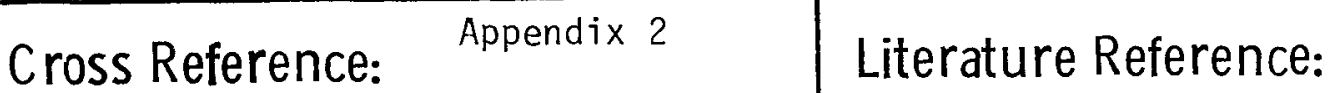

Sampling Wethods: 11-S, 29-S

Analysis Methods: 209-A, 211-A, 213-A

APHA 214 B

"Eco Lab" Literature

Reagents:

\section{Equipment:}

Kaolin

bottles or test tubes or commercial material

Remarks: 1. Interferences: rapidly settleable matter, color, air bubbles.

2. Unstable brines will yield changes in turbidity with time; field analysis of turbidity recommended. Commercial kits available.

3.Precipitation of iron, manganese and silica in highly concentrated brines can cause color which contributes to error.

Edition: 
Analysis: Nephelometric (Turbidimetric)

$213-A$

Method: Scattered light from a turbidity sample is measured at right angles to the incident light in a nephelometer and compared with standard formazin turbidity solutions.

Sample Handling: Use RU brine; determine as quickly after collection as possible.

Range: $0.01-100 \mathrm{NTU} \quad$ Precision: $\pm 1 \%$ Accuracy: $\pm 1 \%$

Cross Reference: Appendix 2

Sampling Methods: 11-S, 29-S

Analysis Methods: 209-A,217-A, 212-A

Reagents:

Standard formazin turbidity solutions
Literature Reference:

APHA 214 (75)

ASTM D1889-71 (77)

EPA 00076 (76)
USGS Book 5 , Chapter AI (1974)

Equipment:

Nephelometer (Turbidimeter)

Remarks: 1. Interferences: true color, air bubbles, quickly settleable matter, dirty glassware.

2. Results reported in nephelometric turbidity units.

3. Unstable brines will yield changes in turbidity with time; field analysis of turbidity recommended.

Edition:

$7 / 78$ 


\section{$\mathrm{Zn}$}

Zinc

Analysis: Atomic Absorption $214-A$

Method: Zinc is determined by aspirating the sample into an air-acetylene flame of an atomic absorption spectrophotometer. The intensity of the zinc absorbance at $213.9 \mathrm{~nm}$ is measured and is proportional to the zinc concentration.

Sample Handling: Use raw acidified or filtered acidified brine. Sample may be stabilized by adding $5 \mathrm{ml} \mathrm{HNO}_{3}$ per liter.

Range: (1inear) $0.05-7 \mathrm{mg} / 1$ Precision: $\pm 5 \%$

Accuracy: $\pm 10 \%$

Cross Reference:

Appendix 2

Sampling Methods: 11-S, 29-S

Analys is Methods: $215-\mathrm{A}$
Literature Reference:

EPA 01092 (1976)

APHA 301 A (1975)

USGS Book 5, Chapter Al (1974)

Instrument Manufacturer's Std. Methods Manual

\section{Equipment:}

Atomic absorption spectrophotometer

ASTM D2576-70

D1691-77C (1977) tion or zinc metal

Hydrochloric acid if zinc metal is used

Reagents:

Zinc atomic absorption standard solu-

Remarks: 1. No chemical interferences in an air-acetylene flame.

2. Non atomic species absorb strongly in an air acetylene flame. Use of a deuterium background correction system is recommended.

3. Careful matrix matching between sample and standards must be made (i.e. use same amounts of $\mathrm{NaCl}$, other alkali metal and alkaline earth metal ions).

Edition:

4. Use of a graphite furnace will increase sensitivity.

$7 / 78$

(Cont. on back)

C-218 
5. If sample shows Tyndall effect, filter through $0.45 \mu \mathrm{m}$ membrane filter.

6. Sodium and calcium cause spectral interferences which must be corrected. Sodium interferences cannot be corrected by using $D_{2}$ background compensation.

7. Use of standard additions recommended. 
Zinc

Atomic Absorption Using

Analysis: APDC and MIBK Extraction

\begin{tabular}{l|l|}
\hline No. & $215-\mathrm{A}$ \\
\hline
\end{tabular}

Method: Zinc is chelated with ammonium pyrrolidine dithiocarbamate (APDC) and extracted with mthyl isobutyl ketone (MIBK). The extract is then aspirated directly into an air acetylene flame of an atomic absorption spectrophotometer. The intensity of the siiver absorbance at $213.9 \mathrm{~nm}$ is measured and is proportional to the zinc concentration.

Sample Handling: Use filtered acidified or raw acidified brine.

Range: $<0.2 \mathrm{mg} / 1 \quad$ Precision: $\pm 10 \% \quad$ Accuracy: $\pm 10 \%$

Cross Reference:

Appendix 2

Sampling Methods: 11-S, 29-S

Analys is Methods: $214-A$

Reagents:

Zinc atomic absorption standard solution or zinc metal

Hydrochloric acid if zinc metal is used

Literature Reference:

APHA 301 A (1975)

Methyl isobutyl ketone

Ammonium pyrrolidine dithiocarbamate

\section{Equipment:}

Atomic absorption spectrophotometer

Separatory funnels

Remarks: 1. No chemical interferences in an air-acetylene flame.

2. Non atomic species absorb strongly in an air-acetylene flame. Use of a deuterium background correction system is recommended.

3. Careful matrix matching between sample and standards must be made (i.e. use same amounts of $\mathrm{NaCl}$, other alkali metal and alkaline earth metal ions).

Edition:

$7 / 78$

4. Use of a graphite furnace will increase sensitivity.

$$
\text { (cont, on back) C-219 }
$$





\section{$\mathrm{Zn}$}

Zinc

Analysis: Inductively Coupled Plasma-Atomic

Analysis: Emission Spectroscopy

No. $216-A$

Method: Sample is aspirated into the argon plasma and the intensity of the emission spectrum is analyzed and compared with standards. Intensity is measured at $213.86 \mathrm{~nm}$ or alternate wavelength.

Sample Handling: Use filtered acidified or raw acidified brine.

3-5 orders of magnitude from

Range: a single spectral line Precision: $\pm 1-10 \%$

Accuracy:

Cross Reference:

Appendix 2

Sampling Methods: 11-S, 29-S

\section{Literature Reference:}

Evaluation of an Inductively Coupled Plasma, Multichannel Spectrometric Analys is System, EPA-600/4-77-032, June 1977.

\section{Reagents:}

Zinc metal or other zinc standard Hydrochioric acid (to dissolve zinc)

\section{Equipment:}

Inductively coupled plasma-atomic emission spectrometer

Remarks: 1. External standards using $\mathrm{NaCl}$ concentrations equivalent to sample concentrations of $\mathrm{NaCl}$ are required.

2. Additional reference: R. H. Scott and M. L. Kokot, "Application of Inductively Coupled Plasmas to the Analys is of Geochemical Samples", Anal. Chim. Acta 75, 257-270 (1975).

Edition: 
3. Background correction and standard additions method recommended.

4. Upper limit of concentration range may be extended by using alternate spectral lines. 


\section{$\mathrm{Zn}$}

Zinc

Analysis: Spark Source Mass Spectrometry

\begin{tabular}{|l|l|l|}
\hline No. & $217-A$ \\
\hline
\end{tabular}

Method: Dehydrated sample is vaporized and ionized by an arc source and enters an evacuated chamber. Zinc is separated and detected by its mass/charge ratio, and determined quantitatively by comparison with standards.

Sample Handling: Use filtered acidified, raw acidified, filtered unacidified, or raw unacidified brine. Evaporate samples and analyze residue.

Range: $0.1-1000 \mathrm{mg} / 1$

Precision: $\pm 2 \%$

$\pm 5 \%$ (isotope dil.)

Cross Reference:

Appendix 2

Sampling Methods: 11-S, 29-S

Literature Reference:

Trace Analysis by Mass Spectrometry, A. J. Aheard, ed., Academic Press, NY (1977).

D. L. Donohue, J. A. Carter and J. C. Franklin, Ana 1. Letters, 10(5) 371-379 (1977).

\section{Reagents:}

Zinc metal or other zinc standard Hydrochloric acid (to dissolve zinc)

\section{Equipment:}

Spark source mass spectrometer

Remarks: 1. Additional references: J. A. Carter, D. L. Donohue, and J. C. Franklin, Trace Substances in Environmental Health-IX. U. of Missouri, 303 (1975). J. C. Franklin, J. A. Carter, D. L. Donohue, and R. W. Stelzner, 23d Donf. on Mass Spectrometry and Allied Topics, Houston, TX 354 (1975). R. Alvarez, B. J. Paulsen, and D. E. Kelleher, Anal. Chem. 41955 (1969).

Edition: 
Zinc

Analysis: Neutron Activation

\begin{tabular}{|l|l|l|}
\hline No. & $218-\mathrm{A}$ \\
\hline
\end{tabular}

Method: Sample is exposed to neutron source (reactor) and radioactive zinc isotopes are formed. The isotopes and their associated beta and gamma spectra are iedntified by multichannel analyzers. The amount of zinc present is proportional to the measured activity.

Sample Handling: Use raw acidified or filtered acidified brine. Evaporate samples and irradiate residue with neutron source.

Range:

Precision:

Accuracy:

\section{Cross Reference:}

Appendix 2

Sampling Methods: 11-S, 29-S
Literature Reference:

Robertson and Carpenter, "Neutron Activation Techniques for the Measurement of Trace Metals in Environmental Samples", NAS-NS-3114, Jan. 1974.

\section{Reagents:}

\section{Equipment:}

Reactor (neutron source)

Multichannel analyzer

Remarks: Sufficient time must be allowed for sodium decay if the sodium spectrum masks the element of interest. 


\section{$\mathrm{Zn}$}

Zinc

Analysis: Emission Spectrometry

No. 219-A

Method: The sample containing zinc in either solid or liquid state is vaporized

by a flame, $d-c$ arc, or a-c spark and the intensity of the selected

emission line is measured against standards.

Sample Handling: Use filtered acidified or raw acidified brine.

Range: $10-100 \mathrm{mg} / 1$

Precision:

$\pm 10 \%$

Accuracy:

Cross Reference:

Appendix 2

Sampling Methods: 11-S, 29-5

\section{Literature Reference:}

Instrument Manufacturer's Literature

\section{Equipment:}

Emission spectrometer

Photo processor

Microphotometer

Remarks: 1. Matrix matching (using equivalent amounts of alkali and alkaline earth metals) in standards important.

2. Large differences in matrix effects will be observed depending on the type of excitation source (flame, AC spark, or DC arc).

Edition: 
A. Standard and Recommended Methods Publications and Handbooks:

1. 1977 Annual Book of ASTM Standards, Part 37, Water, American Society for Testing and Materials, Philadelphia, PA, 1976.

2. API Recommended Practice for Analysis of Oiz-Field Waters, American Petroleium Institute, Dallas, TX, 1968.

3. Brown, Eugene, M.W. Skougstad, M.J. Fishman, Methods for Collection and Analysis of Water Samples for Dissolved Minerals and Gases, Book 5, Chapter A1, U.S. Geological Survey, Washington, D.C., 1974.

4. Douglas, J.G., R.J. Serne, D.W. Shannon, E.M. Woodruff, "Geothermal Water and Gas-Collected Methods for Sampling and Analysis", Comment Issue, BNWL-2094, August, 1976.

5. Hach Water Analysis Handbook, Hach Chemical Co., Ames, IA, 1976.

6. Methods for Chemical Analysis of Water and Wastes, Environmental Protection Agency, Environmental Monitoring and Support Laboratory, Cincinnati, $\mathrm{OH}, 1976$.

7. Presser, T.S. and Ivan Barnes, Special Techniques for Determining Chemical Properties of Geothermal Water, WRI-22-74, United States Geological Survey, Menlo Park, CA, August, 1974.

8. Standard Methods for the Examination of Water and Wastewater, 14th ed. American Public Health Association, Washington, D.C., 1975 .

B. Atomic Absorption and Flame Emission Spectroscopy:

1. "Analytical Methods for Atomic Absorption Spectroscopy Using the HGA Graphite Furnace", Perkin Elmer Corp., Norwalk, CT, Apri1, 1974.

2. Atomic Absorption Methods Manual, Vol. 1, Instrumentation Laboratory, Inc., Wi7mington, MA, 1976.

3. Dean, John A. and Theodore C. Rains, eds., Flame Emission and Atomic Absorption Spectrometry, Vol. III, Marcel Dekker, Inc., New York, 1975.

4. Snelleman, W. Spectrochim. Acta, 23B (1968) 403.

C. Incuctively Coupled Plasma-Atomic Emission Spectroscopy:

1. "Evaluation of an Inductively Coupled Plasma, Multichannel Spectrometric Analys is System", EPA-600/4-77-032, Environmental Protection Agency, Environmental Research Laboratory, Athens, GA, 1977. 
2. Scott, R. H. and M. L. Kokot, "Application of Inductively Coupled Plasmas to the Analysis of Geochemical Samples", Anal. Chim. Acta 75, (1975) 257.

3. R. K. Winge, V. A. Fassel, R. N. Kniseley, E. DeKalb, and W. J. Haas, Jr., "Determination of trace elements in soft, hard, and saline waters by the inductively coupled plasma, multi-element atomic emission spectroscopic (ICP-MAES) technique" Accepted for publication in Spectrochim. Acta.

D. Ion Exchange Chromatography:

1. Bouyoucos, Spiros A. "Determination of Ammonia and Methylamines in Aqueous Solutions by Ion Chromatography", Anal. Chem. 49 (3) (1977) 401 .

2. Ion Exchange Chromatography Literature, Dionex Corp., 1228 Titan Way, Sunnyvile, CA 94086.

3. Mulik, J., R. Puckett, D. Williams, E. Sawicki, "Ion Chroriatographic Analysis of Sulfate and Nitrate in Ambient Aerosols, Analytical Letters, 9 (7) (1976) 653.

4. Sma11, Hamish, T.S. Stevens, W.C. Bauman, "Novel Ion Exchange Chromatographic Method Using Conductimetric Detection", Anal. Chem. 47 (11) (1975) 1801 .

5. Smith Jr., F., A. McMurtrie, H. Galbraith, "Ion Chromatographic Determination of Sulfur and Chlorine Using Milligram and Submilligram Sample Weights", Microchem. J. 22 (1977) 45.

E. X-Ray Fluorescence:

1. Cooper, J.A. "Comparison of Particle and Photon Excited X-Ray Fluorescence Applied to Trace Element Measurements of Environmental Samples", Wue. Inst. and Methods, 206 (1973) 525.

F. Neutron Activation:

1. Robertson, D.E. and R. Carpenter, "Neutron Activation Techniques for the Measurement of Trace Metals in Environmental Samples", NAS-NS-3114, January 1974.

G. Ion Selective Electrodes:

1. Buck, Richard P., "Ion Selective Electrodes, Potentiometry and Potentiometric Titrations," Anal. Chem. 44(5) (1972) 270.

2. Light, Truman S. and H. L. Swartz, "Analytical Evaluation of the SiTver Sulfide Membrane Electrode," Analytical Letters, I(13) (1968) 825 .

3. Orion Research Electrode Literature, Orion Research, Inc., 380 Putnam Av., Cambridge, MA, 02139.

H. Miscellaneous References:

1. Bolleter, W.T., Bushman, C.J. and Tidwell, P.H., Anal. Chem., 33 , (1961) 592 . 
2 Burdick and Jackson Labs, Inc., 1953 S. Harvey St., Muskegon, MI 49442 (Amadac FR Procedure for Fluoride).

3. Cullum, D.C., and D.B. Thomas, Anazyst 85 (1960) 668.

4. Fischer, Robert B. and Dennis G. Peters, Quantitative Chemical Analysis, 3rd ed., W.B. Saunders Co., Philadelphia, PA, 1968.

5. Furman, N.H., ed., "Scott's Standard Methods of Chemical Analysis", D. Van Nostrand, Princeton, NJ, 1962.

6. Kolthoff, I.M. and E.B. Sande11, "Textbook of Quantitative Inorganic Analysis", MCMillan and Co., NY 1952.

7. Technicon Auto Analyzer Industrial Method 98-70W Revised.

I. Radioactive Counting:

i. Gibson, W. M., "The Radiochemsitry of Lead," NAS-NS 3040, August, 1961.

2. Grindler, James E., "The Radiochemistry of Uranium," NAS-NS 3050, March, 1962.

3. Harley, J. R., ed., HASL Procedures Manual, Health and Safety Laboratory, HASL-300, August, 1974.

4. Johns, Frederick B., ed., Handbook of Radiochemical Methods, EPA-630/4-75-001, February, 1975.

5. Moore, F. L., "Radiochemical Determination of Ionium in Uranium Fluorination Ash," Anal. Chem. 30 (1958) 1020.

6. "Radium 226: Analysis, Principles, Interferences and Practice," National Lead Co., Inc., WIN-112, February 1, 1960.

7. Smith, Helen L., ColZected Radiochemical Procedures, 4th ed., LA-1721, UC-4, Chemistry, Apri1, 1975.

8. Trujillo Jr., P. E., "Analytical Procedures for the Determination of Padionuclides in Air Filters, Water and Soils, "Los Alamos Scientific Laboratory, H8-MR-72-3, May, 1972.

J. Colorimetric Techniques:

1. Boltz, D. F., Colorimetric Determination of Nonmetals, Interscience Publishers, Inc., Hew York, 1958.

K Spark Source Mass Spectrometry:

1. Aheard, J.A., ed., Trace Analys is by Mass Spectrometry, Academic Press, NY, 1977.

2. Alvarez, R., B.J. Paulsen, and D.E. Kelleher, Anal. Chem. 41 955 (1969).

3. Carter, J. A., D. L. Donohue, and J. C. Franklin, "Trace Substances in Environmental Health, IX," U. Of Missouri, 303 (1975). 
4. Donohue, D. L., J. A. Carter, and J. C. Frank1in, Analytical Letters, 10(5) (1977) 371.

5. Franklin, J. C., J. A. Carter, D. L. Donohue, and R. W. Stelzner, 23rd Conference on Mass Spectometry and Allied Topics, Houston, TX (1975). 


\section{Correction of Brine Component Concentrations for \\ Steam Loss During Flashing}

It may be necessary to correct the concentration of a dissolved brine component for steam loss. This can be estimated for a single stage flash if the concentration of that component after the flash is known along with the temperatures of the brine before and after flashing, the heat capacity and the heat of vaporization of the liquid at the flash temperature. The concentration of the component before flashing is calculated using the equation:

$$
A=B\left(1-\frac{C p \Delta T}{\Delta H}\right)
$$

where $A$ is the concentration before flashing, $B$ is the concentration after flashing and steam loss, $\Delta T$ is the temperature change during the flash in degrees centigrade, $\mathrm{Cp}$ is the heat capacity of the Tiquid, and $\Delta H$ is the heat of vaporization at the temperature of the flashed brine. $\Delta \mathrm{H}$ and $\mathrm{Cp}$ are dependent on the weight percent $\mathrm{NaCl}$ and the values used in the equation should be those values corresponding to the weight percent $\mathrm{NaCl}$ in the flashed sample. $C p$ and $\Delta H$ values at various weight percentages of $\mathrm{NaCl}$ are given in Tables 1 and 2 respectively.

Examples of this type of calculation are given below:

Example 1: Data is taken from "Geothermal Loop Experimental Facility," San Diego Gas \& Electric Bi-Monthly Report, SAN/1137-6, May 1977, by H. K. Bishop, J. R. Bricare110, F. L. Enos, N. C. Hodgson, W. O. Jacobson, K. K. Li, and C. R. Swanson.

From Table 2-1 of this report, the conditions of the GLEF using Woolsey \#1 well are:

Inlet

1st Stage flash unit

2nd Stage flash unit 3rd Stage flash unit 4th Stage flash unit
Temperature $\left({ }^{\circ} \mathrm{F}\right)$ 399.6

284.4

194.5 
TABLE 1

Heat Capacities ( $\mathrm{cal} \mathrm{deg}^{-1} \mathrm{~g}^{-1}$ ) for solutions containing various weight percentages of $\mathrm{NaCl}$

Cp

Temp.

$\% \mathrm{NaCl}$

$\begin{array}{llll}0 & 5 & 10 & 15\end{array}$

20

25

30 35

$\stackrel{\circ}{\circ}$

80

85

90

95

100

105

110

115

요 120

125

130

135

140

145

150

155

160

165

170

175

180

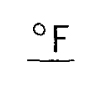

176

185

194

203

212

221

230

239

248

257

266

275

284

293

302

311

320

329

338

347

356

\begin{tabular}{|c|c|c|c|c|c|c|}
\hline 0.996 & 0.936 & 0.874 & 0.809 & 0.740 & 0.664 & \\
\hline 0.997 & 0.937 & 0.876 & 0.812 & 0.745 & 0.671 & \\
\hline 0.997 & 0.938 & 0.878 & 0.815 & 0.749 & 0.678 & \\
\hline 0.998 & 0.939 & 0.880 & 0.818 & 0.754 & 0.684 & \\
\hline 0.998 & 0.940 & 0.882 & 0.821 & 0.758 & 0.690 & \\
\hline 0.999 & 0.941 & 0.883 & 0.824 & 0.762 & 0.696 & \\
\hline 0.999 & 0.942 & 0.884 & 0.826 & 0.765 & 0.701 & \\
\hline 0.999 & 0.943 & 0.892 & 0.839 & 0.786 & 0.729 & \\
\hline 1.000 & 0.945 & 0.892 & 0.839 & 0.786 & 0.730 & \\
\hline 1.001 & 0.945 & 0.892 & 0.840 & 0.786 & 0.730 & \\
\hline 1.001 & 0.946 & 0.893 & 0.840 & 0.786 & 0.731 & \\
\hline 1.002 & 0.946 & 0.893 & 0.840 & 0.786 & 0.731 & \\
\hline 1.003 & 0.946 & 0.893 & 0.840 & 0.786 & 0.731 & \\
\hline 1.003 & 0.947 & 0.893 & 0.840 & 0.786 & 0.731 & \\
\hline 1.004 & 0.947 & 0.893 & 0.840 & 0.786 & 0.730 & \\
\hline 1.005 & 0.948 & 0.893 & 0.839 & 0.786 & 0.730 & \\
\hline 1.006 & 0.948 & 0.893 & 0.839 & 0.785 & 0.730 & 0.669 \\
\hline 1.007 & 0.949 & 0.893 & 0.839 & 0.785 & 0.729 & 0.668 \\
\hline 1.008 & 0.949 & 0.894 & 0.839 & 0.784 & 0.728 & 0.668 \\
\hline 1.009 & 0.950 & 0.894 & 0.839 & 0.784 & 0.728 & 0.667 \\
\hline 1.011 & 0.951 & 0.894 & 0.839 & 0.784 & 0.727 & 0.666 \\
\hline
\end{tabular}


TABLE 1 (cont.)

\begin{tabular}{|c|c|c|c|c|c|c|c|c|}
\hline Temp. & $\% \mathrm{NaCl}$ & 5 & 10 & 15 & 20 & 25 & 30 & 3 \\
\hline${ }^{\circ} \mathrm{F}$ & & & & & & & & \\
\hline 365 & 1.012 & 0.951 & 0.894 & 0.839 & 0.783 & 0.726 & 0.665 & \\
\hline 374 & 1.014 & 0.952 & 0.895 & 0.839 & 0.783 & 0.726 & 0.664 & \\
\hline 383 & 1.015 & 0.953 & 0.895 & 0.838 & 0.782 & 0.725 & 0.663 & \\
\hline 392 & 1.017 & 0.954 & 0.895 & 0.839 & 0.782 & 0.725 & 0.663 & \\
\hline 401 & 1.018 & 0.955 & 0.896 & 0.839 & 0.782 & 0.724 & 0.662 & \\
\hline 410 & 1.020 & 0.956 & 0.897 & 0.839 & 0.782 & 0.724 & 0.661 & \\
\hline 419 & 1.022 & 0.957 & 0.897 & 0.839 & 0.782 & 0.724 & 0.661 & \\
\hline 428 & 1.024 & 0.359 & 0.898 & 0.840 & 0.782 & 0.724 & 0.661 & \\
\hline 437 & 1.026 & 0.960 & 0.899 & 0.840 & 0.783 & 0.724 & 0.661 & \\
\hline 446 & 1.028 & 0.962 & 0.900 & 0.841 & 0.783 & 0.725 & 0.661 & \\
\hline 455 & 1.031 & 0.963 & 0.901 & 0.842 & 0.784 & 0.726 & 0.662 & \\
\hline 464 & 1.033 & 0.965 & 0.903 & 0.843 & 0.785 & 0.727 & 0.664 & \\
\hline 473 & 1.036 & 0.967 & 0.904 & 0.845 & 0.787 & 0.728 & 0.665 & \\
\hline 482 & 1.038 & 0.969 & 0.906 & 0.846 & 0.789 & 0.731 & 0.668 & \\
\hline 491 & 1.041 & 0.971 & 0.908 & 0.848 & 0.791 & 0.733 & 0.677 & \\
\hline 500 & 1.044 & 0.974 & 0.970 & 0.851 & 0.794 & 0.737 & 0.675 & 0.599 \\
\hline 509 & 1.047 & 0.976 & 0.913 & 0.854 & 0.797 & 0.741 & 0.680 & 0.605 \\
\hline 518 & 1.050 & 0.979 & 0.916 & 0.857 & 0.801 & 0.746 & 0.687 & 0.613 \\
\hline 527 & 1.054 & 0.982 & 0.919 & 0.861 & 0.806 & 0.752 & 0.682 & 0.622 \\
\hline 536 & 1.057 & 0.985 & 0.923 & 0.866 & 0.812 & 0.759 & 0.704 & 0.633 \\
\hline 545 & 1.061 & 0.989 & 0.927 & 0.871 & 0.819 & 0.768 & 0.715 & 0.646 \\
\hline 554 & 1.065 & 0.993 & 0.932 & 0.877 & 0.827 & 0.779 & 0.728 & 0.663 \\
\hline 563 & 1.069 & 0.997 & 0.937 & 0.884 & 0.837 & 0.791 & 0.744 & 0.682 \\
\hline 572 & 1.073 & 1.002 & 0.944 & 0.893 & 0.848 & 0.806 & 0.763 & 0.706 \\
\hline
\end{tabular}


TABLE 1 (cont.)

\begin{tabular}{|c|c|c|c|c|c|c|c|c|c|c|}
\hline \multirow{2}{*}{\multicolumn{2}{|c|}{ Temp. }} & \multirow[b]{2}{*}{$\% \mathrm{NaCl}$} & \multicolumn{8}{|c|}{$C p$} \\
\hline & & & $\underline{0}$ & 5 & 10 & 15 & 20 & 25 & 30 & 35 \\
\hline${ }^{\circ} \mathrm{C}$ & & ${ }^{\circ} \mathrm{F}$ & & & & & & & & \\
\hline 305 & & -581 & 1.077 & 1.007 & 0.951 & 0.903 & 0.861 & 0.824 & 0.786 & 0.734 \\
\hline 310 & & 590 & 1.082 & 1.013 & 0.959 & 0.915 & 0.877 & 0.845 & 0.813 & 0.768 \\
\hline 315 & & 599 & 1.087 & 1.019 & 0.969 & 0.929 & 0.896 & 0.870 & 0.845 & 0.808 \\
\hline 320 & & 608 & 1.092 & 1.027 & 0.980 & 0.945 & 0.919 & 0.901 & 0.884 & 0.857 \\
\hline 325 & & 617 & 1.098 & 1.035 & 0.993 & 0.964 & 0.946 & 0.937 & 0.931 & 0.916 \\
\hline
\end{tabular}

\section{Reference}

Haas, J. L., Jr. Preliminary "Steam Tables" For NaCl Solutions, U.S. Geological Survey, Reston, VA 1975 Document No. USGS-OFR-75-675. Values in Table above were calculated from USGS values. 
TABLE 2

Heats of vaporization ( $\mathrm{cal}^{-1}$ ) for solutions containing various weight percentages of $\mathrm{NaCl}$

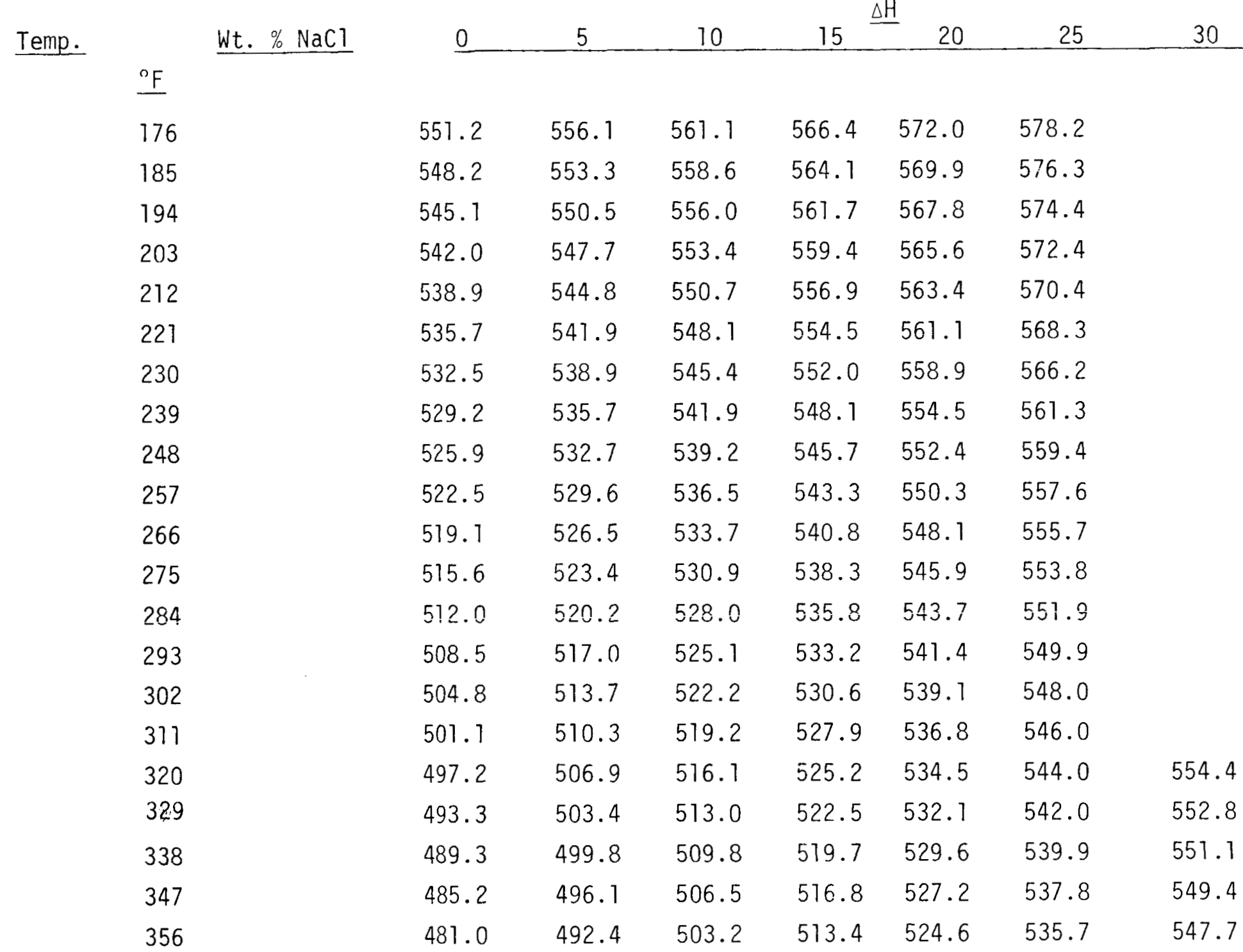


TABLE 2 (cont.)

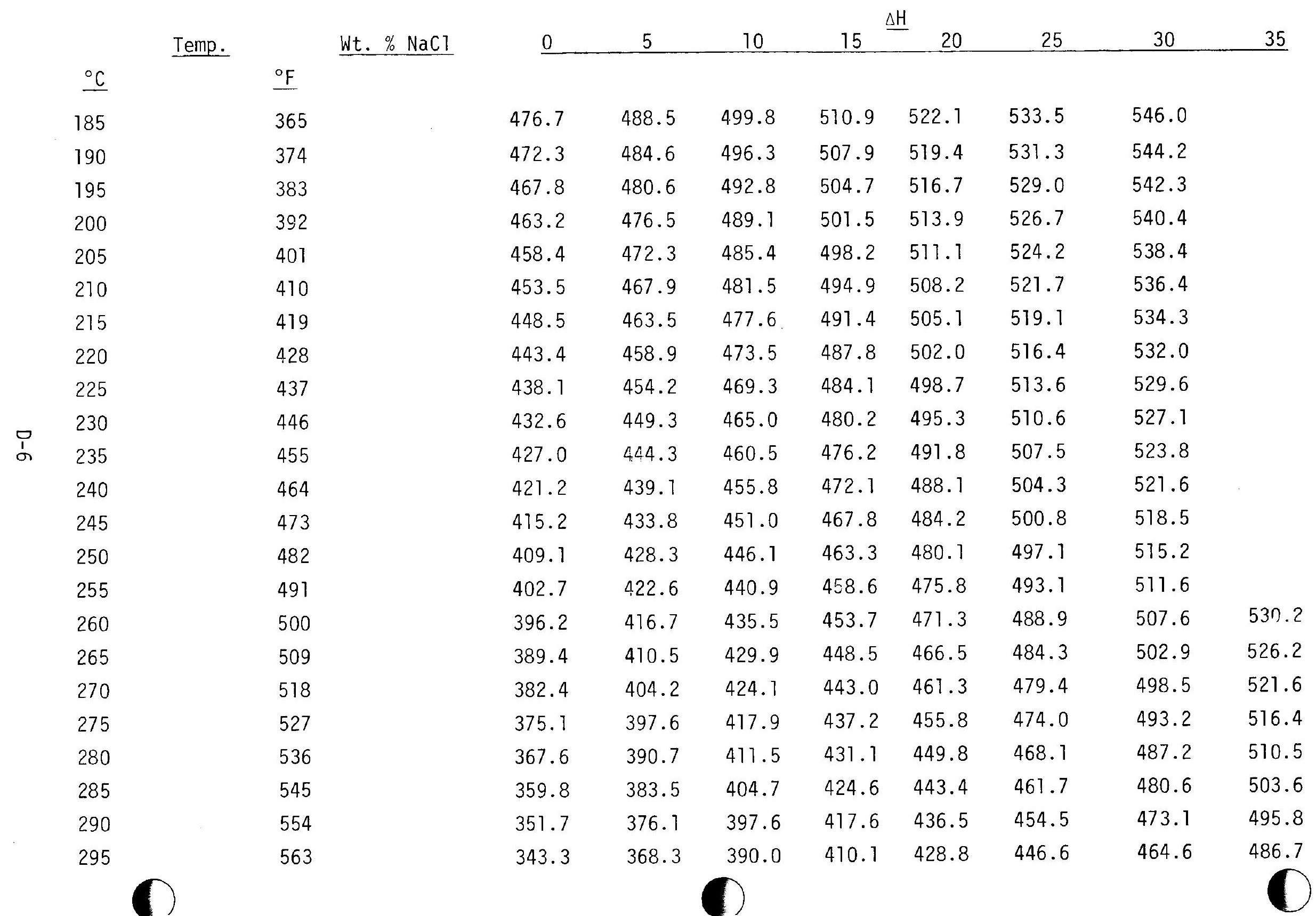


TABLE 2 (cont.)

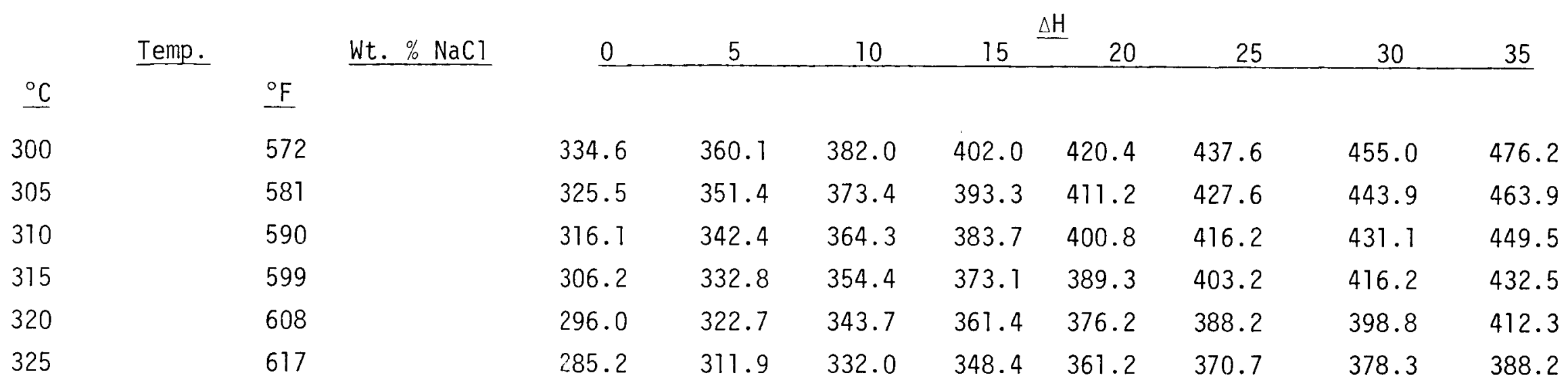

Reference

Haas, J. L., Jr. Preliminary "Steam Tables" For NaCl Solutions U.S. Geological Survey, Reston, VA 1975

Document No. USGS-0FR-75-675. Values in Table above were calculated from USGS values. 
From Table 3-3 of the same report:

$\mathrm{mg} / \ell$ Potassium Weight $\% \mathrm{NaCl}$

Wellhead

lst Brine

3rd Brine

4th Brine
9800

10,500

11,200

12,000
16

17

18

19

The potassium concentration in the third stage brine can be calculated from the potassium concentration in the fourth stage:

$$
A=12,000 \mathrm{mg} / \ell\left(1-\frac{C p \Delta T}{\Delta H}\right)
$$

From Table 1 the temperatures in degrees centigrade most closely corresponding to $284.4^{\circ} \mathrm{F}$ and $194.5^{\circ} \mathrm{F}$ are $140^{\circ} \mathrm{C}$ and $90^{\circ} \mathrm{C}$ respectively. $\mathrm{Cp}$ and $\Delta \mathrm{H}$ at $90^{\circ} \mathrm{C}$ for $19 \% \mathrm{NaCl}$ (using the closest values for $\mathrm{Cp}$ and $\Delta \mathrm{H}$

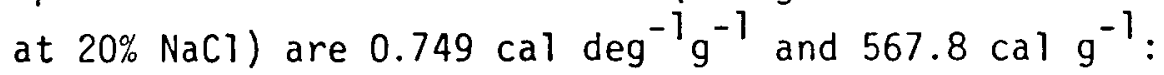

$$
\begin{aligned}
A & =12,000 \mathrm{mg} / \ell\left(1-\frac{0.749 \mathrm{cal} \mathrm{deg}^{-1} \mathrm{~g}^{-1}(140-90) \mathrm{deg}}{567.8 \mathrm{cal} \mathrm{g}^{-1}}\right) \\
& =11,209 \mathrm{mg} / \mathrm{l}
\end{aligned}
$$

This compares favorably with the experimentally determined value of $11,200 \mathrm{mg} / \ell$ potassium in the third stage flash unit.

Example 2: The potassium concentration of the Woolsey \#1 wellhead brine can be calculated from the potassium concentration of the first stage flashed brine. From Table 1 the temperatures of the wellhead and first stage flashed brine (in ${ }^{\circ} \mathrm{C}$ ) which most closely correspond to those reported are $205^{\circ} \mathrm{C}$ for the wellhead brine and $160^{\circ} \mathrm{C}$ for the flashed brine.

From Tables $\mathrm{I}$ and 2 the $\mathrm{Cp}$ and $\Delta \mathrm{H}$ values at $16 \% \mathrm{NaCl}$ (using the closest values at $15 \% \mathrm{NaCl}$ and $160^{\circ} \mathrm{C}$ ) are $0.839 \mathrm{cal} \mathrm{deg}^{-1} \mathrm{~g}^{-1}$ and $525.2 \mathrm{cal} \mathrm{g}^{-1}$, respectively: 


$$
\begin{aligned}
A & =10,500 \mathrm{mg} / \ell\left(1-\frac{0.839 \mathrm{cal} \mathrm{deg}^{-1} \mathrm{~g}^{-1}(205-160) \mathrm{deg}}{525.2 \mathrm{cal} \mathrm{g}-1}\right) \\
& =9745 \mathrm{mg} / \ell
\end{aligned}
$$

This compares favorably with the experimentally determined potassium wellhead concentration of $9800 \mathrm{mg} / \mathrm{l}$. 


\section{DISTRIBUTION}

No. of

No. of

Copies

Copies

UNITED STATES

A. A. Churm

DOE Chicago Patent Group

Argonne, IL 60439

10 R. R. Reeber

Division of Geotherma? Energy

Department of Energy

Washington, DC 20545

1 John V. Walker

Division of Geothermal Energy

Department of Energy

Washington, DC 20545

1 George A. Kolstadt

U.S. Department of Energy

Division of Basic Energy Sciences

Washington, DC 20545

531 DOE Technical Information Center

Harold Bell

Arizona Public Service Co.

P.0. Box 21666

Phoenix, AR 85036

Richard L. Miller

EG\&G Idaho Inc.

307 Second Street

Idaho Falls, ID 83401

1 A. J. Aducci

DOE

San Francisco Operations Office

1333 Broadway

Oakland, CA 94612

Jon Baidwin

Allied Chemical Corporation

550 Second Street

Idaho Falls, ID 83401
Jerome W. Hankin

Bechtel Corporation

50 Beale Street

San Francisco, CA 94105

Edward L. Ghormley

The Ben Holt Co.

201 S. Lake Avenue

Pasadena, CA 91101

Ben Holt

The Ben Holt Co.

201 S. Lake Avenue

Pasadena, CA 91101

Thomas M. Laronge

P.0. Box 847

Vancouver, WA 98666

Larry Kukacka

Brookhaven National Laboratory

Upton, NY 11973

Wayne A. Fernelius

U.S. Department of the Interior

Bureau of Reclamation, Lower

Colorado Region, Planning Div.

Boulder City, NV 89005

F. W. Schremp

Chevron Dil Field Research Co.

P.0. Box 446

La Habra, CA 90631

John E. Howard

Department of Water and Power

City of Los Angeles

Water and Power Square

Room $1136 \mathrm{~A}$

$111 \mathrm{~N}$. Hope Street

Los Angeles, CA 90051 
Coury and Associates

7400 W. 14 Avenue, Suite 2

Lakewood, CO 80214

Hector Alonso

Commission Federal de Electridad

Planta Cerro Prieto

P.0. Box 248

Calexico, CA 92281

Samuel Poredes

Commission Federal de Electridad

Planta Cerro Prieto

P.0. Box 248

Calexico, CA 92281

Alfredo Manon

Commission Federal de Electridad

Planta Cerro Prieto

P.0. Box 248

Calexico, CA 92281

John S. Wilson

Dow Chemical Company

Texas Division

Freeport, TX 77541

Roy A. Burke

Sr. Vice President

Union 0il Co. of California

Los Angeles, CA 90017

Anthony J. Chasteen

Union $0 i 1$ Co. of California

135 Ma in Street

Brawley, CA 92227

Dr. Hunter Pallman

Dow Chemical Company

2800 Mitchell Drive

Walnut Creek, CA 94598

A. C. Makrides

EIC Corporation

55 Chapel Street

Newton, MA 02158
V. Roberts

Electric Power Research Institute

P.0. Box 10412

Palo Alto, CA 94304

Stanley G. Unitt

Fluor Engineers and Constructor, Inc.

3333 Michelson Drive

Irvine, CA 92715

Sidney L. Phillips

Lawrence Berkeley Laboratory

University of California

Berkeley, CA 94720

Geothermal Resources Council

P.0. Box 1033

Davis, CA 95616

Salem Toney

General Electric Company

Medium Steam Turbine Dept.

1100 Western Avenue

Lynn, MA 01910

Dr. Carel otte

Union 0il Co. of California

P.0. Box 7600

Los Angeles, CA 90017

W. C. Lieffers

Union 0 il Co. of California

Research Dept.

P.0. Box 76

Brea, CA 92621

Thomas C. Hinrichs

Imperial Magma

P.0. Box 2082

Escondido, CA 92025

B. R. Banerjee

Ingersol Rand Company

Research Center

P.0. Box 301

Princeton, NY 08540 
Richard A. McKay Jet Propulsion Laboratory 4800 0ak Grove Drive Pasadena, CA 91103

C. M. Laffoon

C. M. Laffoon Consulting

P.0. Box 1892

El Cajon, CA 92022

John A. Apps

Lawrence Berkeley Laboratory

University of California

Berkeley, CA 94720

Kenneth F. Mirk

Lawrence Berkeley Laboratory

University of California

Berkeley, CA 94720

George Tardiff

Lawrence Livermore Laboratory

P.0. Box 808

Livermore, CA 94551

R. D. McCright

Lawrence Livermore Laboratories

P.0. Box 208

Livermore, CA 94550

Morton C. Smith

Los Alamos Scientific Laboratory

P.0. Box 1663

Los Alamos, NM 87544

Harry W. Falk, Jr.

Magma Power Company

P.0. Box 9

Los Altos, CA 94022

Reinald Nielsen

The Mitre Corporation

Bedford, MA 01730

Martin School

The Mitre Corporation

Energy Resource \& Environmental

System Analysis

Westgate Research Park

McLean, VA 22101
E. R. Fuller

National Bureau of Standards

Materials Building

Washington, DC 20234

R. B. Coryel1

National Science Foundation

Geothermal Energy Studies

1800 G Street

Washington, DC 20550

John W. Arlidge

Nevada Power Company

P. 0. Box 230

Las Vegas, NV 89151

W. S. Lyon

ORNL

Analytical Chemistry Division

Oak Ridge, TN 37830

R. W. Bowman

0ilwell Research, Inc.

2419 E. Main Street, Suite E

Ventura, CA 93003

Geo-Heat Utilization Center

Oregon Institute of Technology

Klamath Falls, OR 97601

Paul Mathew

Pacific Gas \& Electric Co.

77 Beale

San Francisco, CA 94105

John Finney

Pacific Gas \& Electric Co.

77 Beale

San Francisco, CA 94105

Gordon W. Allen

Pacific Gas \& Electric Co.

3400 Crow Canyon Road

San Ramon, CA 94583

Frank J. Dodd

Pacific Gas \& Electric Co. 3400 Crow Canyon Road

San Ramon, CA 94583 
Hubert L. Barnes

Pennsylvania State University 208 Deike

University Park, PA 16802

Gary W. Crosby

Phillips Petroleum Company 17526 Sorrento Valley Road

San Diego, CA 92121

Alan D. Grant

Portland General Electric

121 S.W. Salmon Street

Portland, OR 97204

Art Martinez

Public Service Co. New Mexico

P.0. Box 2267

Albuquerque, NM 87103

David $W$. DeBerry

Radian Corporation

P.0. Box 9948

Austin, TX 78766

James E. Murphy

Reno Metallurgy Research Center

U.S. Bureau of Mines

1605 Evans Avenue

Reno, NV 89505

Dr. James Barkman

Republic Geotherma 7, Inc.

11823 E. STauson Avenue, Suite 1

Santa Fe Springs, CA 90670

Dr. Don E. Michels

Republic Geothermal, Inc.

17823 E. Slauson Avenue, Suite 1

P.0. Box 3388

Santa Fe Springs, CA 90670

James Kuwada

Rogers Engineering

16 Beale Street

San Francisco, CA 94105
Thomas Springer

Rockwell International

Atomics International Division

8900 DeSoto Avenue

Canoga Park, CA 91304

Paul B. Needham

U.S. Department of the Interior

U.S. Bureau of Mines, College Park Metallurgy Research Center

College Park, MD 20740

Frank X. McCawley

U.S. Department of the Interior

Bureau of Mines

College Park, MD 20740

R. 0. Fournier

U.S. Department of Interior

Office of Geochemistry and Geophysics

345 Middlefield Road

Mento Park, CA 94025

J. D. Gibson

U.S. Department of Interior

Alaska Resources Library

555 Cordova Street

Anchorage, AK 99501

W. Ogle

U.S. Department of Interior

3801 B. West 44th Avenue

Anchorage, AK 99503

Charles A. Reedy

United Chemical Company

145 W. 16th Street

Long Beach, CA 90813

Val Finlayson

Utah Power and Light Company

P.0. Box 899

Salt Lake City, UT 84170 
No. of

Copies

Kenneth R. Starling

University of 0klahoma

School of Chemical Engineering and Materials Science

Norman, OK 73069

Bruce Heath

University of $0 \mathrm{k} 1$ ahoma

School of Petroleum Engineering

Norman, OK 73069

Gene Culver

Geo-Heat Utilization Center

Oregon Institute of Technology

Klamath Falls, OR 97601

Myron H. Dorfman

University of Texas

Center for Energy Studies

Austin, TX 78712

University of Hawai at Monoa

2424 Maili Way

Honolulu, HI 96822

Otto Vetter

Vetter Associates

3189 C Airway Avenue

Costa Mesa, CA 92626

W. C. Wolkenhauer

Washington PUblic Power Supply

system

3000 George Washington Way

Richland, WA 99352

Dr. David J. Atkinson

Hydro-Search, Inc.

333 Flint Street

Reno, NV 89501

L. H. Axtel1

Geothermal Services, Inc.

7860 Convoy Ct.

San Diego, CA 92111
No. of

Copies

\author{
Harry M. Castrantas \\ FMC Corporation \\ 407 S. Norwood Avenue \\ Newton, F'A 18940 \\ Leonard A. Cavanagh \\ Stanford Research Institute \\ 1550 Calaveras Avenue \\ San Jose, CA 95126 \\ Raymond Cedillo \\ Southern California Edison Co. \\ 9329 Glendon Way \\ Rosemead, CA 91770 \\ Frank Dellechaie \\ AMAX Exploration, Inc. \\ 4704 Harlan Street \\ Denver, Co 80212 \\ Sam Dermengian \\ Geothermal Energy Magazine \\ 318 Cherrywood Street \\ West Covina, CA 91741 \\ Jay D. Dick \\ Denver Research Institute \\ University of Denver \\ Denver, CO 80208 \\ Gene E11iott \\ Federal Bureau of Mines \\ 1605 Evans Avenue \\ Reno, NV 89512 \\ Peter Fintschenko \\ FMC Corporation \\ 2000 Market Street \\ Philadelphia, PA 19103 \\ Jack F. Foehr \\ CER Corporation \\ P.0. Box 15090 \\ Las Vegas, NV 89714
}


George Frye

Aminoil USA, Inc.

P.0. Box 11279

Santa Rosa, CA 95406

Murray C. Gardner

GeothermEX, Inc.

901 Mendocino Avenue

Berkeley, CA 94707

W. Rober Hail

W. A. Wahler \& Assoc.

1023 Corporation Way

Palo Alto, CA 94303

Jonathon Herrmann

U.S. EPA

1860 Lincoln Street, Suite 900

Denver, CO 80011

Anders F. Jepsen

Eureka Resource Associates, Inc.

2161 Shattuck Avenue, Suite 317

Berkeley, CA 94704

Richard L. Jodry

Suntech, Inc.

P.0. Box 936

Richardson, TX 75080

Stuart D. Johnson

Phillips Petroleum Co.

P.0. Box 752

Del Mar, CA 92014

Christopher W. Klein

GeothermEx, Inc.

901 Mendocino Avenue

Berkeley, CA 94707

Paul Kruger

Civil Engineering Dept.

Stanford University

Stanford, CA 94305

Katherine F. Meadows

Geothermal World Directory

P.0. Box 997

Glendora, CA 91740
Mae Z. Meidav

Geonomics, Inc.

3165 Adeline Street

Berkeley, CA 94703

H. Tsvi Meidav

Geonomics, Inc.

3165 Adel ine Street

Berkeley, CA 94703

John G. Moylan

Lockheed Electric Co.

4220 S. Maryland Parkway

Las Vegas, NV 89109

L. W. Ross

Denver Research Institute

University of Denver

Denver, CO 80208

Lew Schalit

Acurex/Aerotherm

485 Clyde Avenue

Mountain View, CA 94042

Chandler A. Swanberg

Department of Physics, Box 30

New Mexico State University

Las Cruces, NM 88003

Herbert $C$. Wells

Engineering Dept.

University of Nevada

4505 Maryland Parkway

Las Vegas, NV 89154

Richard $V$. Wyman

Engineering Department

University of Nevada

4505 Maryland Parkway

Las Vegas, NV 89154

D. W. Wheeler

Aminoil USA, Inc.

P.0. Box 191

Huntington Beach, CA 92648 
Richard McCurdy

PG\&E, Dept. of Engineering Research

3400 Crow Canyon Road

San Ramon, CA 94583

Robert E. Moran

U.S. Geological Survey, WRD

M.S. 415, Federal Cen.

Denver, CO 80215

Alan 0. Ramo

Sunoco Energy Dev. Co.

12700 Park Central Place, Suite 1500

Dallas, TX 75251

Franco B. Tonani

GeochemEx

3165 Adel ine Street

Berkeley, CA 94703

Albert C. Trakowski

U.S. EPA

401 M. Street S.W.

Washington, DC 20460

J. P. Chiaravalloti

Shell 0il Co.

Ventura, CA 93001

Harry Ebbeson, Jr. Lake Co. APCD

$225 \mathrm{~N}$. Forbes

Lakeport, CA 95453

Larry J. Price

No. Sonoma Co. APCD

421 March Avenue

Healdsburg, CA 95448

Robert P. Hartley

U.S. EPA, IERL

5555 Ridge Avenue

Cincinnati, OH 45268
Marshal1 Reed

U.S. Geological Survey, M.S. 92

345 Middlefield Road

Menlo Park, CA 94025

B. W. Chettle

Betz

32107 Lindero Canyon Road

Suite 115

Westlake, CA 91361

M. G. Reed

Chevron 0 il Field Research Laboratory

P.0. Box 446

La Habra, CA 90631

R. McKay

Jet Propulsion Laboratory

4800 0ak Grove Drive

Pasadena, CA 91103

E. F. Wahl

Occidenta! Petroleum

Research Laboratory

1855 Carrion Road

LaVerne, CA 91750

G. Sharp

Pacific Gas and Electric Co.

400 Crow Canyon Road

San Ramon, CA 94583

A. G. Collins

DOE

P.0. Box 1398

Bartlesville, OK 74003

D. W. Boem

DOE Division of Environmental

Control Technology

Washington, DC 20545

R. P. Epple

DOE Division of Physical Research Washington, DC 20545 
No. of

Copies
No. of

Copies

C. P. Vanderlyn

EPA Office of Water and Hazardous

Materials Control

Washington, DC 20460

E. J. Maienthal

National Bureau of Standards Air and Water Pollution Analysis

Section

Washington, DC 20234

J. K. Taylor

National Bureau of Standards Air and Water Pollution Analys is

Section

Washington, DC 20234

W. Kirchhoff

National Bureau of Standards

Office of Air and Water

Measurement

Washington, DC 20234

D. A. Becker

National Bureau of Standards

Institute for Materials

Research

Washington, DC 20234

I. Barnes

U.S. Geological Survey

345 Middlefield Road

Menlo Park, CA 94025

E. Jenne

U.S. Geological Survey

345 Middlefield Road

Menlo Park, CA 94025

R. C. Kent

U.S. Geological Survey

345 Middlefield Road

Men lo Park, CA 94025

L. P. J. Muffler

U.S. Geological Survey

345 Middlefield Road

Men1o Park, CA 94025
D. N. Anderson

State of California

1111 Howe11 Avenue

Sacramento, CA 95825

S. K. Gupta BHE 213

University of Southern California

Los Angeles, CA 90007

R. C. Axtmann

Princeton University

Dept. Chem. Eng.

Princeton, NJ 08540

Dr. Peter Kroopnick

Hawai Institute of Isophysics

University of Hawai $i$

2525 Corria Road

Honolulu, HI 96827

Robert Morrison

Hydrogeologist

SCS Engineers, Inc.

4014 Long Beach Blvd.

Long Beach, CA 90807

R. E. McAtee

Allied Chemical Corp.

550 Second Street

Idaho Falls, ID 83401

Larry Kraft

TRW Systems and Energy

\# 1 Space Park, 01/2020

Redondo Beach, CA 90278

Warren Hamersma

TRW Systems and Energy

\# $]$ Space Park, 01/2020

Redondo Beach, CA 90278

Wayne J. Subcasky

Chevron 0 il Field Research Co.

P.0. Box 446

La Habra, CA 90631 
No. of

Copies
No. of

Copies
Carson L. Nealy

Atomics International

8900 DeSoto Avenue

Canoga Park, CA 91304

George E. Dunstan

LFE Environmental Analysis Labs 2030 Wright Avenue

Richmond, CA 94804

Robert A. Reynolds

GHT Labs

106 South 8th Street

Brawley, CA 92227

J. Eric Schuster

Geology and Earth Resources

Division

Department of Natural Resources

01 ympia, WA 98504

R. N. Wheatley

Union 0il Co. - Research Center

P.0. Box 76

Brea, CA 92621

Royce K. Winge

Ames Laboratory, DOE

28 Spedding $\mathrm{Ha} 11$

Ames, IA 50011

K. Y. Chen

Environmental Engineering Dept. University of Southern California

Los Angeles, CA 90007

John H. Hitl

Lawrence Livermore Lab

P.0. Box $808, L-325$

Livermore, CA 94550

Jerry A. Rieh1

$\mathrm{BGC}$, Inc .

5709 80th Avenue, S.E.

Mercer Island, WA 98040

William D. Riley

U.S. Bureau of Mines

College Park Metallurgy Res. Cen.

College Park, MD 20740
Richard Walters

U.S. Bureau of Mines

College Park Metallurgy Res. Cen.

College Park, MD 20740

Erich Bretthauer

U.S. Environmental Protection Agency EMSL-LV

P.0. Box 15027

Las Vegas, NV 89114

Mary Mckown

Gulf South Research Institute

5010 LeRoy Johnson Drive

New Orleans, LA 70186

J. M. Thompson

U.S. Geological Survey, Geologic Div.

Branch of Exp. Geochemistry and Mineralogy

345 Middlefield Road

Menlo Fark, CA 94025

Dr. Harold Papazian

Martin Marietta Co.

Denver, CO 80201

Dr. Arthur J. Soinski

State of California Energy Resources Conservation and Development Commission

1111 Howe Avenue

Sacramento, CA 95825

John Bricarello

San Diego Gas \& Electric Co.

Materials Test Lab

114 10th Avenue

San Diego, CA 92101

Marshal Conover

Radian Corporation

8500 Shoal Creek Road

Austin, TX 78766

Don Carr

Oregon Iristitute of Technology

Klamath Falls, OR 97601 
No. of

Copies

Paul Lineau

Oregon Institute of Technology

Klamath Falls, OR 97601

Roger Sung

Environmental Engineering

TRW System and Energy

B1dg. R-4/2142

One Space Park

Redondo Beach, CA 90278

Charles Grigsby

CNC-2 M.S. 738

Los Alamos Scientific Lab.

Los ATamos, NM 87545

Al len Kerns

Lawrence Berkeley Laboratory

University of California

Berkeley, CA 94720

M. 0. Andreae

A-008 Scripps Institute of Oceanography

La Jolla, CA 92093

Richard Weiss

2335 Benbenue

Berkeley, CA 94705

John Farison

Union 0i1-Geothermal

P.0. Box 6854

Santa Rosa, CA 95401

Mr. Stan Ward

University of Utah

Dept. of Geology

717 Mineral Science B1dg.

Salt Lake City, UT 84112

Donald Klick

Deputy Chief for Geothermal Research

U.S. Geological Survey

National Center-Stop 906

Reston, VA 22092
No. of

Copies
Dr. J. D. Ingle

Dept. of Chemistry

Oregon State University

Corval1is, OR 97331

Mr. Paul Mills

Environmental Protection Agency, IERL

5555 Ridge Avenue

Cincinnati, $\mathrm{OH} 45213$

Fred Simon

U.S. Geological Survey

National Center, M.S. 923

2201 Sunrise Valley Drive

Reston, VA 22092

U.S. Department of the Interior Bureau of Reclamation

East Mesa Test Site

P.0. Box 416

Holtville, CA 92250

Mr. Ed Backstrom

U.S. Department of the Interior

Bureau of Reclamation

Engineering and Research Center P.0. Box 25007

Bldg. 67, Denver Fed. Cen.

Denver, CO 80225

Leon Leventha7, P.E.

Vice President and Technical Director

LFE Environmental, Analysis Laboratory Division

2030 Wright Avenue

Richmond, CA 94804

Lawrence B. Owen

Lawrence Livermore Laboratory, $L-220$

University of California

Livermore, CA 94550 
No. of

Copies

H. K. Bishop, Ph.D.

Central Laboratory Supervisor San Diego Gas \& Electric Co.

P.0. Box 1831

San Diego, CA 92112

C. M. Gracey

Aerojet Liquid Rocket Co.

P.0. Box 13222

Sacramento, CA 95813

Or. Daniel A. Demeo

Aerospace Groups

Hughes Aircraft Co.

Culver City, CA 90230

R. W. Taylor

Lawrence Livermore Lab, L-365

University of California

Livermore, CA 94550

R. L. Hall, Geothermal UPD

EGig Idaho, Inc.

P.0. Box 1625

Idaho Falls, ID 83407

Steve Hoke

Box 1398

U.S. Department of Energy

Bartlesville, OK 74003

Hasu H. Majmundar

Manager Geochemical Section

San Francisco District Office

Dept. of Conservation, Div, of

Mines and Geology

State of California

Resources B1dg. Room 1341

1416 Minth Avenue

Sacramento, CA 95814

John Featherstone

C/O Tom Hinrichs, President:

Magma Electric Co.

P.0. Box 2082

Escondido, CA 92025
No. of

Copies

Mr. Bill Laughl in

Los Alamos Scientific Laboratory

G-6 Group, M.S. 978

Los Alamos, NM 87545

Mr. Don Gilmore

Environmenta] Protection Agency, EMSL

Las Vesgas, NV 89114

Mr. H. E. Englander

Chevron 0 il Field Research Center

P.0. Box 446

La Habra, CA 90631

Mr. Fred Schoepflin

Bechtel Corporation

50 Beale Street

San Francisco, CA 94105

S. K. Sanyal

Stanford University

Palo Alto, CA 94305

\section{FORE IGN}

Jorge Guiza

Commission Federal de Electridad

Dept. of Geothermal Resources

Mexico 5, D.F. Mexico

Sergio Mercado

Commission Federal de Electridad

Department of Geothermal Resources

Mexico 5, D.F. Mexico

CNUCE

Istintuto Del Consiglio

Nazionale Delle Ricerche

36 Via S. Maria/56100

Pisa, Italy

Russell James

Department of Scientific and Industrial Research

Taupo, New Zealand 
No. of

Copies

Japan Geothermal Energy Association

Yurakucho Denki Building

1-7-1 Yuraku-Cho Chiyoda-Ku

Tokyo, Japan

3 Dr. A. J. Ellis

Director

Dept. of Scientific and Industrial Research

Private Bag Petone, New Zealand

Gustavo Cuellar

CEL

Calle Los Claveles-21

Col. La Sultana - Antiguo

Cuscatlan

El Salvador

Carlos V. Lopez

Empresa Nacional de Luz Y Fuerza

Altamira d'Este 317

Managua, Nicaragua

Jorge R. Molina

CEL

31 Av. Sur \#209 Col. Cucumacryan

San Salvador, El Salvador

George W. Coulter

Ecology Division

Department of Scientific and

Industrial Research

P.0. Box 415

Taupo, New Zealand
No. of

Copies

ONSITE

DOE Richland Operations office

H. E. Ransom

Battelle-Northwest

L. L. Ames

D. B. Cearlock

M. J. Danielson

L. J. Defferding

R. L. Dillon

J. R. Eliason

J. S. Fruchter

W. S. Kelly

R. P. Marshal1

W. R. McSpadden

J. Nielson

R. E. Nightingale

L. T. Pederson

L. H. Parry

D. W. Shannon

R. P. Smith

R. G. Sullivan

J. W. Upton

R. A. Walter

J. C. Watson

E. M. Woodruff

J. R. Divine

A. M. Sutey

J. G. Douglas

D. K. Kreid

J. B. Martin

D. E. Robertson

R. J. Serne

J. W. Upton

P. C. Walkup

5 Technical Information

2 Publishing Coordination 